U.S. Department of Energy

Vehicle Technologies, EE-2G

1000 Independence Avenue, S.W.

Washington, D.C. 20585-0121

FY2009

\title{
EVALUATION OF THE 2008 LEXUS LS 600H HYBRID SYNERGY DRIVE SYSTEM
}

Prepared by:

Oak Ridge National Laboratory

Mitch Olszewski, Program Manager

\section{Submitted to:}

Energy Efficiency and Renewable Energy

FreedomCAR and Vehicle Technologies

Vehicle Systems Team

Susan A. Rogers, Technology Development Manager

January 2009 
NATIONAL LABORATORY

MANAGED BY UT-BATTELLE

FOR THE DEPARTMENT OF ENERGY

\section{Energy and Transportation Science Division}

\section{EVALUATION OF THE 2008 LEXUS LS 600H HYBRID SYNERGY DRIVE SYSTEM}

T. A. Burress

C. L. Coomer

S. L. Campbell

A. A. Wereszczak

J. P. Cunningham

L. D. Marlino

L. E. Seiber

H. T. Lin

Publication Date: January 2009

Prepared by the

OAK RIDGE NATIONAL LABORATORY

Oak Ridge, Tennessee 37831

managed by

UT-BATTELLE, LLC

for the

UT-BATTELLE

ORNL-27 (4-00)

U.S. DEPARTMENT OF ENERGY

Under contract DE-AC05-00OR22725 


\title{
DOCUMENT AVAILABILITY
}

Reports produced after January 1, 1996, are generally available free via the U.S. Department of Energy (DOE) Information Bridge:

Web site: http://www.osti.gov/bridge

Reports produced before January 1, 1996, may be purchased by members of the public from the following source:

\author{
National Technical Information Service \\ 5285 Port Royal Road \\ Springfield, VA 22161 \\ Telephone: 703-605-6000 (1-800-553-6847) \\ TDD: $703-487-4639$ \\ Fax: 703-605-6900 \\ E-mail: info@ntis.fedworld.gov \\ Web site: http://www.ntis.gov/support/ordernowabout.htm
}

Reports are available to DOE employees, DOE contractors, Energy Technology Data Exchange (ETDE) representatives, and International Nuclear Information System (INIS) representatives from the following source:

Office of Scientific and Technical Information

P.O. Box 62

Oak Ridge, TN 37831

Telephone: 865-576-8401

Fax: 865-576-5728

E-mail: reports@osti.gov

Web site: http://www.osti.gov/contact.html

This report was prepared as an account of work sponsored by an agency of the United States Government. Neither the United States government nor any agency thereof, nor any of their employees, makes any warranty, express or implied, or assumes any legal liability or responsibility for the accuracy, completeness, or usefulness of any information, apparatus, product, or process disclosed, or represents that its use would not infringe privately owned rights. Reference herein to any specific commercial product, process, or service by trade name, trademark, manufacturer, or otherwise, does not necessarily constitute or imply its endorsement, recommendation, or favoring by the United States Government or any agency thereof. The views and opinions of authors expressed herein do not necessarily state or reflect those of the United States Government or any agency thereof. 


\section{TABLE OF CONTENTS}

LIST OF FIGURES . Page

2. HYBRID ELECTRIC DRIVE SYSTEM DESIGN AND PACKAGING .......................................... 3

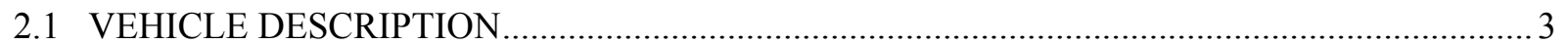

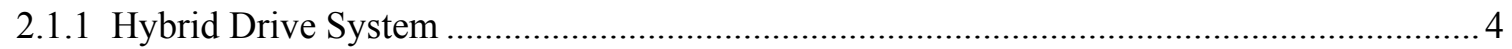

2.2 PCU

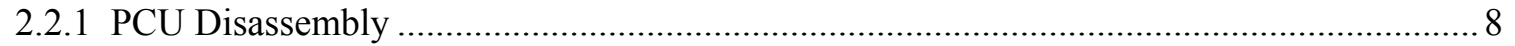

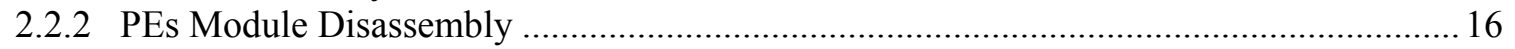

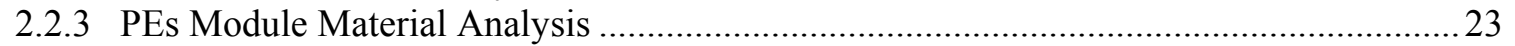

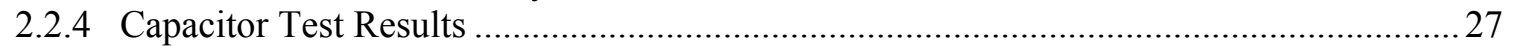

2.2.4.1 Static capacitor test results of the $2629 \mu \mathrm{F}$ dc-link smoothing capacitor

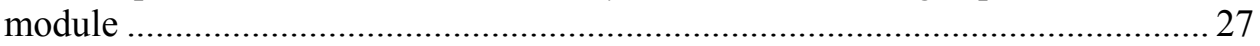

2.2.4.2 Dynamic capacitor test results from large dc-link capacitor module.................. 33

2.2.4.3 Static capacitor test results of battery level filter capacitor evaluations .............. 35

2.2.4.4 Static capacitor test results of small dc-link capacitor evaluations....................... 36

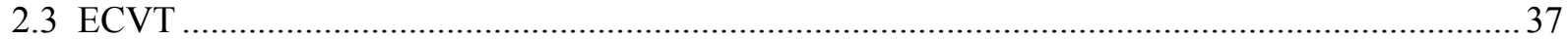

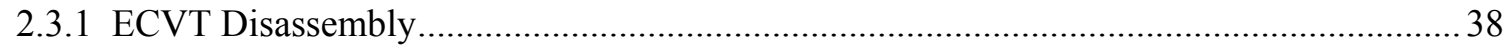

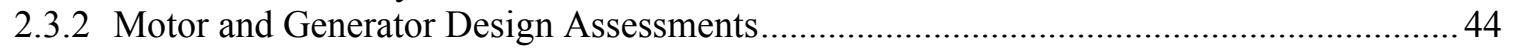

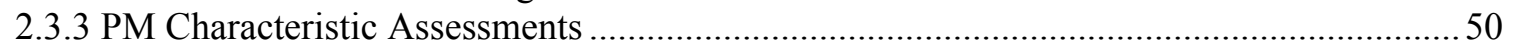

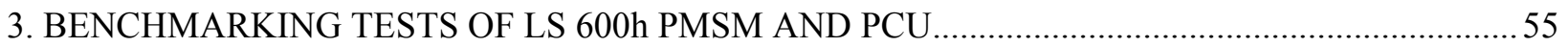

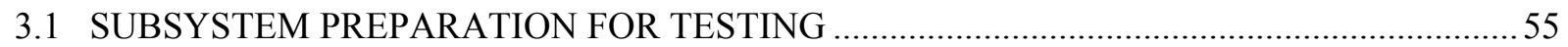

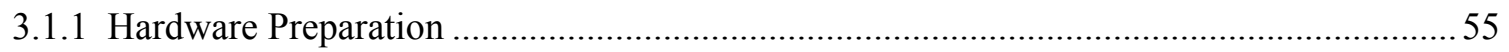

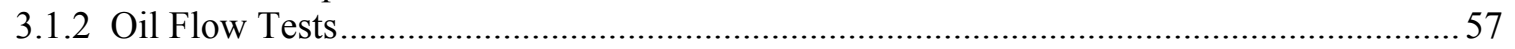

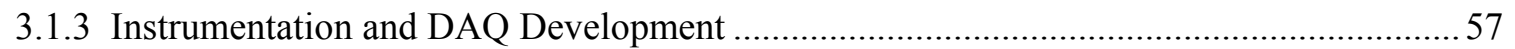

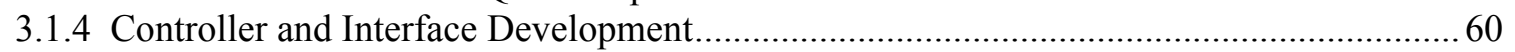

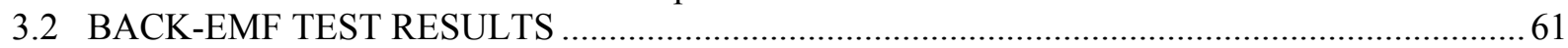

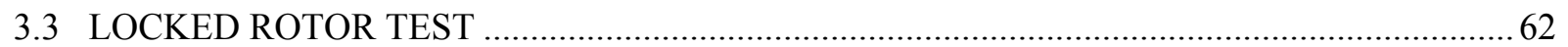

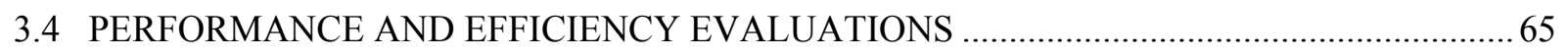

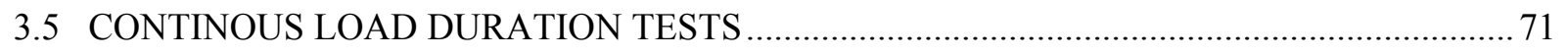

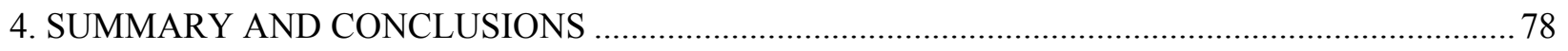

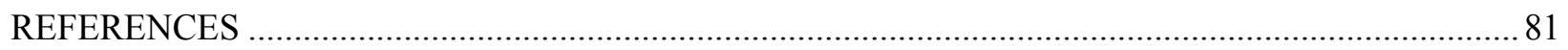

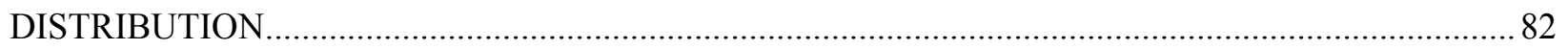




\section{LIST OF FIGURES}

\section{Figure}

Page

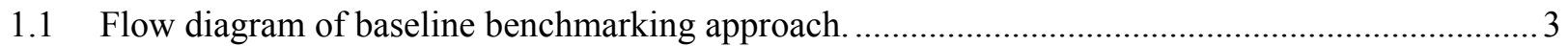

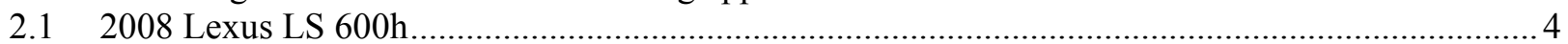

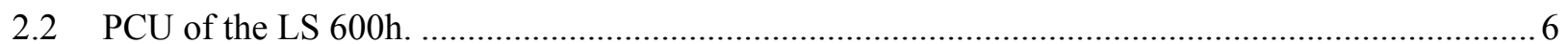

2.3 Compartments of the LS 600h inverter and converter assembly ......................................... 7

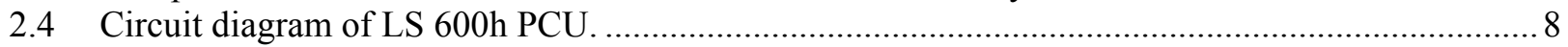

2.5 Controller/driver electronics compartment with lid removed. ................................................... 9

2.6 Controller and driver circuitry for $\mathrm{dc}$-dc convert and inverters.................................................. 9

2.7 PEs compartment (upside down) with dc-link capacitor and casing removed............................. 10

2.8 Underside of PCU with large and small capacitor modules removed. ......................................... 11

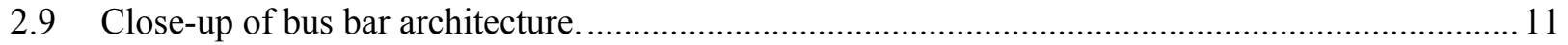

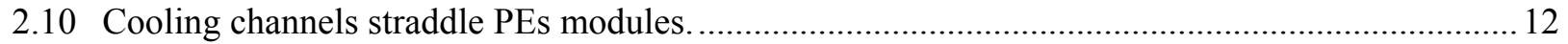

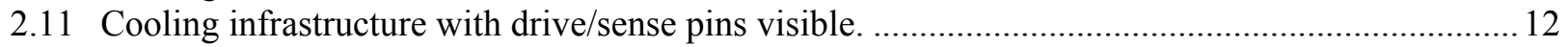

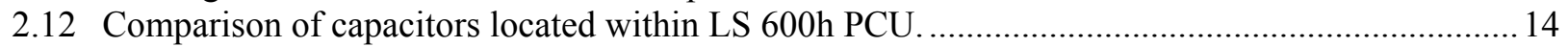

2.13 DC-link capacitor module (upper) and x-ray of module (lower). ........................................... 15

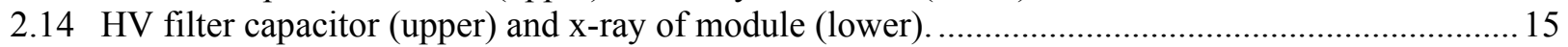

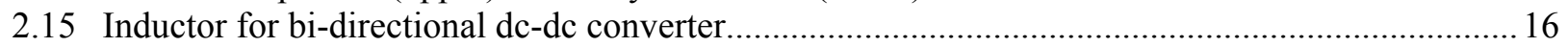

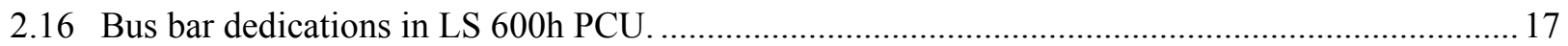

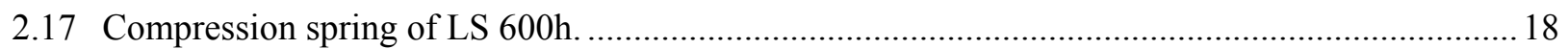

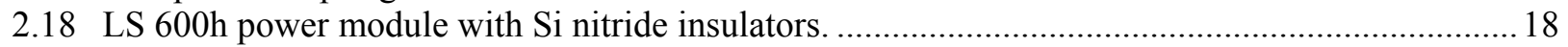

2.19 LS 600h power module emitter and collector plates and bus bars. ............................................. 19

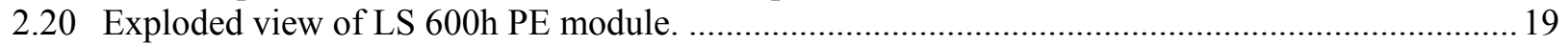

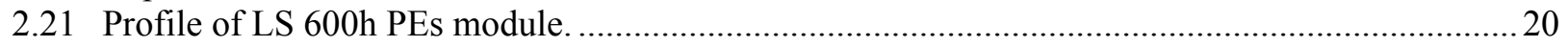

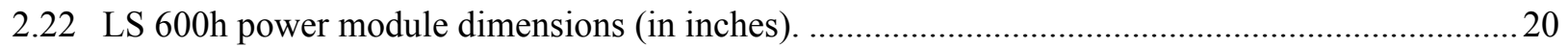

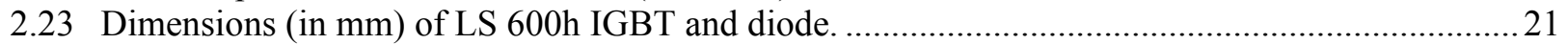

2.24 Dimensions (in $\mathrm{mm}$ ) of Camry dc-dc converter IGBT and diode............................................22

2.25 Dimensions (in mm) of Camry inverter PEs (left) and Prius inverter PEs (right)........................22

2.26 Overview of layers analyzed in PE module material analyses. ...................................................23

2.27 SEM image of layer between emitter plate and IGBT spacer within LS 600h module..................24

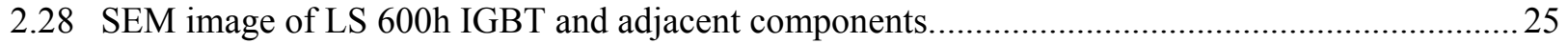

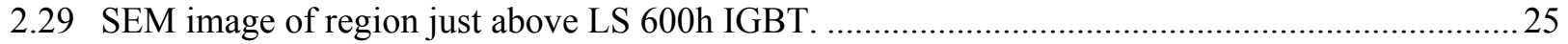

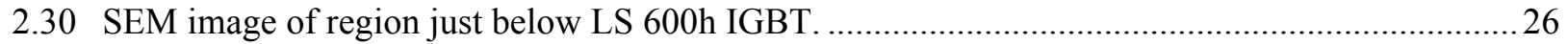

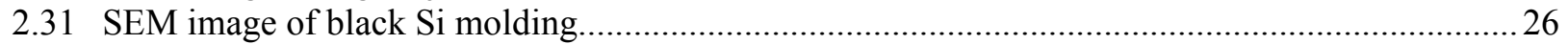

2.32 LS 600h capacitor module equivalent capacitance vs. frequency. .........................................28

2.33 Camry capacitor module equivalent capacitance vs. frequency.................................................28

2.34 LS 600h capacitor module equivalent capacitance variation with ambient temperature................29

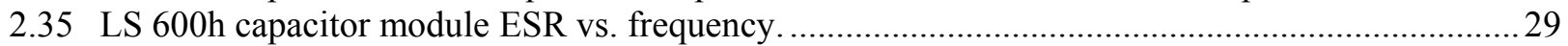

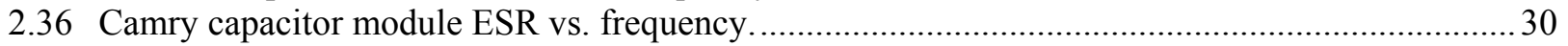

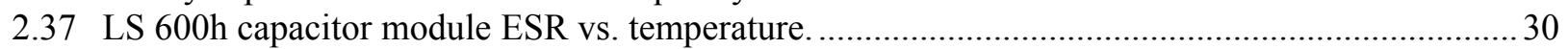

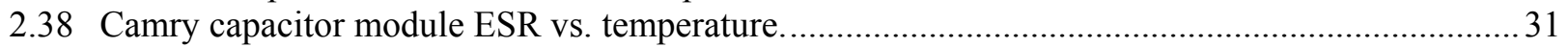

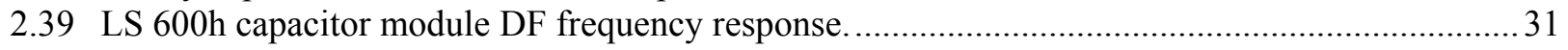

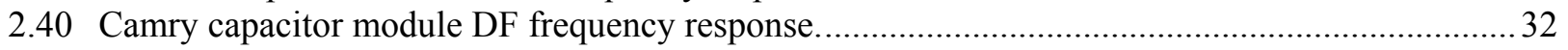

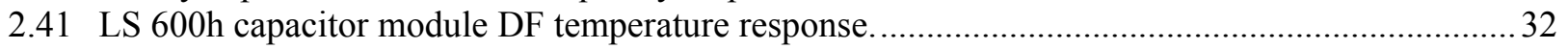

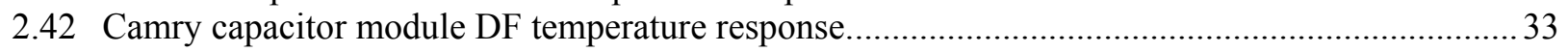

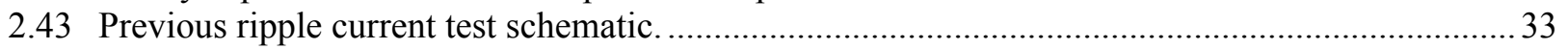

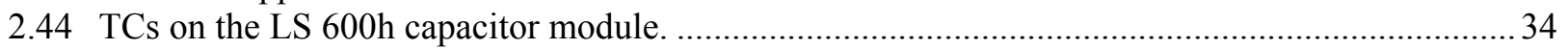

2.45 LS $600 \mathrm{~h}$ capacitor module steady state temperature response vs. ripple current. ......................... 34 


\section{LIST OF FIGURES (cont'd)}

Figure

Page

2.46 Camry capacitor module steady state temperature response vs. ripple current............................35

2.47 Capacitance, ESR, and DF vs. frequency for LS 600h battery level $378 \mu \mathrm{F}$ capacitor................... 35

2.48 Capacitance, ESR, and DF vs. frequency for Camry battery level $378 \mu \mathrm{F}$ capacitor.....................36

2.49 Capacitance, ESR, and DF vs. frequency for LS $600 \mathrm{~h}$ dc-link $0.6 \mu \mathrm{F}$ capacitor. ......................... 36

2.50 Capacitance, ESR, and DF vs. frequency for LS $600 \mathrm{~h}$ dc-link $1.2 \mu \mathrm{F}$ capacitor. ........................ 37

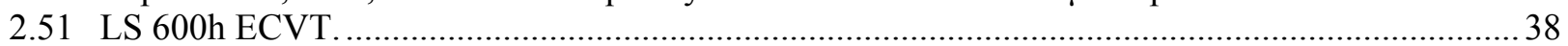

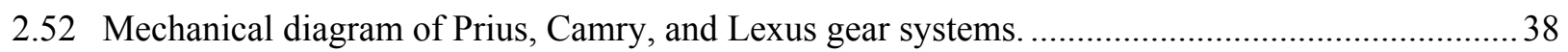

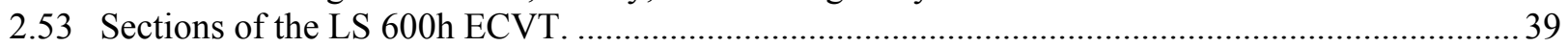

2.54 Generator section of ECVT; front (left), plate removed (middle), and rear (right)........................ 39

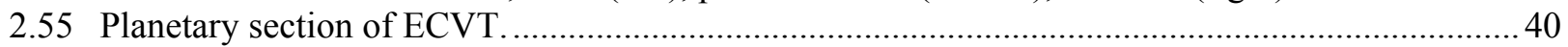

2.56 Motor section of ECVT; front with planetary gear installed (left) and rear (right)...................... 40

2.57 Motor section of ECVT; underside (left) and front view with plate removed (right). .................. 41

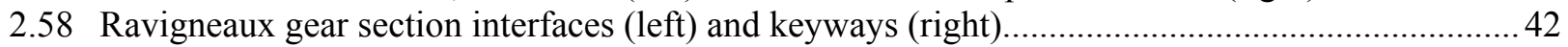

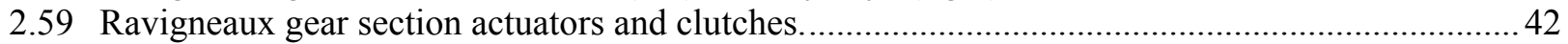

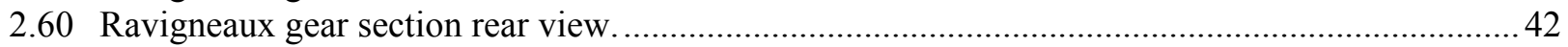

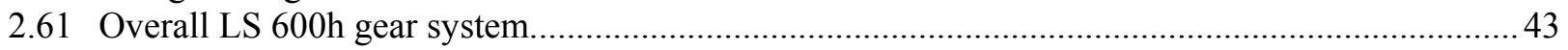

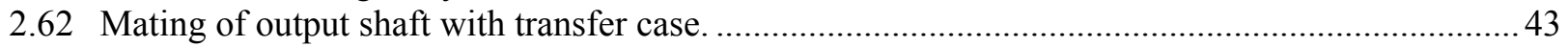

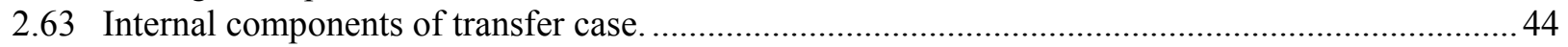

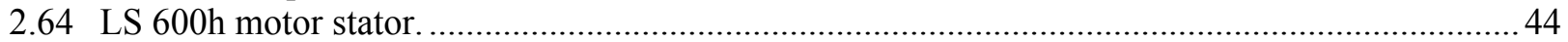

2.65 Comparison of motor stator laminations, Camry (left) vs.LS 600h (right).................................45

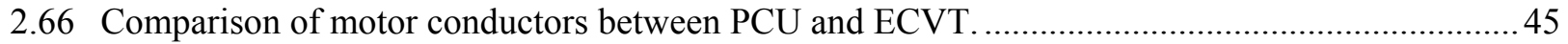

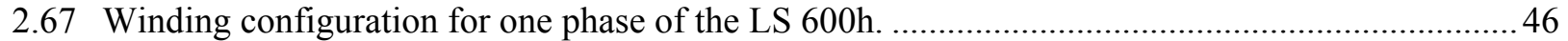

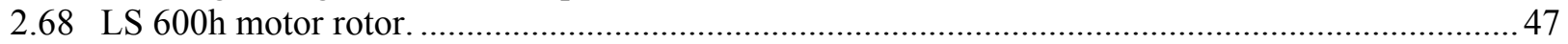

2.69 Comparison of motor rotor laminations, Camry (left) vs. LS 600h (right). ............................... 47

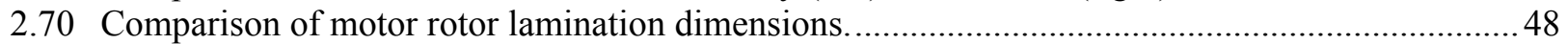

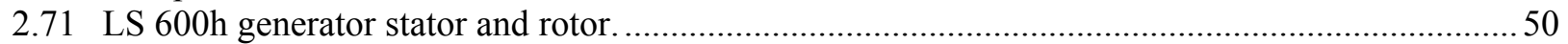

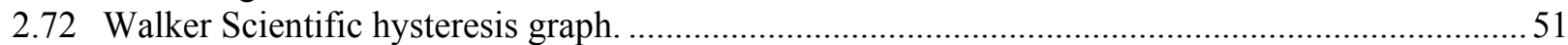

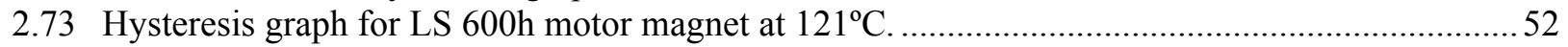

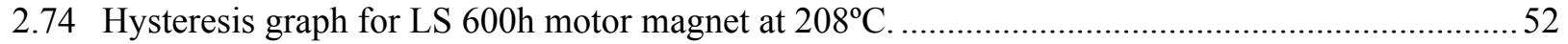

2.75 Intrinsic hysteresis graphs for LS 600h motor magnet at various temperatures............................53

2.76 Intrinsic hysteresis graphs for Camry motor magnet at various temperatures. .............................53

2.77 Remanent flux density for LS 600h, Camry, and Prius motor magnet....................................... 54

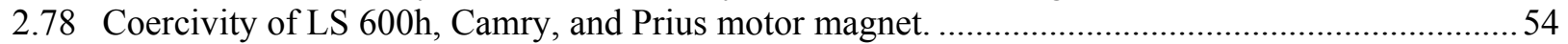

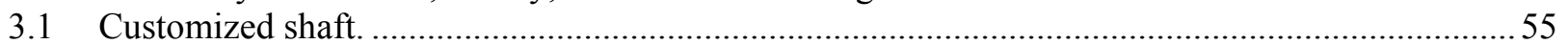

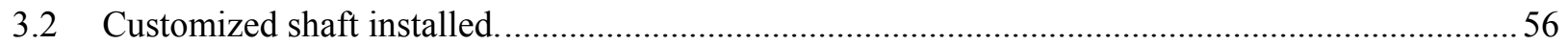

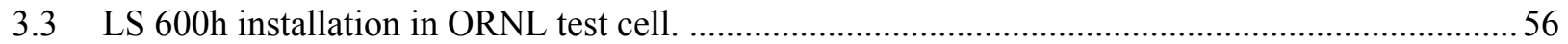

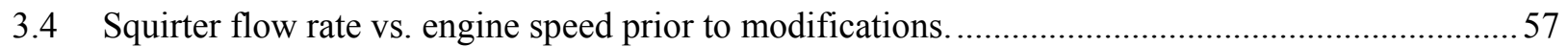

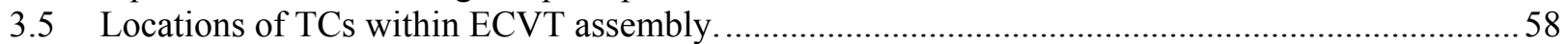

3.6 TC locations within LS 600h PCU (underside view of cooling infrastructure). ...........................59

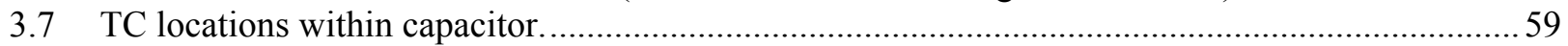

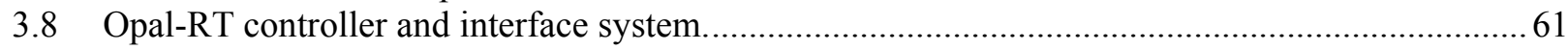

3.92008 LS 600h vs. 2007 Camry motor back-emf test results....................................................62

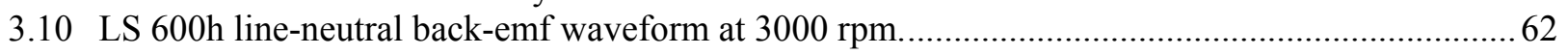

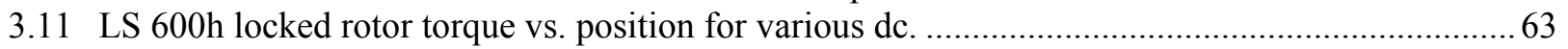

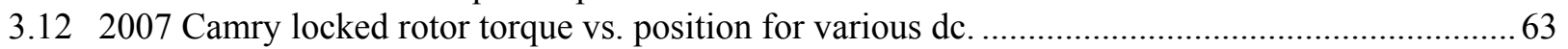

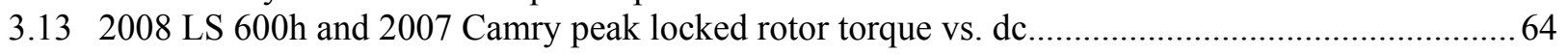




\section{LIST OF FIGURES (cont'd)}

Figure

Page

3.14 Reluctance and PM components of torque for general PMSM. 64

3.152008 LS 600h motor efficiency contours. 65

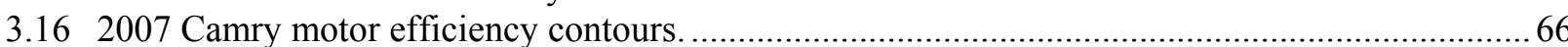

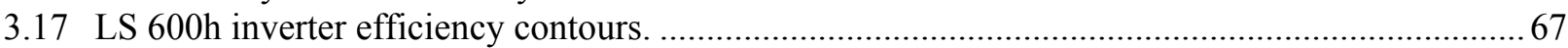

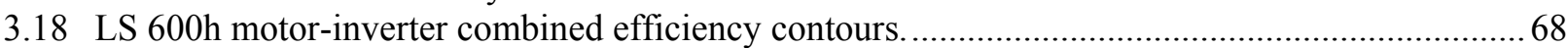

3.19 LS 600h motor-inverter combined efficiency contours for $77 \%$ and above................................6 68

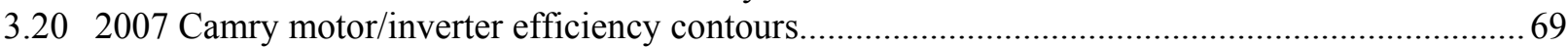

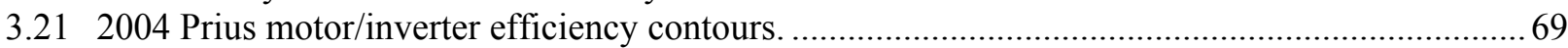

3.22 LS 600h dc-dc converter efficiency vs. input current for various dc-link voltages and $\mathrm{f}_{\mathrm{sw}} \ldots \ldots \ldots \ldots . . . . .70$

3.232007 Camry boost converter efficiency vs. input current for various dc-link voltages................... 71

3.24 Prius boost converter efficiency vs. input current for various dc-link voltages. ...........................71

3.25 LS $600 \mathrm{~h}$ motor temperatures during $25 \mathrm{~kW}$ continuous duration test at $3,000 \mathrm{rpm} \ldots \ldots \ldots \ldots \ldots \ldots \ldots . . . \ldots 2$

3.26 LS $600 \mathrm{~h}$ motor temperatures during $50 \mathrm{~kW}$ continuous duration test at $3,000 \mathrm{rpm} \ldots \ldots \ldots \ldots \ldots \ldots . . . . . . . . .73$

3.27 LS 600h PCU temperatures during $50 \mathrm{~kW}$ continuous duration test at 3,000 rpm.................... 73

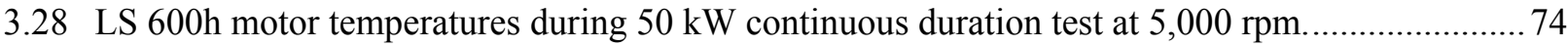

3.29 LS 600h PCU temperatures during $50 \mathrm{~kW}$ continuous duration test at 5,000 rpm.................... 74

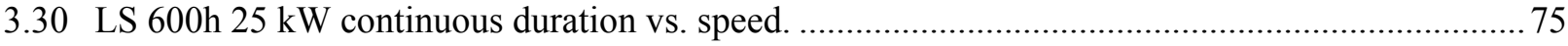

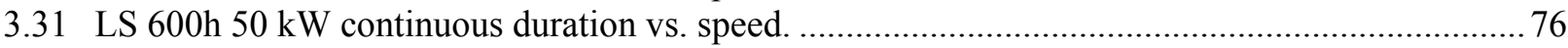

3.32 LS 600h continuous duration at 3,000 rpm with various power levels. ....................................... 77

3.33 LS 600h and Camry continuous duration at 5,000 rpm with various power levels.......................77

3.34 LS 600h and Camry continuous duration at 7,000 rpm with various power levels...................... 78 


\section{LIST OF TABLES}

Table

Page

2.1 Comparison of HEV design features and published specifications ....................................... 5

2.2 Comparison of hybrid Camry and the Prius PCU component specifications ............................... 8

2.3 Mass and volume measurements for the hybrid Camry inverter and converter........................... 13

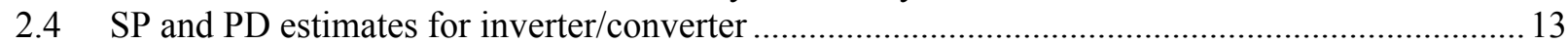

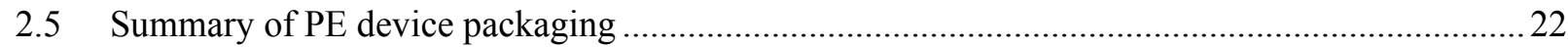

2.6 LS 600h, Camry, and Prius motor design characteristics. ......................................................... 49

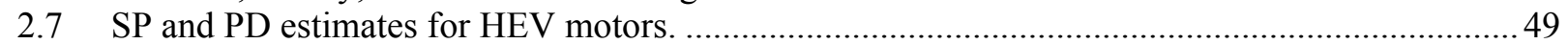

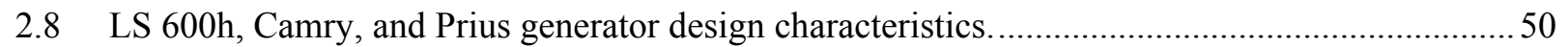

3.1 Conditions monitored during LS 600h evaluations. .............................................................5

4.1 2008 LS 600h, 2007 Camry, and 2004 Prius design comparison highlights .............................. 80 


\section{ACRONYMS AND ABBREVIATIONS}

\begin{tabular}{|c|c|c|c|}
\hline $2 \mathrm{D}$ & two-dimensional & MSRP & manufacturers suggested retail price \\
\hline $3 \mathrm{D}$ & three-dimensional & $\mathrm{NdFeB}$ & neodymium iron boron \\
\hline $\mathrm{A} / \mathrm{C}$ & air conditioning & Ni-MH & nickel metal hydride \\
\hline $\mathrm{ac}$ & alternating current & $\mathrm{Nm}$ & Newton meter \\
\hline APEEM & Advanced Power Electronics and & NTRC Na & Jational Transportation Research Center \\
\hline AWG & $\begin{array}{r}\text { Electric Machines } \\
\text { American wire gauge }\end{array}$ & $\begin{array}{l}\text { OD } \\
\text { OEM }\end{array}$ & $\begin{array}{r}\text { outer diameter } \\
\text { original equipment manufacturers }\end{array}$ \\
\hline $\mathrm{CD}$ & compact disk & ORNL & Oak Ridge National Laboratory \\
\hline $\mathrm{CT}$ & current transducer & $\mathrm{PC}$ & personal computer \\
\hline DAQ & data acquisition system & PCB & printed circuit board \\
\hline $\mathrm{dc}$ & direct current & $\mathrm{PCU}$ & power control unit \\
\hline DF & dissipation factor & $\mathrm{PD}$ & power density \\
\hline DOE & U.S. Department of Energy & $\mathrm{PE}$ & power electronic \\
\hline ECU & electronic control unit & PEEMRC & Power Electronics and Electric \\
\hline \multirow[t]{2}{*}{ ECVT } & electronically-controlled continuously & & Machinery Research Center \\
\hline & variable transmission & PI & proportional-integral \\
\hline EDX & energy-dispersive $\mathrm{x}$-ray spectroscopy & PM & permanent magnet \\
\hline \multirow[t]{2}{*}{ EETT } & Electrical and Electronics & PMSM & permanent magnet synchronous motor \\
\hline & Technical Team & $\mathrm{R} \& \mathrm{D}$ & research and development \\
\hline emf & electromotive force (measured in volts) & rms & root mean square \\
\hline ESR & equivalent series resistance & rpm & revolutions per minute \\
\hline $\mathrm{EV}$ & electric vehicle & SEM & scanning electron microscopy \\
\hline FCVT & FreedomCAR and Vehicle Technologies & $\mathrm{Si}$ & silicon \\
\hline $\mathrm{HEV}$ & hybrid electric vehicle & SP & specific power \\
\hline $\mathrm{HV}$ & high voltage & $\mathrm{TC}$ & thermocouple \\
\hline $\mathrm{IC}$ & integrated circuit & THS & Toyota Hybrid System \\
\hline ICE & internal combustion engine & USCAR & United States Council for \\
\hline ID & inner diameter & & Automotive Research \\
\hline IGBT & insulated-gate bipolar transistor & VSATT & Vehicle Systems Analysis \\
\hline LV & low voltage & & Technical Team \\
\hline MG & motor-generator & & \\
\hline MPG & niles per gallon & & \\
\hline
\end{tabular}




\section{INTRODUCTION}

Subsystems of the 2008 Lexus $600 \mathrm{~h}$ hybrid electric vehicle (HEV) were studied and tested as part of an intensive benchmarking effort carried out to produce detailed information concerning the current state of nondomestic alternative vehicle technologies. Feedback provided by benchmarking efforts is particularly useful to partners of the Vehicle Technologies collaborative research program as it is essential in establishing reasonable yet challenging programmatic goals which facilitate development of competitive technologies. The competitive nature set forth by the Vehicle Technologies program not only promotes energy independence and economic stability, it also advocates the advancement of alternative vehicle technologies in an overall global perspective. These technologies greatly facilitate the potential to reduce dependency on depleting natural resources and mitigate harmful impacts of transportation upon the environment.

\subsection{PROGRAM OVERVIEW}

The U.S. Department of Energy (DOE) and United States Council for Automotive Research (USCAR) (composed of automotive manufacturers General Motors, Ford, and Chrysler) are currently part of a cooperative research effort known as the FreedomCAR Partnership. The cooperative effort represents DOE's commitment to developing public/private partnerships to fund high-risk, high-payoff research into advanced automotive technologies. The long-term focus of DOE's Vehicle Technologies Program is to develop "leap frog" technologies that will provide Americans with greater freedom of mobility and energy security, while lowering costs and reducing impacts on the environment [1]. Program activities include research, development, demonstration, testing, technology validation, and technology transfer.

As a part of the Vehicle Technologies program, the Advanced Power Electronics and Electric Machines (APEEM) subprogram provides support through a three-phase approach which is intended to:

- Identify overall propulsion and vehicle-related needs by analyzing programmatic goals and reviewing industry's recommendations and requirements, then develop the appropriate technical targets for systems, subsystems, and component research and development (R\&D) activities;

- Develop and validate individual subsystems and components, including electric motors and power electronics (PEs), accessories, and devices to reduce parasitic losses; and

- Determine how well the components and subassemblies work together in a vehicle environment or as a complete propulsion system and whether the efficiency and performance targets at the vehicle level have been achieved.

The research performed in this area will help remove technical and cost barriers to enable the development of technology for use in such advanced vehicles as hybrid electric, plug-in hybrid electric, electric, and fuel-cell-powered vehicles.

\subsection{RESEARCH FACILITIES}

Subsystem-level evaluations are conducted by Oak Ridge National Laboratory's (ORNL) Power Electronics and Electric Machinery Research Center (PEEMRC), which is a broad-based research center for PEs and electric machinery (motor) development. Located in the national user facility known as the National Transportation Research Center (NTRC), the PEEMRC has more than 9,000 square feet of space for developing and building the next generation prototypes of PEs and electric machine technologies. 


\subsection{SCOPE AND OBJECTIVE}

Benchmarking efforts at the PEEMRC support the Vehicle Technologies program by providing the current status and capabilities of nondomestic technologies found in alternative vehicles such as HEVs. This information is crucial in determining and verifying targets for various initiatives within the Vehicle Technologies program. For example, feedback from an intensive electric motor evaluation aids program direction such that electric motor design projects have overall targets which are highly competitive with nondomestic technologies. The overall agenda of the benchmarking project is described by the following objectives:

- Provide status of non-domestic alternative vehicle technologies through assessment of design, packaging, fabrication, operation, and performance during comprehensive evaluations:

o Compare results with other alternative vehicle technologies; and

o Distribute findings in open literature.

- Support Vehicle Technologies program planning and assist in guiding research efforts:

o Confirm validity of the program technology targets; and

o Provide insight for program direction.

- Produce a technical basis that aids in modeling/designing :

o Supply data and other information necessary to develop and/or verify subsystem models.

- Foster collaborations with the Electrical and Electronics Technical Team (EETT) and the Vehicle Systems Analysis Technical Team (VSATT):

o Identify unique permanent magnet synchronous motor (PMSM), inverter, converter, drivetrain, and thermal management technologies; and

o Ascertain what additional testing is needed to support R\&D.

The PEEMRC performed subsystem benchmarking assessments of the 2004 Toyota Prius HEV in 20042005. This work has been fully reported in two reports [2,3]. Similar research and testing efforts were conducted with the hybrid subsystems of the 2005 Honda Accord [4] and 2007 Toyota Camry [5] in 2006 and 2007, respectively. This report presents the results from benchmarking evaluations of the 2008 Lexus LS 600h electric drive subsystems.

\subsection{APPROACH}

Benchmarking evaluations are separated into two primary categories: (1) design and packaging assessments and (2) subsystem and component testing. Design and packaging assessments include intensive studies of components and subsystems which yield benefits of lower cost, increased power density (PD), increased specific power (SP), enhanced operation, or improved durability in alternative vehicles. Component testing procedures entail comprehensive examinations of peak performance, continuous capabilities, and general operation characteristics. These studies typically focus on PEs, electric machines, and components integrated or associated with PEs and electric machines.

In order to ensure the HEV technology used in the 2008 Lexus LS 600h was fully benchmarked in tandem with the needs of the Vehicle Technologies program partners, an ORNL benchmarking evaluation plan was developed. After the plan was subjected to an internal review it was dispersed to the automotive manufacturer partners of USCAR within the EETT and various DOE national laboratories. A flow diagram which portrays the baseline benchmarking approach is shown in Fig. 1.1. Conclusions from the LS 600h design and packaging assessments are presented in Section 2 and empirical results from PMSM 
and power control unit (PCU) tests are provided in Section 3. Side-by-side comparisons of the LS 600h technologies are made with 2007 Toyota Camry and 2004 Toyota Prius.

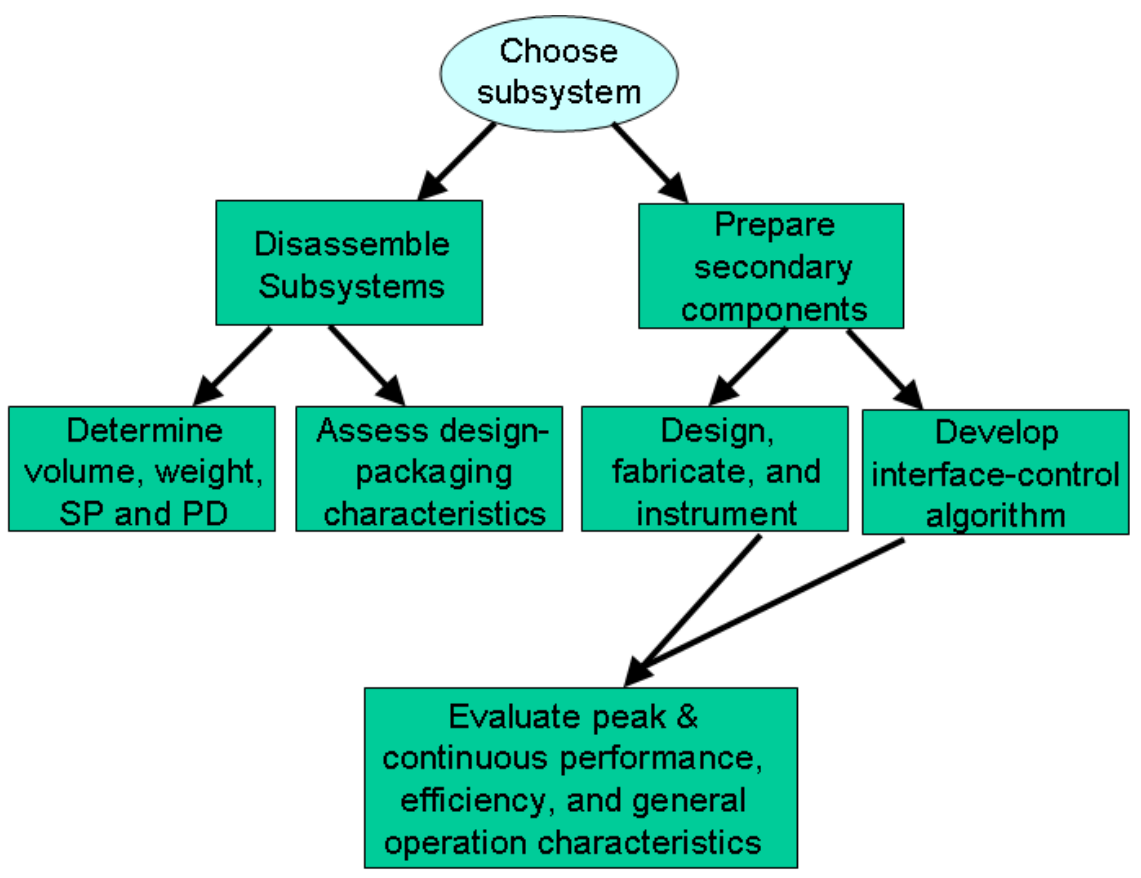

Fig. 1.1. Flow diagram of baseline benchmarking approach.

\section{HYBRID ELECTRIC DRIVE SYSTEM DESIGN AND PACKAGING}

This section presents a comprehensive report of the design and packaging characteristic assessments of the 2008 Lexus LS 600h HEV subsystems. After a general description of the vehicle design is provided, explanations of the hybrid system functionalities are presented with accompanying illustrations and photographs. Then in depth exposition begins with the PCU, wherein converter and inverter components such as PEs devices and capacitors are fully examined. Finally, the electronically-controlled continuously variable transmission (ECVT) is thoroughly reviewed and focus is placed on the thermal management system, gear train, PMSM design, and PM characteristics. Detailed comparisons between the 2008 Lexus LS 600h, 2007 Toyota Camry, and 2004 Toyota Prius design and packaging characteristics are provided in each subsection.

\subsection{VEHICLE DESCRIPTION}

The 2008 Lexus LS 600h, shown in Fig. 2.1 [6], is the third hybrid to be added to the Lexus product lineup. Considered a premium luxury hybrid with a base manufacturers suggested retail price (MSRP) of $\$ 104,000$, it is an upgrade from its predecessor, the GS $450 \mathrm{~h}$, which is considered the first highperformance hybrid in mass production. In terms of fuel economy, the LS $600 \mathrm{~h}$ is far from reaching the efficiency of the Camry and Prius, with an estimated fuel economy of 20 miles per gallon (MPG) for city driving conditions and $22 \mathrm{MPG}$ for highway driving conditions. The full-time all-wheel-drive train is powered by a $389 \mathrm{hp}(290 \mathrm{~kW}) 5.0$-Liter V8 internal combustion engine (ICE) and with the help of the $49 \mathrm{hp}(36.5 \mathrm{~kW})$ battery pack, the system has a net power rating of $438 \mathrm{hp}(326.6 \mathrm{~kW})$. The fuel-tank on the LS $600 \mathrm{~h}$ has the capacity to hold 22.2 gallons of the required premium-grade 91 octane unleaded fuel [7]. 


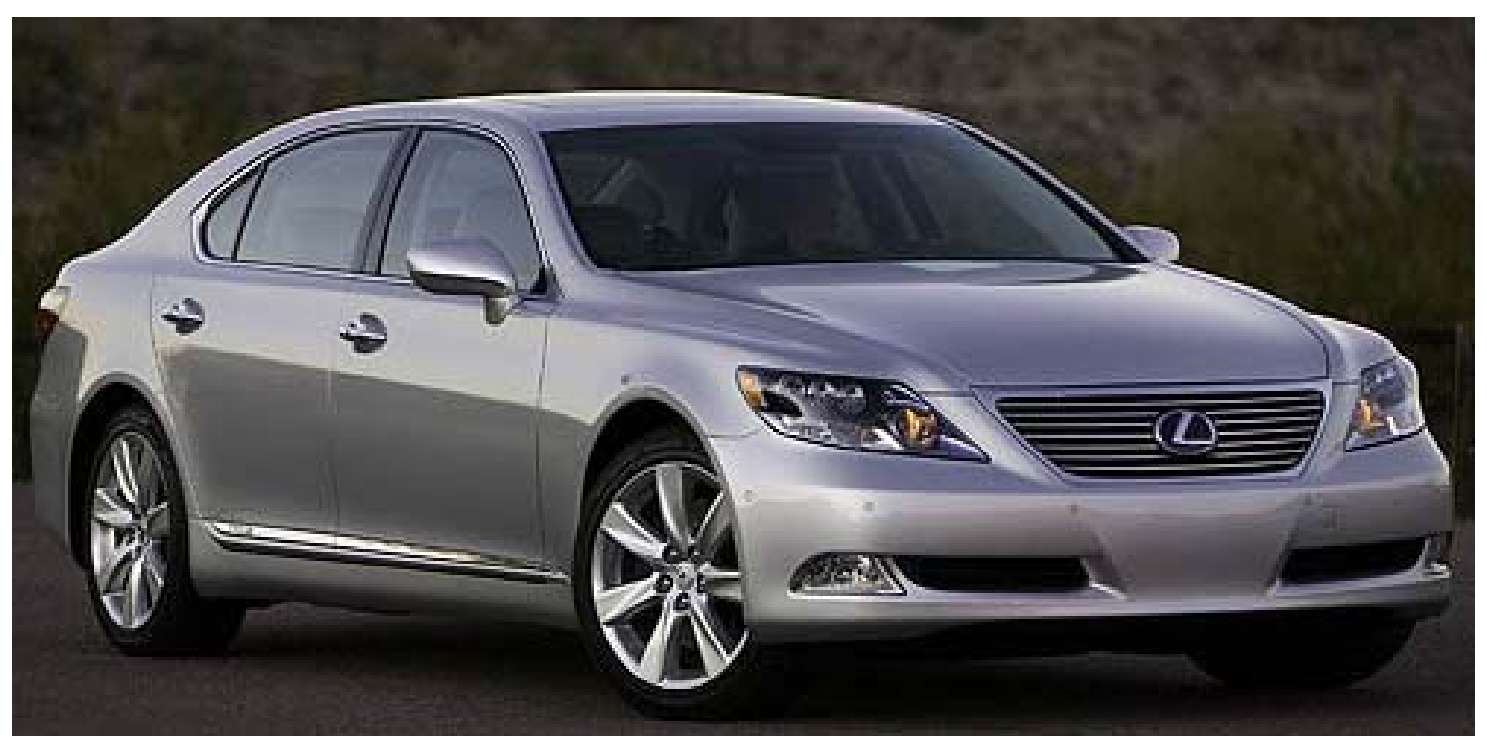

Fig. 2.1. 2008 Lexus LS 600h [6].

\subsubsection{Hybrid Drive System}

The overall functionality of the Lexus LS 600h hybrid drive system is quite similar to the functionality of the Hybrid Synergy Drive of the Toyota Prius and Camry. The systems include an ICE, an electric motor, and a generator which are interconnected by a power splitting planetary gear which provides various power flow configurations for different modes of operation. The primary electric motor (MG2) assists the ICE in providing mechanical drive power for the vehicle and also acts as a generator to recharge the battery during regenerative braking. A secondary electric motor (MG1) functions as a generator to transfer power from the ICE to recharge the battery and also to utilize the ICE as a power source to supply MG2.

These vehicles can utilize the electric motor to provide all of the traction power during acceleration from a stop. This operation mode is valid unless the engine is needed for any of several reasons (more torque, low battery state of charge, high battery temperature, proper engine temperature, etc.). The clutch-less, ECVT contains a planetary gear which allows various schemes of power flow from the battery, ICE, and motor to the output shaft. The planetary gear configuration of the ECVT provides the opportunity to operate the ICE throughout a more efficient torque-speed range by appropriately controlling the torques and speeds of MG1 and MG2. Contained within the PCU are electronics devices which manage power flow to and from the battery, generator, and motor. The Lexus and Camry electric-machines are rated at $650 \mathrm{Vdc}$ and are liquid-cooled by means of a typical ethylene glycol mixture. Both systems use a sealed nickel metal hydride (Ni-MH) battery, yet the voltage has increased from $\sim 245 \mathrm{Vdc}$ to $288 \mathrm{Vdc}$, with 240 cells at 1.2 volts each. The maximum power output of the battery is $49 \mathrm{hp}(\sim 36.5 \mathrm{~kW})$.

Although the functionality of the ECVT and PCU are similar to the Hybrid Synergy Drive components of the Toyota HEVs, there are considerable differences in the design and packaging characteristics of the systems. The primary discrepancy between the LS 600h PCU and previous PCU designs is the introduction of a double-sided cooling technique which incorporates a PEs module with cooling plates for both the collector and emitter sides of the insulated-gate bipolar transistor (IGBT), as opposed to having a cooling plate only for the collector side of the IGBT. The double-sided cooling method greatly increases the capability to remove heat from the IGBTs and diodes and thereby reduces the constraints placed upon these high-power semiconductors. As for the ECVT, the LS 600h has an elongated transmission housing 
to supplement all-wheel drive capability in contrast with the front-wheel-drive transaxle configurations previously benchmarked. Consequently, the primary interior PM motor of the LS 600h has a smaller diameter, but is more elongated than its front-wheel-drive counterparts. This geometrical reformation is suited to the constraints associated with the undercarriage location of the ECVT. Published specifications suggest that the primary drive motor of the ECVT is rated at $165 \mathrm{~kW}$ and can purportedly produce 300 Newton meter $(\mathrm{Nm})$ up to 5,250 revolutions per minute $(\mathrm{rpm})$ and has a maximum rotational speed of $10,230 \mathrm{rpm}$. The motor is connected to the primary drive shaft through a gear ratio much like that of the Camry, however, the gear ratio of the Lexus can be selected to be high or low by means of a Ravigneaux gear system with a clutch and brake system. A differential gear is housed within the transmission housing of the Prius and Camry, yet the Lexus ECVT contains a transfer case which transfers power from the hybrid power system to both front and rear wheel drive shafts.

Table 2.1 presents an overview of several general HEV design features and published specifications and indicates similarities and differences between the Lexus, Camry, and Prius vehicles. The primary drive PMSM is referred to as MG2 and the generator is referred to as MG1. Although both PMSMs can function as a motor or a generator, MG2 is commonly referred to as "motor" and MG1 is commonly referred to as "generator." Both MG1 and MG2 are powered by separate three-phase inverters which share the same direct current (dc)-link. The battery voltage is boosted by a bi-directional dc-dc converter which feeds the dc-link. This configuration facilitates the use of multiple power flow modes wherein the ICE, MG1, and/or MG2 may supply energy to the battery pack, the battery pack may supply MG1/MG2 alone, or the ICE and battery pack can simultaneously power the vehicle.

Table 2.1. Comparison of HEV design features and published specifications

\begin{tabular}{|c|c|c|c|}
\hline Design Feature & 2008 LS 600h & Hybrid Camry & 2004 Prius \\
\hline Motor peak power rating & $\begin{array}{c}165 \text { kW@ } 5250 \text { rpm } \\
\text { (disputed) }\end{array}$ & $\begin{array}{l}105 \mathrm{~kW} @ 4500 \mathrm{rpm} \\
\text { (disputed to be } 70 \mathrm{~kW} \text { ) }\end{array}$ & $\begin{array}{c}50 \text { kW@1200- } \\
1540 \text { rpm }\end{array}$ \\
\hline Motor peak torque rating & $300 \mathrm{Nm}$ & $270 \mathrm{Nm}$ & $400 \mathrm{Nm}$ \\
\hline Rotational speed rating & $10,230 \mathrm{rpm}$ & $14,000 \mathrm{rpm}$ & $6,000 \mathrm{rpm}$ \\
\hline Separate generator used? & $\begin{array}{l}\text { Yes (although the motor also } \\
\text { serves as a generator during } \\
\text { regenerative braking) }\end{array}$ & Same as Lexus & Same as Lexus \\
\hline Generator specifications & Not published & Not published & $33 \mathrm{~kW}$ \\
\hline Source of power to MG2 & $\begin{array}{l}\text { Battery and/or ICE via } \\
\text { generator }\end{array}$ & Same as Lexus & Same as Lexus \\
\hline PMSM rotor design & $\begin{array}{l}\text { Interior PMs with triangular } \\
\text { configuration }\end{array}$ & Interior PMs with "V" & Similar to Camry \\
\hline $\begin{array}{l}\text { Motor winding } \\
\text { configuration }\end{array}$ & Parallel & Parallel & Series \\
\hline Number of rotor poles & 8 & Same as Lexus & Same as Lexus \\
\hline $\begin{array}{l}\text { Bi-directional dc-dc } \\
\text { converter output voltage }\end{array}$ & $\sim 288-650 \mathrm{Vdc}$ & $250-650 \mathrm{Vdc}$ & $200-500 \mathrm{Vdc}$ \\
\hline $\begin{array}{l}\text { Bi-directional dc-dc } \\
\text { converter power rating }\end{array}$ & $36.5 \mathrm{~kW}$ & $30 \mathrm{~kW}$ & $20 \mathrm{~kW}$ \\
\hline PMSM cooling & $\begin{array}{c}\text { Same as Camry, yet with oil } \\
\text { squirters for stator }\end{array}$ & $\begin{array}{c}\text { Oil circulation and } \\
\text { water/glycol heat exchanger }\end{array}$ & Same as Camry \\
\hline Inverter/converter cooling & Water/glycol loop & Same as Lexus & Same as Lexus \\
\hline Hybrid transmission & $\begin{array}{c}\text { Same as Camry, yet } \\
\text { Ravigneaux high and low } \\
\text { gear used for speed reduction }\end{array}$ & $\begin{array}{l}\text { Planetary gears used for } \\
\text { speed reduction and power } \\
\text { split }\end{array}$ & $\begin{array}{l}\text { A single planetary gear } \\
\text { used for power split }\end{array}$ \\
\hline $\begin{array}{l}\text { Fan-cooled high-voltage } \\
\text { (HV) Ni-MH battery }\end{array}$ & $\begin{array}{c}288 \mathrm{~V}, 6.5 \mathrm{Ah}, \\
36.5 \mathrm{~kW}\end{array}$ & $\begin{array}{c}244.8 \mathrm{~V}, 6.5 \mathrm{Ah}, \\
30 \mathrm{~kW}\end{array}$ & $\begin{array}{c}201.6 \mathrm{~V}, 6.5 \mathrm{Ah}, \\
20 \mathrm{~kW}\end{array}$ \\
\hline
\end{tabular}


Design and packaging assessments are presented in Subsections 2.2 and 2.3 beginning with the PCU and concluding with the ECVT, respectively. Studies on the PCU include subjects such as general design and packaging, double-sided cooling infrastructure, PE devices, and multifaceted capacitor assessments. Assessment topics associated with the ECVT are general design and packaging, PMSM design, and magnet hysteresis measurements. These assessments provide useful feedback regarding technological developments and other characteristics needed to determine packaging complexity and fabrication costs.

\subsection{PCU}

Much like the 2007 Camry PCU design, the size and proportions of the 2008 Lexus LS 600h shown in Fig. 2.2 are similar to that of a conventional $12 \mathrm{Vdc}$ car battery. The LS $600 \mathrm{~h}$ PCU weighs $17.90 \mathrm{~kg}$ and the Camry PCU weighs $17.86 \mathrm{~kg}$, yet the volume of the LS 600h PCU is moderately higher, primarily due to the larger side housing assembly which facilitates connectivity with the motor and generator. Coolant input and output ports are on each side of the $288 \mathrm{~V}$ connectors. The ethylene-glycol and water mixture flows from the PCU output port through a heat exchanger on the ECVT and to a radiator subsequently. One $288 \mathrm{~V}$ connector is used to connect directly to the battery pack and within the PCU is a fused link which branches off of the battery supply in order to deliver energy to the air conditioning $(\mathrm{A} / \mathrm{C})$ compressor. Motor and generator interconnections differ significantly from the Camry design in which only three bolts secure the cable harness to the PCU, where as the LS 600h design includes bolts which secure the cables directly to copper terminals in addition to the mechanical support from cable harness bolts.

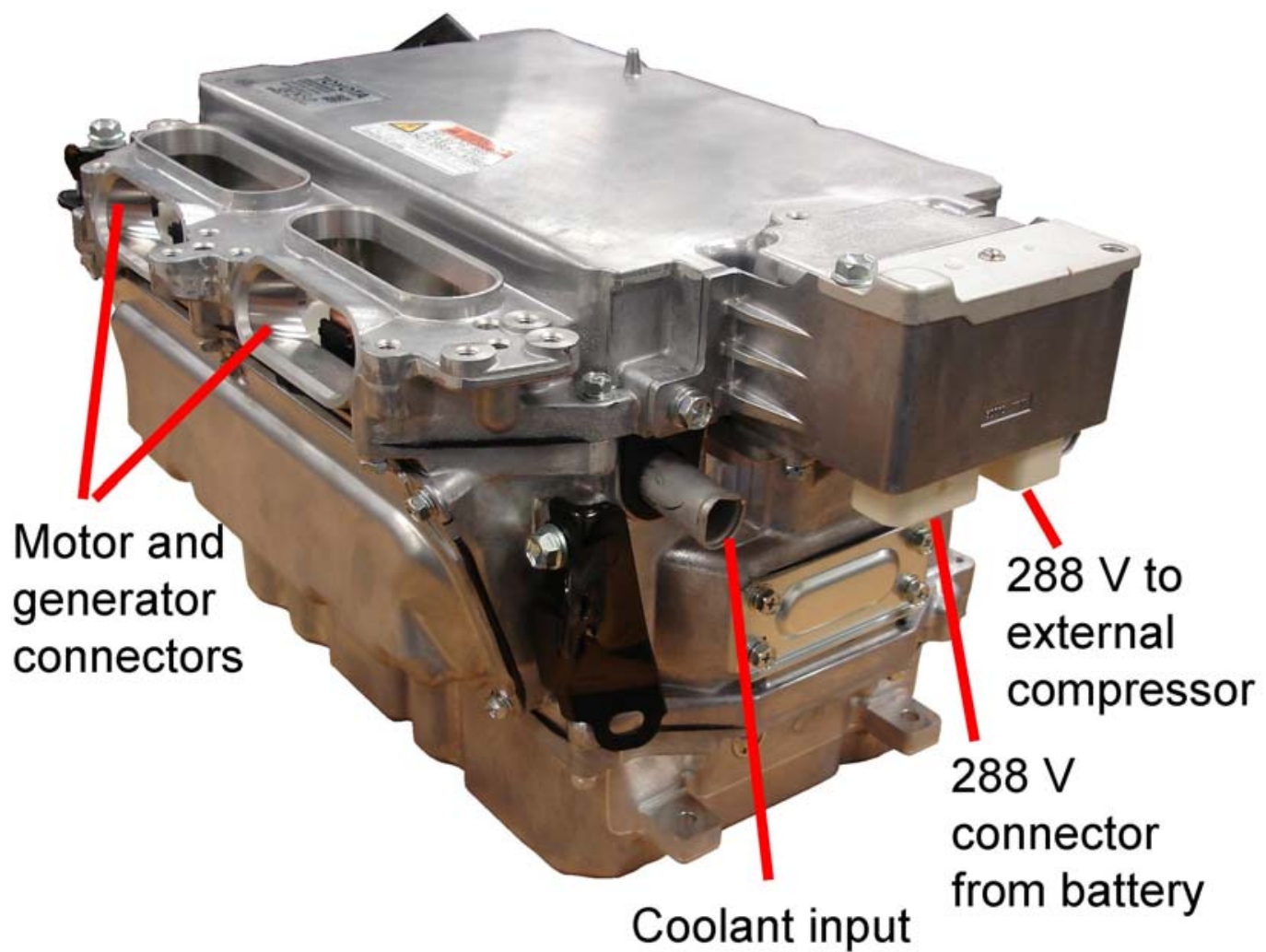

Fig. 2.2. PCU of the LS 600h.

Within the LS 600h PCU are components associated with a bi-directional dc-dc converter, motor inverter, and generator inverter and their general locations are shown in Fig. 2.3. Contrary to the Camry PCU 
design described in [5], the LS 600h controller, power supply, and driver electronics for the bi-directional $\mathrm{dc}-\mathrm{dc}$ converter and inverters are grouped together onto two printed circuit boards (PCBs) located in the uppermost compartment indicated in Fig. 2.3. The Camry PCU design includes four separate PCBs dedicated to these functions and the bi-directional dc-dc converter PCBs and PEs are located in a separate compartment. The LS 600h PEs devices are located in the compartment below the controller and driver electronics and the bi-directional dc-dc converter PEs are grouped together with the inverter PEs, as further explained in Section 2.2.1. Also located in this compartment is the double-sided cooling infrastructure. Below the PEs and cooling channel infrastructure are bus bars for the bi-directional dc-dc converter, generator inverter, and motor inverter connectivity. A HV filter cap and inductor are also located in this compartment. Note that the inductor housing extends downward from and completely through the PEs/cooling channels compartment. The bottom compartment contains a potted capacitor module which includes two capacitors. The largest embedded capacitor network attaches to the output of the bi-directional dc-dc converter, hereon referred to as the HV side. The low-voltage (LV) filter capacitor attaches to the input of the bi-directional dc-dc converter with a battery supply voltage of about $288 \mathrm{~V}$. Identical to the Camry PCU design, a small $54 \mathrm{k} \Omega$ ceramic resistor is connected the across the HV dc-link capacitor terminals and is located on the side of the PCU. The resistor functions as a voltage bleed-off for the capacitor and may contribute some filtering effects.

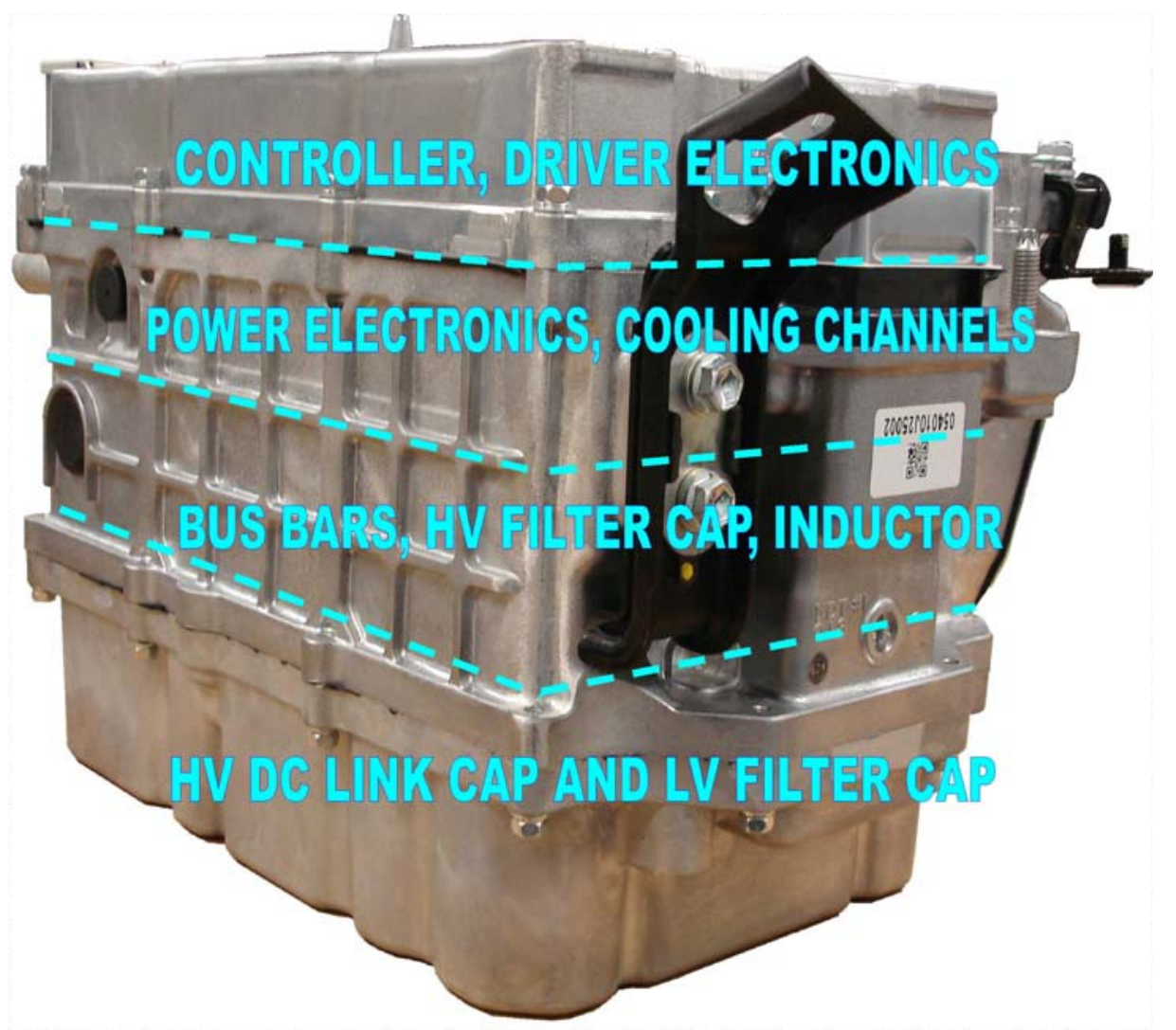

Fig. 2.3. Compartments of the LS 600h inverter and converter assembly.

Because the Ni-MH battery is rated at $36.5 \mathrm{~kW}$, it is assumed that the bi-directional dc-de converter will not operate at power levels exceeding $36.5 \mathrm{~kW}$. Similarly, it is assumed that the motor inverter has a peak power rating that matches the measured power rating of the motor. The overall circuit diagram of the PCU is shown in Fig. 2.4. A 288 Vdc battery supplies power to the PCU, which is connected to the LV side of the boost converter. A $500 \mathrm{~V}, 378 \mu \mathrm{F}$ capacitor is connected across the input with a $329 \mu \mathrm{H}$ 
inductor between the battery and the boost converter PEs module. A small $53.8 \mathrm{k} \Omega$ resistor, $750 \mathrm{~V}, 0.6 \mu \mathrm{F}$ and $1.2 \mu \mathrm{F}$ filter capacitor module, and $750 \mathrm{~V}, 2629 \mu \mathrm{F}$ smoothing capacitor is located on the HV side of the boost converter. This HV bus serves as the de link for both the motor and generator inverter. Table 2.2 provides specification comparisons between the components found in the Prius, Camry, and LS 600h PCU. The boosted voltage ranges from $288-650 \mathrm{Vdc}$ depending on driving conditions such as desired acceleration and required regenerative braking and is controlled accordingly by commands from the motor-generator (MG) electronic control unit (ECU) and the vehicle ECU. Detailed capacitor test results are provided in Section 2.2.4.

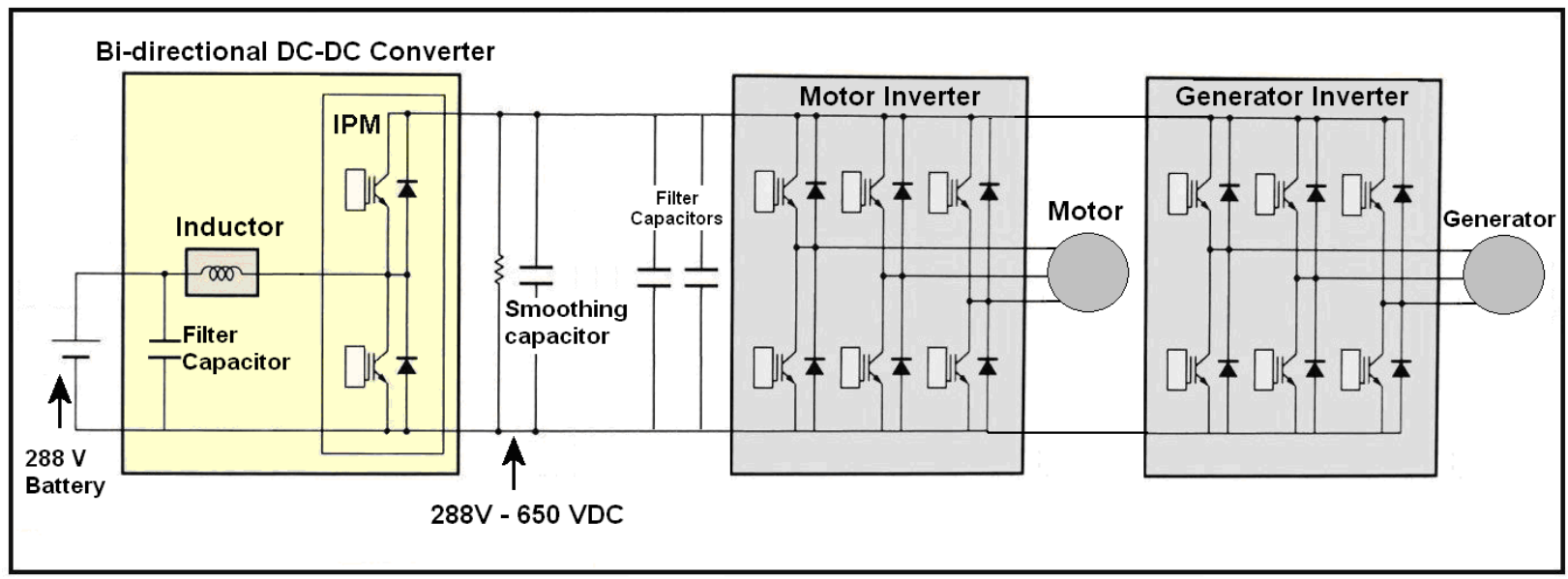

Fig. 2.4. Circuit diagram of LS 600h PCU.

Table 2.2. Comparison of hybrid Camry and the Prius PCU component specifications

\begin{tabular}{|c|c|c|c|}
\hline Design Feature & LS 600h & Hybrid Camry & 2004 Prius \\
\hline DC-dc converter power rating & $36.5 \mathrm{~kW}$ & $30 \mathrm{~kW}$ & $20 \mathrm{~kW}$ \\
\hline Battery voltage & $288 \mathrm{~V}$ & $244.8 \mathrm{~V}$ & $201.6 \mathrm{~V}$ \\
\hline Filter capacitor (LV side) & $500 \mathrm{Vdc}, 378 \mu \mathrm{F}$ & $500 \mathrm{Vdc}, 378 \mu \mathrm{F}$ & $600 \mathrm{Vdc}, 282 \mu \mathrm{F}$ \\
\hline Inductor & $329 \mu \mathrm{H}$ at $1 \mathrm{kHz}$ & $212 \mu \mathrm{H}$ at $1 \mathrm{kHz}$ & $373 \mu \mathrm{H}$ at $1 \mathrm{kHz}$ \\
\hline Small resistor (HV side) & $53.8 \mathrm{k} \Omega$ & $53.8 \mathrm{k} \Omega$ & $64.3 \mathrm{k} \Omega$ \\
\hline Small filter capacitor (HV side) & $\begin{array}{l}750 \mathrm{Vdc}, 0.6 \mu \mathrm{F} \\
750 \mathrm{Vdc}, 1.2 \mu \mathrm{F}\end{array}$ & $750 \mathrm{Vdc}, 0.9 \mu \mathrm{F}$ & $750 \mathrm{Vdc}, 0.1 \mu \mathrm{F}$ \\
\hline Smoothing capacitor (HV side) & $750 \mathrm{Vdc}, 2629 \mu \mathrm{F}$ & $750 \mathrm{Vdc}, 2098 \mu \mathrm{F}$ & $600 \mathrm{Vdc}, 1,130 \mu \mathrm{F}$ \\
\hline
\end{tabular}

\subsubsection{PCU Disassembly}

Figure 2.5 shows the driver and controller electronics compartment with the casing removed. Bus bars attached the battery connector extend from the lid down to the LV capacitor terminals. An interlock signal is fed through the bus bar compartment to the other side of the control board in order to disable the system if the battery connector is removed. As indicated in Fig. 2.6, the uppermost board is double-sided and includes power regulation electronics, two identical MG microprocessors, a boost-converter microprocessor, two Tamagawa AU2802 integrated circuits (ICs) for MG speed/position detection, hardware for vehicle communication, MG current measurement, safety interlock devices, and temperature feedback. Layout schemes of the driver/power supply board are quite different from that of the Camry, yet there are some general similarities between the driver circuits. The driver board includes regulated isolation power supplies, isolated driver electronics, and hardware to prevent faults and overlapping as well as voltage, current, and temperature sensing circuitry for each IGBT. There are 24 groups of 5 pins 
for driving and sensing purposes for each IGBT, as indicated in Fig. 2.6. More information regarding the PEs modules for the inverters and converter is provided in Sections 2.2.2 and 2.2.3.

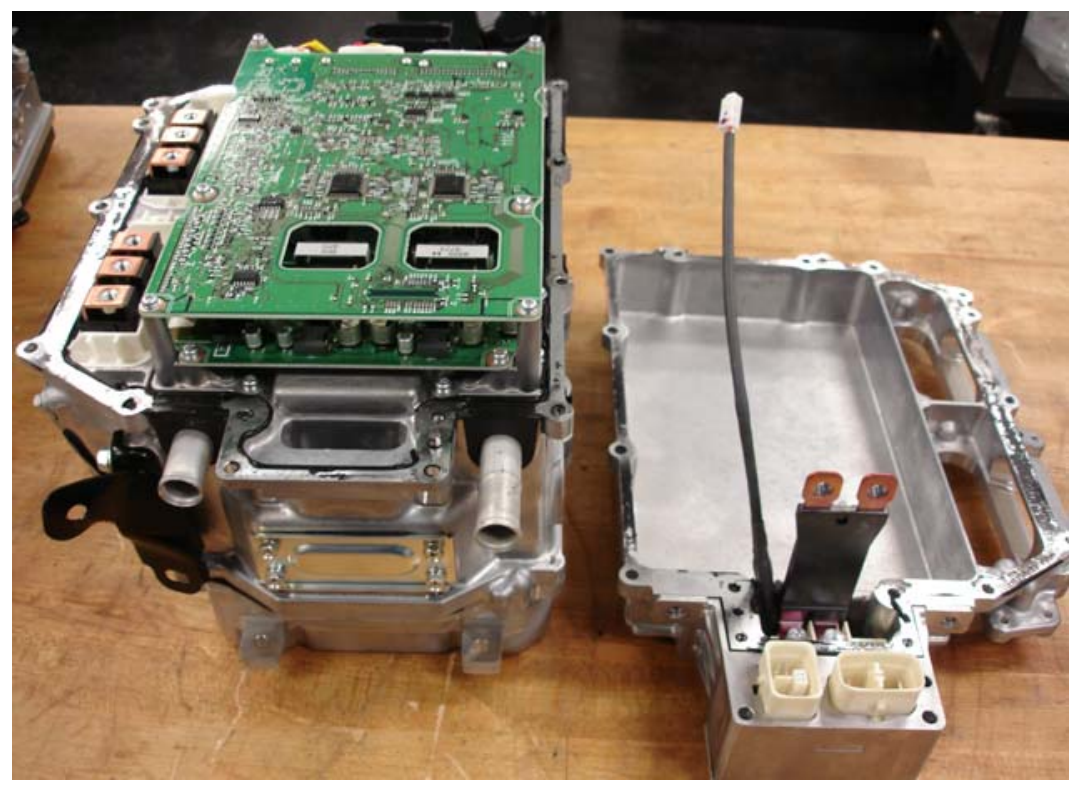

Fig. 2.5. Controller/driver electronics compartment with lid removed.

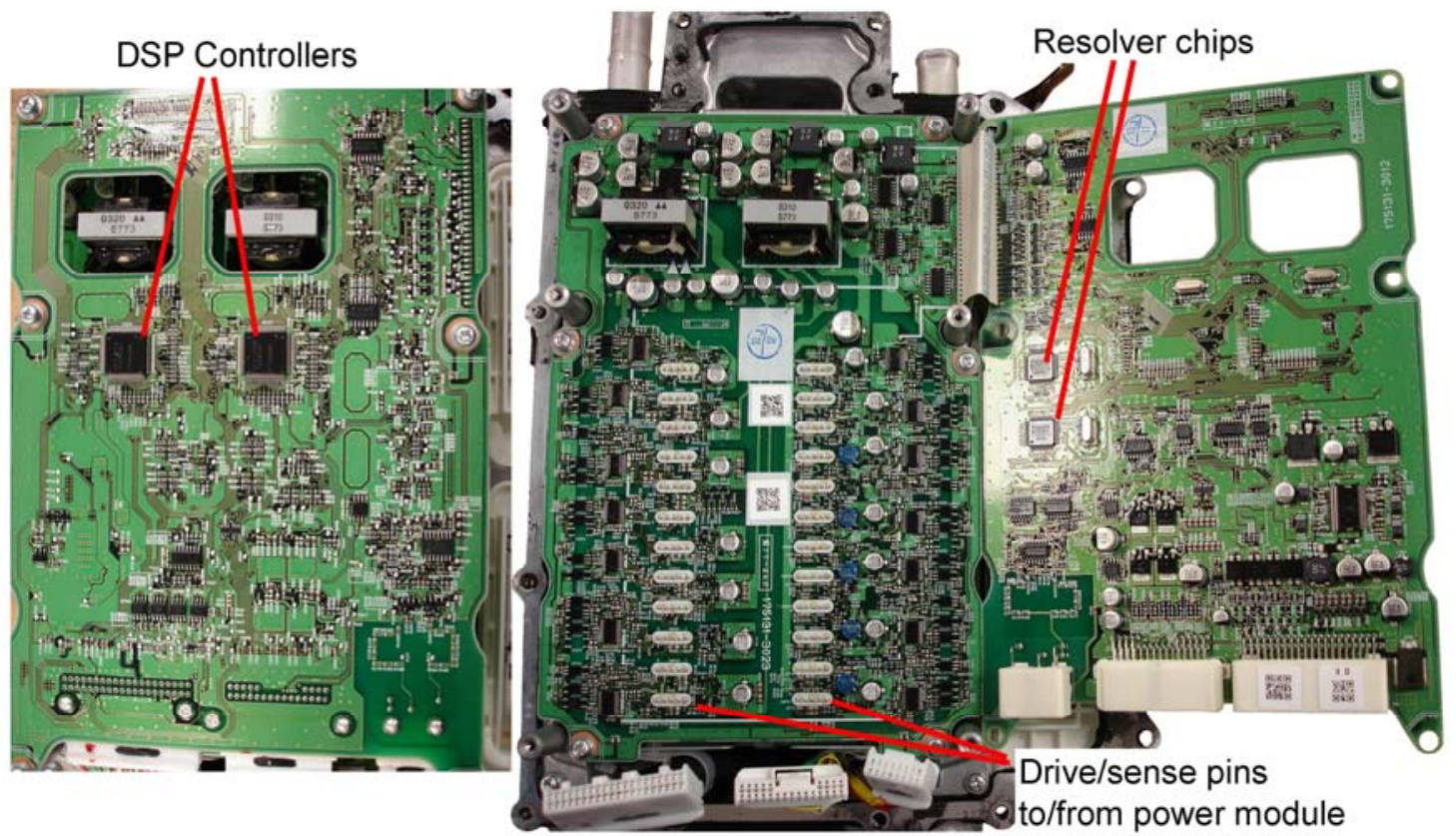

Fig. 2.6. Controller and driver circuitry for dc-de convert and inverters.

In Fig. 2.7, the large capacitor module has been removed and the underside of the PEs and bus bar compartments are visible. A ceramic $54 \mathrm{k} \Omega$ resistor connects to the $\mathrm{HV}$ capacitor terminals and is located within the trapezoidal extension on the right side of the large capacitor in Fig. 2.7. The large capacitor module has five terminals extending upward to the bus bar compartment. Bus bars inside the large capacitor module connect these terminals together and are indicated by blue lines. The long blue line represents the internal bus bar which serves as a common between the LV and HV capacitors, as well as 
the dc-dc converter. All currents supplied by the battery travels through this bus bar. The short blue line represents an internal bus bar which connects the positive $288 \mathrm{Vdc}$ battery voltage to the input of the inductor. The output of the inductor is connected to the middle point of the dc-dc converter leg and the leg is in parallel with the motor and generator inverter legs, thereby connecting directly to the dc-link. This architecture is further described in Section 2.2.2. A thermistor is embedded within the potting compound of the inductor. The small HV filter capacitor module includes two separate capacitors and screws attach each terminal of the small module directly to the dc-link. After the small capacitor module is removed, the inverter and converter bus bar architecture is visible, as indicated in Fig. 2.8. Also shown in Fig. 2.8 are the three-phase motor and generator inverter outputs and current transducers (CTs) on two phases of each inverter. Slightly visible are cooling channels which straddle the PEs modules.

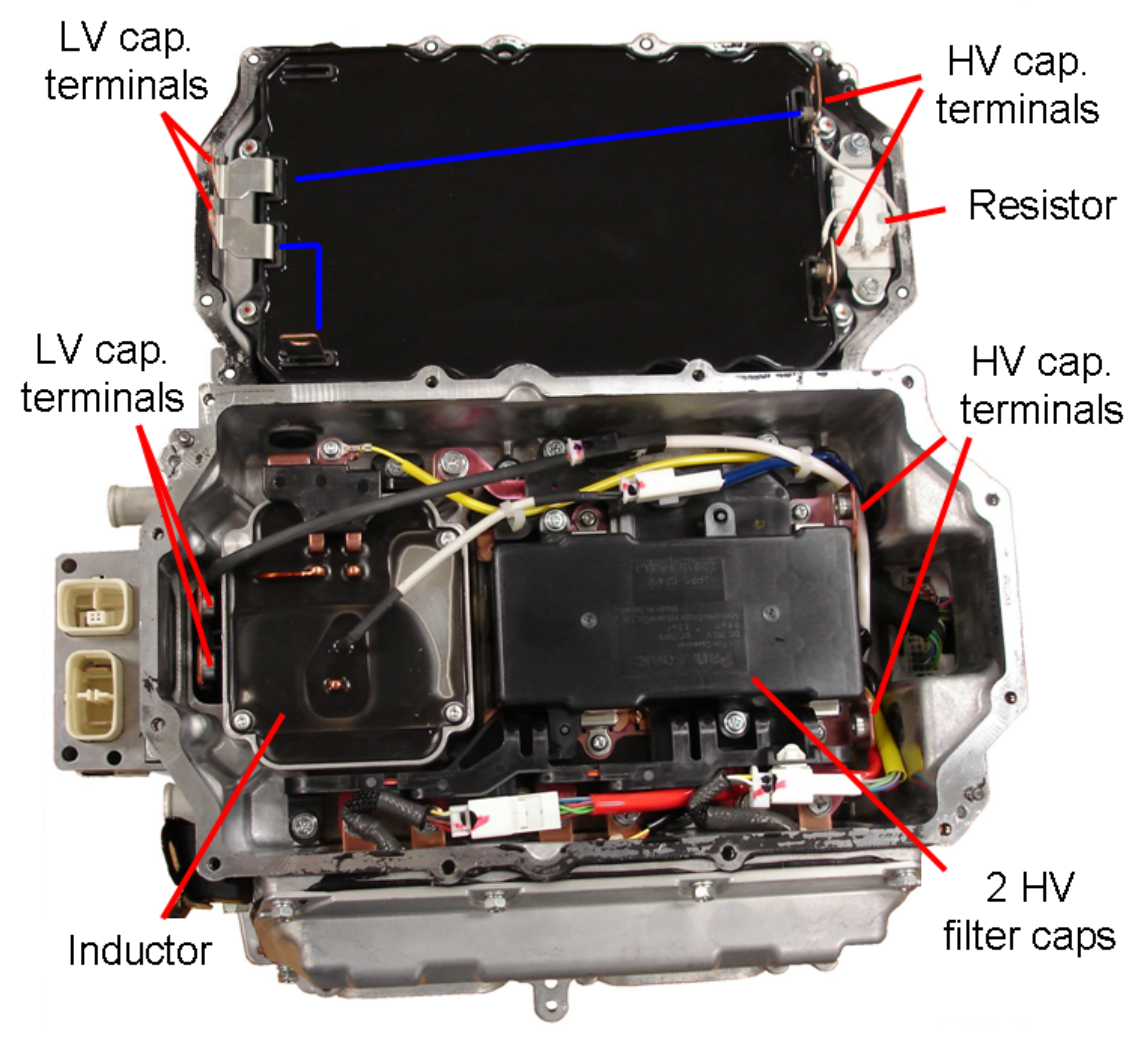

Fig. 2.7. PEs compartment (upside down) with dc-link capacitor and casing removed. 


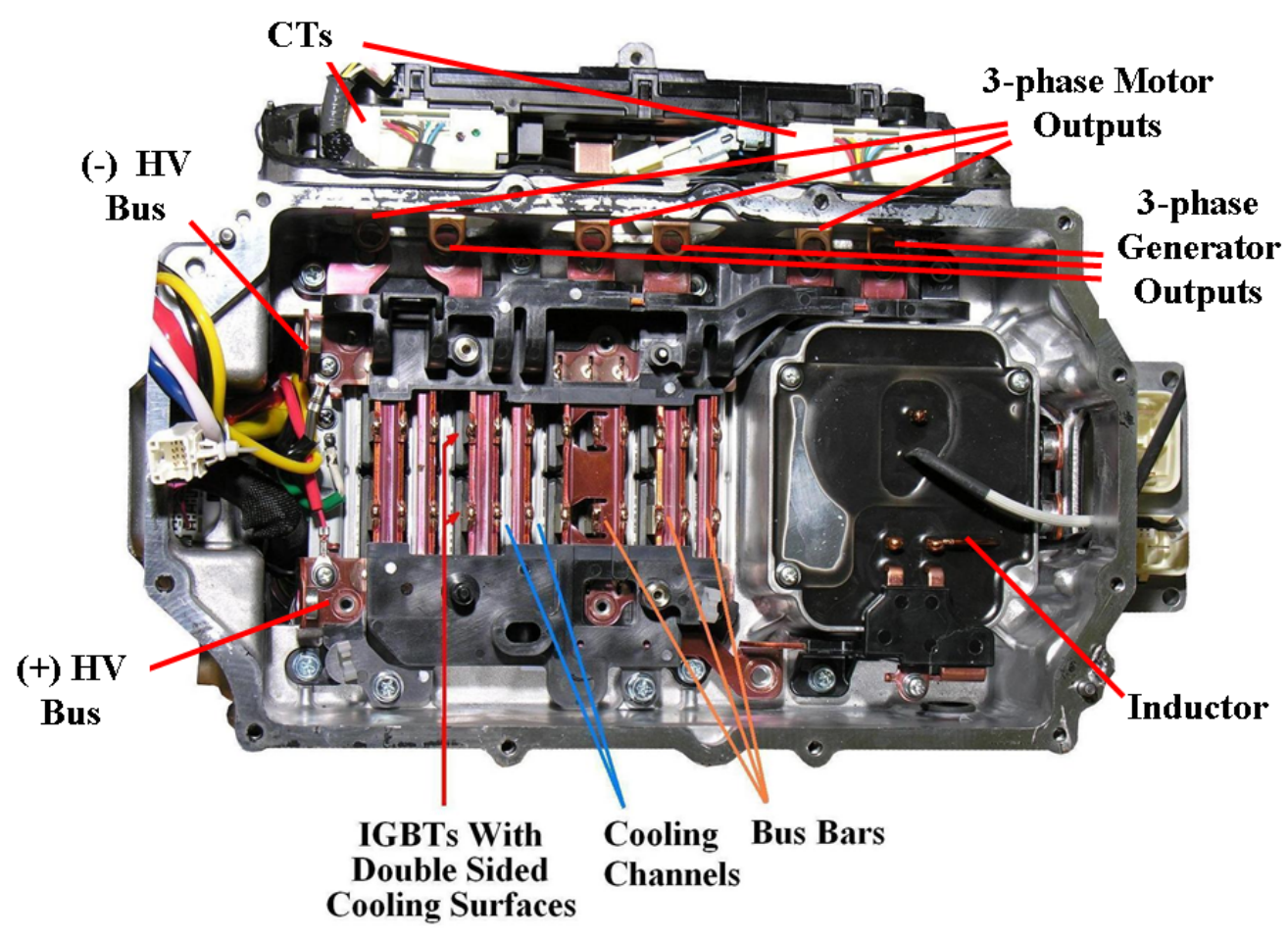

Fig. 2.8. Underside of PCU with large and small capacitor modules removed.

A close-up view of the bus bars is given in Fig. 2.9. Two contacts extend upward from each power module. The power modules are encased in a black, high-temperature plastic molding and each side of a cooling channel mates with an upper and lower PEs module of a converter or inverter. Shown in Fig. 2.10 is the entire PCU cooling infrastructure with the bus bar architecture removed. With a total of 24 double-sided PEs modules, there are 13 cooling channels which straddle the 12 sets of upper and lower PEs modules. As seen in Fig. 2.10, 12 thermocouples (TCs) were installed in various locations throughout the cooling infrastructure. Another perspective of the infrastructure is provided in Fig. 2.11. Note that the inductor has been removed and is normally situated in the rectangular opening adjacent to the driver board.

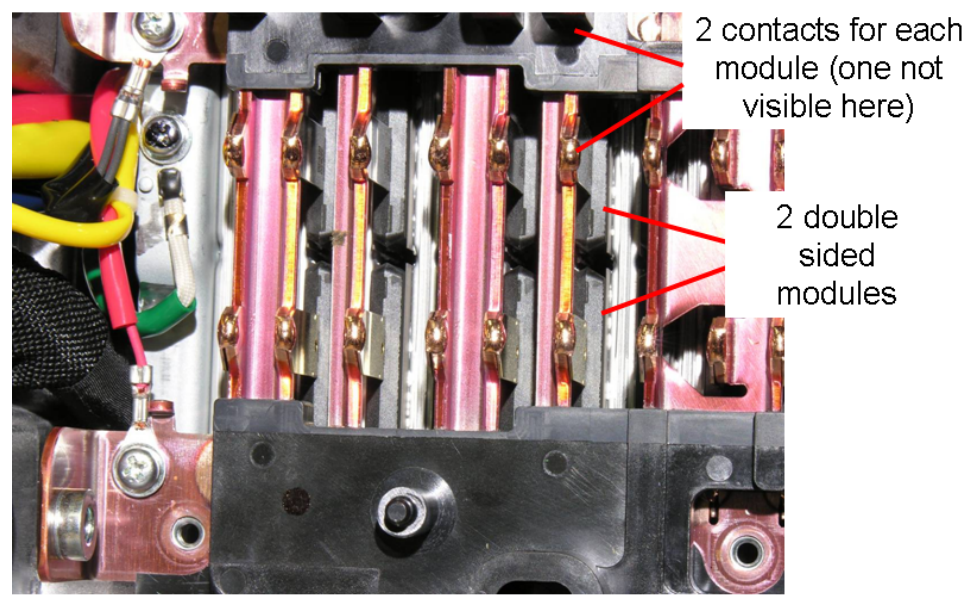

Fig. 2.9. Close-up of bus bar architecture. 


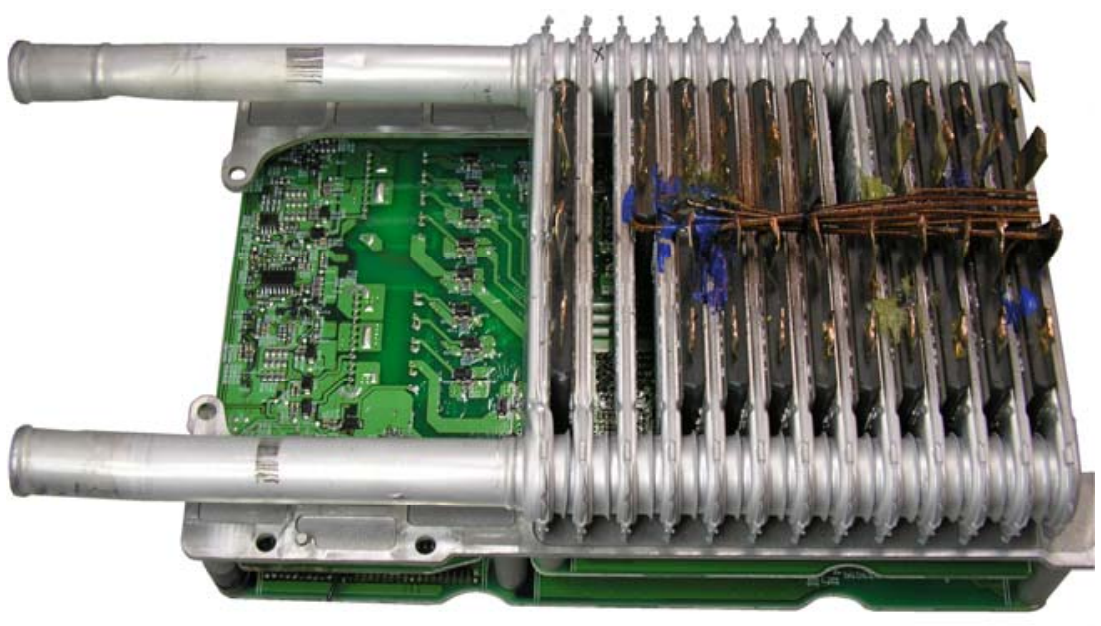

Fig. 2.10. Cooling channels straddle PEs modules.

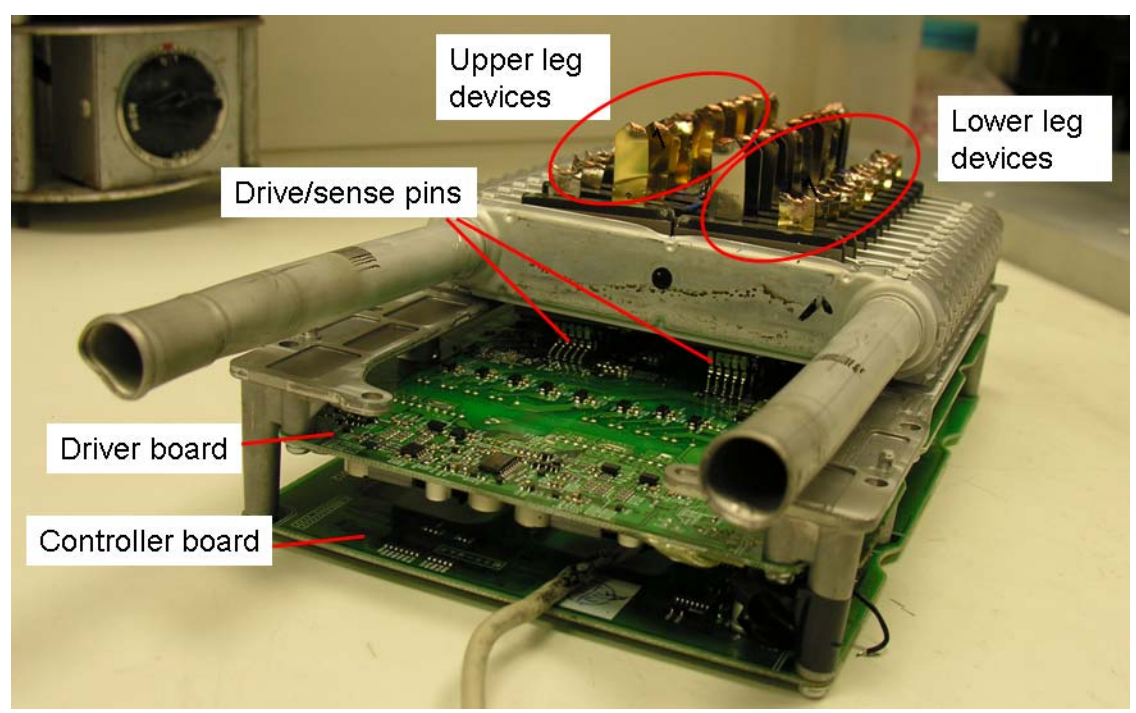

Fig. 2.11. Cooling infrastructure with drive/sense pins visible.

Table 2.3 provides mass and volume measurements of the LS $600 \mathrm{~h}$ motor inverter, dc-dc converter, and their sub-components. For certain components, the dimensions and volumes are approximate since the geometries are sometimes irregular. Much of the items of the PCU are shared between the inverters and dc-dc converter. Thus, the mass and volume of these items were tallied separately and then divided accordingly. As explained further in Section 2.2.2, 50\% of the PEs are dedicated to motor inverter, $25 \%$ to the generator inverter, and $25 \%$ to the dc-dc converter. It is therefore reasonable to distribute the mass and volumes of the shared items across the motor inverter, generator inverter, and dc-dc converter according to the percentages just mentioned. For example, about $50 \%$ of the driver board is dedicated to the motor inverter since $50 \%$ of the IGBTs are included in the motor inverter. Likewise, $25 \%$ of the mass and volume of the shared items is attributed to the dc-dc converter. The large capacitor module is the largest and heaviest item of the PCU. 
Table 2.3. Mass and volume measurements for the hybrid Camry inverter and converter

\begin{tabular}{|l|c|c|}
\hline \multicolumn{1}{|c|}{ Item } & Mass (kg) & Volume (L) \\
\hline $\begin{array}{l}\text { Inverter/converter as received from original } \\
\text { equipment manufacturers (OEM ) }\end{array}$ & 17.9 & $\sim 13.7$ \\
\hline Items shared by inverters and converter & 13.7 & 10.4 \\
\hline PEs, controller/driver boards, cooling infrastructure & 2.1 & $\mathrm{X}$ \\
\hline PEs, cooling infrastructure housing & 3.4 & 1.7 \\
\hline Controller, driver board housing & 1.2 & 2.2 \\
\hline Shared bus bars and small capacitor module & 1.2 & 1.9 \\
\hline Large capacitor module & 5.6 & 4.0 \\
\hline Connectors/sense wires/resistor & 0.2 & 0.6 \\
\hline Motor inverter & & \\
\hline Ratio from shared tally Complete motor inverter & 6.9 & 5.2 \\
\hline $\begin{array}{l}\text { Side housing assembly containing the three-phase bus } \\
\text { connectors and CTs. }\end{array}$ & 0.5 & 1.2 \\
\hline \multicolumn{1}{|c|}{ Complete converter } & $\mathbf{7 . 4}$ & $\sim \mathbf{6 . 4}$ \\
\hline Bi-directional dc-dc converter & 3.4 & 2.6 \\
\hline Ratio from shared tally & 2.8 & 0.9 \\
\hline Inductor (without housing) & & 0.5 \\
\hline Bus bars, terminals, connectors & $\mathbf{4}$ \\
\hline \multicolumn{1}{|c|}{ Co.9 } \\
\hline
\end{tabular}

Based on the results shown in Table 2.3, Table 2.4 provides the peak PD and peak SP of both the motor inverter and the bi-directional dc-dc converter. Comparisons to corresponding estimates for the Camry and Prius are also shown. Although the power capability of the LS 600h motor inverter is much higher than that of the Camry, their masses are essentially equal and the volume increased only by about $7 \%$. Therefore, the SP and PD of the motor inverter improved drastically. Although the power capability of the bi-directional dc-dc converter increased by about $22 \%$, the mass only increased by about $4.5 \%$ and the volume increased by about 14\%. Thus, there was an improvement of the SP and PD of the boost converter, but not as significant as that of the motor inverter.

Table 2.4. SP and PD estimates for inverter/converter

\begin{tabular}{|l|cc|c|}
\hline \multicolumn{1}{|c|}{ Parameter } & LS 600h & Camry & Prius \\
\hline $\begin{array}{l}\text { Motor inverter peak SP (without converter), } \\
\text { kW/kg. }\end{array}$ & $110 / 7.4=\mathbf{1 4 . 9}$ & $70 / \sim 7.5=\sim \mathbf{9 . 3}$ & $50 / 8.8=\mathbf{5 . 7}$ \\
\hline $\begin{array}{l}\text { Motor inverter peak PD (without converter), } \\
\text { kW/L. }\end{array}$ & $110 / 6.4=\mathbf{1 7 . 2}$ & $70 / \sim 6=\sim \mathbf{1 1 . 7}$ & $50 / 8.7=\mathbf{5 . 7}$ \\
\hline Bi-directional dc-dc converter SP, kW/kg. & $36.5 / 6.9=\mathbf{5 . 3}$ & $30 / \sim 6.6=\sim \mathbf{4 . 5}$ & $20 / 4.8=\mathbf{4 . 2}$ \\
\hline Bi-directional dc-dc converter PD, kW/L. & $36.5 / 4=\mathbf{9 . 1}$ & $30 / 3.5=\mathbf{8 . 6}$ & $20 / 5.1=\mathbf{3 . 9}^{1}$ \\
\hline
\end{tabular}

This low converter PD is largely the result of the non-optimal packaging of the converter filter capacitor in the Prius inverter/converter housing.

All capacitors located within the LS 600h PCU are shown in Fig. 2.12 for a comparison of sizes. It is important to note that that the LS 600h capacitor module contains both capacitors which are connected to the HV and LV side of the bi-directional boost converter, whereas the Camry capacitors are housed in separate modules. Figure 2.13 shows the LS $600 \mathrm{~h}$ dc-link capacitor module and a negative image of an $\mathrm{x}-$ ray of the capacitor module. The $\mathrm{x}$-ray shows that there are 15 discrete sub-modules in parallel that form the $2,629 \mu \mathrm{F}$ capacitor, with each sub-module having a capacitance of $175 \mu \mathrm{F}$. The equivalent Camry and Prius capacitor has $12-87 \mu \mathrm{F}$ and $8-142 \mu \mathrm{F}$ sub-modules in parallel to provide a total capacitance of $2,098 \mu \mathrm{F}$ and $1,130 \mu \mathrm{F}$, respectively. Also visible are two $189 \mu \mathrm{F}$ sub-modules which are in parallel and 
form the $378 \mu \mathrm{F}$ battery level filter capacitor. Figure 2.14 shows the HV filter capacitor module and an $\mathrm{x}$ ray of the module which is connected to the inverter dc-link. As suggested by the $\mathrm{x}$-ray image, the $1.2 \mu \mathrm{F}$ capacitance is attained with $4-0.3 \mu \mathrm{F}$ sub-modules in parallel, and the $0.6 \mu \mathrm{F}$ capacitance is comprised of $2-0.3 \mu \mathrm{F}$ sub-modules. Similarly, the small $0.9 \mu \mathrm{F}$ capacitor is made up of two $0.45 \mu \mathrm{F}$ capacitors, as shown in Fig. 2.13. Various characteristics of these capacitors were measured and are presented in Section 2.2.3.

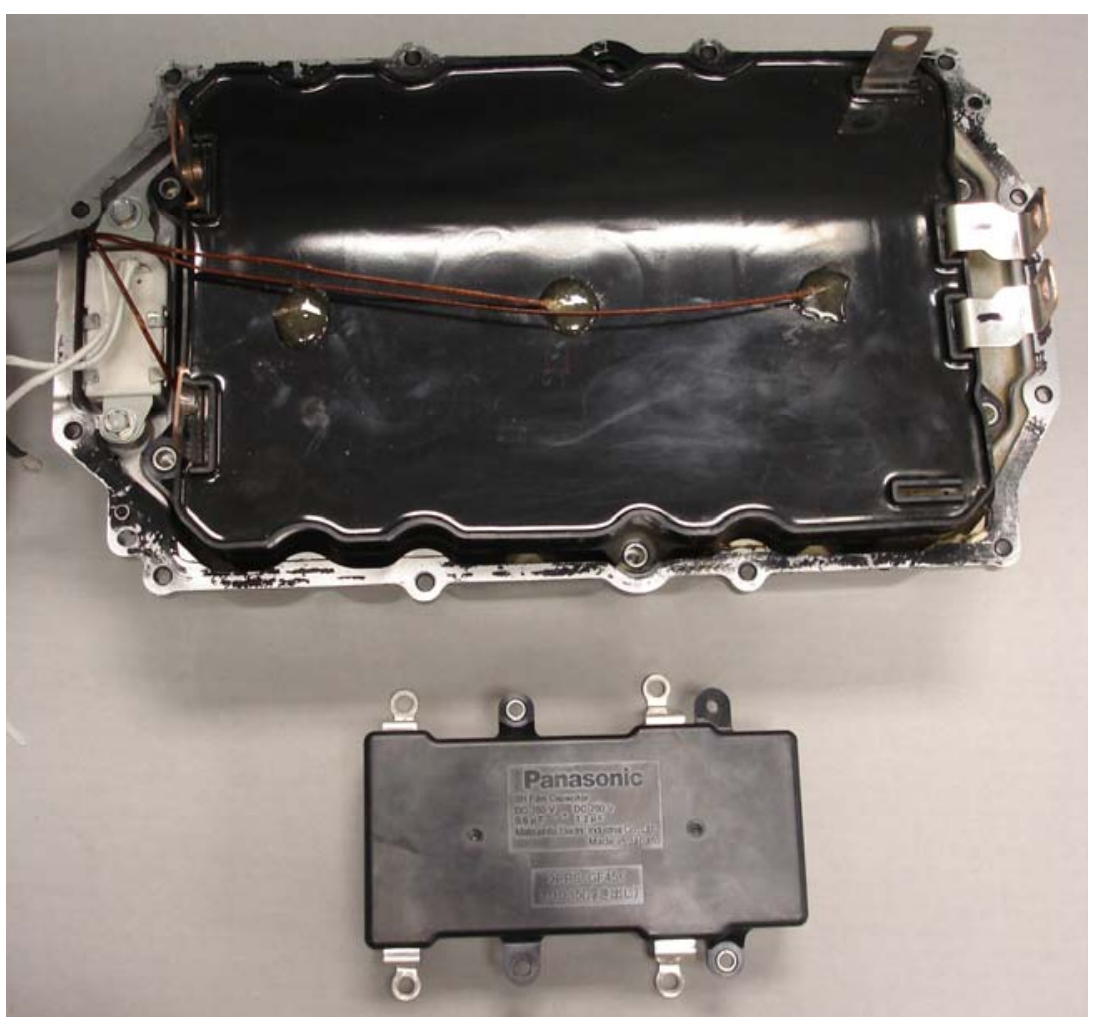

Fig. 2.12. Comparison of capacitors located within LS 600h PCU. 


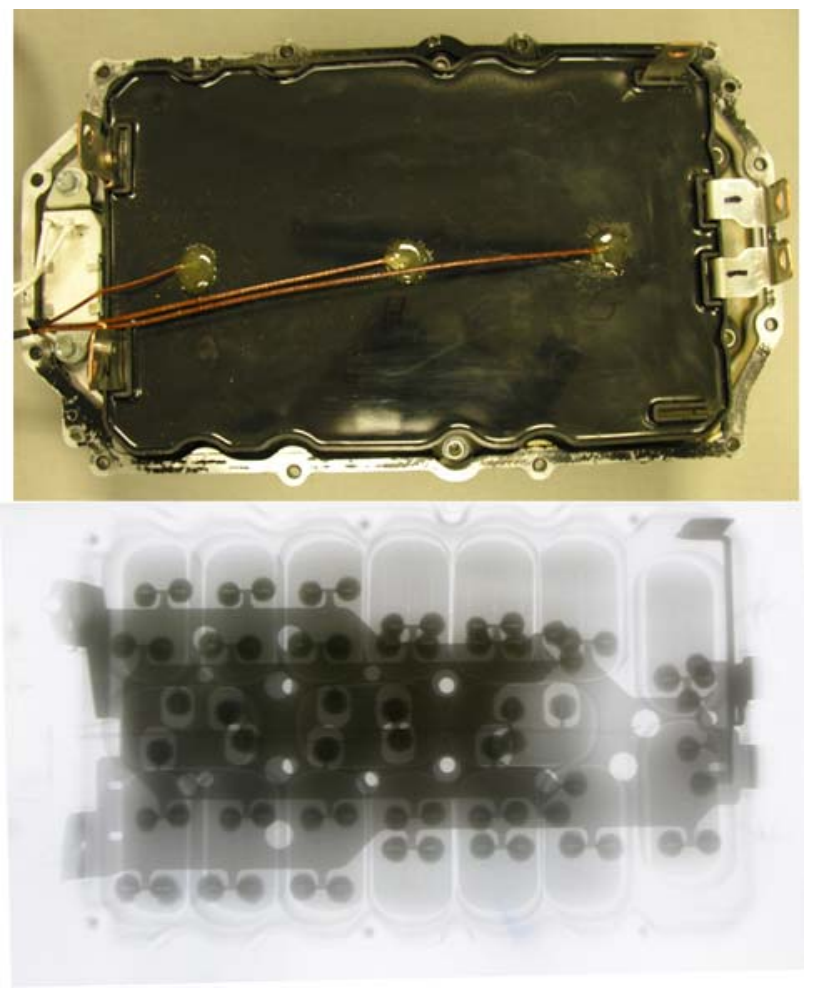

Fig. 2.13. DC-link capacitor module (upper) and $x$-ray of module (lower).
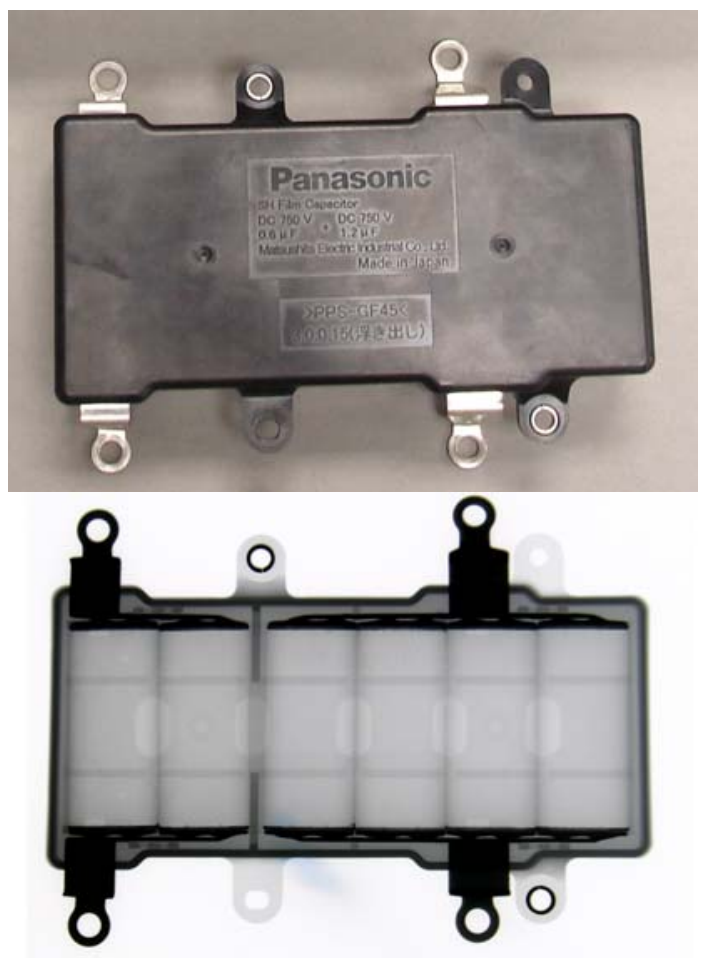

Fig. 2.14. HV filter capacitor (upper) and x-ray of module (lower). 
A primary function of these capacitors is to attenuate voltage transients and surges which are associated with the build-up and collapse of the energy stored in the $329 \mu \mathrm{H}$ inductor (shown in Fig. 2.15). The lower switch (3 IGBTs in parallel) of the dc-dc converter cycles at 5 or $10 \mathrm{kHz}$ with a variable duty cycle in order to build-up and store energy in the inductor. As the duty cycle is varied, the output voltage of the inductor also varies accordingly. Due to the inherent voltage ripple and potentially HVs produced by the collapsing inductor field, these capacitors serve to stabilize the battery voltage and dc-link voltage as well as protect the PEs devices from potential over-voltage conditions. The inductor has two coils in series and the core was secured with bolts and immersed in a potting compound.

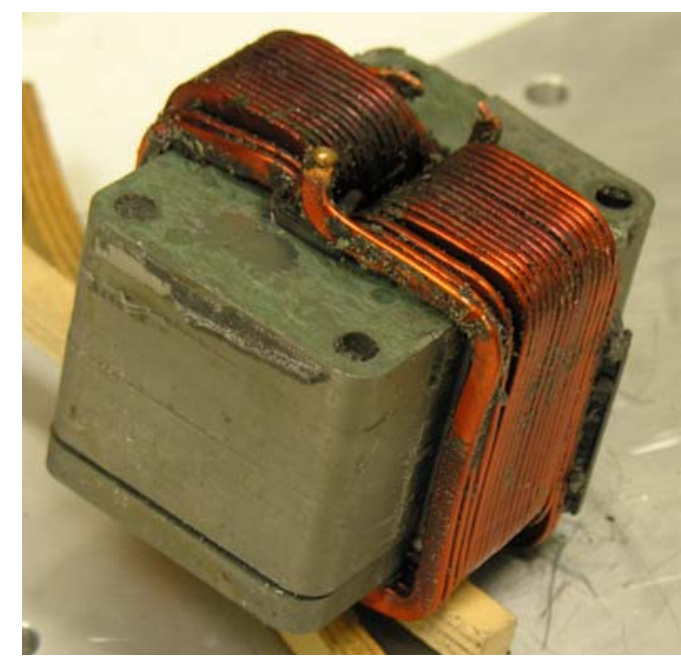

Fig. 2.15. Inductor for bi-directional dc-dc converter.

\subsubsection{PEs Module Disassembly}

A total of 24 PEs modules are located in the PCU, all sharing a common dc-link. These types of modules are often referred to as having a flat-packaged or press-packaged encapsulation. The copper bus bars for the motor inverter, generator inverter, and dc-dc converter are shown in Fig. 2.16. Each module contains one IGBT and one anti-parallel, free-wheeling-diode and has two copper bus bars, one of which connects to the dc-link and the other to the appropriate output bus bar. Only the weld for the latter is visible in Fig. 2.16, with the modules performing as upper and lower devices indicated. The most visible bus bar connects six of the dc-dc converter modules together, with three modules serving as the upper commutator and three serving as the lower commutator. This dc-dc converter output bus bar connects directly to the positive dc-link which supplies all modules of the motor and generator inverters. Each phase of the motor inverter consists of 4 modules, making a total of 12 modules for the entire motor inverter. Only two modules are used for each phase of the generator inverter and only a total of six modules for the entire generator inverter. Therefore, the motor inverter accounts for $50 \%$ of the modules and the dc-dc converter and generator inverter $25 \%$ of the modules. Although the peak power capability of the motor inverter has increased significantly when compared to the Camry, the amount of PEs used is only $2 / 3$ of the Camry design, as the Camry uses 18 IGBT-diode pairs for the motor inverter.

Prior to the disassembly stage shown in Figs. 2.10 and 2.11, a thin yet moderately firm metal bar was removed. As shown in Fig. 2.17, the metal bar serves as a compression spring and as pins secure each end of the spring, the center of the spring applies a compression force to the stacked cooling plates. This compression ensure that there is adequate and relative uniform contact between each PEs module and its adjacent cooling channels, thereby creating proper heat transfer conditions. After removing the spring, the power modules shown in Fig. 2.18 were easily removed. Ceramic silicon ( $\mathrm{Si}$ ) nitride plates are 
located between the power modules and the cooling channels for electrical insulation and thermal grease is present on both sides of the ceramic plates to improve thermal conductivity between the surfaces. The entire module is enclosed inside a black molding, which according to material analysis is primarily comprised of Si. Upon completing the rigorous task of removing the molding, there are two copper plates for the collector and emitter, shown in Fig. 2.19. Not shown in Fig. 2.19 are two conductive spacers that mate with the IGBT and diode and the emitter plate, as portrayed in Fig. 2.20. The IGBT and diode is soldered directly to the collector plate and solder is used on each side of the spacers. A profile of the layers in the module is given in Fig. 2.21. Note that the dimensions are exaggerated in order to provide greater visible of very thin layers.

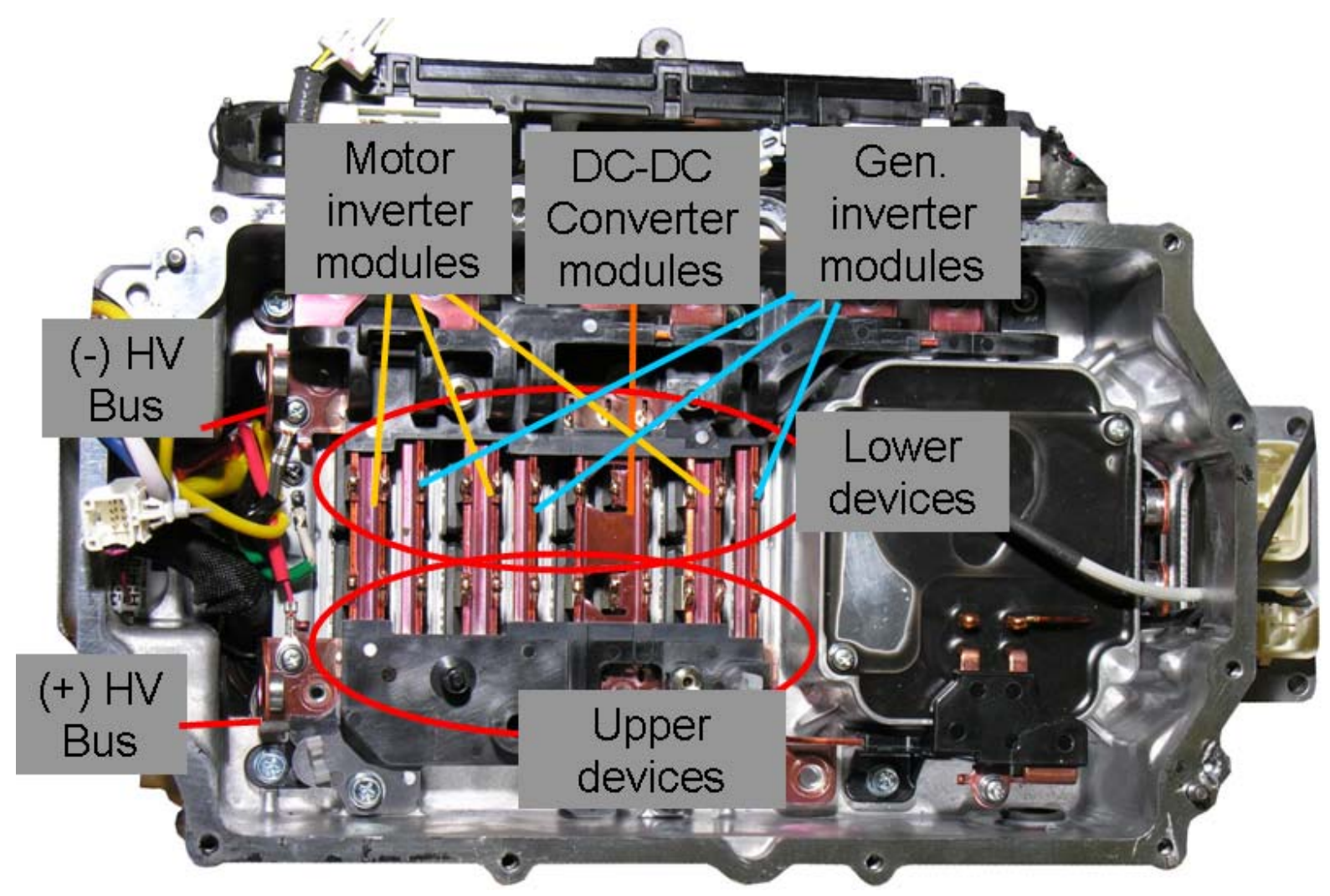

Fig. 2.16. Bus bar dedications in LS 600h PCU. 


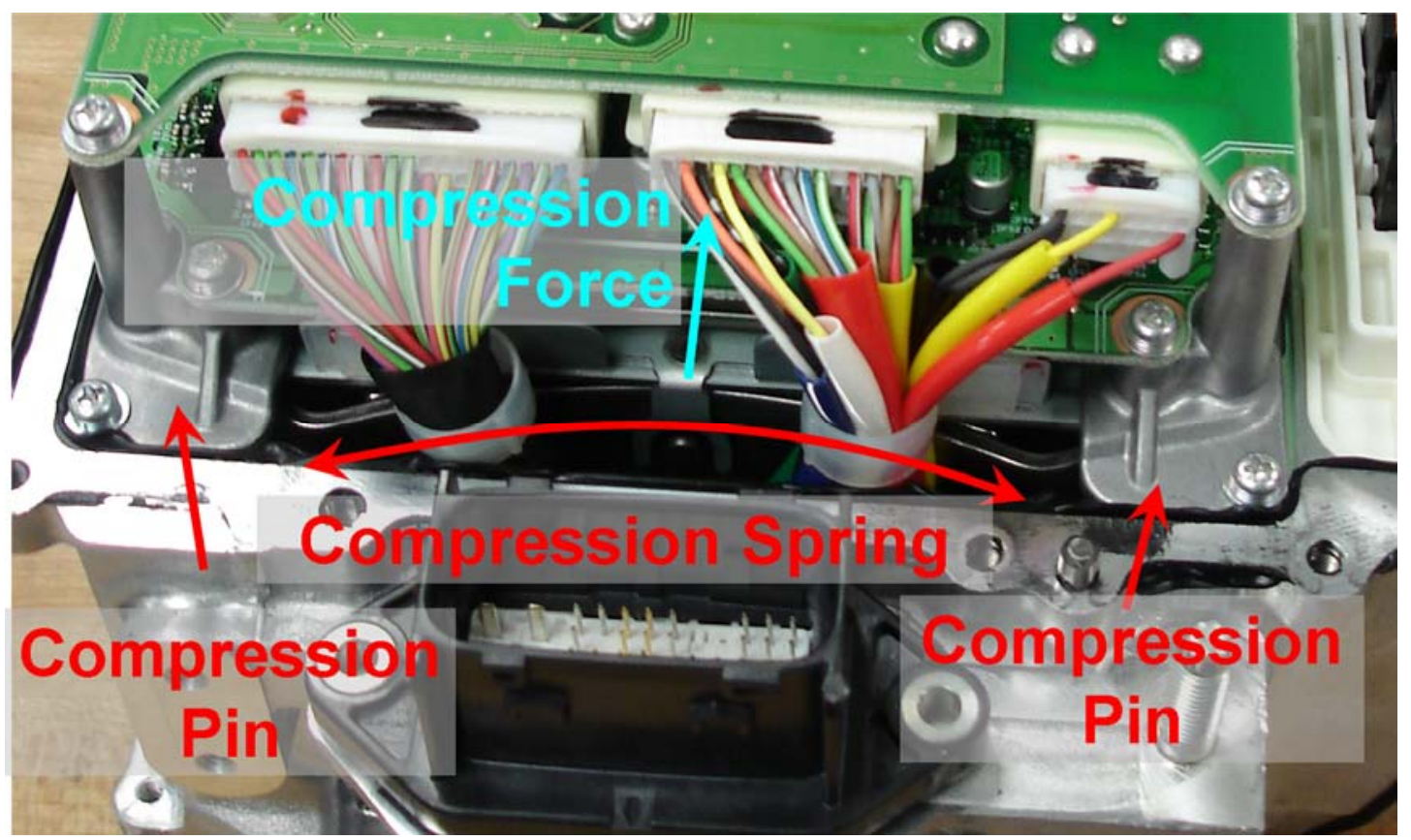

Fig. 2.17. Compression spring of LS 600h.

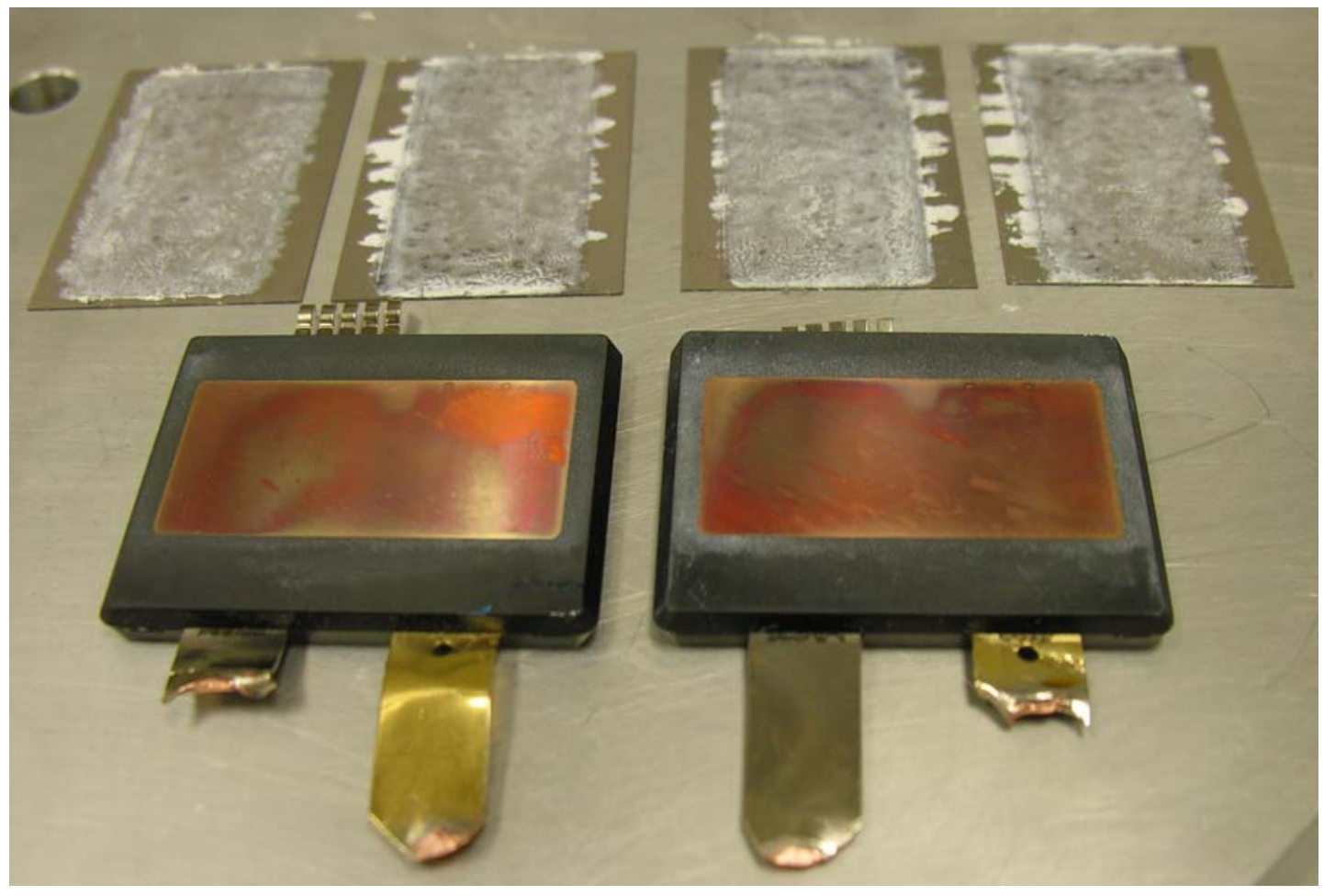

Fig. 2.18. LS 600h power module with Si nitride insulators. 


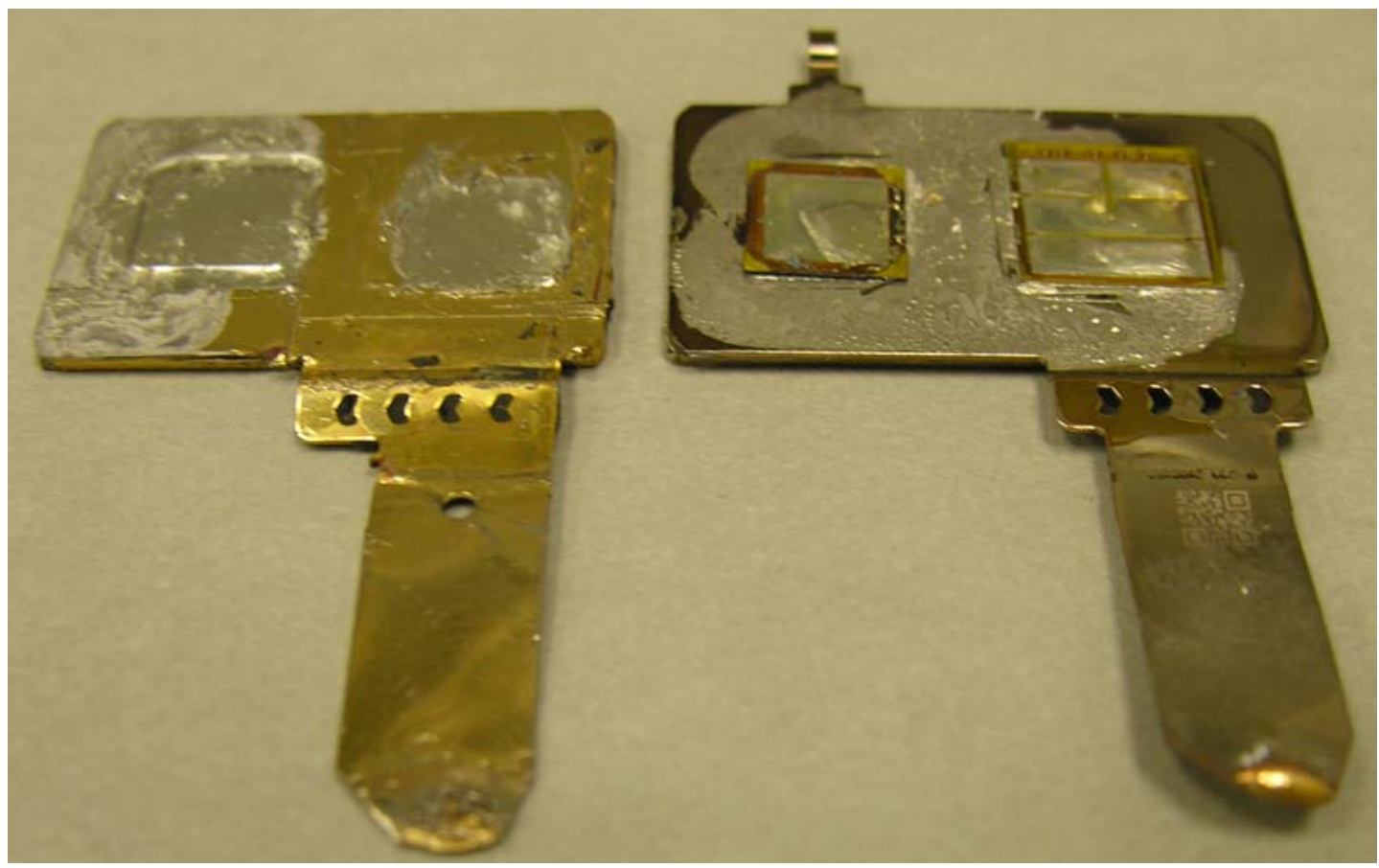

Fig. 2.19. LS 600h power module emitter and collector plates and bus bars.

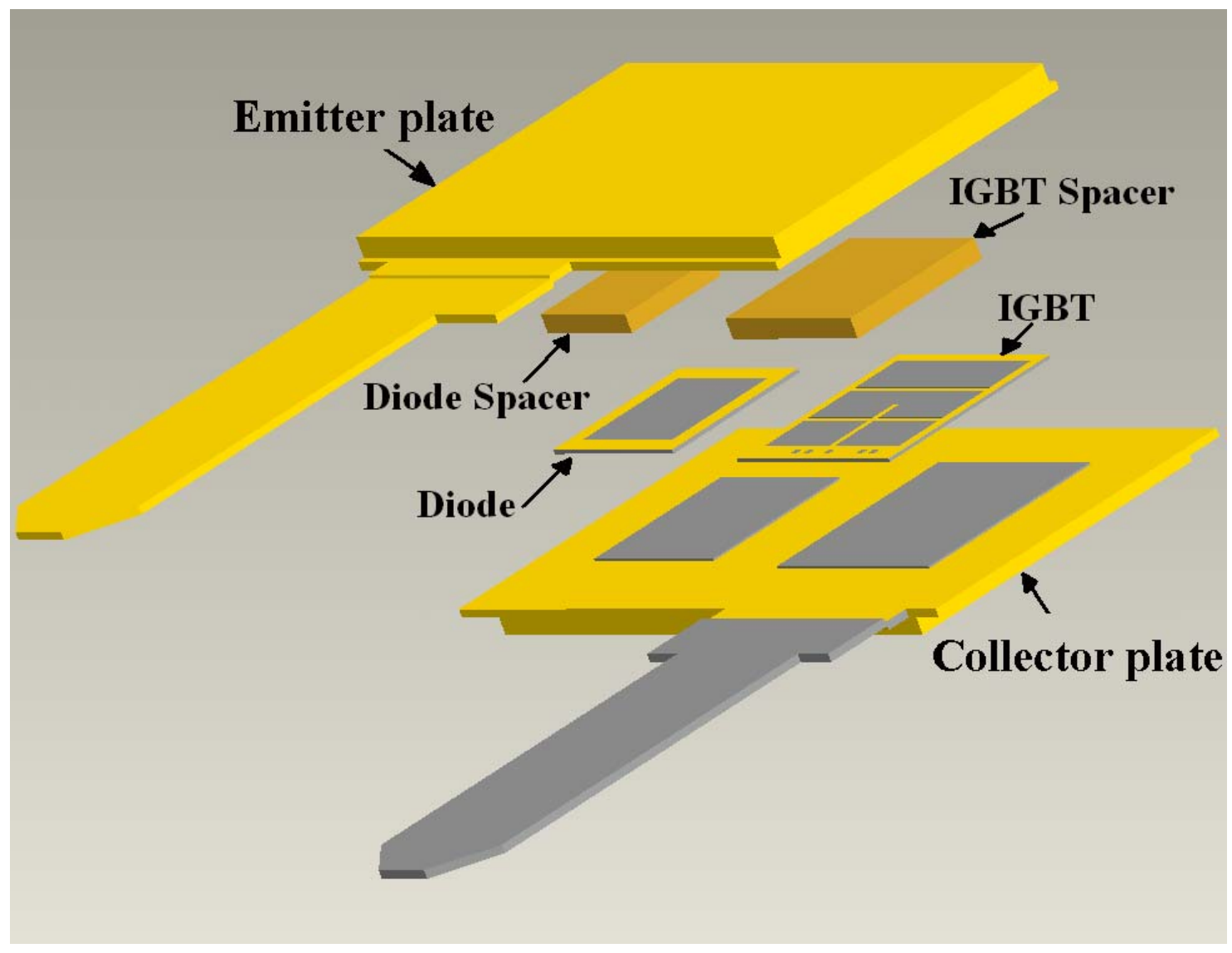

Fig. 2.20. Exploded view of LS 600h PEs module. 


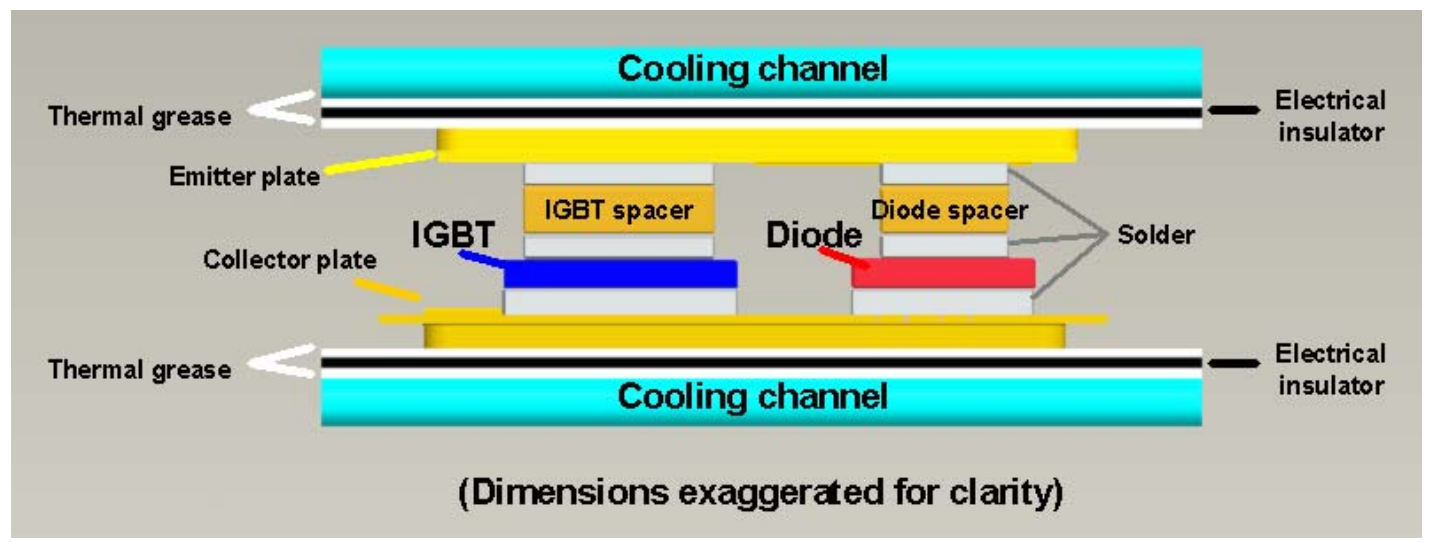

Fig. 2.21. Profile of LS 600h PEs module.

External dimensions of the PEs module are shown in Fig. 2.22. Note that the dimension labeled as 'c' is different for the collector and emitter plates. Near the bottom Fig. 2.22 are five drive/sense pins which extend from the module to the driver board. Dimensions of the IGBT and diode are provided in Fig. 2.23. The size and appearance of the LS 600h IGBTs and diodes are similar to that of the bi-directional dc-dc converter of the Camry, as shown in Fig. 2.24. Also noticeable in Fig. 2.23 are the small contact points for the drive/sense pins. After the drive/sense pins enter the module, they reduce significantly in size and are routed through the black Si molding to these small contact points. The dimensions of the Camry and Prius motor inverter PEs are given in Fig. 2.25. As indicated by the labeled dimensions, the square area of Si for each IGBT has increased from $120.3 \mathrm{~mm}^{2}$ to $163.3 \mathrm{~mm}^{2}$, yet the total square area of Si used on the motor inverter has decreased from $2165 \mathrm{~mm}^{2}$ to $1960 \mathrm{~mm}^{2}$, a $10 \%$ reduction in moving from the Camry to the LS $600 \mathrm{~h}$ design. Table 2.5 summarizes the device count, wire-to-Si bond count on the emitter surface (if any), and amount of Si used in the LS 600h, Camry, and Prius motor inverters and dcdc converters. The ratios of heat spreader area to total PE device Si area for the Camry and Prius motor inverter and dc-dc converter are also provided. However, since the LS 600h design is drastically different, there is not accurate comparison of such parameters. Nonetheless, it is important to note that the dimensions of the expensive Si nitride insulators, shown in the upper portion of Fig. 2.18, are $48.0 \mathrm{~mm} \times 33.0 \mathrm{~mm} \times 0.3 \mathrm{~mm}$. Dimensions of the IGBT and diode spacers are $9.86 \mathrm{~mm} \times 10.52 \mathrm{~mm} \times$ $1.19 \mathrm{~mm}$ and $7.09 \mathrm{~mm} \times 7.09 \mathrm{~mm} \times 1.14 \mathrm{~mm}$, respectively. The emitter and collector copper plates are $1.85 \mathrm{~mm}$ thick.

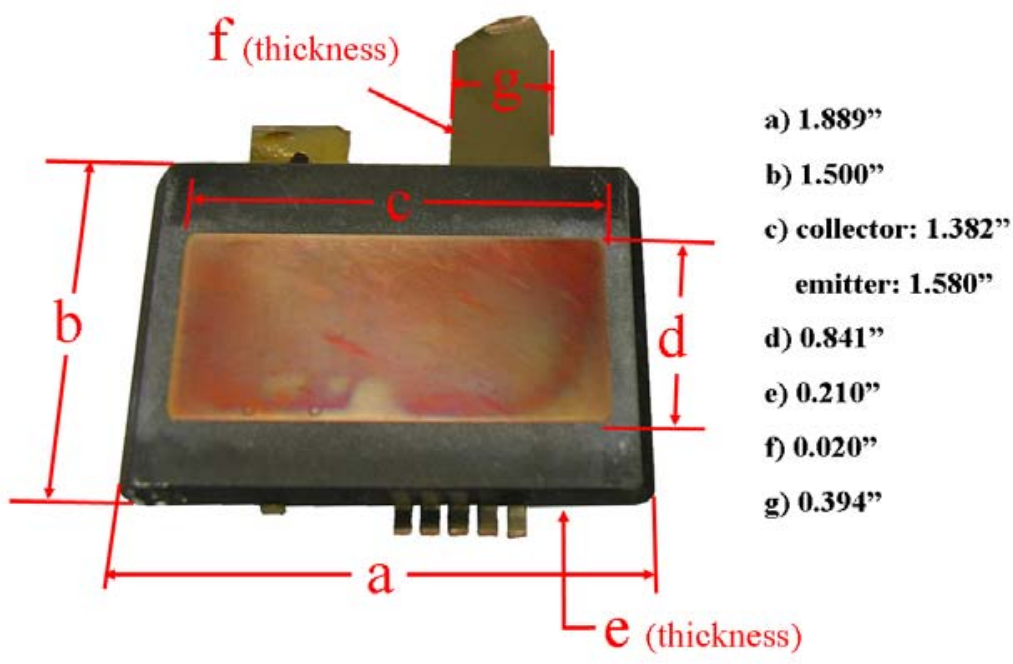

Fig. 2.22. LS 600h power module dimensions (in inches). 


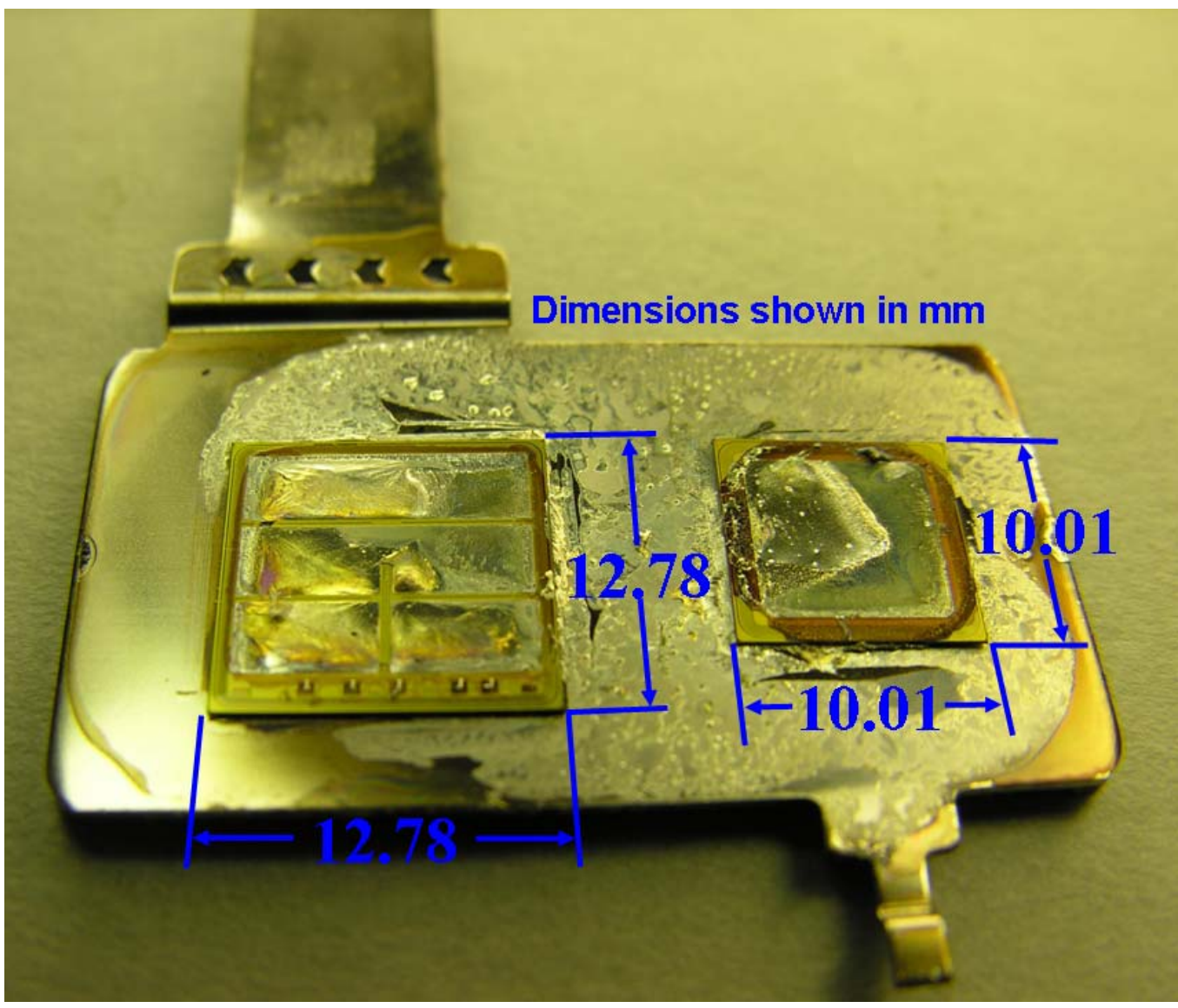

Fig. 2.23. Dimensions (in mm) of LS 600h IGBT and diode.

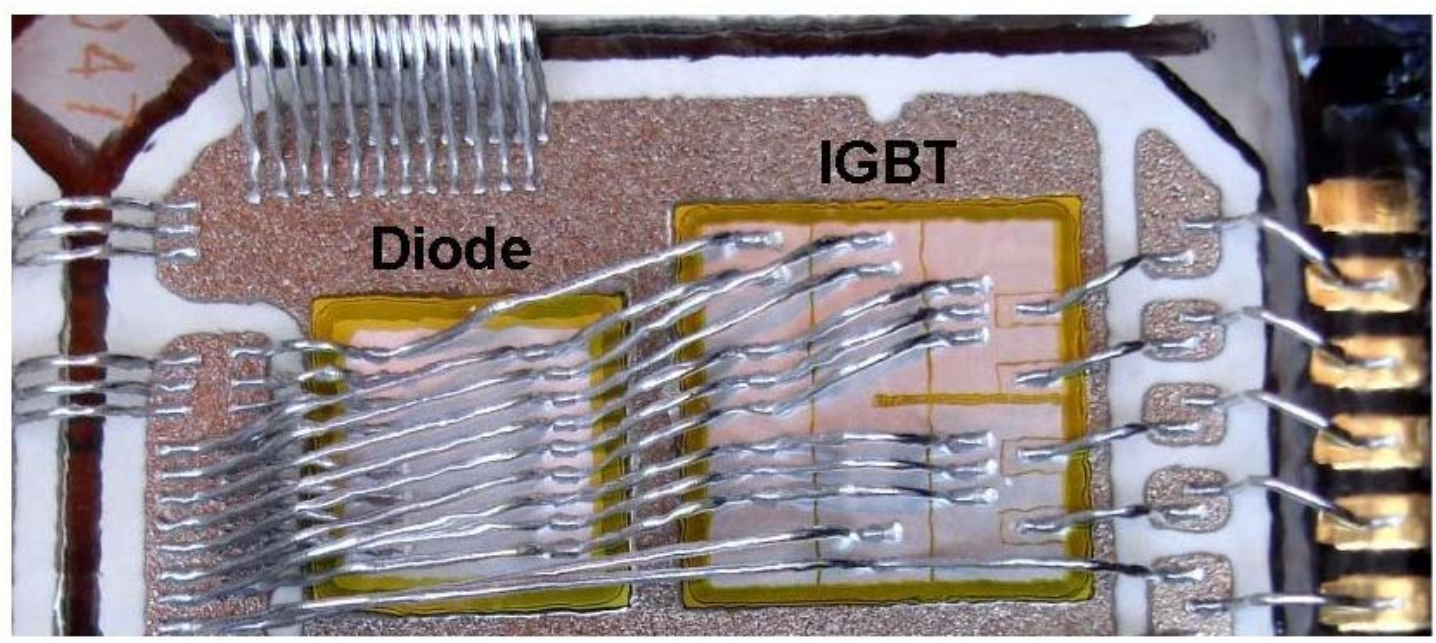

Camry Converter: 8 IGBTs and Diodes

Fig. 2.24. Dimensions (in mm) of Camry de-de converter IGBT and diode. 


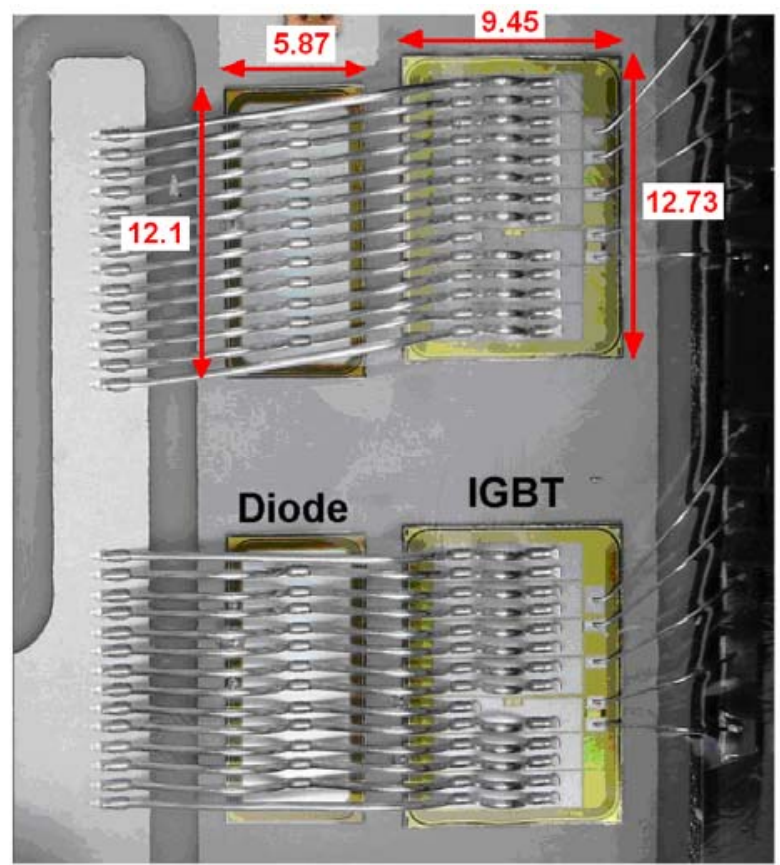

Camry Motor Inverter: 18 IGBTs and Diodes

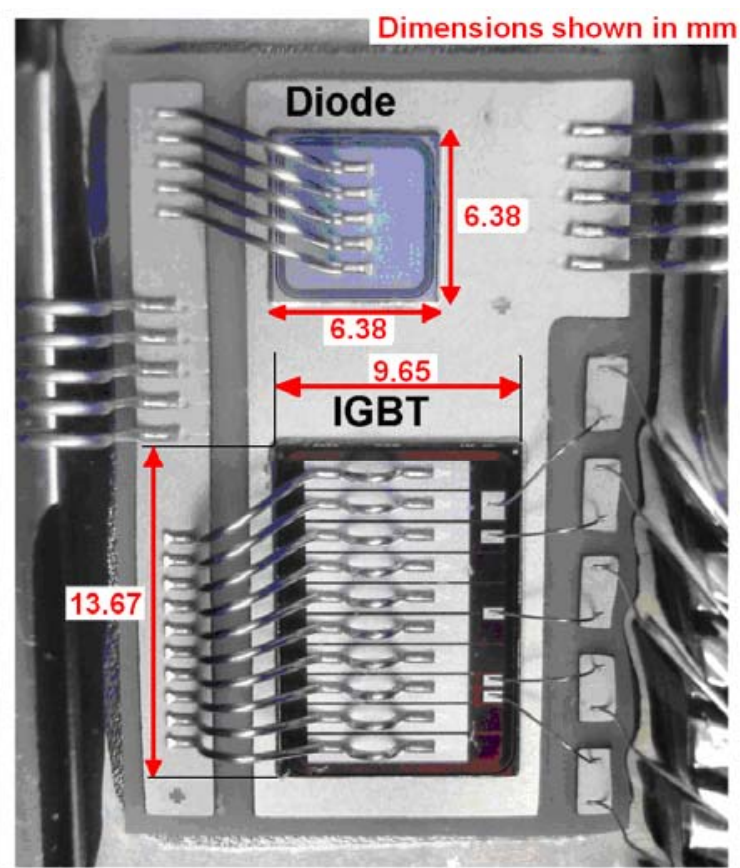

Prius Motor Inverter: 12 IGBTs and Diodes

Fig. 2.25. Dimensions (in mm) of Camry inverter PEs (left) and Prius inverter PEs (right).

Table 2.5. Summary of PE device packaging

\begin{tabular}{|c|c|c|c|c|}
\hline \multirow{2}{*}{ Parameter } & \multicolumn{2}{|c|}{ Motor Inverter } & \multicolumn{2}{|c|}{ Buck/Boost Converter } \\
\hline & IGBTs & Diodes & IGBTs & Diodes \\
\hline \multicolumn{5}{|l|}{ LS 600h } \\
\hline Number of devices & 12 & 12 & 6 & 6 \\
\hline $\begin{array}{l}\text { Area of total Si die per device, } \\
\mathrm{mm}^{2} \text {. }\end{array}$ & 163.3 & 100.2 & 163.3 & 100.2 \\
\hline Summation of Si area, $\mathrm{mm}^{2}$. & 1960 & 1202 & 980 & 601 \\
\hline \multicolumn{5}{|l|}{ Camry } \\
\hline Number of devices & 18 & 18 & 8 & 8 \\
\hline $\begin{array}{l}\text { Emitter wire bond count per } \\
\text { device. }\end{array}$ & 27 & 12 & 18 & 17 \\
\hline $\begin{array}{l}\text { Area of total Si die per device, } \\
\mathrm{mm}^{2} \text {. }\end{array}$ & 120.3 & 71 & 177 & 104 \\
\hline Summation of Si area, $\mathrm{mm}^{2}$. & 2165 & 1278 & 1400 & 830 \\
\hline Heat spreader area/Si area. & \multicolumn{2}{|c|}{$34800 / 3443=10.1$} & \multicolumn{2}{|c|}{$9530 / 2230=4.3$} \\
\hline \multicolumn{5}{|l|}{ Prius } \\
\hline Number of devices. & 12 & 12 & 4 & 4 \\
\hline $\begin{array}{l}\text { Emitter wire bond count per } \\
\text { device. }\end{array}$ & 20 & 5 & 21 & 28 \\
\hline $\begin{array}{l}\text { Area of total Si die per device, } \\
\mathrm{mm}^{2} \text {. }\end{array}$ & 131.9 & 40.7 & 228 & 119 \\
\hline Summation of Si area, $\mathrm{mm}^{2}$. & 1583 & 488 & 910 & 475 \\
\hline Heat spreader area/Si area. & \multicolumn{2}{|c|}{$45100 / 2071=21.7$} & \multicolumn{2}{|c|}{$9400 / 1385=6.8$} \\
\hline
\end{tabular}

An obvious discrepancy between the LS 600h and previous designs is the absence of wire bond connections atop the IGBT and diodes, which are replaced by the conductive spacers to facilitate heat removal from the emitter side of the devices. The conductive and connective functions of the wire bond 
technique have a higher resistances and inductances than that of the flush contact approach found in the LS 600h. During failure modes, the double-sided cooling module prevents explosions from occurring, and the device operates as a short-circuit after destruction, whereas the failure mode of the wire-bond approach is uncertain [2]. The Prius IGBT consists of a planar gate structure and includes areas in the drift region below the emitter " $n+$ " and " $p$ " regions which do not pass as much current as the drift region areas below the gate. This inefficiency is due to the shape of the inversion layer which is formed when using a planar gate structure. The Camry and LS 600h IGBTs consist of a trench gate structure which forms a more uniform inversion layer during on-state operation and therefore higher current densities are created in the drift region. All IGBTs include leads for semiconductor junction temperature measurement feedback, gate voltage control, current measurement, and emitter voltage feedback. These signals are used to control the device and prevent fault conditions from occurring.

\subsubsection{PEs Module Material Analysis}

Scanning electron microscopy (SEM) was used to image the various layers of a LS 600h PEs module and to perform chemical analyses of them using energy-dispersive $\mathrm{x}$-ray spectroscopy (EDX). An overall view of the layers within the PEs module is given in Fig. 2.26. Shown in the lower portion is a crosssectional image of the entire module and an enlarged portion is shown in the upper portion. The cores of the emitter plate, spacers, and collector plate are made of oxygen-free copper, yet there is a thin layer of nickel on the outer surface of each of these components. The nickel layer is added to increase the mechanical stringency above that of copper alone, which has a much lower melting point than nickel, and thus the nickel layer reduces the impact of thermal expansion. Analyses of the three layers shown in Fig. 2.26 are discussed beginning with the uppermost layer and concluding with the lowest layer, and then results from the analysis of the black Si molding are presented.

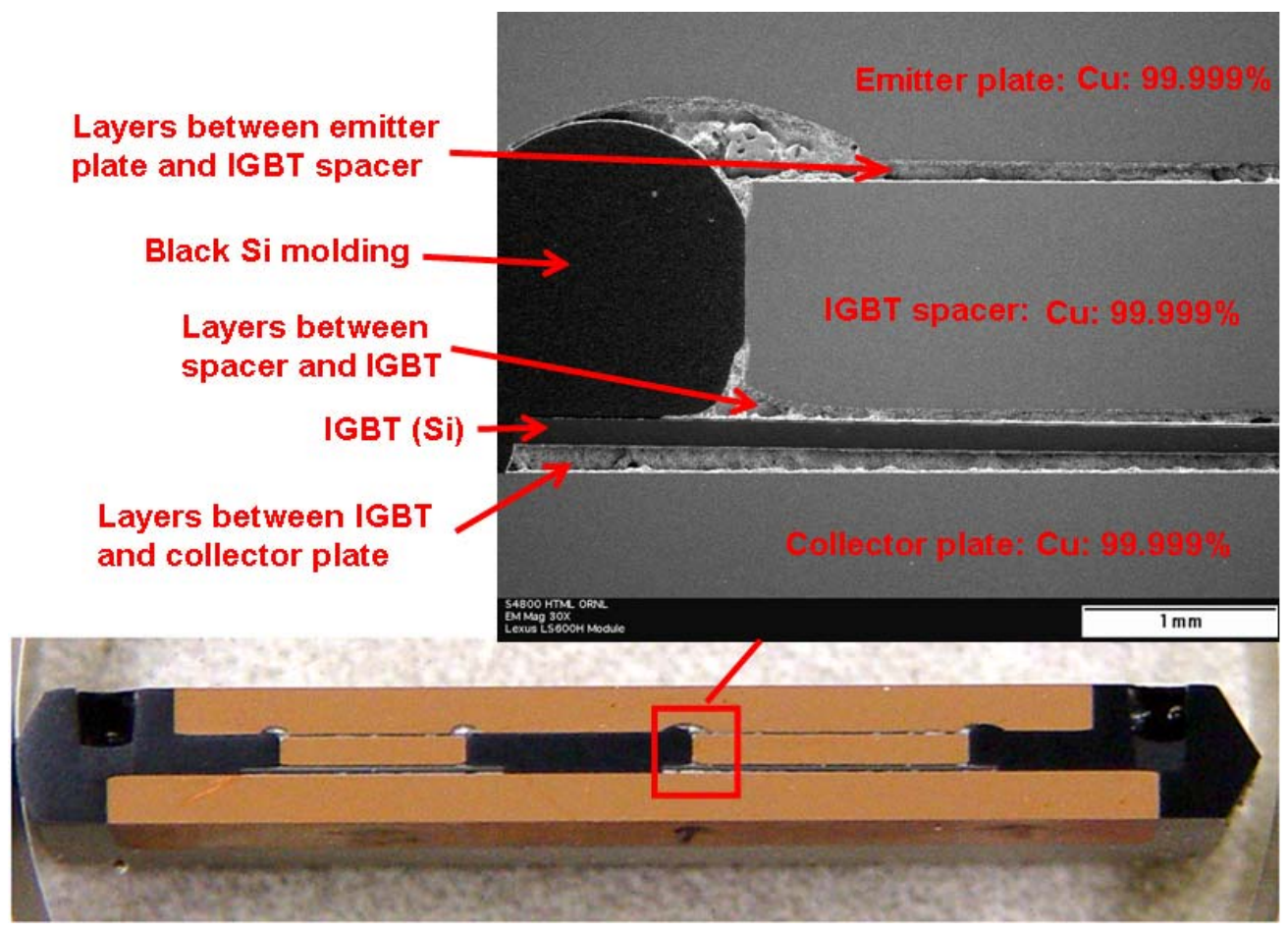

Fig. 2.26. Overview of layers analyzed in PE module material analyses.

Several sub-layers are present between the emitter plate and IGBT spacer as shown in Fig. 2.27. The weight percent of each element found within the layers is shown next to the corresponding label. Aside 
from the emitter plate, three locations were analyzed, with the uppermost reaction layer next to the copper layer containing a slight amount (5.3\% weight) of nickel. The next location is within the reaction layer between the emitter plate and the solder layer, which is primarily comprised of $\mathrm{Ni} \mathrm{(48 \% )}$ and $\mathrm{Sn}(42 \%)$. Analysis of the solder layer reveals that a lead-free solder was used, consisting of approximately $62 \%$ SN and $29 \% \mathrm{Ni}$ at this particular location.

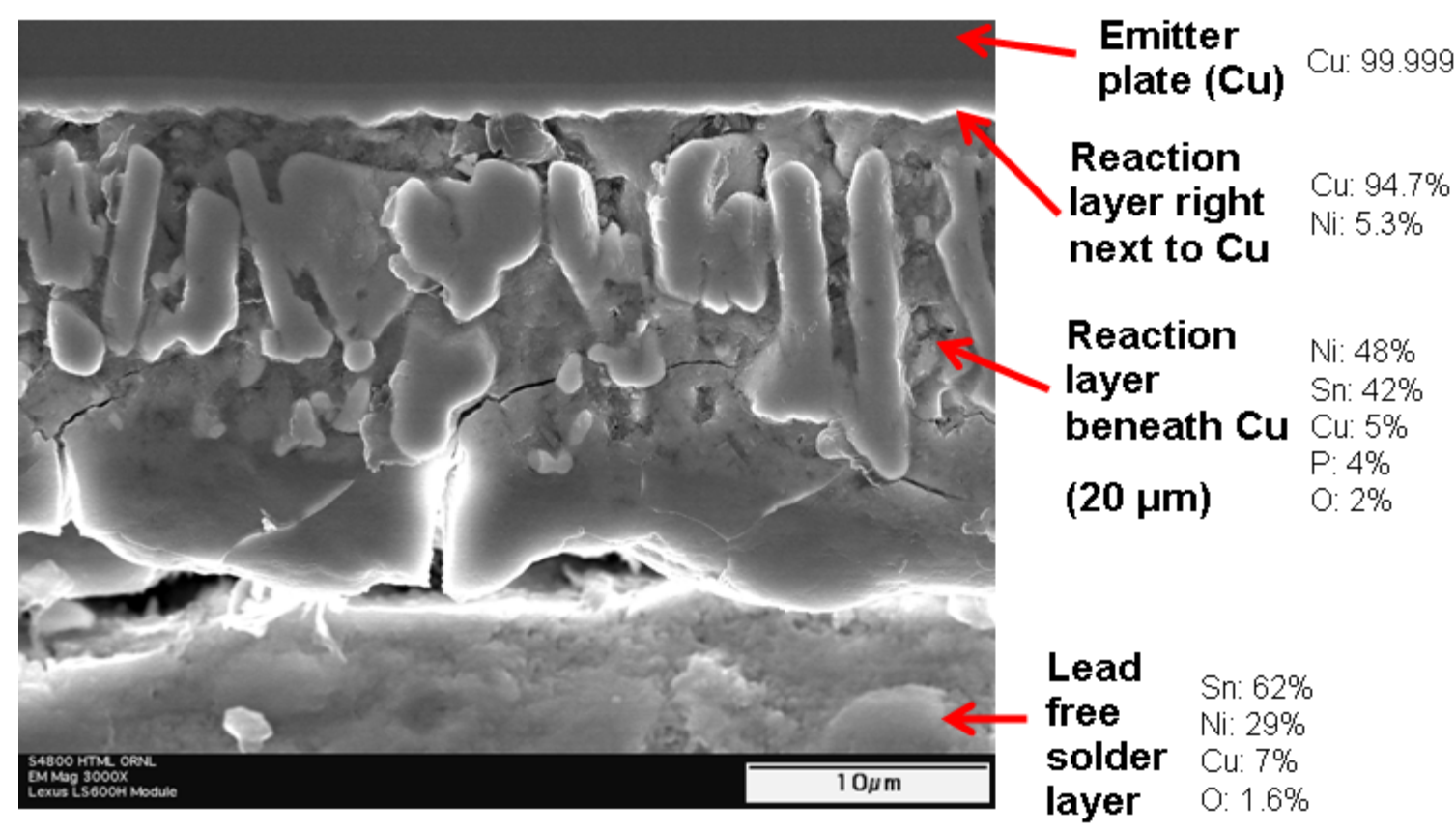

Fig. 2.27. SEM image of layer between emitter plate and IGBT spacer within LS 600h module.

An overall view of the IGBT and its surroundings is provided in Fig. 2.28. The red boxes indicate two regions that were analyzed above and below the Si IGBT. An SEM image of the region analyzed just above the IGBT is provided in Fig. 2.29. In the uppermost layer, labeled "lead-free solder layer", nearly identical amounts of $\mathrm{Sn}, \mathrm{Ni}, \mathrm{Cu}$, and $\mathrm{O}$ are found in comparison with the lead-free solder layer shown in Fig. 2.27. The incorporation of copper into the solder mixture lowers the melting point, reduces susceptibility to thermal cycle fatigue, and improves wetting properties of molten solder during the assembly process. Moving downward, the reaction layer has similar amounts of $\mathrm{Ni}, \mathrm{Sn}, \mathrm{Cu}$, and $\mathrm{P}$ as the reaction layer that was shown in Fig. 2.27. Just below this layer is a mostly nickel layer with a 7\% weight portion of phosphorus, which is an element used as a n-type dopant for layers adjacent to the emitter contact. Beneath the nickel layer, the amounts of Si and O increases as the oxide layers are approached. Additionally, small amounts of $\mathrm{Ti}$ and $\mathrm{Al}$ are observed in this layer, which are likely associated with electrodes of the gate and emitter. As expected, greater amounts of Si appear in moving towards the body of the IGBT.

Shown in Fig. 2.30 is an SEM image of the region analyzed just below the IGBT. Composition percentages are shown for two layers that are relatively close to the Si chip and are not located deeply within the solder layer (as indicated by high percentage of Si present in both layers). Nonetheless, significant amounts of $\mathrm{Sn}$ and $\mathrm{Ni}$ reflect the presence of solder in this region. Additionally, small amounts of $\mathrm{Al}$ and Ti have infused from the collector metallization layer of the IGBT. The black Si mold used to encapsulate the module, visible in Figs. 2.18, 2.22, and 2.26, was analyzed and an SEM image of the composite-like material is shown in Fig. 2.31. Its matrix consists of $94.8 \% \mathrm{Si}, 3.4 \% \mathrm{O}$, and $1.8 \% \mathrm{Sb}$ that surrounds particulates comprised of $81.9 \% \mathrm{Si}$ and $18.1 \% \mathrm{O}$. 


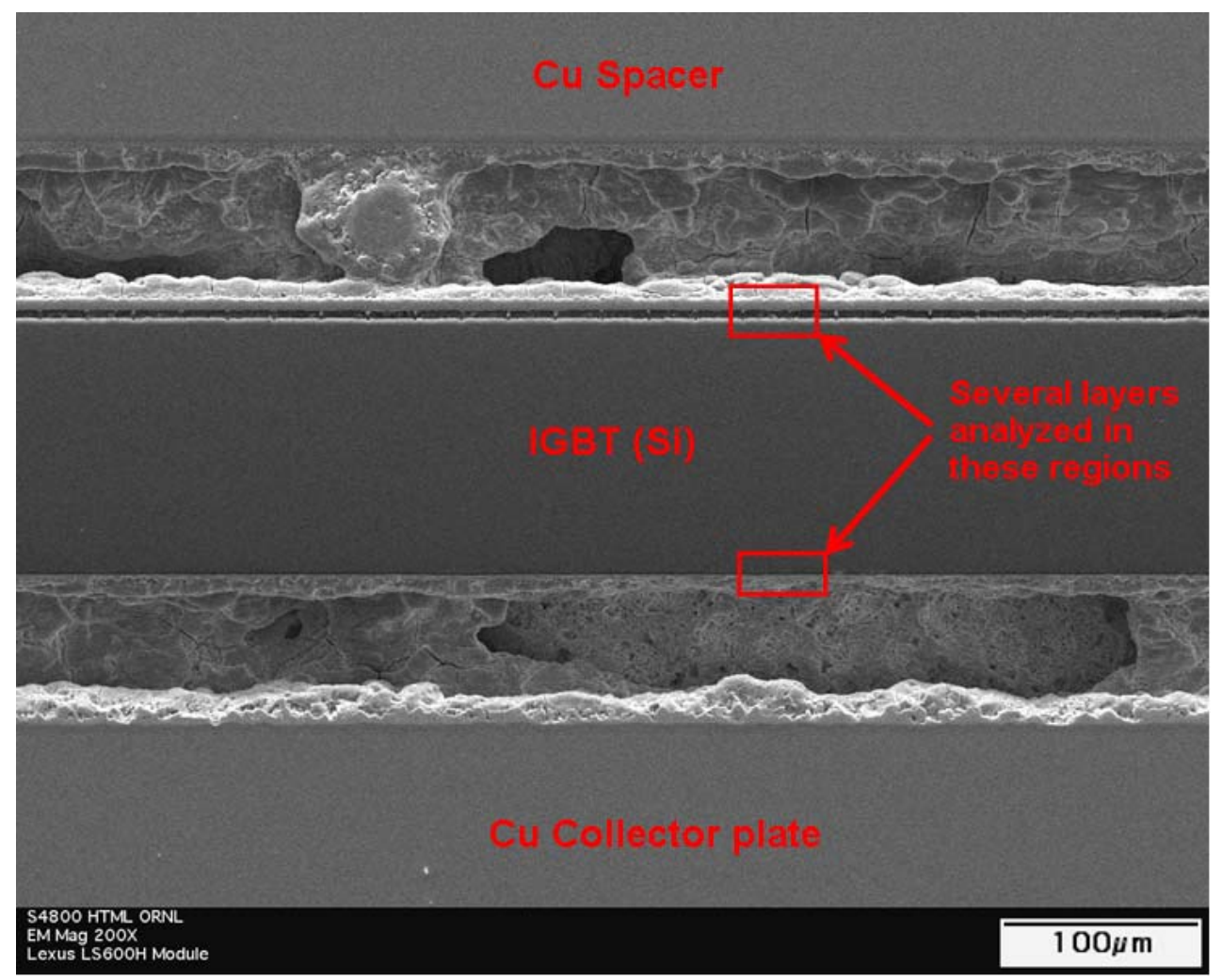

Fig. 2.28. SEM image of LS $600 \mathrm{~h}$ IGBT and adjacent components.

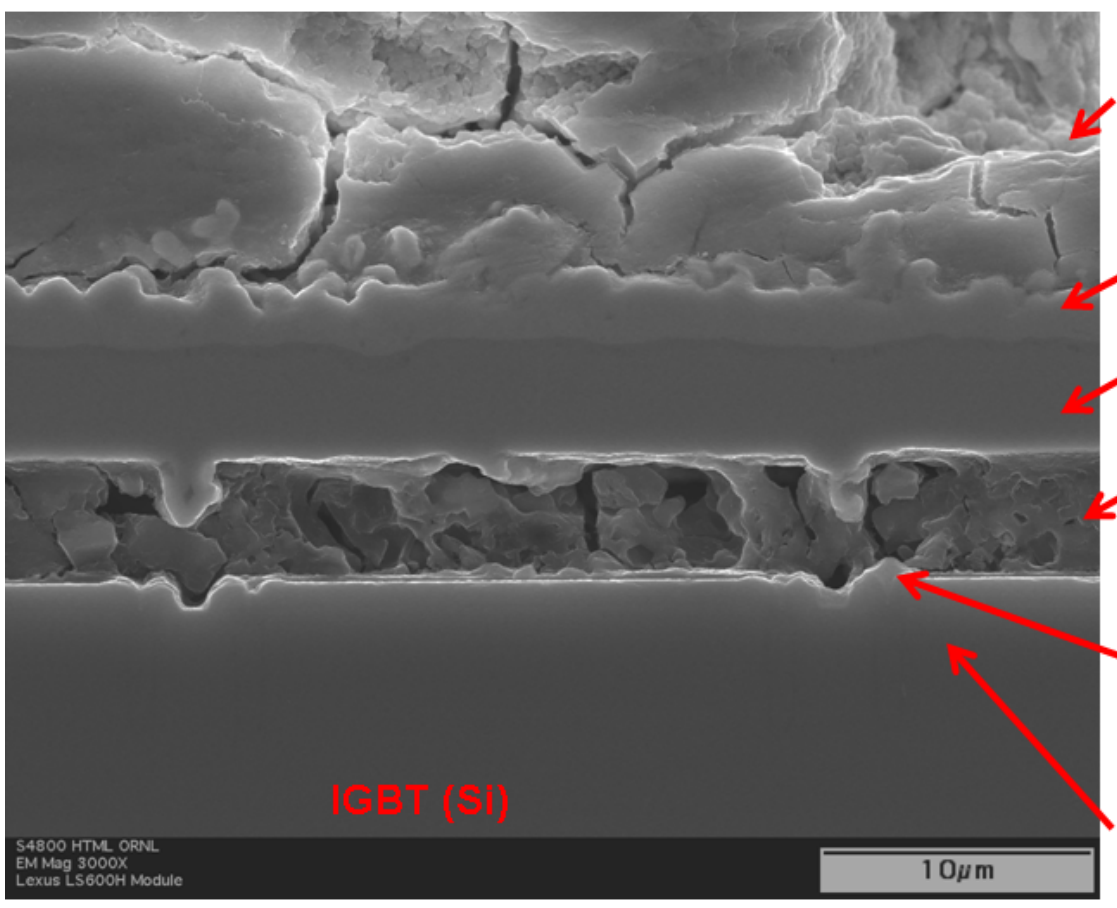

$$
\begin{aligned}
& \text { Lead Sn: } 63 \% \\
& \text { free Ni: } 30 \% \\
& \text { solder } \mathrm{Cu}: 6 \% \\
& \text { layer Si: } 1 \% \text { Sn: } 45 \% \\
& \text { Ni: } 35 \% \\
& \text { Reaction } 0: 10 \% \\
& \text { layer Si: } 3 \% \\
& \text { P: } 2 \% \\
& \text { Ni layer Ni: } 93 \% \\
& \text { Layer Ni: } 66 \% \\
& \text { between Si: } 9 \% \\
& \mathrm{Ni} \text { and Si Ti: } 6 \% \\
& \text { Al: } 6 \% \\
& \text { Cu: } 4 \% \\
& \text { Si: } 58 \% \\
& \text { Upper } \quad \text { : } 25 \% \\
& \text { edge of Si Al: } 9 \% \\
& \text { Ti: } 6 \% \\
& \text { Ni: } 2 \% \\
& \text { Upper Si: } 95 \% \\
& \text { edge of } \mathrm{Si} \text { O: } 2 \%
\end{aligned}
$$

Fig. 2.29. SEM image of region just above LS 600h IGBT. 


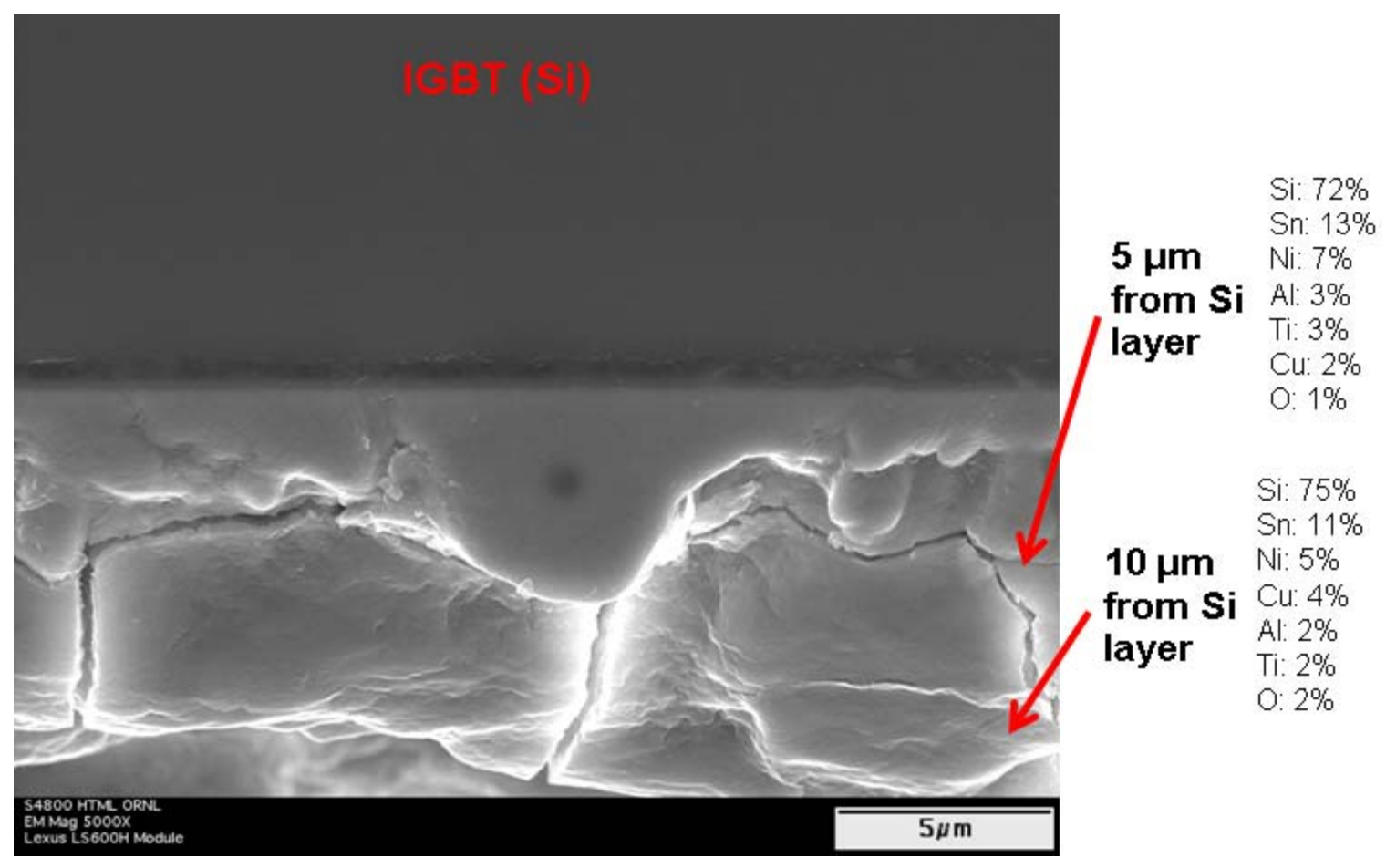

Fig. 2.30. SEM image of region just below LS 600h IGBT.

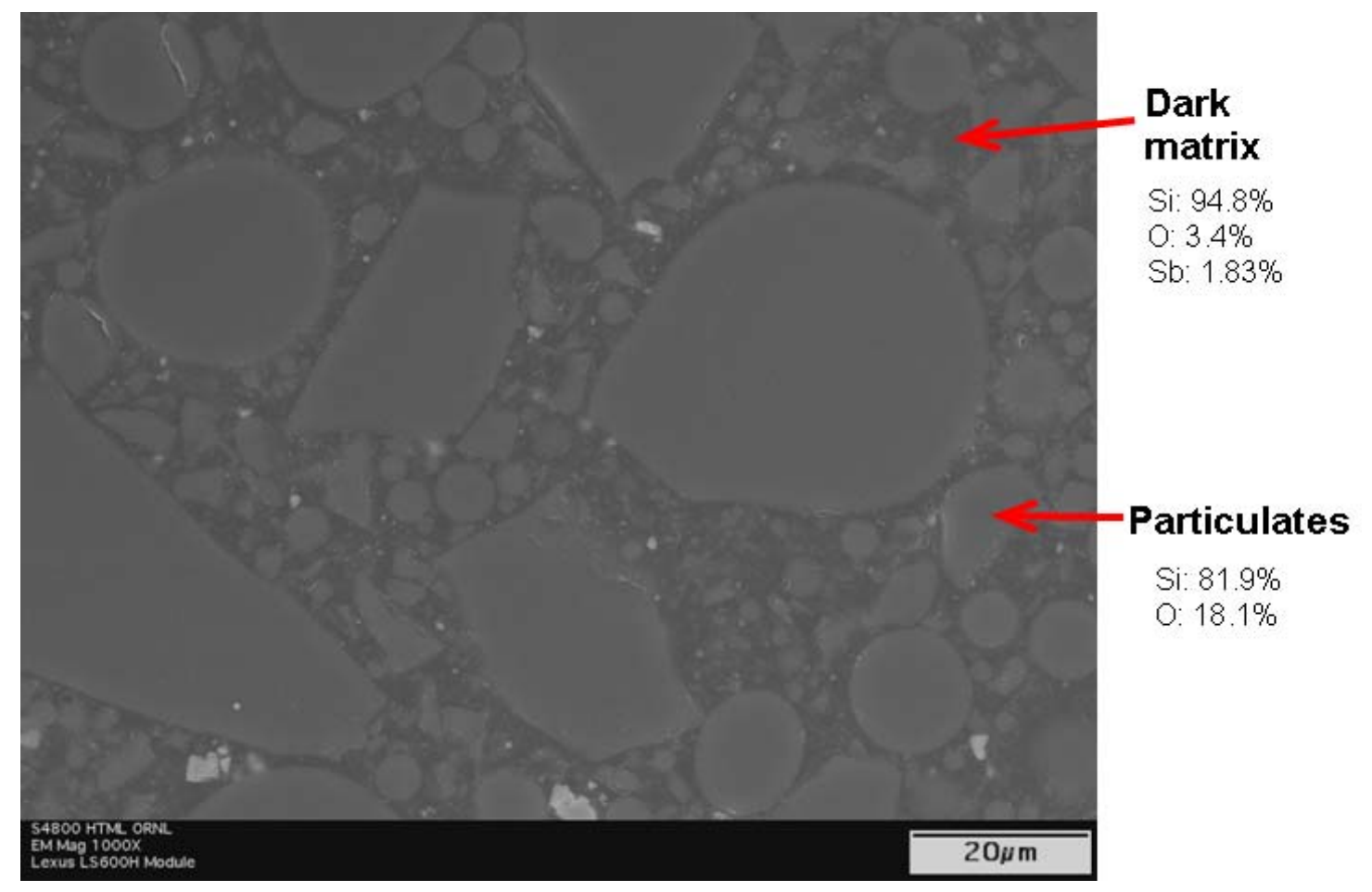

Fig. 2.31. SEM image of black Si molding. 


\subsubsection{Capacitor Test Results}

As capacitor technologies mature, it is important to ascertain the capabilities and limitations of these new technologies by subjecting them to standardized tests to evaluate their characteristics. Test results will assist in benchmarking not only the capabilities and limitations of these technologies, but also to provide a baseline for comparison. All the capacitors studied are of the metalized plastic film type and were manufactured by Matsushita under the Panasonic brand name, except for the large dc-link capacitors of the Camry and LS 600h which were manufactured by Nichicon. As noted in Section 2.2.1, the capacitor modules are made up of several sub-capacitors.

Capacitor tests were conducted both statically and dynamically. The former is a capacitor parameter assessment and the latter is a thermal characteristic assessment. The static test mode does not entail an externally applied dc-bias voltage and ripple current, but uses only signals supplied by an LCR meter. The capacitor parameters that are measured in the static mode are: (1) equivalent series resistance (ESR), (2) dissipation factor (DF), and (3) capacitance value. The capacitor is placed in an environmental chamber and the temperature is cycled through temperatures ranging from $-40-140^{\circ} \mathrm{C}$ using steps of $20^{\circ} \mathrm{C}$. These three parameters are measured at each temperature step.

The ESR is the real component of the equivalent impedance of the capacitor and corresponds directly with total energy loss which is dissipated as heat during operation. The DF is the ratio of the ESR over the capacitive reactance, which simplifies to $\omega R C$ and will be represented as the percentage of real power associated with a particular reactive power component. Both of these parameters were measured during static tests and the results were plotted over a wide frequency and temperature range.

In dynamic tests, a dc-bias voltage and ripple current is applied to the capacitor and the temperature of the capacitor is monitored. When a capacitor is used on a dc bus, the maximum ripple current capability is an important specification. The dynamic test determines the amount of heat generated by the capacitor as a function of ripple current at various ambient temperatures.

\subsubsection{Static capacitor test results of the $2629 \mu \mathrm{F}$ dc-link smoothing capacitor module}

The data acquisition system (DAQ) consists of a Dell Precision 380 Workstation running LABView 8.5. In the static mode, the instruments used to log data are an Espec environmental chamber and an Agilent 4284 LCR meter. At the beginning of the static thermal cycling tests, after all temperature steps and test frequencies have been entered, the program turns on the environmental chamber and commands a target temperature to the chamber. After the target temperature has been reached and a pre-programmed delay time has been met, the program sends a command to the LCR meter to output the first test frequency and then begins to monitor the ESR from the capacitor under test. When that value is stable, the ESR is recorded and the next parameter is measured and recorded. After the values for ESR, DF, and capacitance are recorded at the first test frequency, the command is given to the LCR meter to output the next test frequency and the monitoring and recording process is repeated. After all data are recorded at all test frequencies, the next temperature step is commanded to the environmental chamber and the process is repeated.

The LS $600 \mathrm{~h}$ capacitor module was tested in the static mode from $-40-140^{\circ} \mathrm{C}$ over a frequency range of $100 \mathrm{~Hz}$ to $30 \mathrm{kHz}$. ESR, DF, and capacitance was measured and recorded. An interesting fact is observed in Fig. 2.32 as the capacitance approaches infinity just beyond $12 \mathrm{kHz}$. The module can be represented as an RLC circuit with very small resistance and inductance. However, at high frequencies, even a small parasitic inductance component has a significant influence upon the entire equivalent reactance of the module. There is a certain resonant frequency where the capacitive (negative reactance) effect and inductive (positive reactance) effect are equal, and therefore the total reactance is zero and the imaginary 
admittance or susceptance is infinite. Thus, the equivalent capacitance approaches infinity as the frequency approaches resonant frequency. Just beyond the resonant frequency, the equivalent reactance is inductive and increases from zero as frequency increases. Figure 2.33 shows that the Camry capacitor module also has a similar effect near $16 \mathrm{kHz}$.

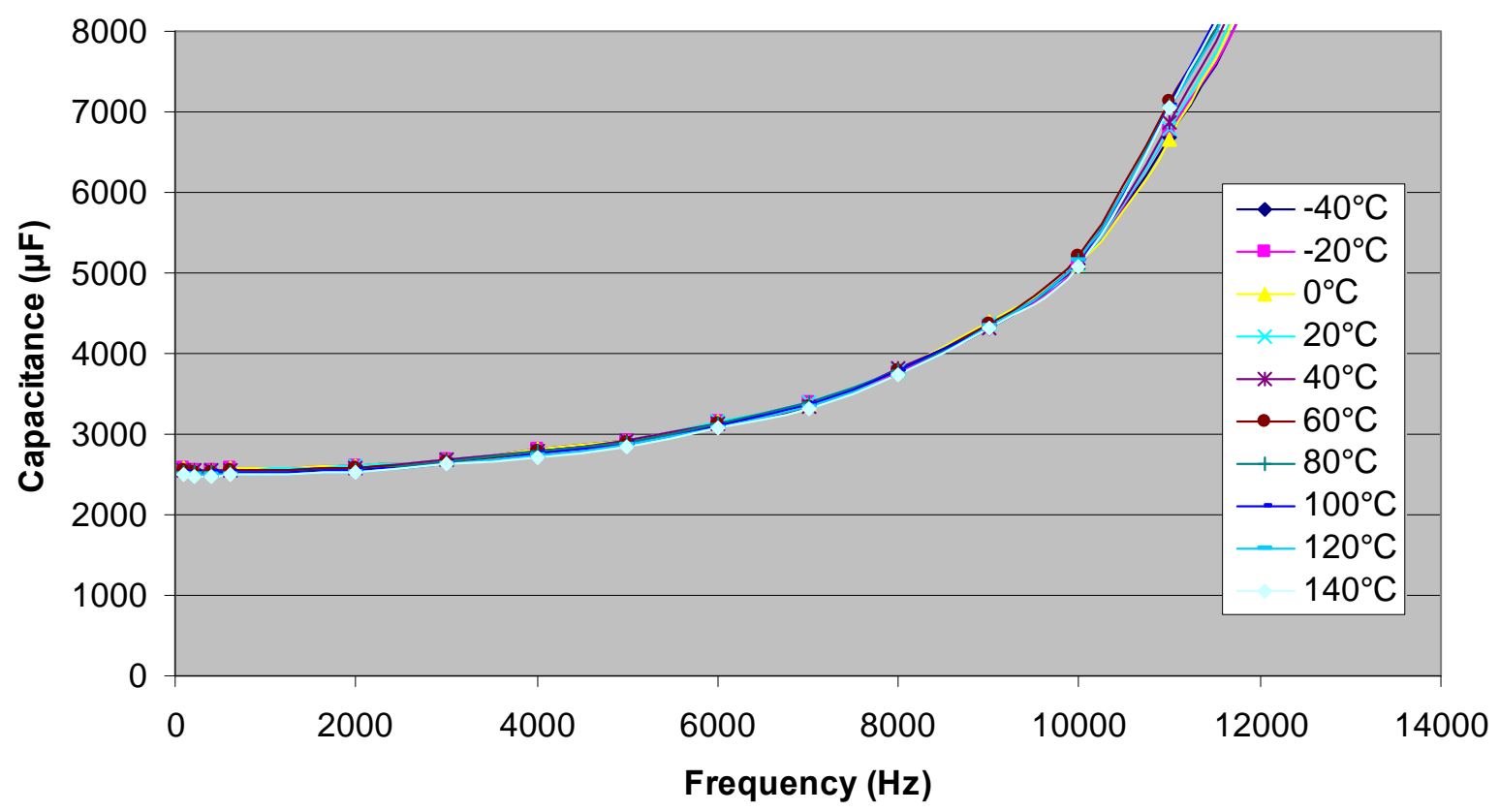

Fig. 2.32. LS 600h capacitor module equivalent capacitance vs. frequency.

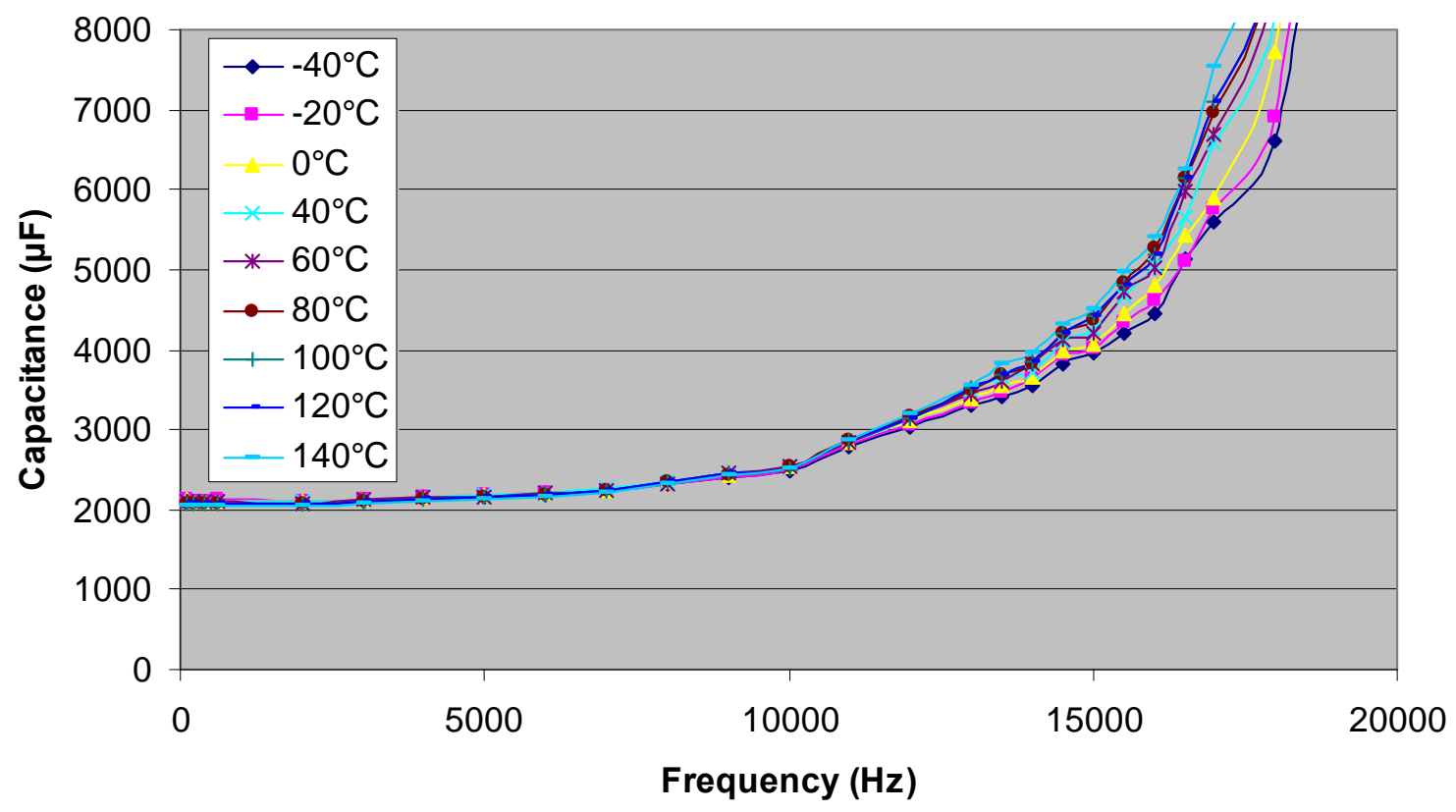

Fig. 2.33. Camry capacitor module equivalent capacitance vs. frequency.

As shown in Fig. 2.34, the response of the entire LS 600h module capacitance was very minimal over the full temperature range. The largest change in capacitance over the temperature range is observed at 
$11 \mathrm{kHz}$, which is also the frequency at which the highest capacitance was measured. For low frequencies, capacitance tended to increase with increasing temperature until peaking at a particular temperature (between $-20^{\circ} \mathrm{C}$ and $50^{\circ} \mathrm{C}$ ) and then the capacitance decreased slightly as temperature increased above this temperature. This peak capacitance temperature generally increased with increasing frequency. The Camry capacitor modules showed similar effect and slight variation of capacitance with temperature.

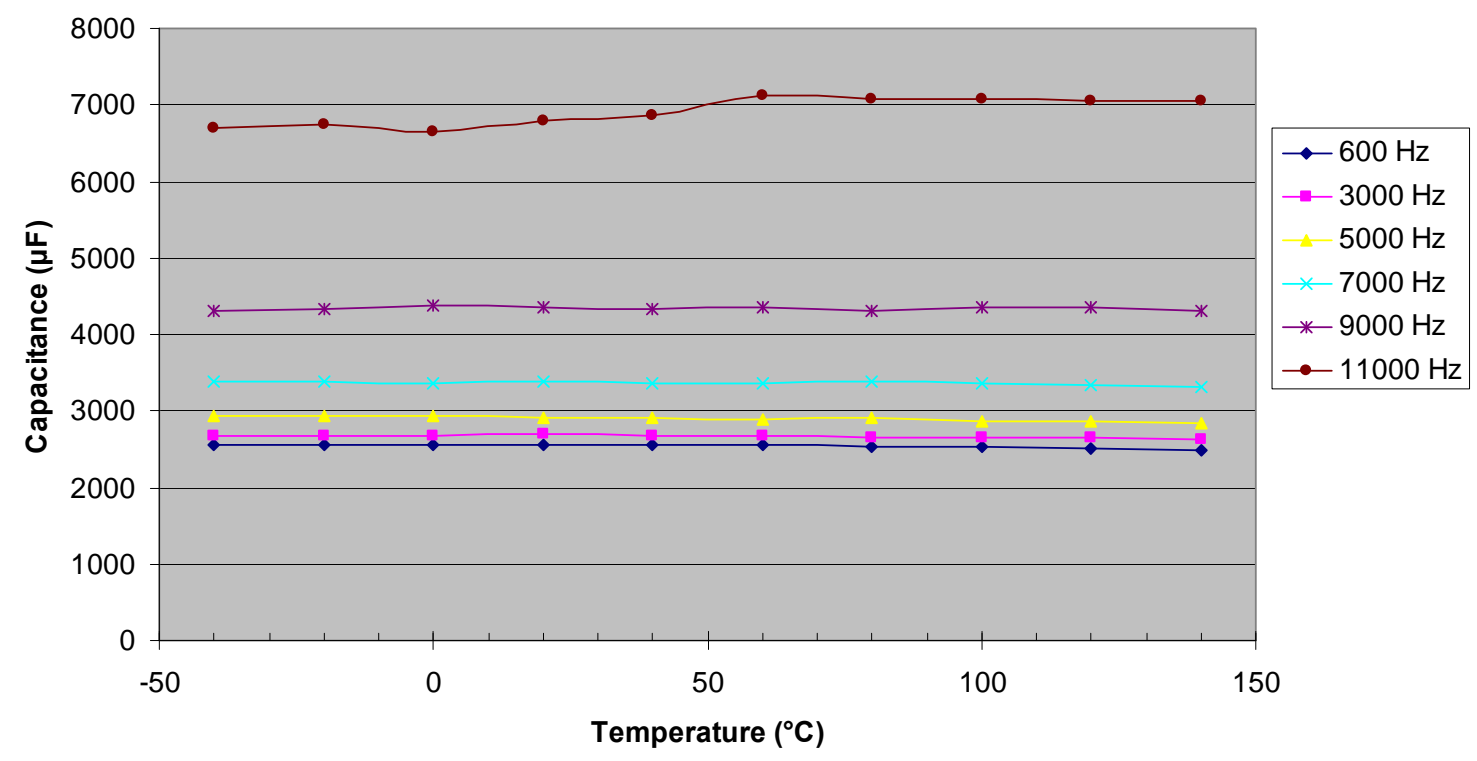

Fig. 2.34. LS 600h capacitor module equivalent capacitance variation with ambient temperature.

Figures 2.35 and 2.36 show the ESR response to frequency for the LS $600 \mathrm{~h}$ and the Camry module, respectively. The curve characteristics indicate that the influence of frequency upon the ESR of both modules is reasonably similar for frequencies above $12 \mathrm{kHz}$. However, the Camry module has much higher ESR values and exhibits peculiar characteristics below $12 \mathrm{kHz}$. Measurements indicate that ESR values generally increased with increasing temperature for both modules at all frequencies.

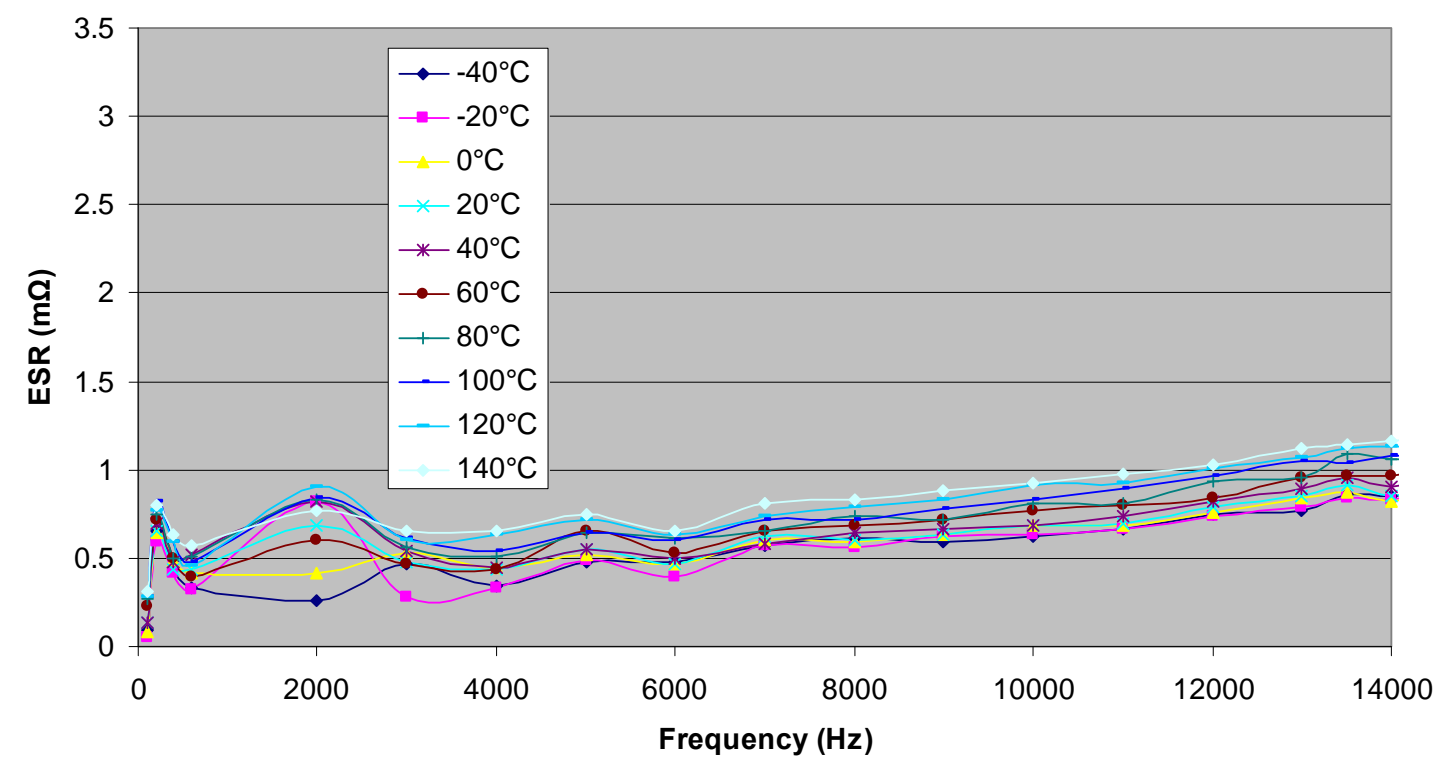

Fig. 2.35. LS 600h capacitor module ESR vs. frequency. 


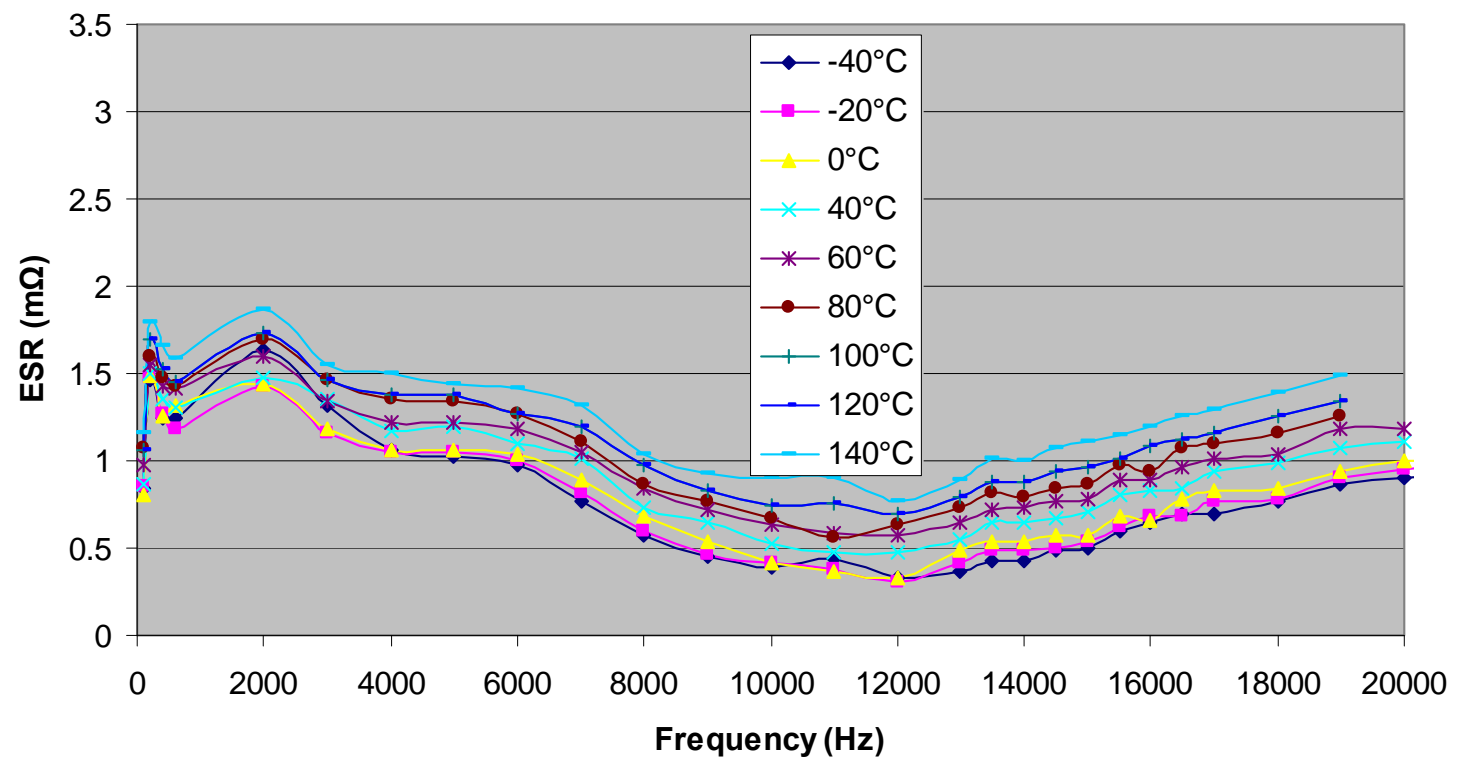

Fig. 2.36. Camry capacitor module ESR vs. frequency.

To obtain a clearer perspective of the impact of temperature upon ESR, Figs. 2.37 and 2.38 shows ESR plotted versus temperature for each frequency for the LS 600h and the Camry capacitor module, respectively.

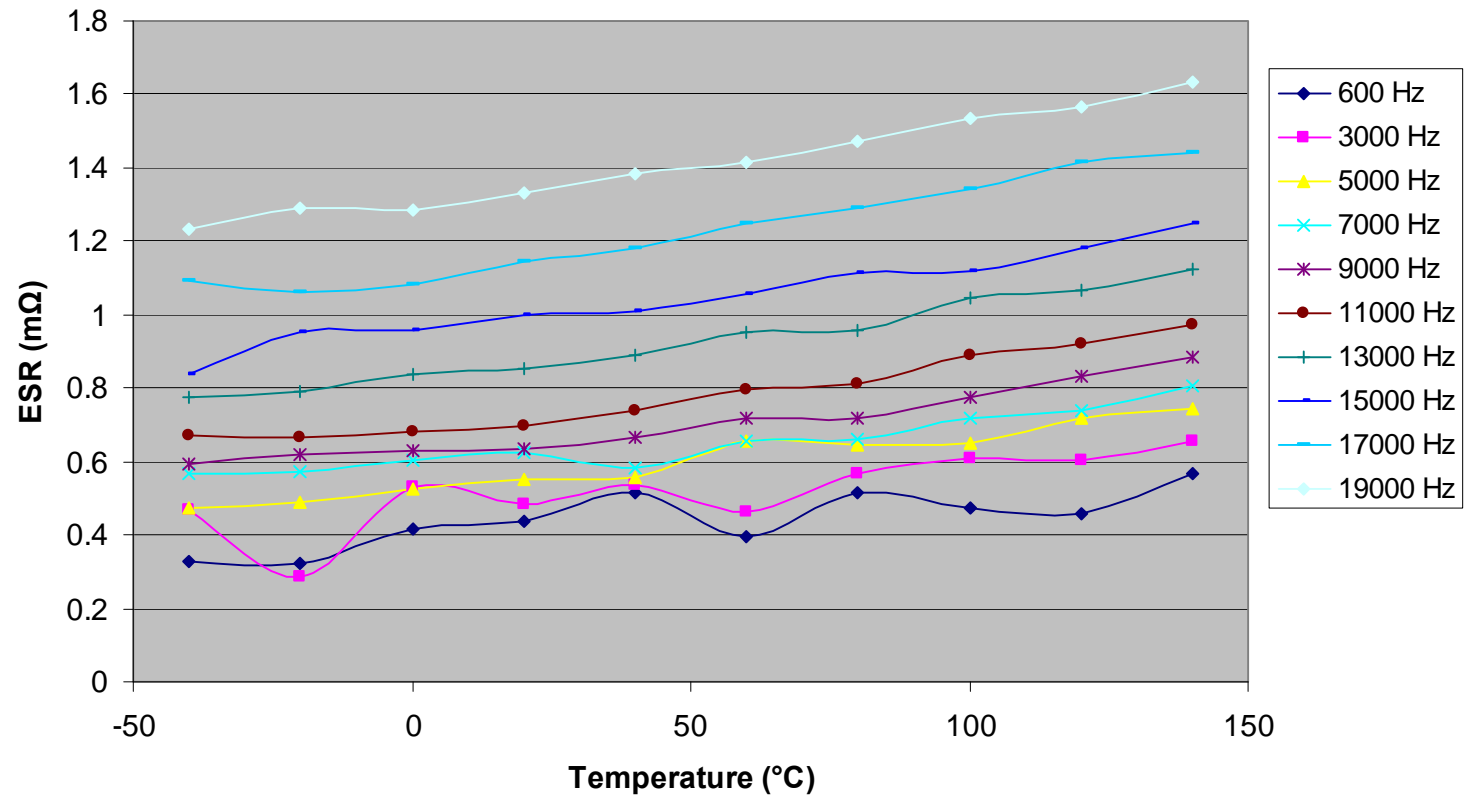

Fig. 2.37. LS 600h capacitor module ESR vs. temperature. 


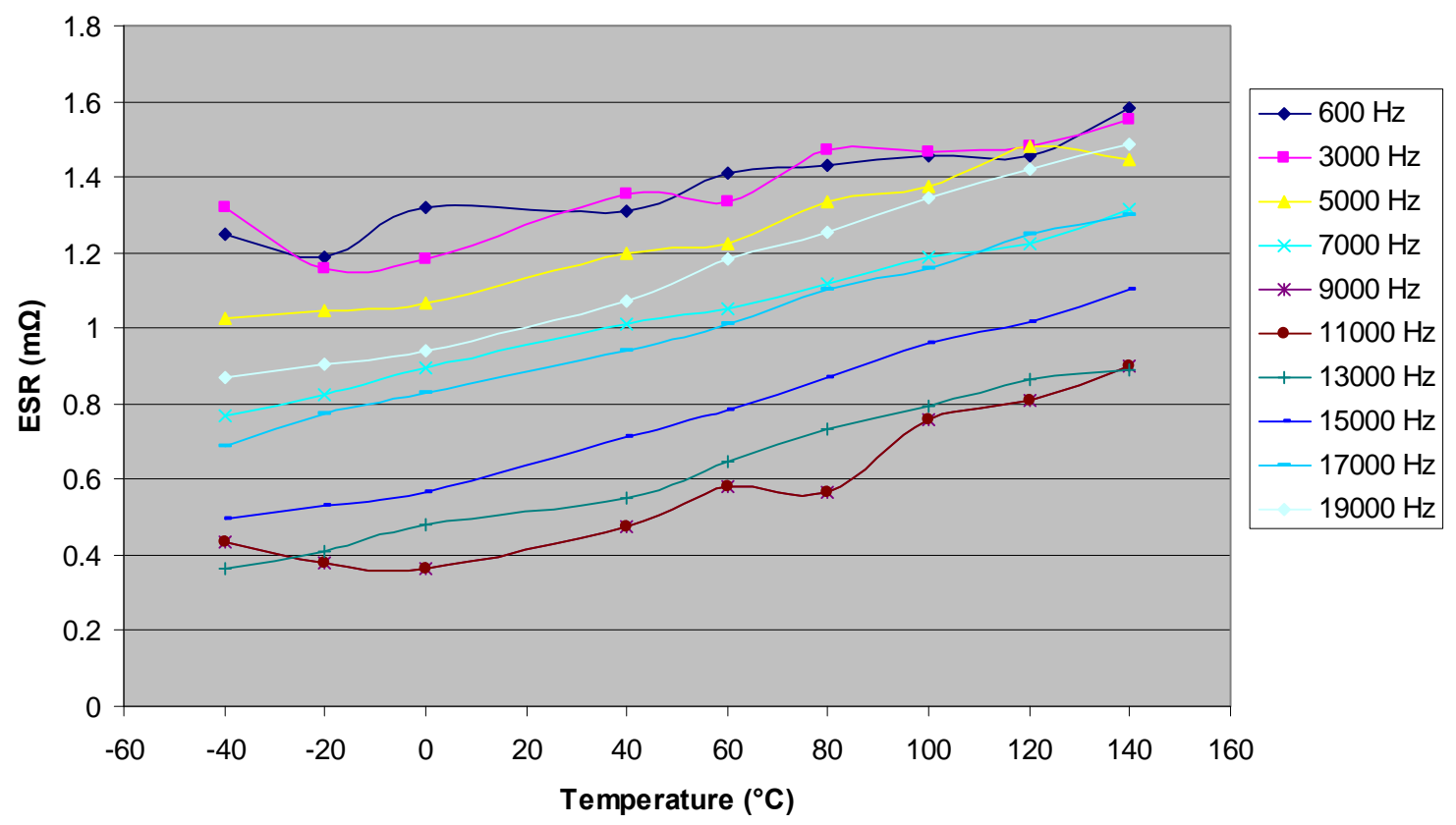

Fig. 2.38. Camry capacitor module ESR vs. temperature.

The variations of DF with frequency for the LS 600h and Camry capacitor modules are shown in Figs. 2.39 and 2.40, respectively. These graphs are similar to the capacitance versus frequency graphs in Figs. 2.32 and 2.33. Since DF is the product of ESR, capacitance, and frequency, both graphs include curves which approach infinity near the resonant frequency. The behavior of the Camry capacitor module $\mathrm{DF}$ as a function of frequency is somewhat peculiar as the frequency increases beyond $6 \mathrm{kHz}$ and then resumes typical behavior beyond about $12 \mathrm{kHz}$.

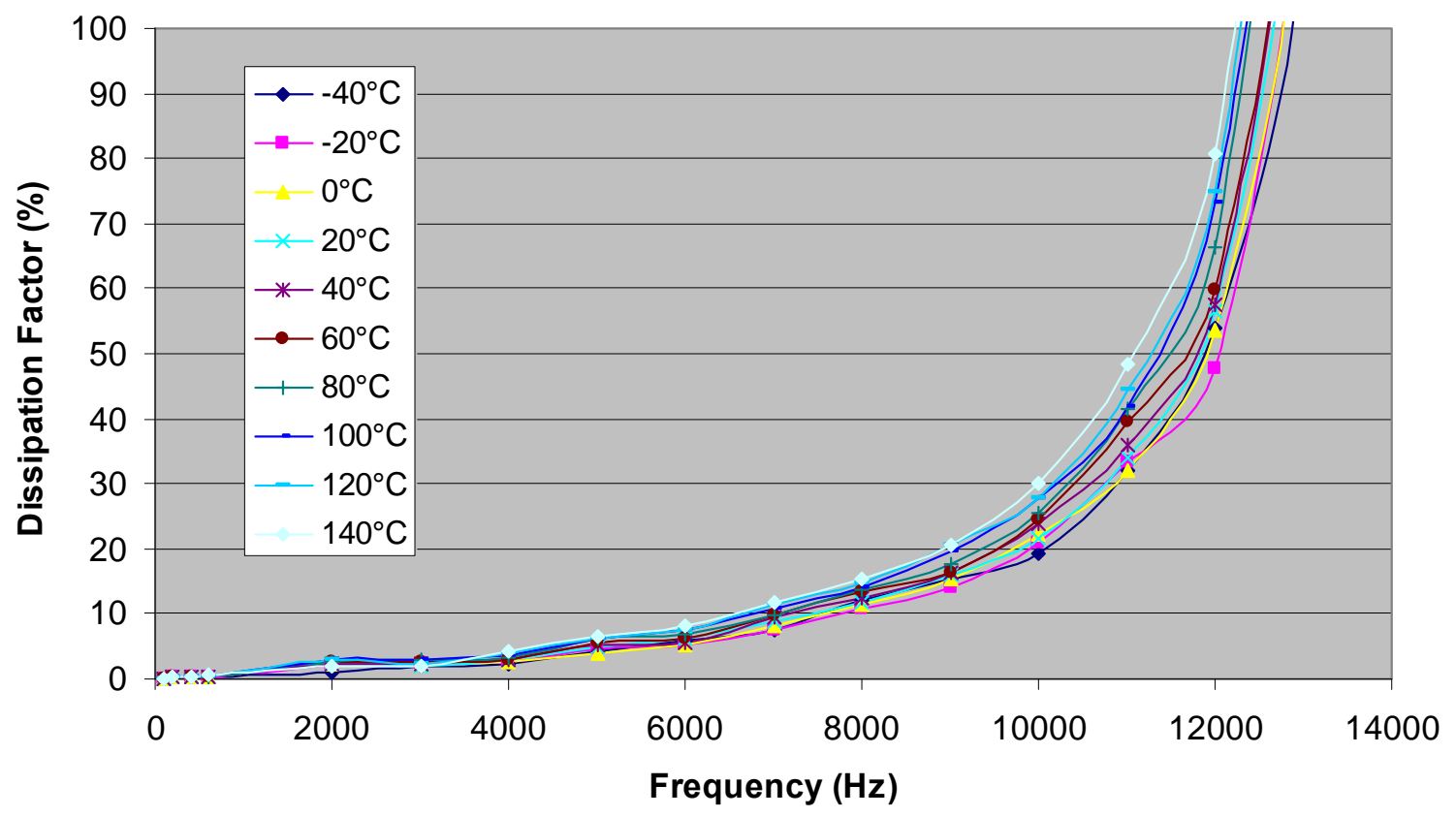

Fig. 2.39. LS 600h capacitor module DF frequency response. 


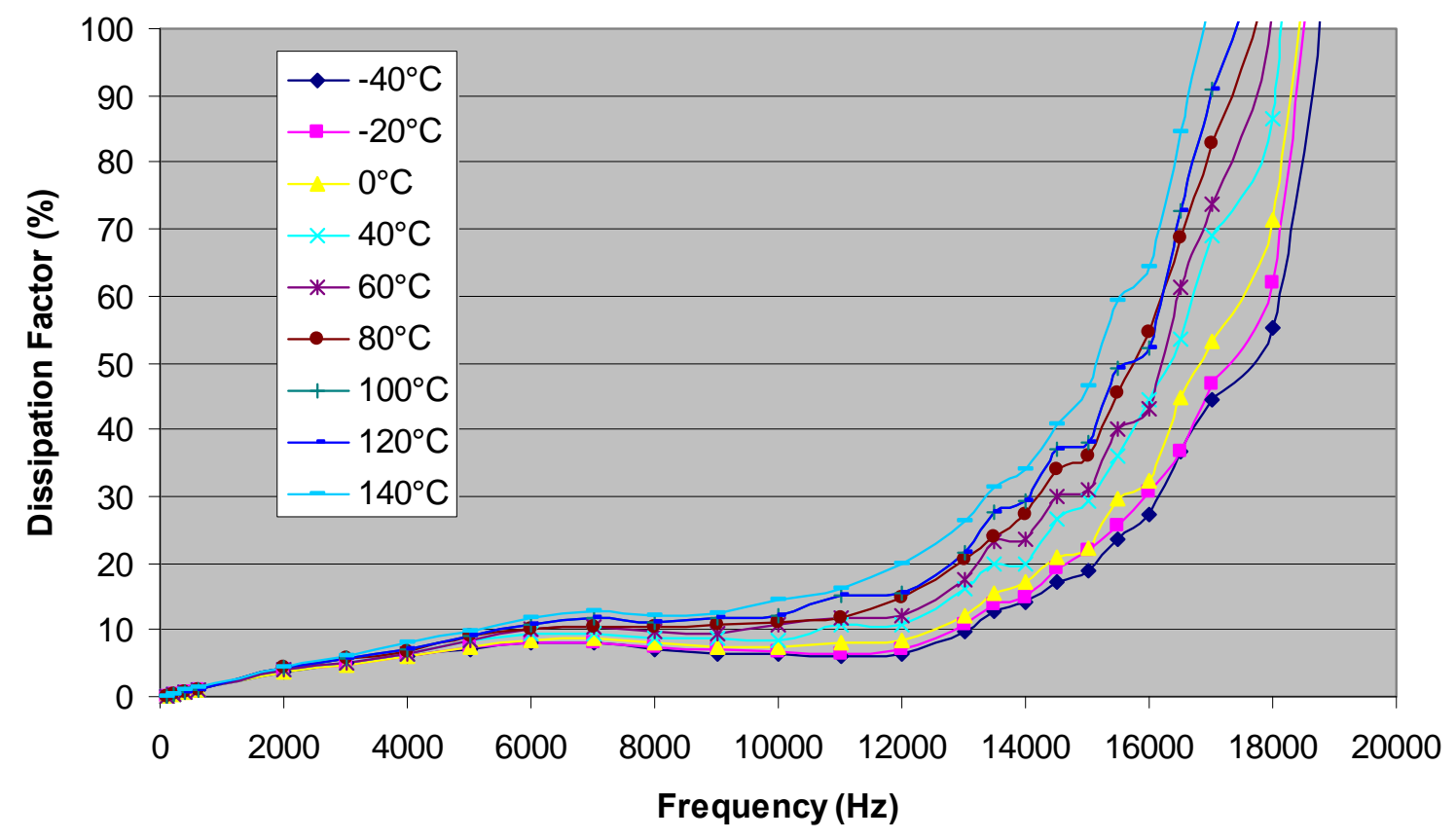

Fig. 2.40. Camry capacitor module DF frequency response.

The impact of temperature on the DF of the Camry and Prius capacitor modules for each test frequency is observed in Figs. 2.41 and 2.42, respectively. Similar to the impact of temperature upon capacitance, the DF generally increases with increasing temperature. Additionally, temperature has a greater impact on DF at higher frequencies. Since the ESR naturally increases with increasing temperature, the amount of real power dissipated for a particular amount of reactive power increases as temperature increases.

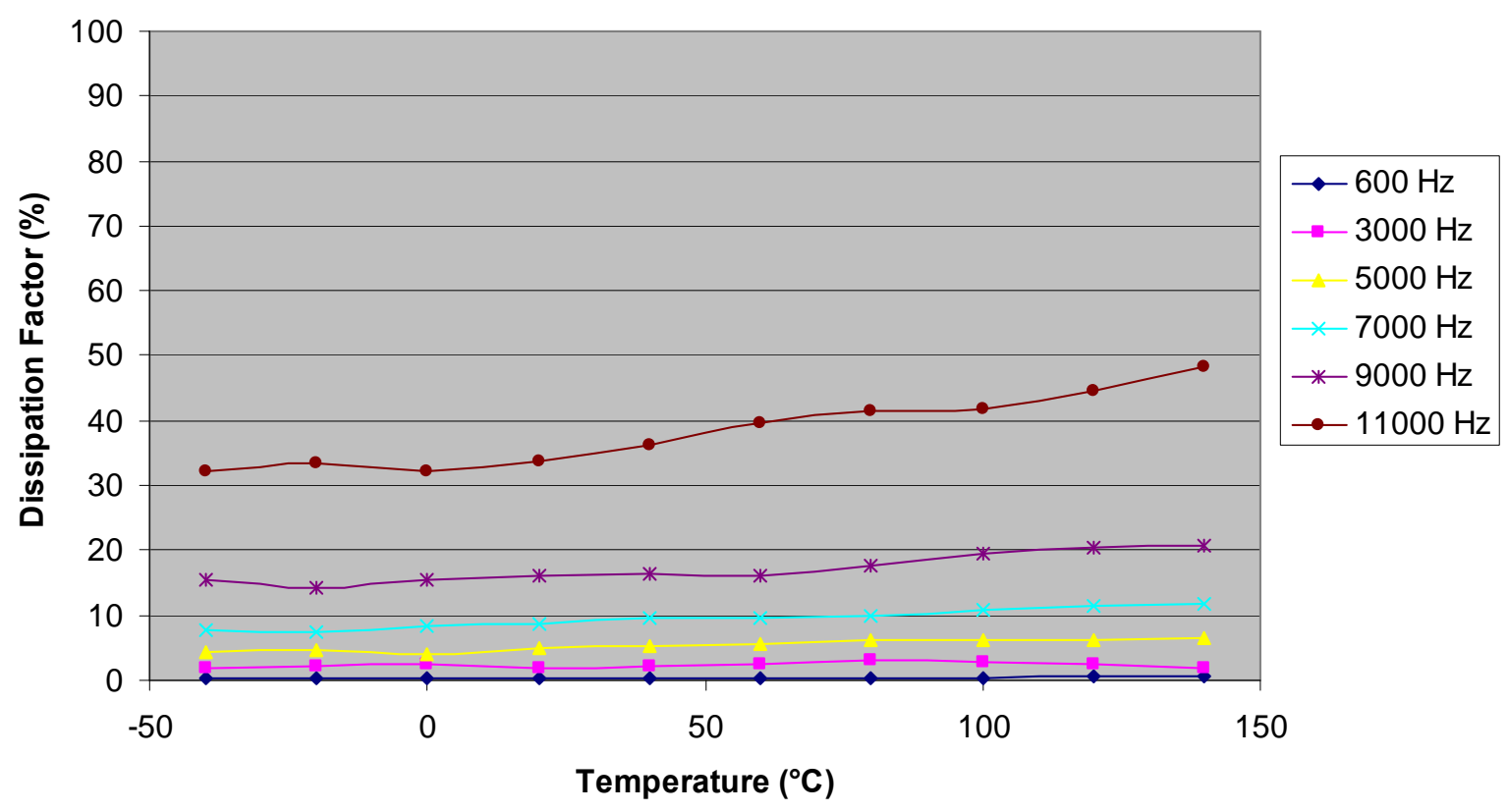

Fig. 2.41. LS 600h capacitor module DF temperature response. 


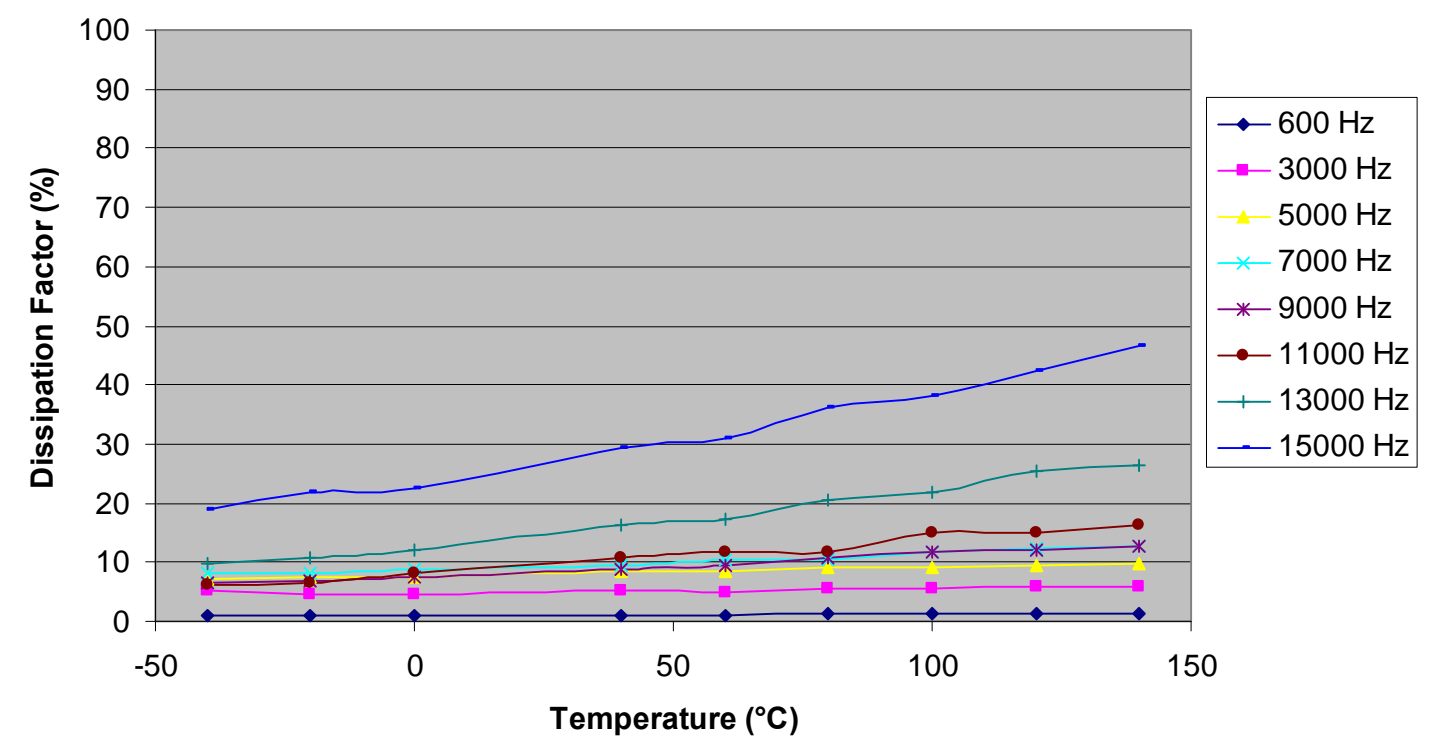

Fig. 2.42. Camry capacitor module DF temperature response.

\subsubsection{Dynamic capacitor test results from large dc-link capacitor module}

The LS $600 \mathrm{~h}$ capacitor module was tested with a maximum ripple current of 250 A. Figure 2.43 shows the circuit used to apply a ripple current with a dc bias to the Camry capacitor module. A capacitor was placed across the output of the dc power supply to decrease the potential of damaging the dc power supply with the high ripple currents generated during testing. However, due to the potentially detrimental impact of this configuration upon the dc supply, the supply and capacitor was removed for the LS 600h tests. Nonetheless, the same fundamental observations can be made without these components.

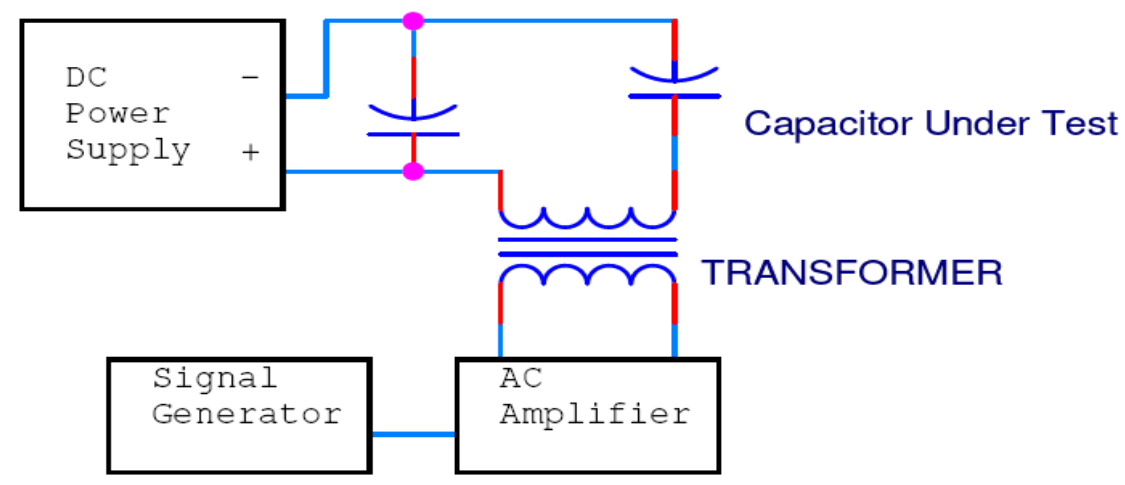

Fig. 2.43. Previous ripple current test schematic.

TCs were applied to the LS $600 \mathrm{~h}$ module in the appropriate locations shown in Fig. 2.44. Ripple current, monitored by the root mean square (rms) value, was applied in $50 \mathrm{~A}$ steps from $100 \mathrm{~A}$ up to $250 \mathrm{~A}$. The temperature was allowed to stabilize for 30 minutes before data was recorded. The upper TC temperatures were plotted to determine the module's temperature response to high ripple current values and the lower TC temperatures were not as greatly influenced by the ripple current, and therefore were not included in these plots. These data are shown in for the LS 600h and Camry modules in Figs. 2.45 and 2.46, respectively. The Camry data for the $7.5 \mathrm{kHz}$ test stops at $190 \mathrm{~A}$ for the Camry module, and stops at even 
less extreme conditions for the LS $600 \mathrm{H}$ module due to the limitations of the voltage amplifiers. Both modules performed similarly and sustained operation with high ripple currents without reaching extreme temperatures. Since the results are so similar, the comparison between Figs. 2.45 and 2.46 is not straightforward since even slightly different ambient temperatures greatly affect each test. Nonetheless, the temperature of the Camry module increases as a function of ripple current more so than the LS 600h, particularly for currents above $150 \mathrm{~A}$.

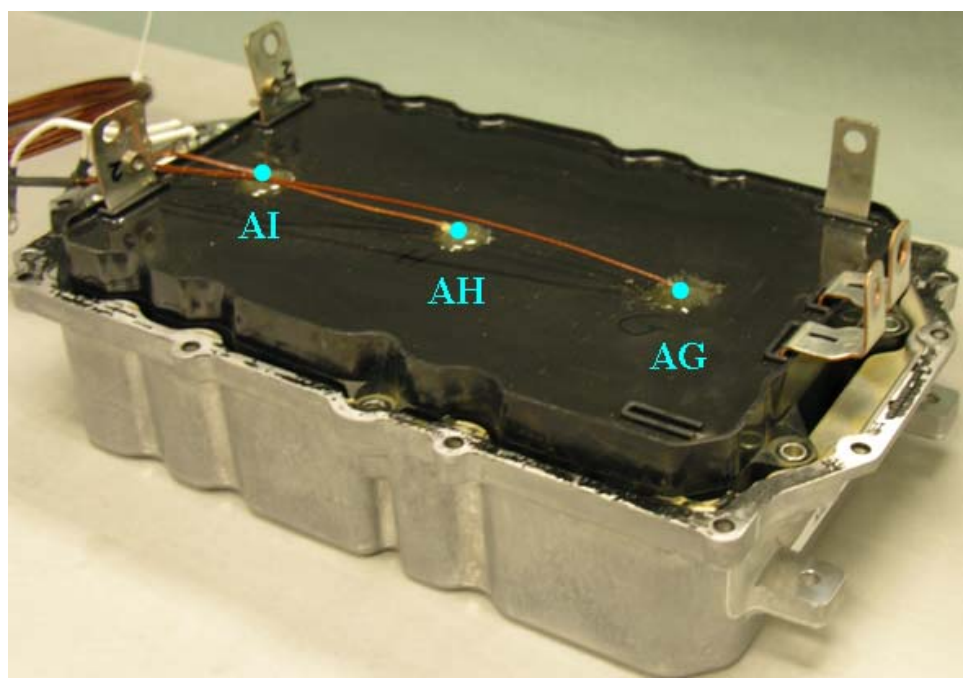

Fig. 2.44. TCs on the LS 600h capacitor module.

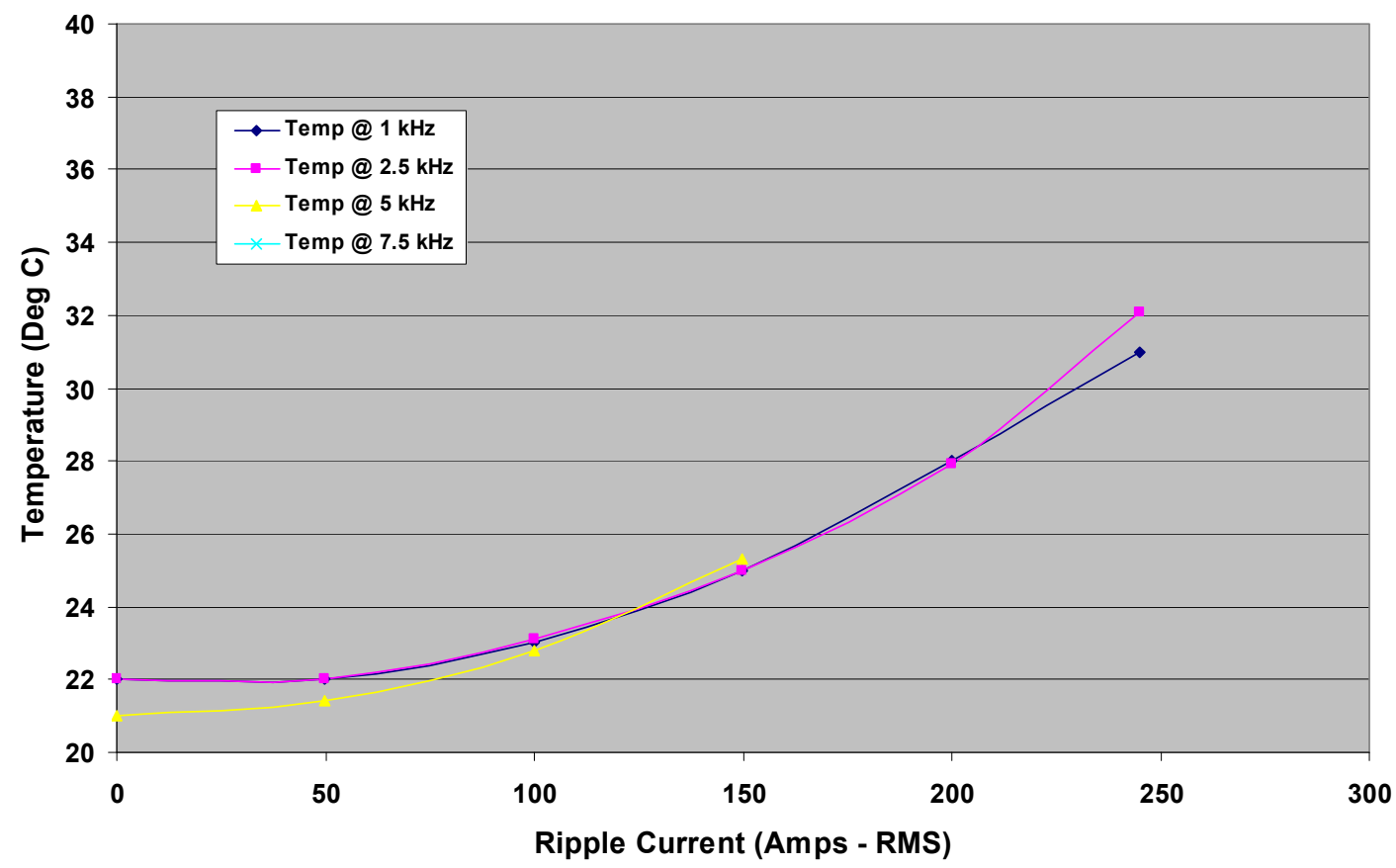

Fig. 2.45. LS 600h capacitor module steady state temperature response vs. ripple current. 


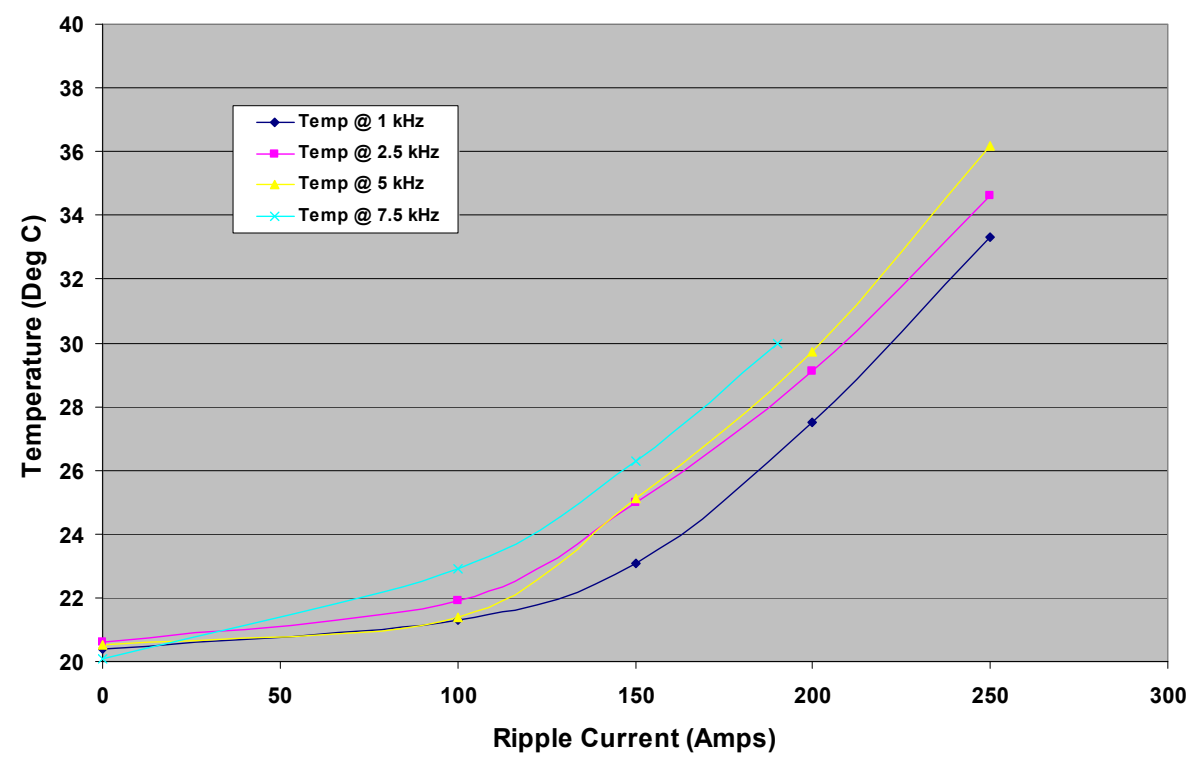

Fig. 2.46. Camry capacitor module steady state temperature response vs. ripple current.

\subsubsection{Static capacitor test results of battery level filter capacitor evaluations}

Figures 2.47 and 2.48 compare the capacitor test results of the $500 \mathrm{~V}, 378 \mu \mathrm{F}$ capacitor of the LS $600 \mathrm{~h}$ and the Camry respectively. Each capacitor resides between the battery and the boost converter and is located within the PCU. Test results from the two modules are quite similar. The capacitance of the LS $600 \mathrm{~h}$ capacitor increases with increasing frequency, slightly more so than the Camry, and the ESR and DF also have the same trend. For example, the DF of the LS $600 \mathrm{~h}$ capacitor at $25 \mathrm{kHz}$ is about $18.6 \%$, whereas the DF of the Camry capacitor at $25 \mathrm{kHz}$ is only about $6.5 \%$.

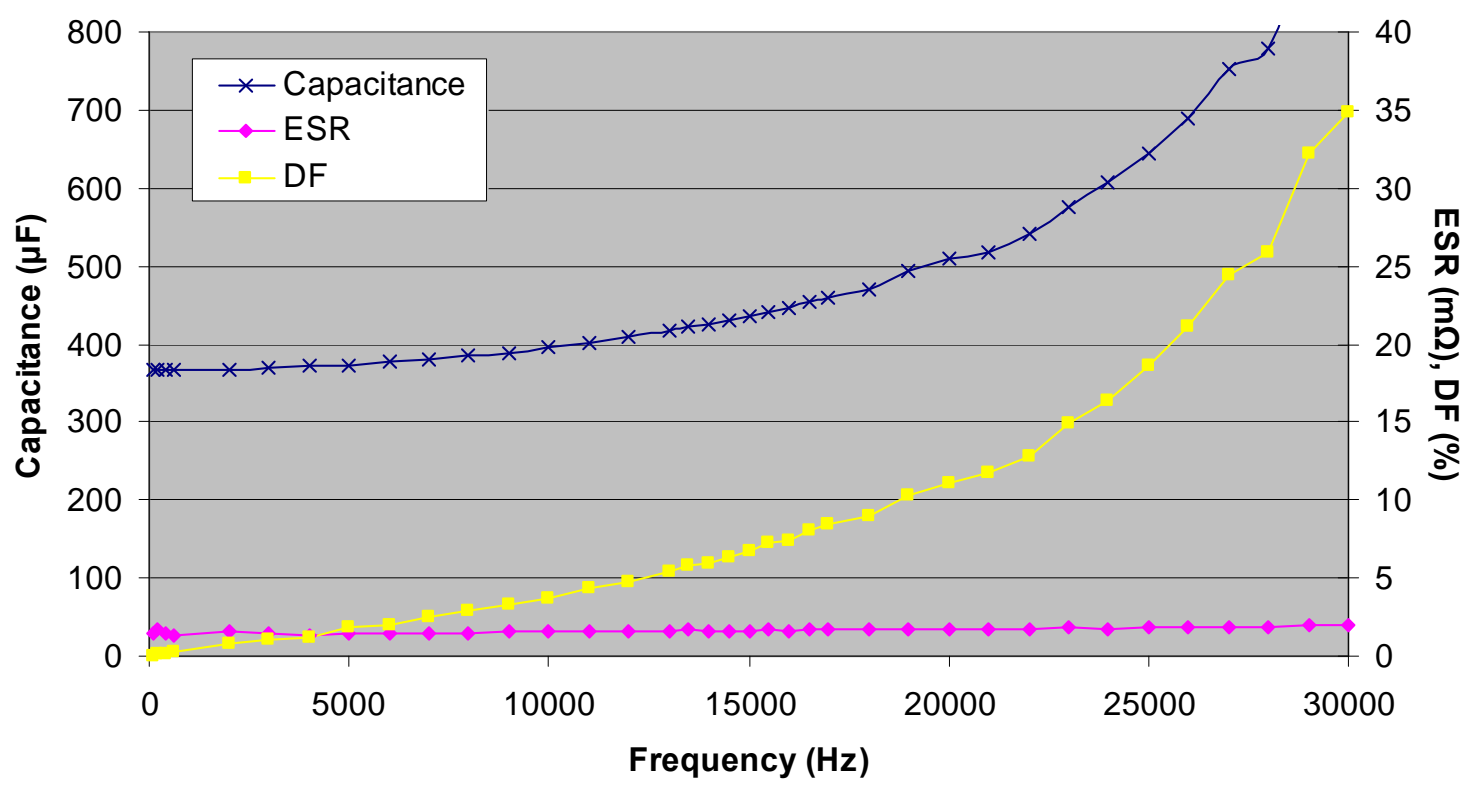

Fig. 2.47. Capacitance, ESR, and DF vs. frequency for LS 600h battery level $378 \mu$ F capacitor. 


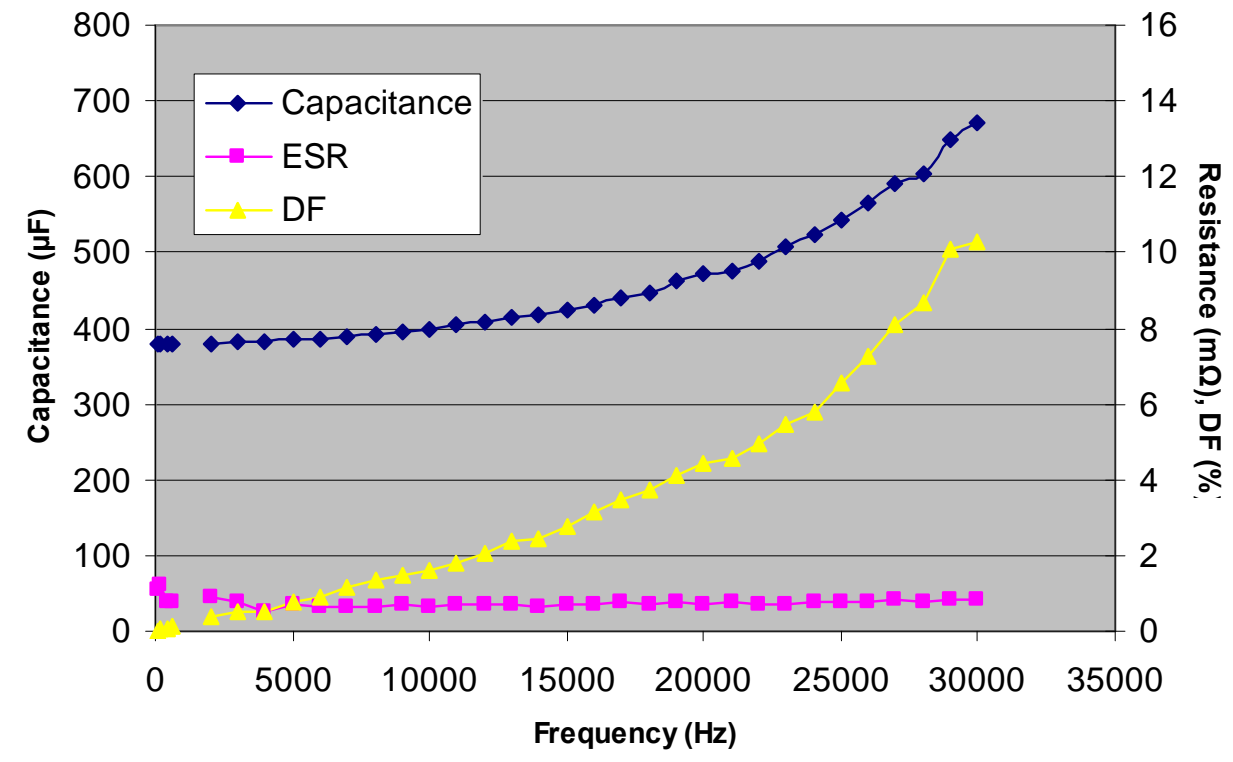

Fig. 2.48. Capacitance, ESR, and DF vs. frequency for Camry battery level $378 \mu \mathrm{F}$ capacitor.

\subsubsection{Static capacitor test results of small dc-link capacitor evaluations}

Figures 2.49 and 2.50 present the capacitor test results of the dc-link $750 \mathrm{~V}, 0.6 \mu \mathrm{F}$ and the $750 \mathrm{~V}, 1.2 \mu \mathrm{F}$ capacitor of the LS $600 \mathrm{~h}$, respectively. Note that the scale for capacitance on the left y-axis has a very small range for both capacitors, and thus their capacitances vary only slightly with frequency. The characteristics of the ESR curves for both capacitors reveal much higher ESR values for low frequencies, a common trend among small capacitors. The DF for both capacitors remains relatively low, even at high frequencies.

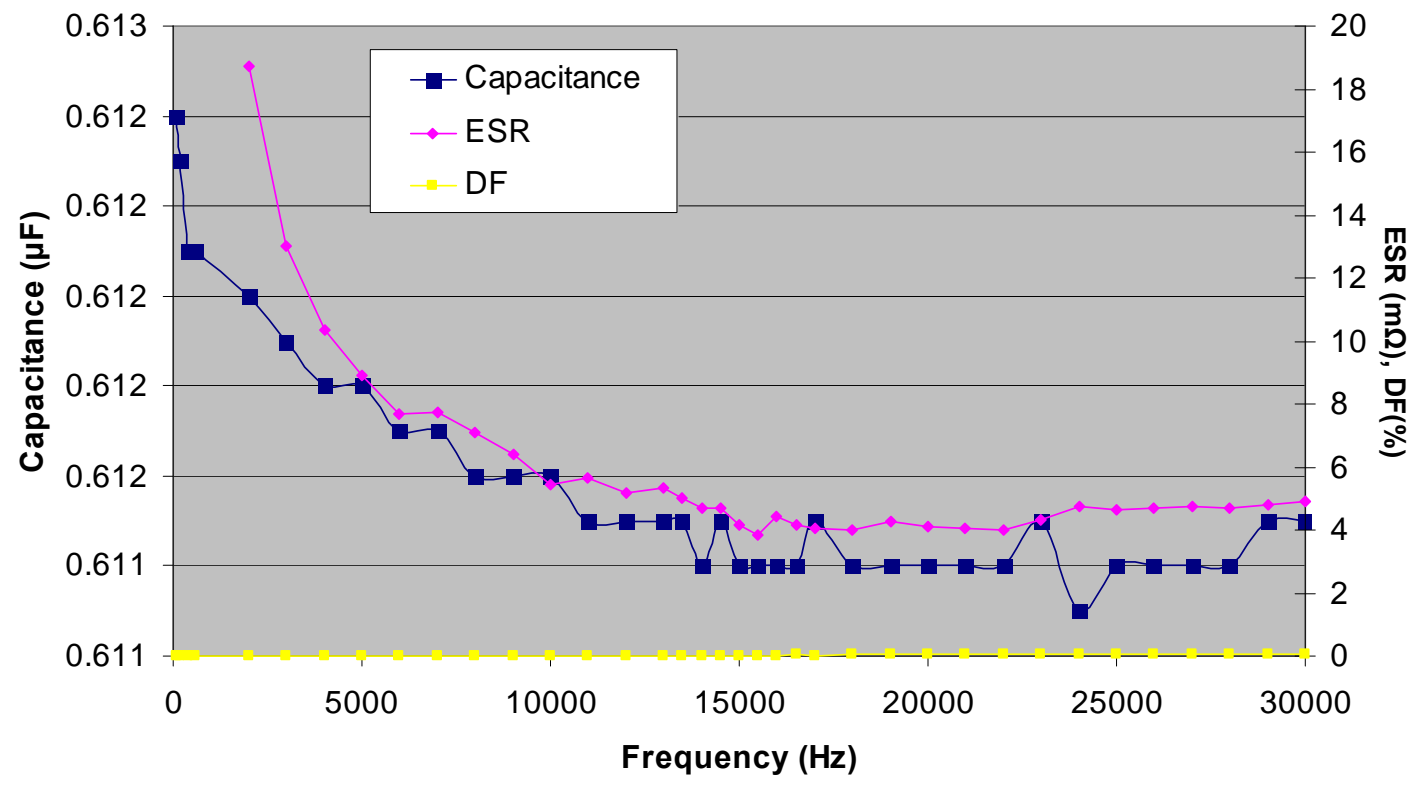

Fig. 2.49. Capacitance, ESR, and DF vs. frequency for LS $600 \mathrm{~h}$ dc-link $0.6 \mu \mathrm{F}$ capacitor. 


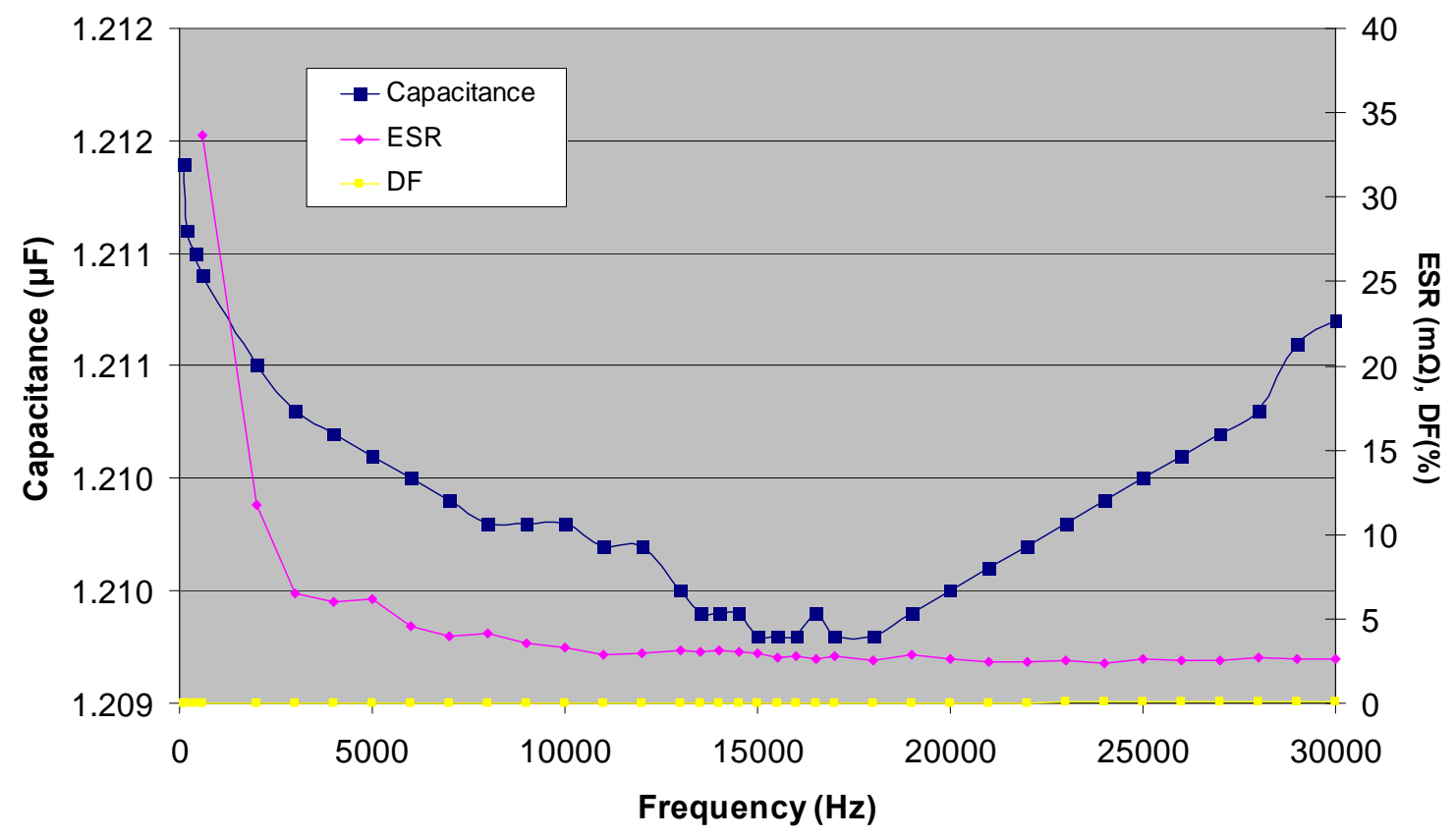

Fig. 2.50. Capacitance, ESR, and DF vs. frequency for LS 600h dc-link $1.2 \mu \mathrm{F}$ capacitor.

\subsection{ECVT}

The 2008 Lexus LS 600h ECVT assembly, shown in Fig. 2.51, is comprised of motor, generator, and gear box subassemblies. The overall functionality of the ECVT is similar to the Camry and Prius, yet there are significant differences between the subsystem designs. A comparison of the designs can be made by observing mechanical diagrams of the systems, given in Fig. 2.52. All systems use the sun gear of a planetary gear set to receive input from the generator rotor with a hollow rotor shaft, through which a shaft connected to the ICE passes and connects to the planetary carrier. The ring of the planetary gear is connected directly to the motor output in the Prius, and to the motor through a high-speed reduction gear in the Camry. The Prius and Camry planetary rings drive the differential output through a series of drive gears. Similar to the Camry, the LS $600 \mathrm{~h}$ ring gear connects to the motor output through a gear system. However, the LS 600h utilizes a Ravigneaux gear configuration to facilitate a high and low gear selection through a clutch, brake, and pressure plate mechanism similar to what is found in many conventional automatic transmissions. A Ravigneaux gear system consists of two planetary gear sets and its operation can be manipulated depending on which clutch set has pressure applied to it, thereby locking the ring of the corresponding planetary gear set to the chassis. A long shaft passes through the center of the drive motor rotor and connects the power split planetary ring to the output of the Ravigneux gear system and the two are unified into one spline. This spline mates with the input of the transfer case, which also utilizes a small planetary gear to distribute power to the front and rear wheels appropriately. 


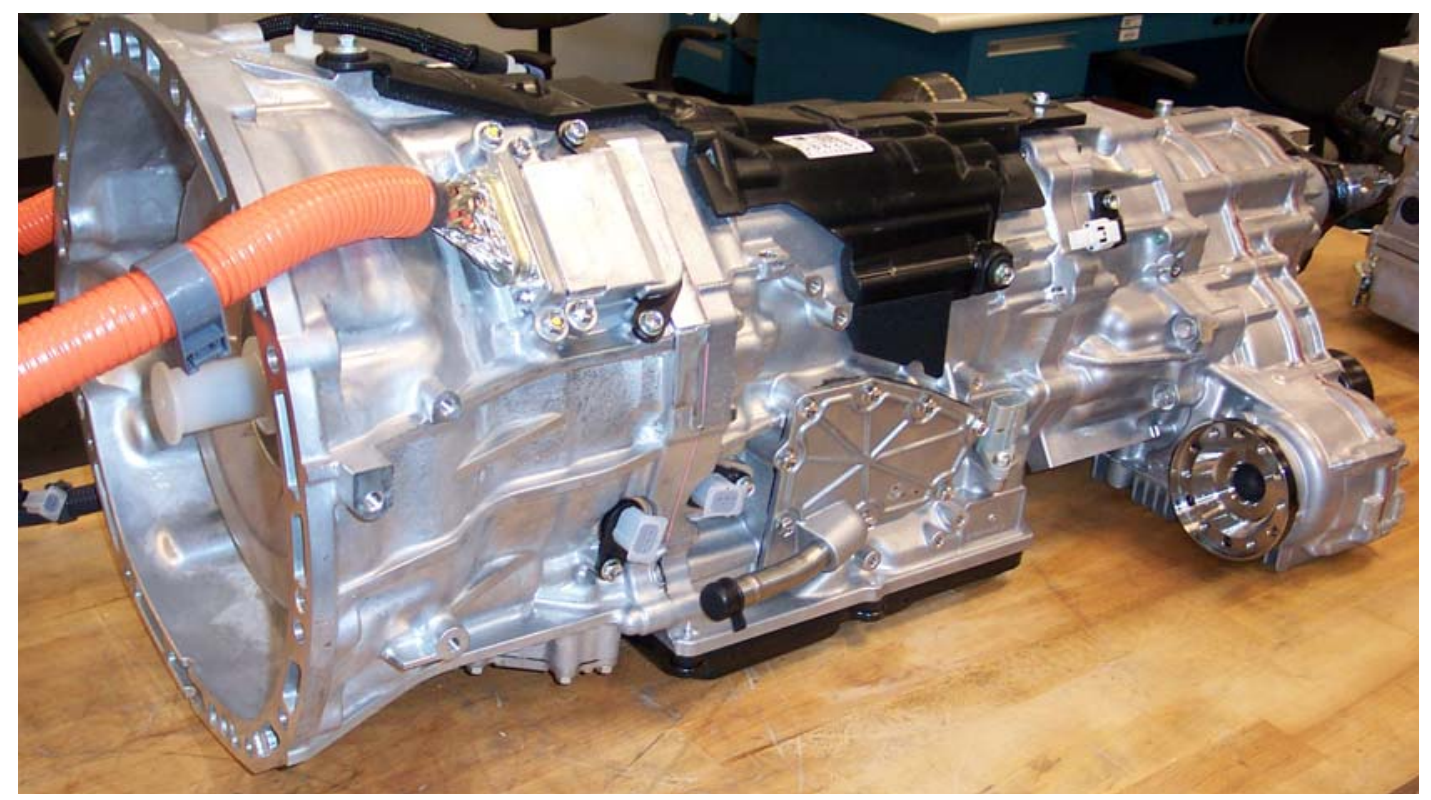

Fig. 2.51. LS 600h ECVT.

Prius

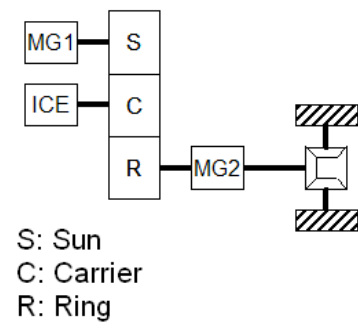

Camry

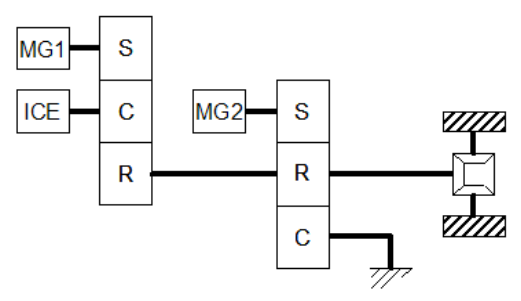

GS450h / LS600h

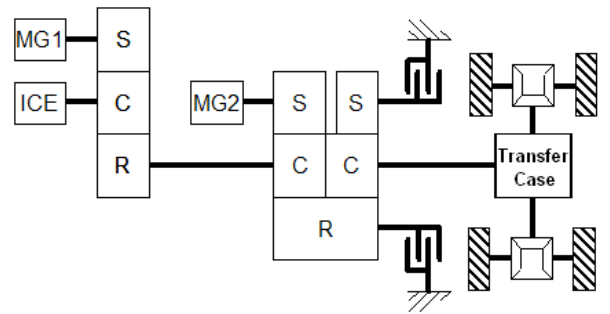

Fig. 2.52. Mechanical diagram of Prius, Camry, and Lexus gear systems.

\subsubsection{ECVT Disassembly}

An overview of the sections within the ECVT housing is shown in Fig. 2.53. In this figure, much of the interior components have been removed and assembled in front of the entire ECVT housing. Primary sections of the ECVT are dedicated to the generator, power split planetary gear set, motor, Ravigneaux gear system, and transfer case. As shown in Fig. 2.53 and better portrayed in Fig. 2.54, the engine mounts directly to the ECVT and supplies power through a splined shaft. After removing the generator cover plate, the generator rotor with a hollow shaft is visible. Note that the generator stator was removed when the picture was taken. The engine shaft passes through the hollow generator shaft and connects to the planetary carrier, while the generator rotor shaft connects to the sun of the planetary gear. Thus far, the Prius, Camry, and Lexus gear systems are identical, in terms of functionality. 


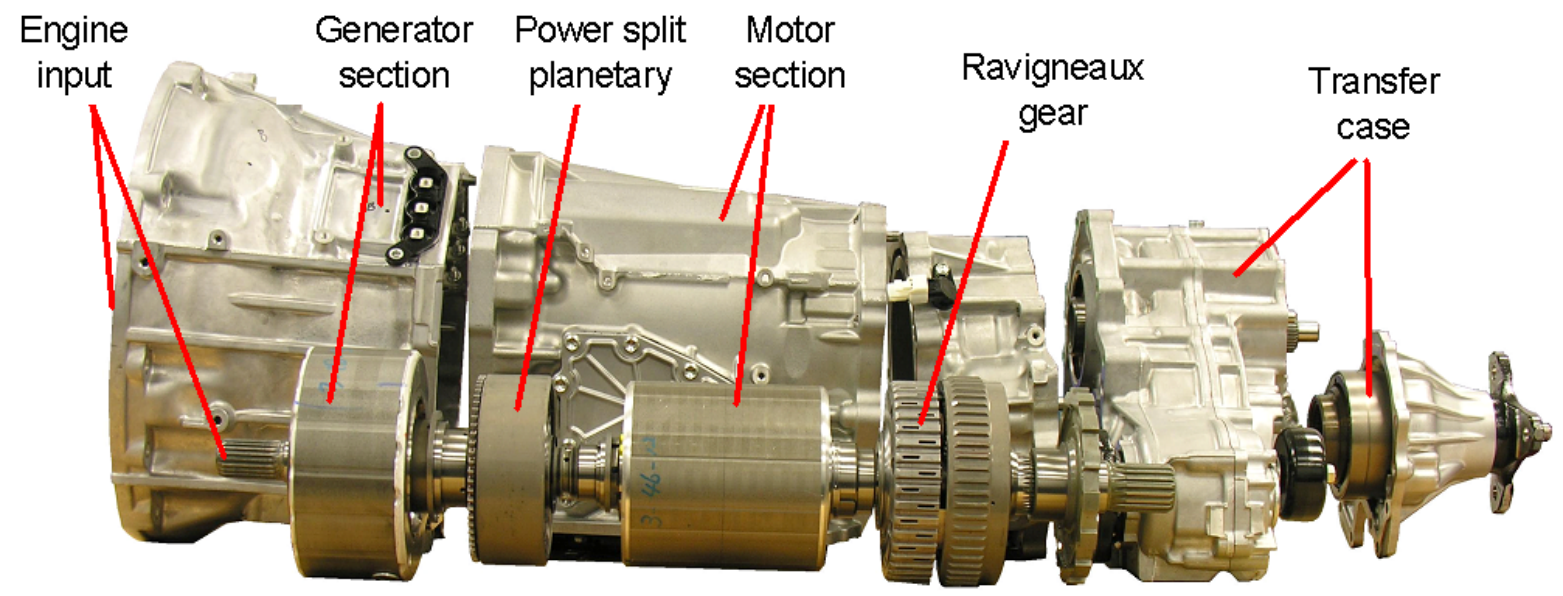

Fig. 2.53. Sections of the LS 600h ECVT.
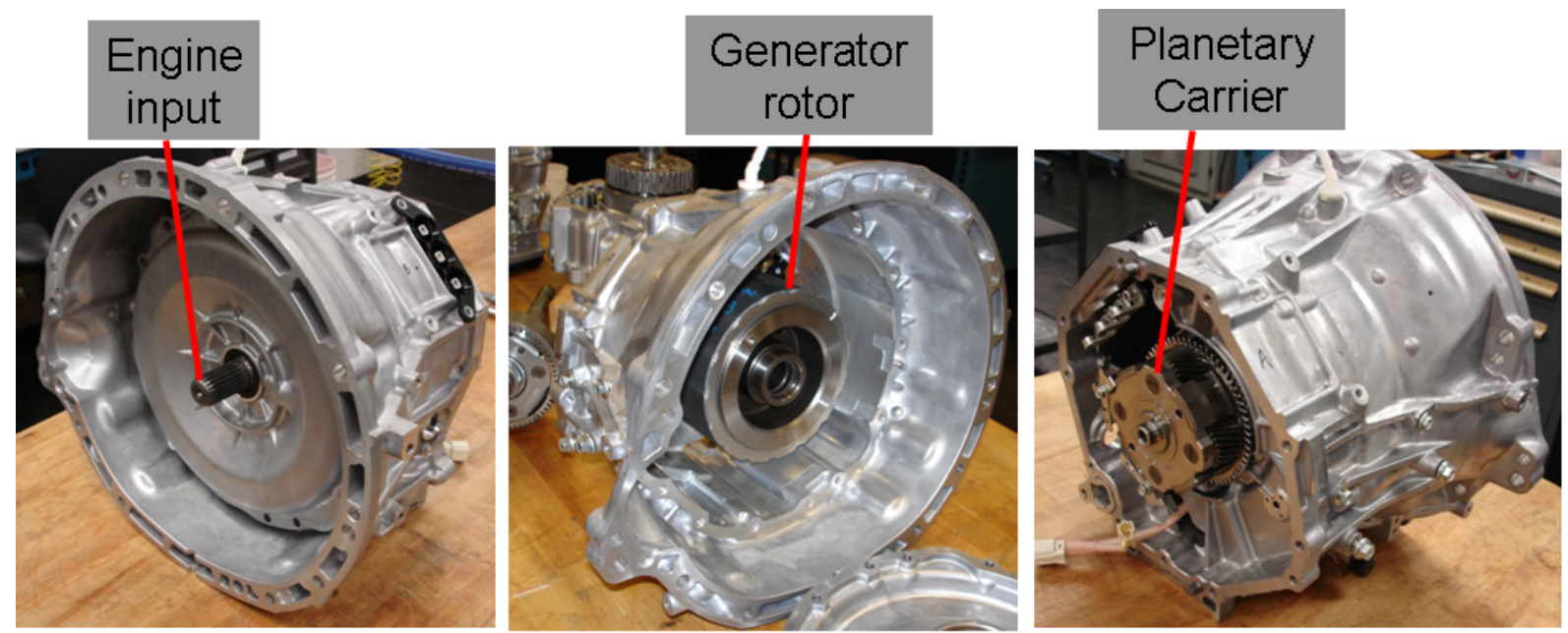

Fig. 2.54. Generator section of ECVT; front (left), plate removed (middle), and rear (right).

Shown in Fig. 2.55 is the ring gear and ring gear shaft, which passes through the motor rotor. Also shown is a more detailed photograph of the power split planetary gear set which has been disassembled to better reveal the components. The sun gear and ring gear have 30 and 78 teeth, respectively. Each of the 4 planets contained within the planetary carrier has 22 teeth. Also visible on the outer circumference of the planetary carrier are teeth which are used to drive a trochoid oil pump. The output end of the ring gear shaft connects to an interior spline of the primary output shaft which mates with the transfer case. The primary output shaft mates with the output of the Ravigneaux gear set and the ring gear shaft is thereby indirectly connected to the motor output. Figure 2.56 shows a view of the motor section with the planetary gear set installed. The driven gear of the mechanical oil pump shaft is also visible. A rear-view of the motor section in Fig. 2.56 reveals how the ring gear shaft protrudes through the motor section into the Ravigneaux gear section. The motor rotor output is barely visible in this figure, but is in the form of a female spline, which interconnects with the sun of the Ravigneaux gear set. 


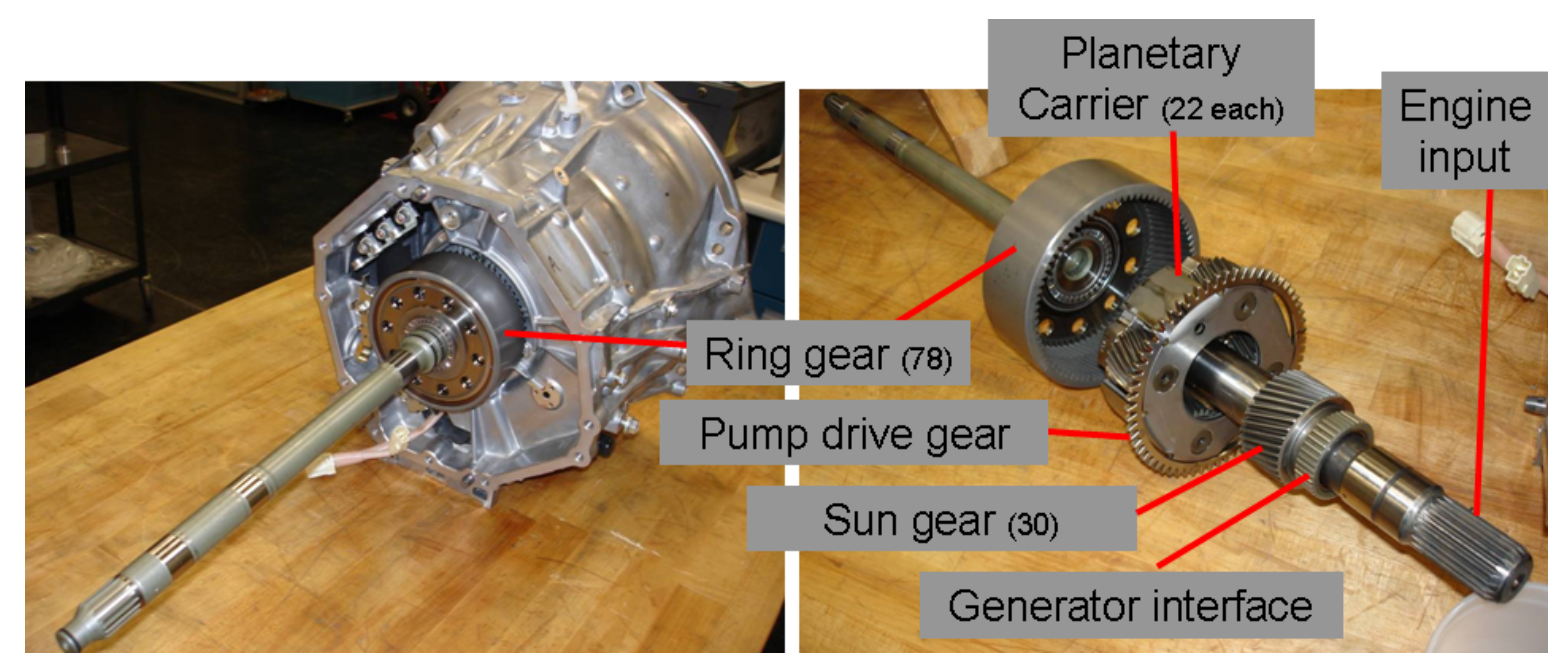

Fig. 2.55. Planetary section of ECVT.
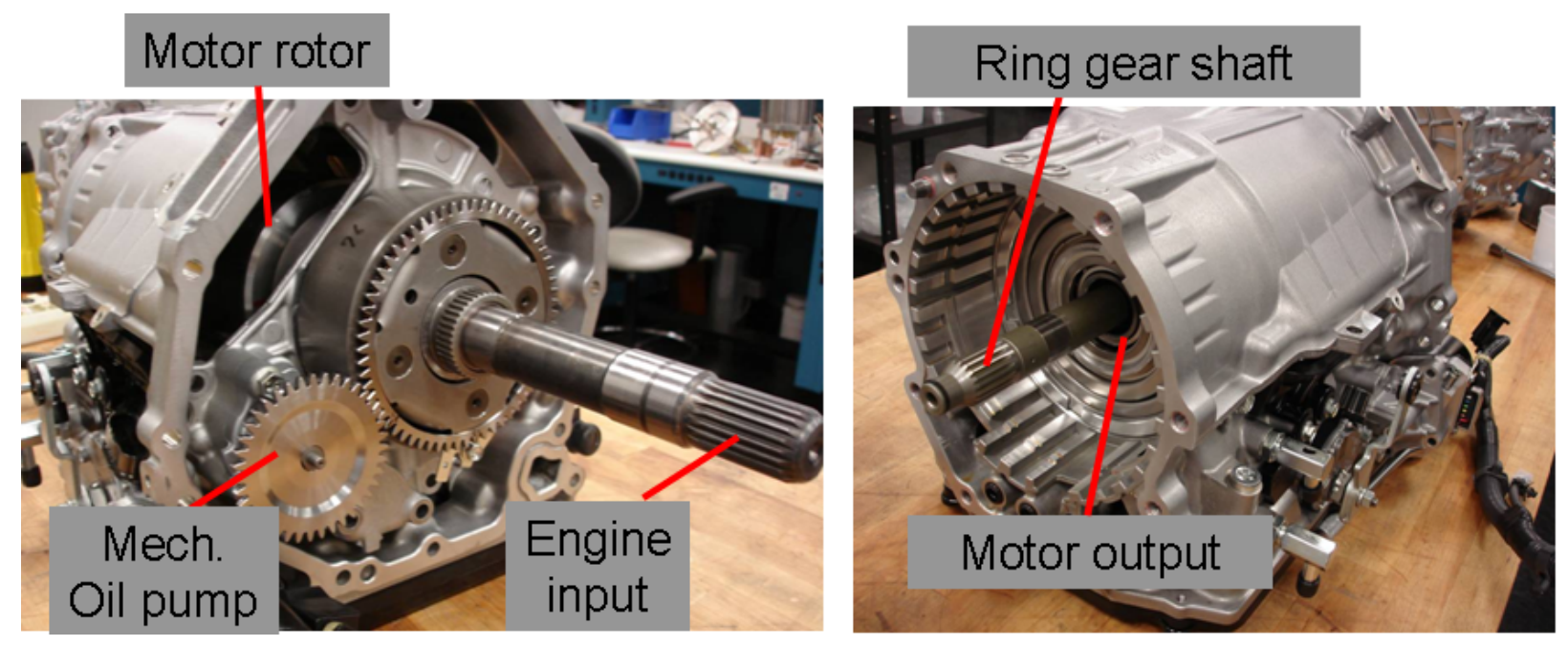

Fig. 2.56. Motor section of ECVT; front with planetary gear installed (left) and rear (right).

Another view of the motor section is provided in Fig. 2.57. With the motor section upside-down, a valve body cover is visible. Upon further inspection, the valve body is much like that of a conventional automatic transmission. The Ravigneaux gear system requires the use of a brake and clutch mechanism, and the valve body contains intricate pathways, solenoids, and passive mechanical pressure regulators needed to supply oil of the appropriate pressure to pressure plates. These pressure plates are further described shortly. Due to the nature of the clutch and brake system, the oil incurs significant heating and is routed to an oil-cooler in front of the vehicle. An ethylene-glycol/water heat exchanger is located on one side of the motor section and a coolant pathway passes to the generator section. The plate seen in the right portion of Fig. 2.57 contains a resolver, oil pump, oil squirter, and bearing. The resolver is used to obtain accurate measurements of speed and absolute position. The oil pump feeds the primary oil reservoir and also feeds the oil squirter through a pathway which routes around the bearing. When the plate is attached to the motor housing, the oil squirter focuses on the opposite end of the stator near the Ravigneaux gear interface. Support is provided to the motor rotor by this bearing, and the ring gear shaft is supported by the motor rotor shaft by means of a bushing. 


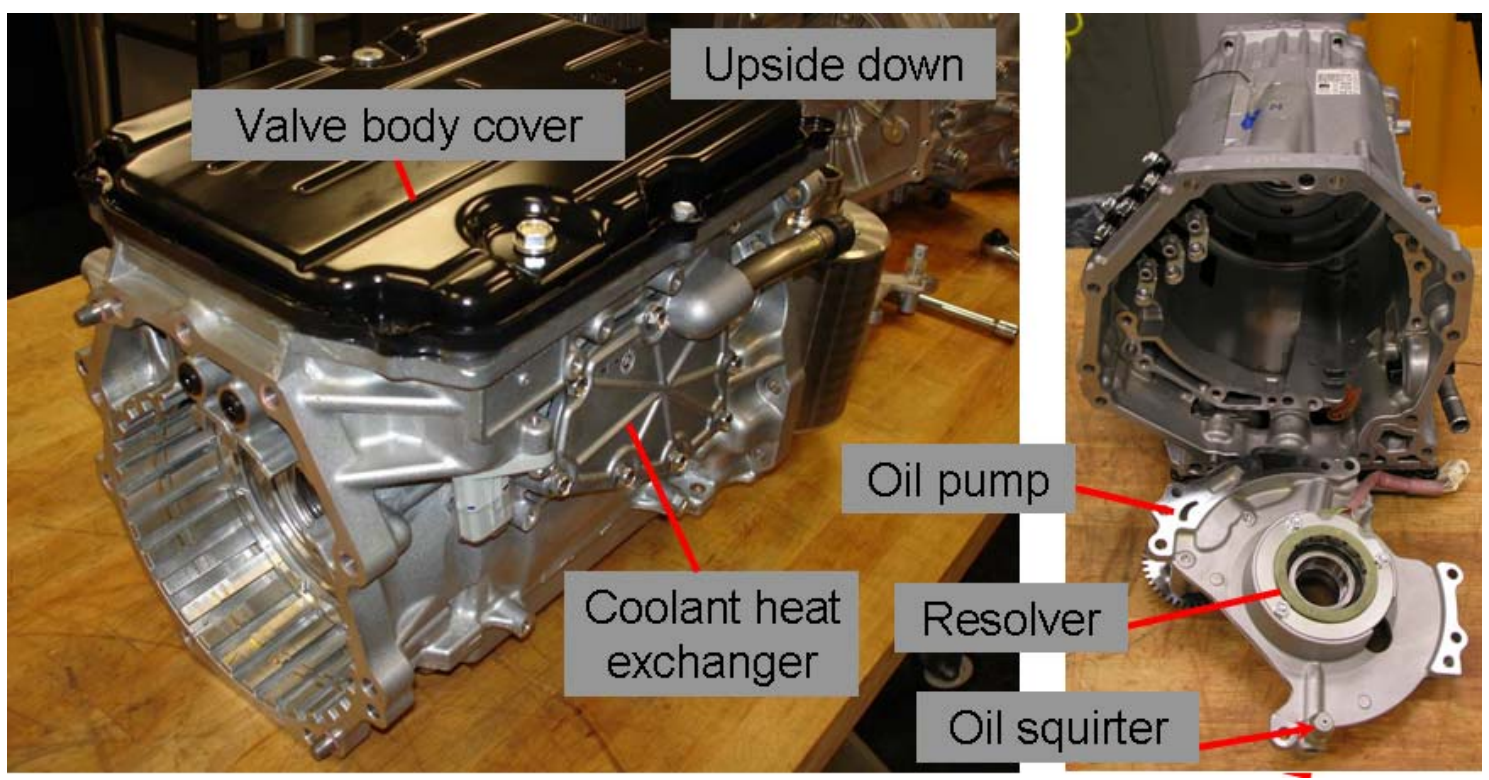

Fig. 2.57. Motor section of ECVT; underside (left) and front view with plate removed (right).

The Ravigneaux gear section is shown in Fig. 2.58. An exterior-splined (male) hollow shaft extends from the 30-tooth sun gear of the Ravigneaux gear system and connects to the interior-splined motor rotor shaft. The ring gear shaft passes through the sun and mates with an interior spline of the primary output shaft, which is also fixed to the carrier of the Ravigneaux system, which is a compound planetary gear set. Two sun gears, visible in the right portion of the Fig. 2.58, rotate independently with the sun gear closest to the motor (which has 27 teeth) fixed to the adjacent clutch interface. This 27 -tooth sun gear meshes with the larger 20-tooth planets of the compound planetary gear set. Smaller 20-tooth liaison planets are fixed to and rotate at the same speed as the large 20-tooth planets. These gears are not utilized unless the associated clutches are engaged by the corresponding actuator, as shown in the right portion of Fig. 2.59. Only one of the two actuators is activated at a time. If the actuator in the left portion of Fig. 2.59 is activated, the 87-tooth ring gear is locked to the chassis with the clutches, with the other set clutches allowed to spin since no actuator pressure is applied. In this case, the compound planetary gear system behaves as a simple planetary gear system with a stationary 87 -tooth ring gear, three 28 -tooth planets, and a 30-tooth sun with the input from the motor connected to the sun, and the carrier serves as the output, as it is fixed to the primary output shaft mating with the transfer case. This is equivalent to a gear ratio which reduces the motor speed by about 3.9 times. If the actuator on the right is engaged, the clutch set on the left is allowed to spin freely, as power is transferred through the 20-tooth planets and the carrier is rotated due to the opposing force applied by the 27-tooth sun which is fixed to the chassis through the activated clutches. This configuration causes the output speed of the carrier to be only about 1.9 times less than the motor speed, and is therefore used at high vehicle speeds. Also visible in Fig. 2.59 is the mechanism used to lock the output shaft when the vehicle in placed in park. A rear-view of the Ravigneaux gear section is provided in Fig. 2.60, wherein the splined shaft which interfaces with the transfer case is protruding outwards. To provide a better overall understanding of the entire gear system, it is shown in Fig. 2.61 with all components assembled in the upper portion and disassembled in the lower portion of the figure. Note that this does not include the gears associated with the transfer case. 


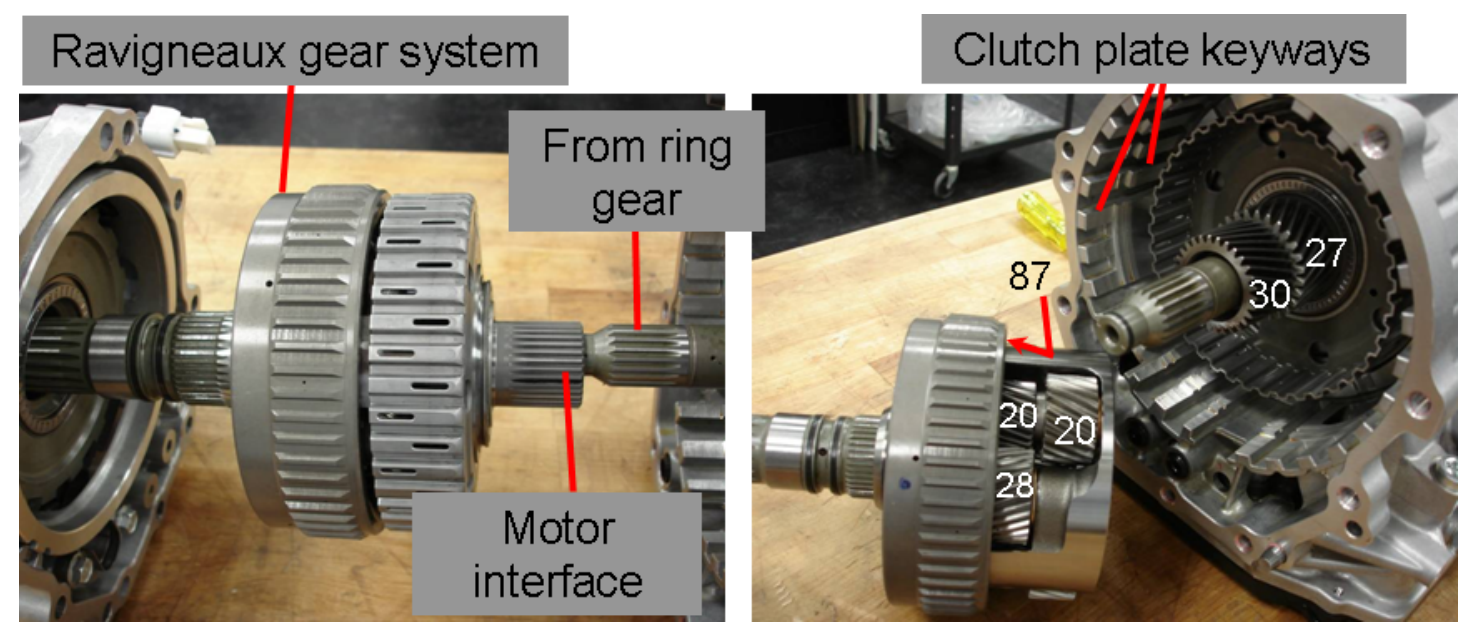

Fig. 2.58. Ravigneaux gear section interfaces (left) and keyways (right).

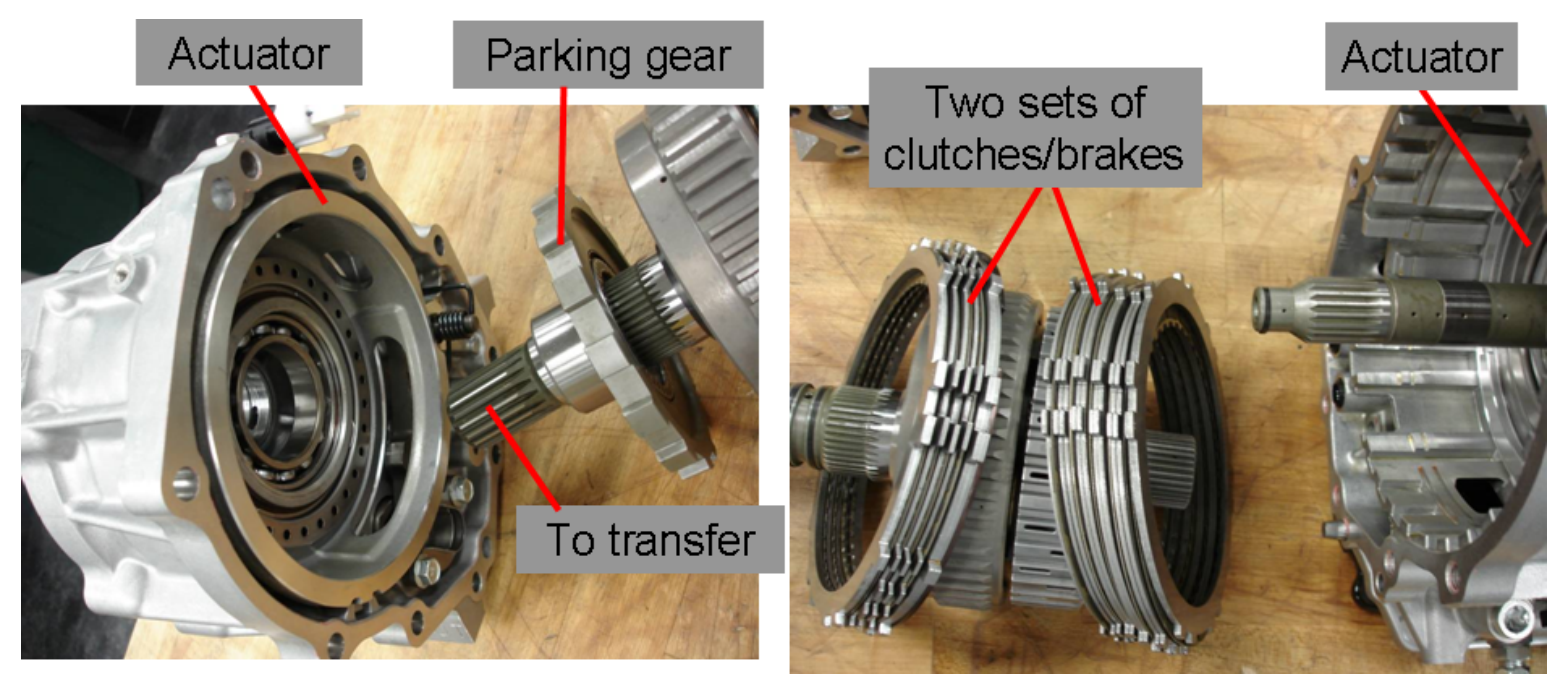

Fig. 2.59. Ravigneaux gear section actuators and clutches.

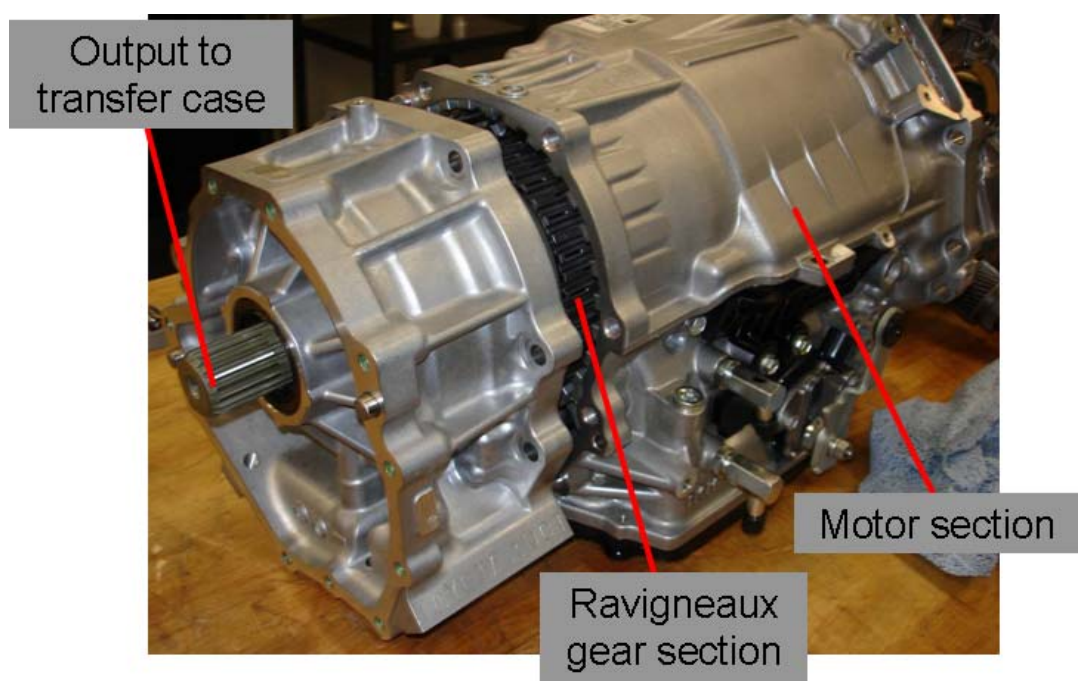

Fig. 2.60. Ravigneaux gear section rear view. 


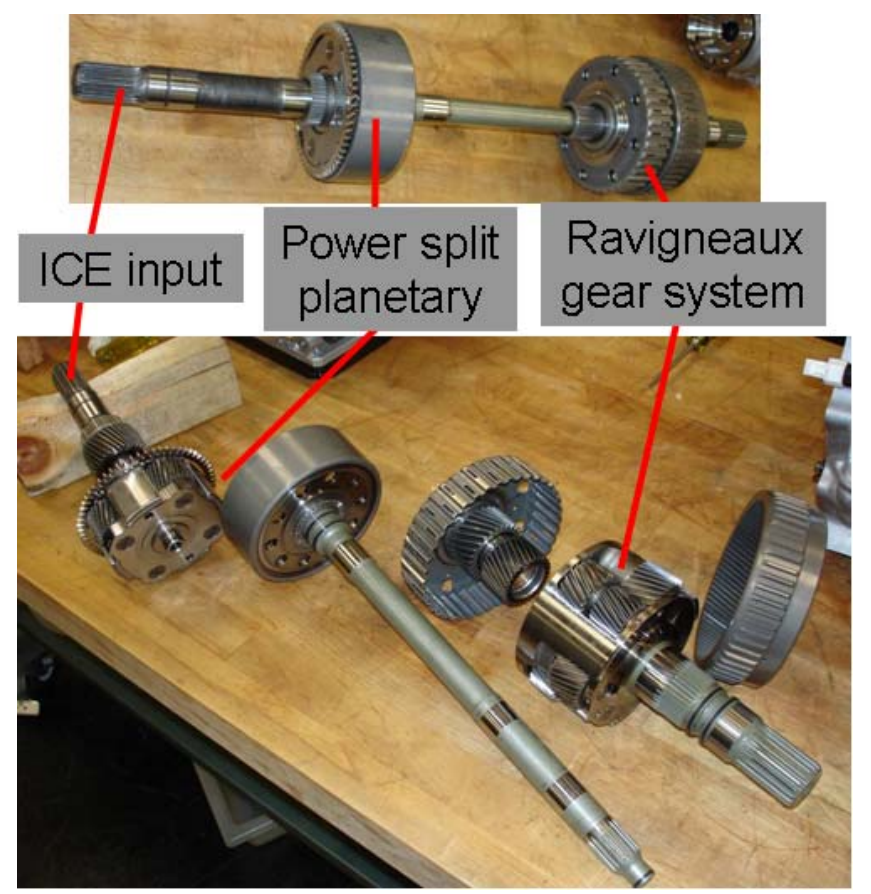

Fig. 2.61. Overall LS 600h gear system.

The output from the Ravigneaux carrier and the ring gear shaft of the power split planetary combine and mate with the transfer case, as indicated in Fig. 2.62. Another planetary gear set, shown in the right portion of Fig. 2.63, is used to split the output to the front and rear wheels. A series of drive gears is placed between the output of the transfer case planetary gear set and the output to the front wheels.

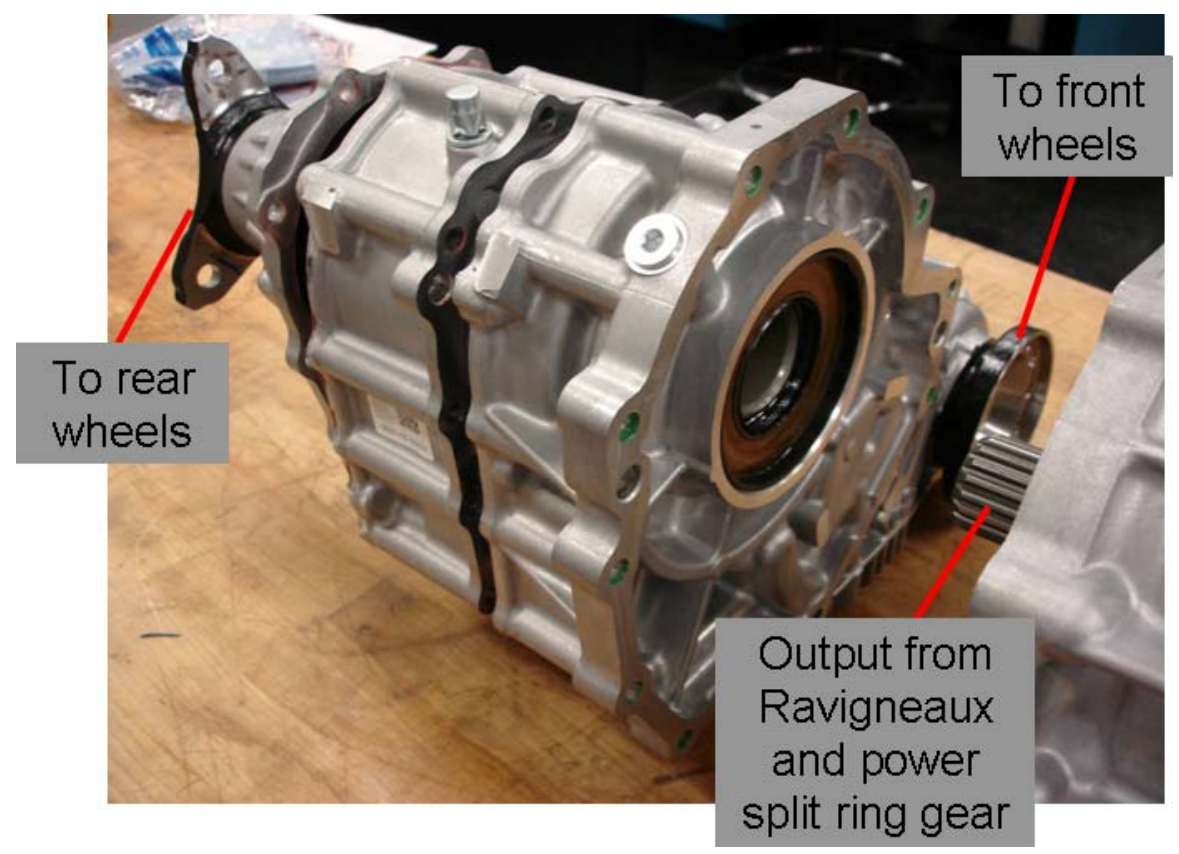

Fig. 2.62. Mating of output shaft with transfer case. 

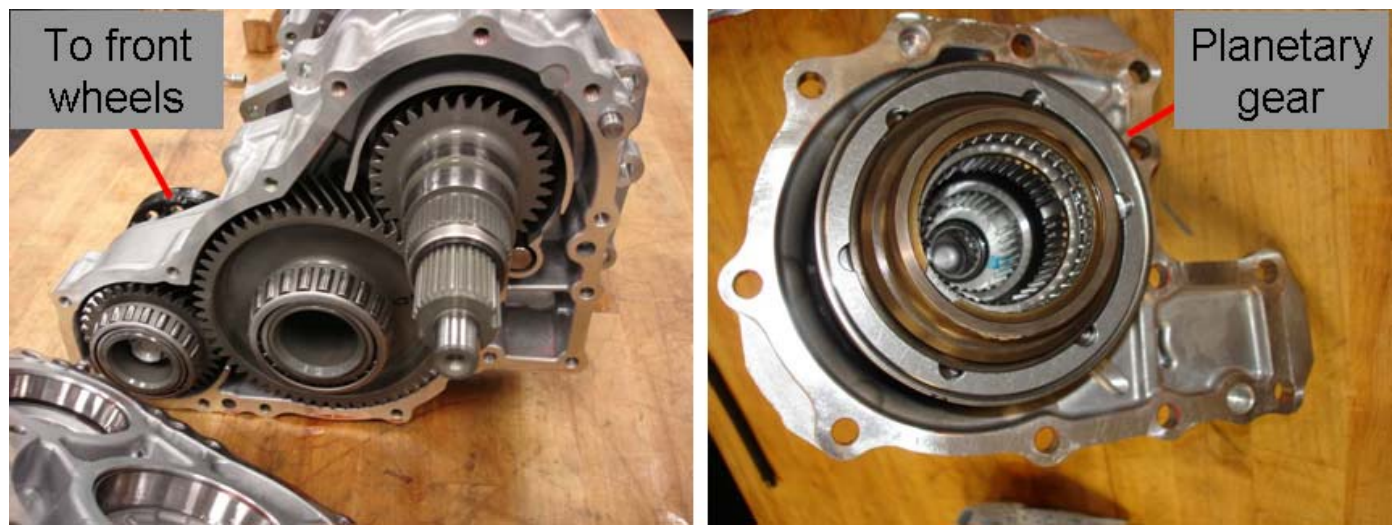

Fig. 2.63. Internal components of transfer case.

\subsubsection{Motor and Generator Design Assessments}

One of the most noticeable features of the electric machines in the LS 600h is the elongated shape of the primary drive motor. Figure 2.64 shows the stator assembly without the rotor after it was removed from the LS 600h ECVT. Three bolts secure the stator as they protrude through the outer circumference of the stator in a direction parallel to the rotor shaft. Three-phase input leads (output leads during regenerative braking) and the neutral connection for the windings (wrapped in red-orange material) and visible in the right portion of Fig. 2.64. The mass of the LS $600 \mathrm{~h}$ stator assembly is about $18.75 \mathrm{~kg}$, which is similar to the mass of the Camry stator assembly is about $18 \mathrm{~kg}$. A drastic reduction in the usage of copper is noticed as the LS $600 \mathrm{~h}$ contains only $3.6 \mathrm{~kg}$ of copper, whereas the Camry motor contains $5.7 \mathrm{~kg}$ of copper. As indicated in Fig. 2.64, the motor stator stack length is about 5.33", where as the Camry stack length is only 2.4". Although the stack length is much longer than the Camry, the outer diameter (OD) of the motor stator has reduced from 10.4" to 7.9" in going from the Camry stator to the LS 600h stator. This reduction of diameter is more visible in the comparison of motor laminations in Fig. 2.65.
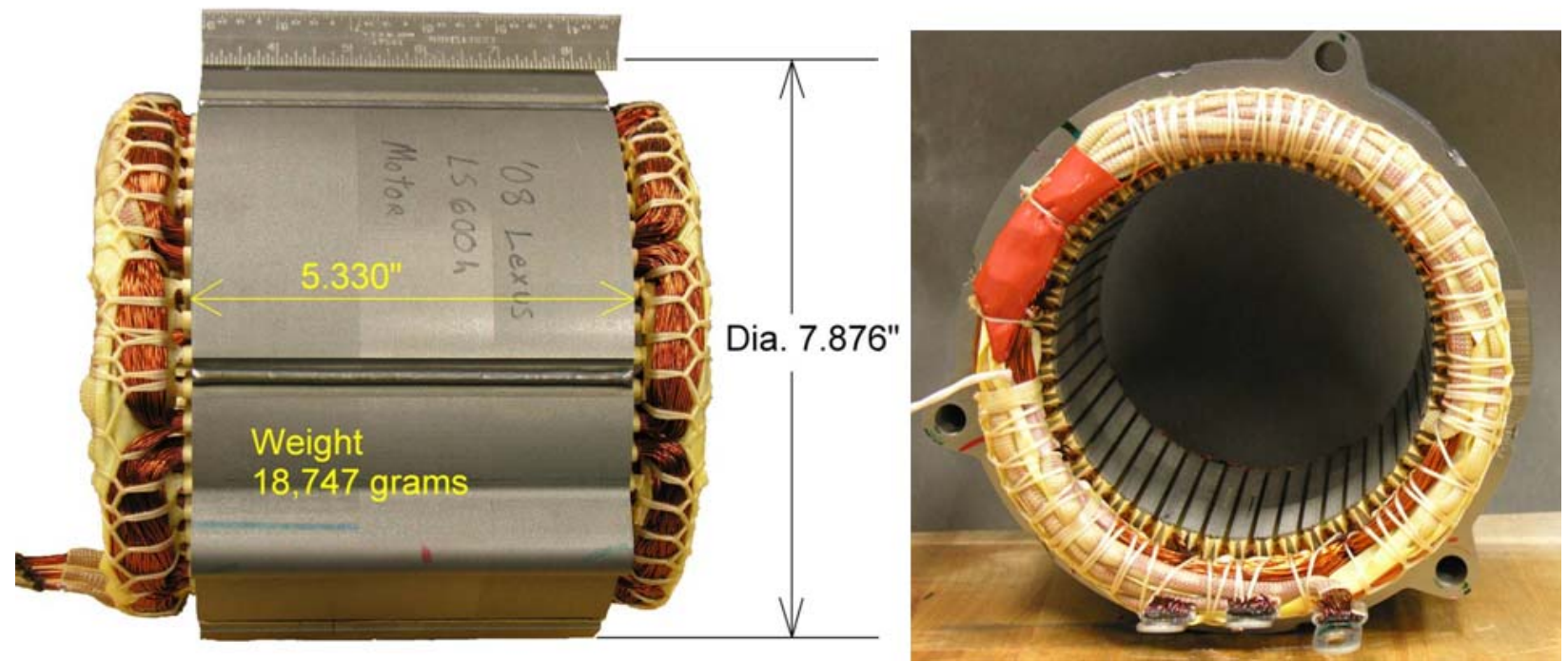

Fig. 2.64. LS 600h motor stator. 


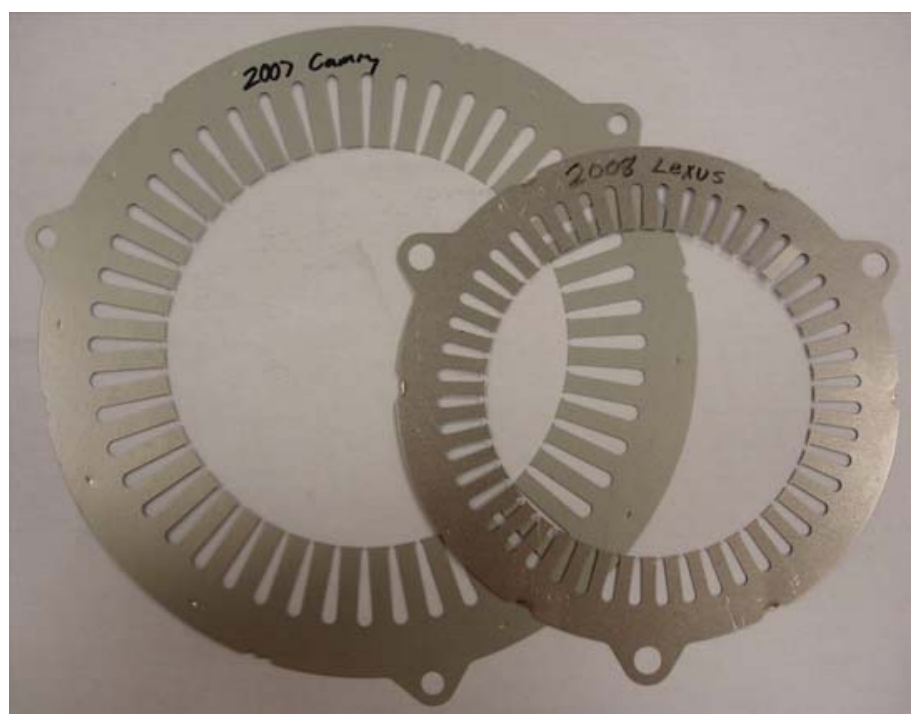

Fig. 2.65. Comparison of motor stator laminations, Camry (left) vs. LS 600h (right).

A comparison of the motor conductors used to carry energy between the PCU and the ECVT is provided in Fig. 2.66. A dime is situated next to the conductors to portray the minute size of the conductors. The conductor size has increased in moving to the LS $600 \mathrm{~h}$, as the published power rating of the motor increased by more than 50\%. The Prius and Camry conductors contain 19 bundles of $9-0.32 \mathrm{~mm}$ diameter wires (171 total), whereas the LS $600 \mathrm{~h}$ contains 124 unbundled, $0.45 \mathrm{~mm}$ diameter wires.

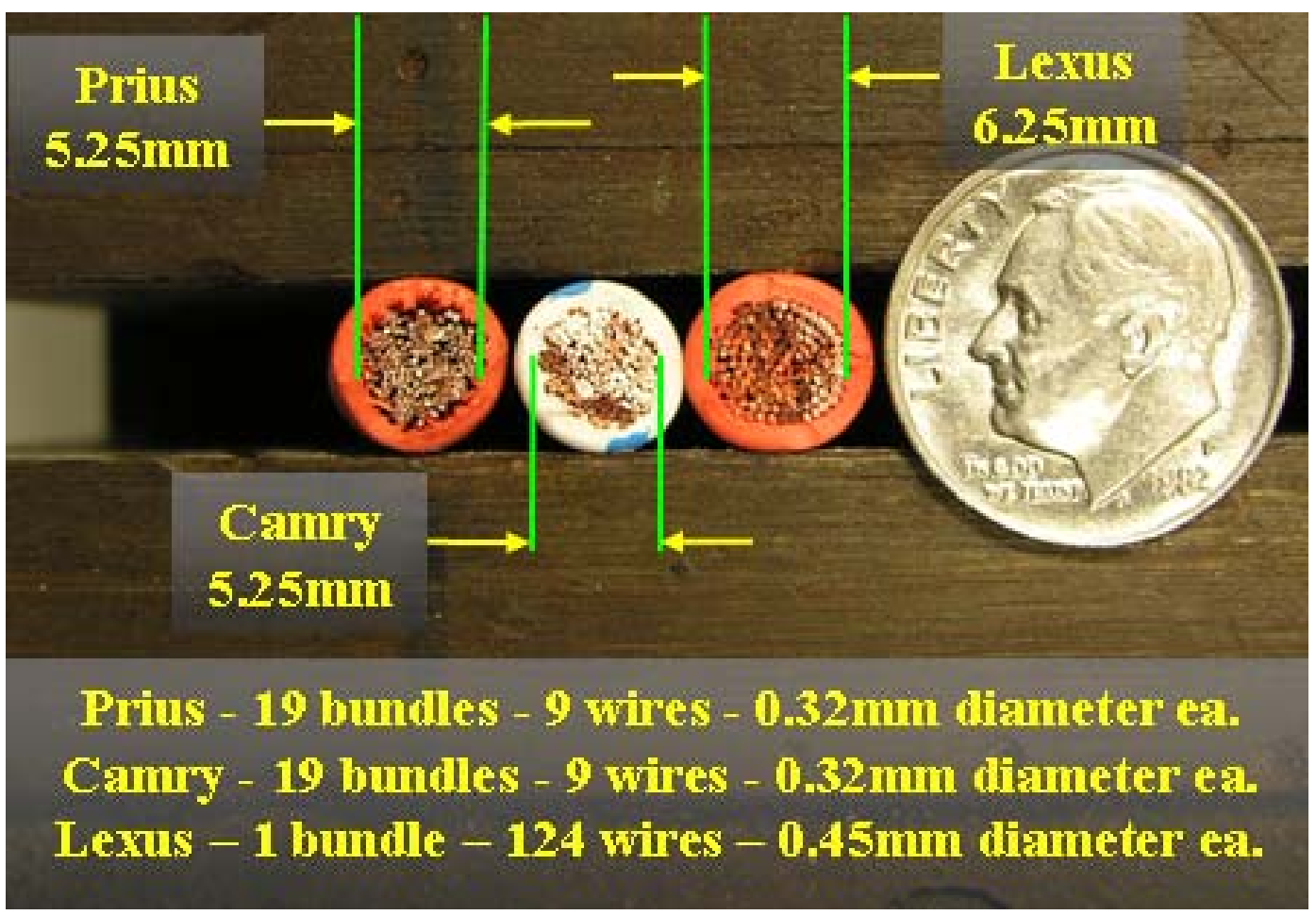

Fig. 2.66. Comparison of motor conductors between PCU and ECVT. 
After the external motor conductors reach the ECVT, a feed-through terminal (visible in Fig. 2.57) is used to secure the cable-harness (visible in Fig. 2.51). The three-phase motor leads connect to the other side of the feed-through terminal. Each motor lead (phase) consists of 18 wires, which split into two 9-wire legs upon reaching the stator. Figure 2.67 details the winding configuration of one phase of the LS $600 \mathrm{~h}$ motor. Overall, there are two legs in parallel which contain four coils in series. Each coil consists of roughly seven turns. The diagram in Fig. 2.67 indicates each nine-wire leg, $\mathrm{I}_{\mathrm{A}}$ and $\mathrm{I}_{\dot{\alpha}}$, with colors blue and red, respectively. Small arrows indicate the current direction, with a convention of positive current associated with a direction that is coming from the PCU to the motor. In this diagram, as a line passes through stator core, this represents a three-dimensional (3D) routing of the conductor through the stator slots (which would actually protrude into the page if accurately depicted). An actual 3D representation of the configuration on a two-dimensional (2D) sheet of paper could be confusing. Starting with the blue leg, $\mathrm{I}_{\mathrm{A}}$, the first coil is wrapped in a counter-clockwise fashion, and with positive current, would direct flux inward towards the rotor. After about seven turns, the next coil is wrapped in a clockwise fashion, and with positive current, would direct flux outward, away from the rotor. The conductor then weaves through two coils of other leg of the phase and is then used to form two more coils on the opposite side of the stator. The other leg of the phase,, is wound in a similar fashion and the neutral points, $\mathrm{I}_{\mathrm{NA}}$ and $\mathrm{I}_{\mathrm{N} \alpha \dot{ }}$, connect together, along with the neutral points of the other phases.

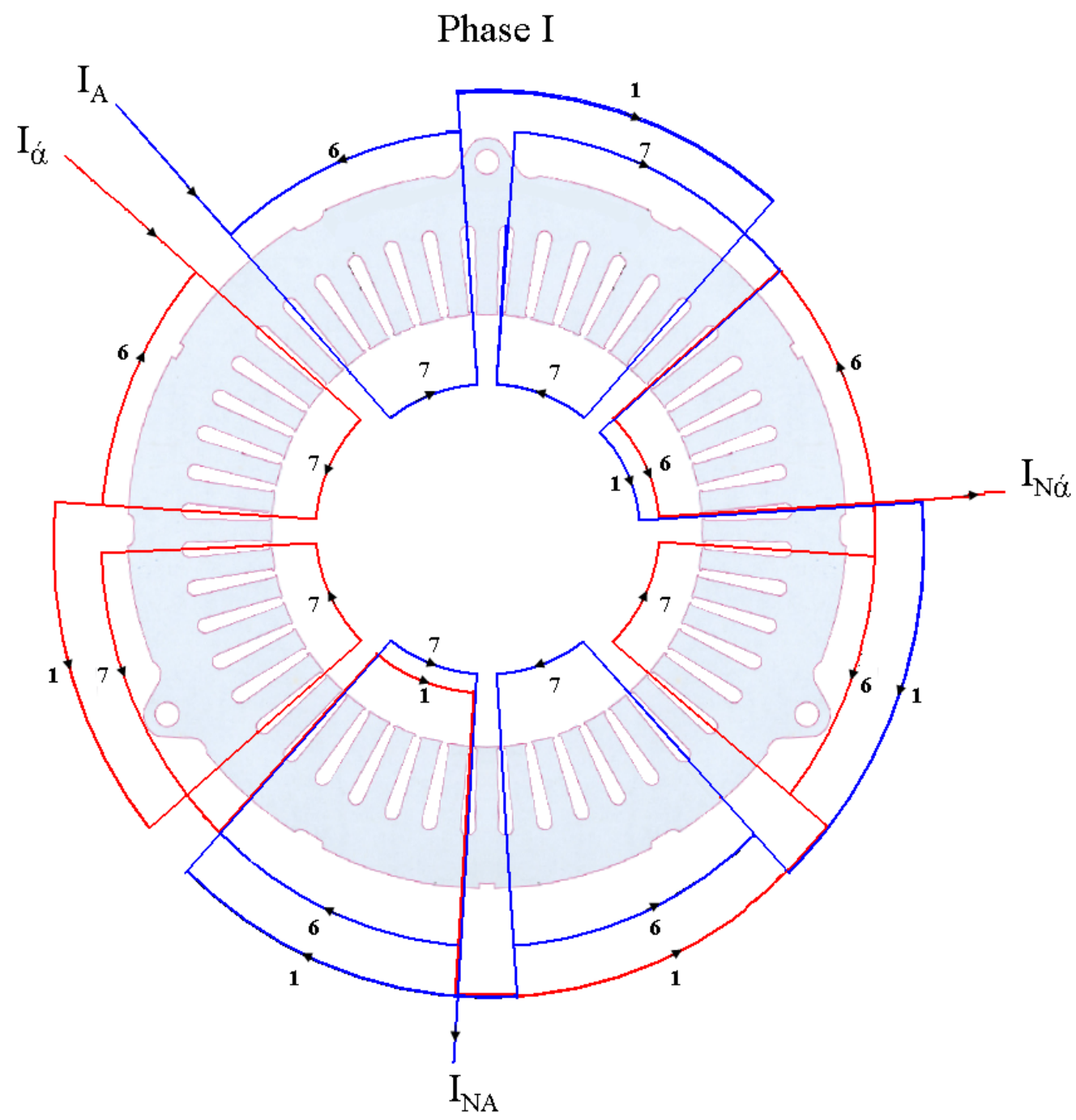

Fig. 2.67. Winding configuration for one phase of the LS 600h. 
Shown in Fig. 2.68 is the motor rotor attached to a portion of the Ravigneaux gear set. The OD the LS $600 \mathrm{~h}$ rotor is only 5.08 " $(12.95 \mathrm{~cm})$, whereas the Camry rotor OD is $6.32 "(16.05 \mathrm{~cm})$. As expected, the LS 600h rotor stack length closely matches the stack length of stator. The mass of the LS $600 \mathrm{~h}$ rotor is $11.9 \mathrm{~kg}$, whereas the mass of the Camry rotor is $9.0 \mathrm{~kg}$. Therefore, although the stator mass reduces, the rotor mass increases in going from the Camry to the LS 600h motor design. A comparison of the Camry and LS 600h rotor laminations can be observed in Fig. 2.69. When a standard sized compact disk (CD) is placed on top of the LS $600 \mathrm{~h}$ rotor laminations, only about $0.475 \mathrm{~cm}$ (radially) of the LS $600 \mathrm{~h}$ rotor lamination is visible. The overall appearance of the two rotor laminations is drastically different. There is an opening for an additional magnet to the previous " $\mathrm{V}$ " configuration of the Prius and Camry and the openings for the magnets are much thinner. Additional large, triangular openings are observed near the interior circumference of the rotor. Removal of these large sections greatly reduces the mass of the rotor, and they are possibly shaped to direct or block flux pathways within the lamination. Note that the additional magnet to the "V" configuration reduces the saliency of the rotor, since the effective permeability of PM material is similar to that of air.

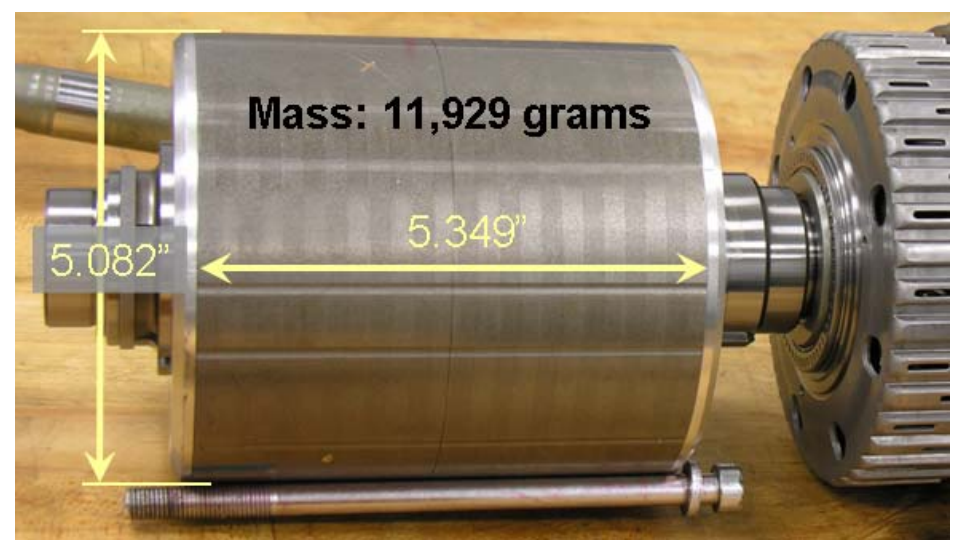

Fig. 2.68. LS 600h motor rotor.

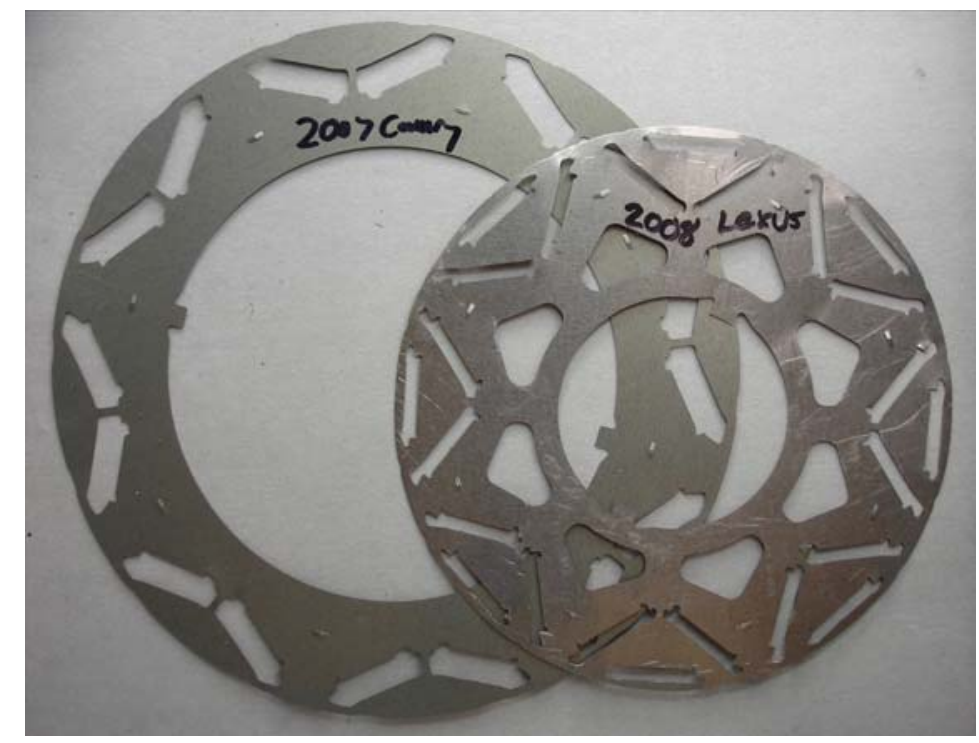

Fig. 2.69. Comparison of motor rotor laminations, Camry (left) vs. LS 600h (right).

A closer look at the rotor lamination design contrasts is given in Fig. 2.70. Typically, when the diameter of the rotor is reduced, the centrifugal force of the magnet upon the lamination reduces and higher speeds 
are attainable without mechanical failure. However, the additional magnet in the "V" configuration of the LS 600h introduces a compromise of mechanical integrity, especially with a minimal bridge distance of $1.45 \mathrm{~mm}$. Additionally, the increased stack and shaft length introduces the potential for the rotor assembly to bend near the center between the two support bearings. These two detriments are likely the primary reasons the published maximum rotational speed of the LS $600 \mathrm{~h}$ rotor is only $10,230 \mathrm{rpm}$, whereas the Camry reaches speeds up to $14,000 \mathrm{rpm}$. Although the size of each magnet has reduced from $60.6 \mathrm{~mm} \times 19.1 \mathrm{~mm} \times 6.6 \mathrm{~mm}$ to $66.4 \mathrm{~mm} \times 18.67 \mathrm{~mm} \times 3.04 \mathrm{~mm}$ in comparing the Camry and LS $600 \mathrm{~h}$ magnets, there are two magnets aligned in each row of the LS $600 \mathrm{~h}$ rotor to account for the extended stack length. With each LS $600 \mathrm{~h}$ magnet weighing 28.1 grams, 48 magnets contribute to a total magnet mass of $1.349 \mathrm{~kg}(\sim 3 \mathrm{lb})$ versus the total Camry magnet mass of $0.928 \mathrm{~kg}(\sim 2 \mathrm{lb})$. Therefore, the LS $600 \mathrm{~h}$ design incorporates a considerably lower amount of copper, but includes a considerably higher amount of PM material.

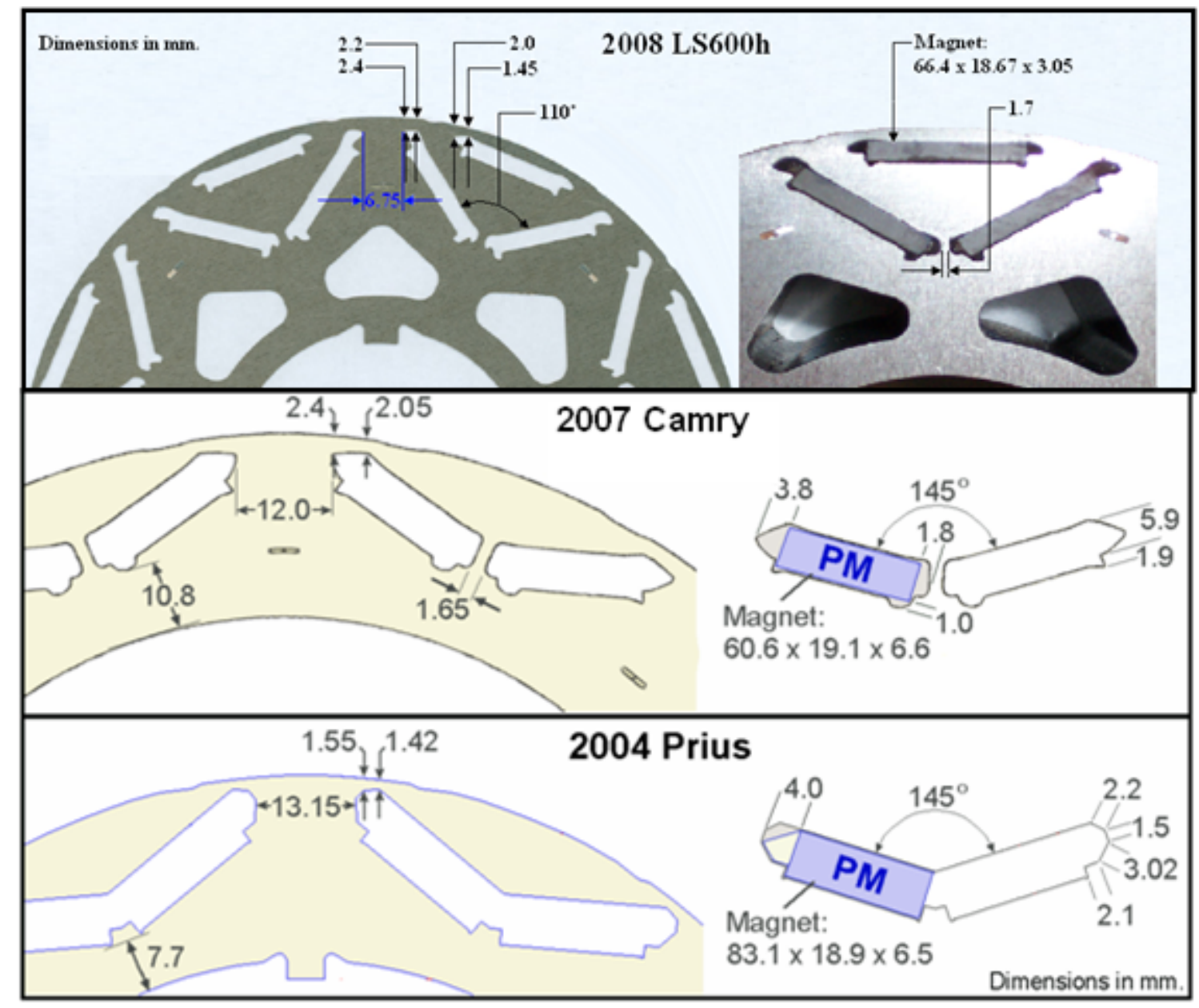

Fig. 2.70. Comparison of motor rotor lamination dimensions.

Various design characteristics of the LS 600h, Camry, and Prius motors are provided in Table 2.6. Results from the packaging assessments were used in combination with findings from the experimental evaluation to determine the SP and PD of the LS $600 \mathrm{~h}$ and a comparison is provided in Table 2.7. Details regarding the power rating are provided in Section 3.4. There are significant improvements of PD and SP, although copper usage decreased and PM material remained nearly constant with respect to power capability. However, this elongated design is limited to specific applications. 
Table 2.6. LS 600h, Camry, and Prius motor design characteristics

\begin{tabular}{|c|c|c|c|c|}
\hline Parameter & LS 600h & Camry & Prius & Comments \\
\hline \multicolumn{5}{|l|}{ Lamination Dimensions } \\
\hline Stator OD, cm & 20.0 & 26.4 & 26.9 & \\
\hline Stator inner diameter (ID), $\mathrm{cm}$ & 13.086 & 16.19 & 16.19 & \\
\hline Stator stack length, cm & 13.54 & 6.07 & 8.4 & \\
\hline Rotor OD, cm & 12.91 & 16.05 & 16.05 & \\
\hline Rotor lamination ID, $\mathrm{cm}$ & 5.3 & 10.5 & 11.1 & \\
\hline Rotor stack length, cm & 13.59 & 6.2 & 8.36 & \\
\hline Air gap, mm & 0.89 & 0.73025 & 0.73025 & \\
\hline Lamination thickness, $\mathrm{mm}$ & 0.28 & 0.31 & 0.33 & \\
\hline \multicolumn{5}{|l|}{ Mass of Assemblies } \\
\hline Rotor mass, $\mathrm{kg}$ & 11.93 & 9.03 & 10.2 & Includes rotor shaft. \\
\hline Stator mass, kg & 18.75 & 18.0 & 25.9 & \\
\hline Stator core mass, $\mathrm{kg}$ & 15.15 & 12.38 & 19.05 & Laminations only. \\
\hline \multicolumn{5}{|l|}{ Stator Wiring } \\
\hline Number of stator slots & 48 & 48 & 48 & \\
\hline Stator turns per coil & 7 & 14 & 9 & \\
\hline Parallel circuits per phase & 2 legs & 2 legs & 0 & \\
\hline Coils in series per phase & 4 per leg & 4 per leg & 8 & \\
\hline Number of wires in parallel & 9 per leg & 9 per leg & 13 & 18 total per phase \\
\hline $\begin{array}{l}\text { Wire size, American wire } \\
\text { gauge (AWG) }\end{array}$ & $\sim 0.032 " \equiv 20$ & 20 & 19 & \\
\hline Phase resistance at $21^{\circ} \mathrm{C}$, ohms & 0.0225 & 0.023 & 0.069 & $\begin{array}{l}\text { Average of phase-to- } \\
\text { phase divided by two }\end{array}$ \\
\hline Total mass of stator copper, $\mathrm{kg}$ & 3.59 & 5.6 & 6.8 & \\
\hline Slot depth, mm & 19.25 & 30.9 & 33.5 & \\
\hline Slot opening, $\mathrm{mm}$ & 1.88 & 1.88 & 1.93 & At air-gap \\
\hline \multicolumn{5}{|l|}{ Casing } \\
\hline Motor casing mass, $\mathrm{kg}$ & 14 & 9.5 & 8.9 & Resolver, pump, etc \\
\hline Motor casing diameter, $\mathrm{cm}$ & 27.5 & 30.2 & 29.9 & \\
\hline Motor casing axial length, $\mathrm{cm}$ & 27.9 & 17.0 & 20.5 & \\
\hline \multicolumn{5}{|c|}{ Magnets (neodymium iron boron [NdFeB]) } \\
\hline Magnet dimensions, $\mathrm{mm}$ & $66.4 \times 18.7 \times 3.05$ & $60.6 \times 19.1 \times 6.6$ & $83.1 \times 18.9 \times 6.5$ & One magnet. \\
\hline Magnet volume, $\mathrm{cm}^{3}$ & 3.78 & 7.63 & 10.2 & One magnet. \\
\hline Magnet mass, grams & 28.1 & 58 & 77 & One magnet. \\
\hline Total mass of magnets, $\mathrm{kg}$ & 1.349 & 0.928 & 1.232 & \begin{tabular}{|l} 
Entire magnet mass \\
in rotor. \\
\end{tabular} \\
\hline
\end{tabular}

Table 2.7. SP and PD estimates for HEV motors

\begin{tabular}{|l|cc|c|}
\hline \multicolumn{1}{|c|}{ Parameter } & LS 600h & Camry & Prius \\
\hline $\begin{array}{l}\text { Motor peak SP (without } \\
\text { converter), } \mathrm{kW} / \mathrm{kg}\end{array}$ & $110 / 44.7=\mathbf{2 . 4 6}$ & $70 / 41.7=\mathbf{1 . 6 8}$ & $50 / 45.0=\mathbf{1 . 1 1}$ \\
\hline Motor peak PD, $\mathrm{kW} / \mathrm{L}$ & $110 / 16.7=\mathbf{6 . 5 9}$ & $70 / 14.8=\mathbf{4 . 7 3}$ & $50 / 15.4=\mathbf{3 . 2 5}$ \\
\hline
\end{tabular}

The LS 600h generator stator and rotor is shown in Fig. 2.71. Both LS 600h generator stator and rotor laminations are identical to that of the Camry motor stator and rotor. The stack length of the LS 600h generator stator is 2.785 ", where the stack length of the Camry motor stator is only 2.4". Likewise, the LS 600h generator stator and rotor have masses of $20.5 \mathrm{~kg}$ and $9.7 \mathrm{~kg}$, whereas the Camry motor stator and rotor have masses of $18.0 \mathrm{~kg}$ and $9.0 \mathrm{~kg}$, respectively. When comparing the LS $600 \mathrm{~h}$ motor with the LS $600 \mathrm{~h}$ generator, the motor stator mass is $18.8 \mathrm{~kg}$ (vs. $20.5 \mathrm{~kg}$ ) and the motor rotor mass is $11.9 \mathrm{~kg}$ 
(vs. $9.7 \mathrm{~kg}$ ). Thus the generator stator weighs more than the motor stator, but the generator rotor weighs less than the motor rotor. This reflects a few of the tradeoffs in moving to the elongated motor design. Design characteristics of the LS 600h generator are provided in Table 2.8 along with that of the Camry and Prius.

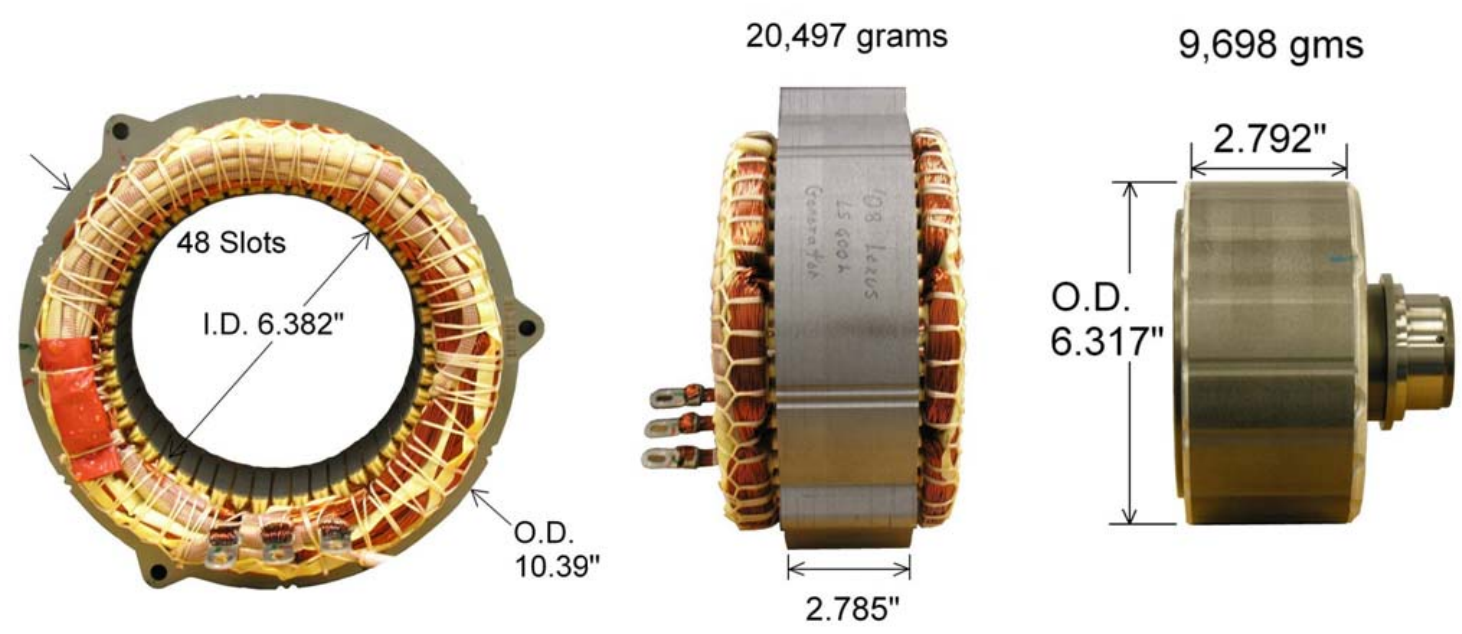

Fig. 2.71. LS 600h generator stator and rotor.

Table 2.8. LS 600h, Camry, and Prius generator design characteristics

\begin{tabular}{|l|c|c|c|c|}
\hline \multicolumn{1}{|c|}{ Parameter } & LS 600h & Camry & Prius & Comments \\
\hline Lamination Dimensions & 263.9 & Same as LS & 236.2 & \\
\hline Stator OD, mm & 162.1 & Same as LS & 142.6 & \\
\hline Stator ID, mm & 7.07 & 3.58 & 3.05 & \\
\hline Stator stack length, cm & 160.5 & Same as LS & 140.72 & \\
\hline Rotor OD, mm & $\sim 87.0$ & 95.63 & 85.09 & \\
\hline Rotor lamination ID, mm & $\sim 0.30$ & 0.31 & 0.33 & \\
\hline Lamination thickness, mm & 9.70 & 5.19 & 4.01 & Including rotor shaft \\
\hline Mass of Assemblies & 20.50 & 12.09 & 9.16 & \\
\hline Rotor mass, kg & 48 & 48 & 48 & \\
\hline Stator mass, kg & $28(14)$ & $18(9)$ & 12 & \\
\hline Stator Wiring & 20 & 20 & 20 & \\
\hline Number of stator slots & $\begin{array}{l}\text { Number of wires per } \\
\text { phase (number in parallel) }\end{array}$ & \begin{tabular}{l}
$|l|$ \\
\hline Wire size, AWG
\end{tabular} &
\end{tabular}

\subsubsection{PM Characteristic Assessments}

Hysteresis tests were conducted on the LS 600h motor PMs using the Walker Scientific AMH-40 hysteresisgraph (shown in Fig. 2.72), which is capable of producing 30,000 Oersteds of magnetic field strength. A hysteresis test provides information regarding the remanent flux density and coercivity of a magnet and these tests are often conducted over a wide range of temperatures. The remanent flux density, $\mathrm{B}_{\mathrm{r}}$, is the remaining flux density created by the magnet with no external field applied. Or simply stated the remanent flux density represents the strength of the magnet. The remanent flux density decreases to some extent with increasing temperature. The coercivity of a magnet is defined to be the intensity of the magnetic field required to reduce the magnetization of the magnet to zero (i.e. demagnetize the magnet), 
and the coercivity of a magnet also decreases with increasing temperature. Coercivity is an especially important characteristic of PMs that are used in HEV applications, which often involve high temperature and high field weakening operation conditions.

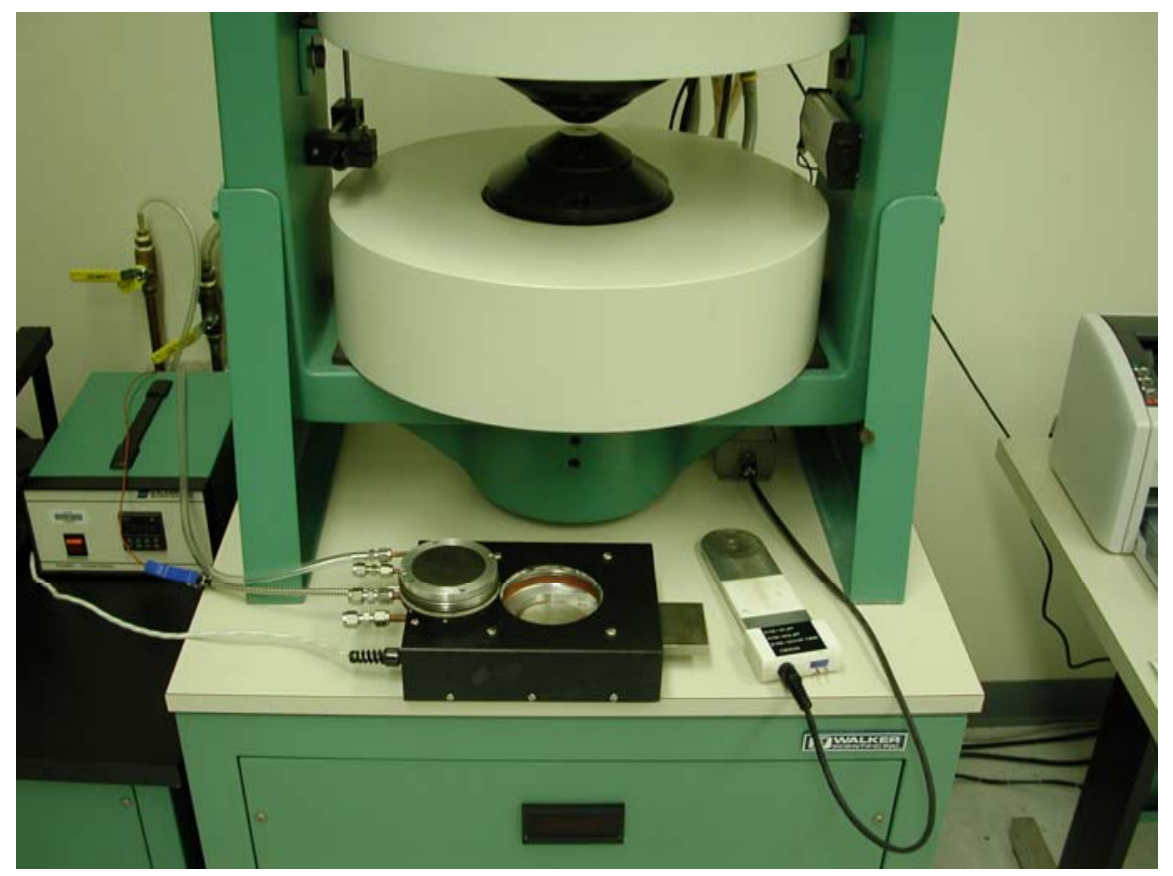

Fig. 2.72. Walker Scientific hysteresis graph.

During hysteresis tests, the magnet is subjected to positive and negative magnetic fields while the impact of the externally applied magnetic field on the magnet is observed. A graph from hysteresis tests conducted on a magnet from the LS $600 \mathrm{~h}$ motor rotor at $121^{\circ} \mathrm{C}$ is shown in Fig. 2.73. Two curves are shown on the graph with the burgundy trace being the normal, or total magnetic flux density, and the turquoise trace representing the intrinsic magnetic flux density. The intrinsic flux density is the flux density solely created by the magnet, which is obtained by subtracting the applied flux density from the total flux density. The remanent flux density is the value at which both curves intersect with the y-axis, which is at $y=11.72 \mathrm{kG}$ in this case. The value of coercivity is found at the point where the intrinsic curve crosses the $\mathrm{x}$-axis, which is $\mathrm{x}=15.52 \mathrm{kOe}$ in this case. A similar graph is provided in Fig. 2.74, with the hysteresis evaluation conducted at an ambient temperature of $208^{\circ} \mathrm{C}$. Notice that the curves are much closer to the origin when compared to Fig. 2.73 . As the temperature increased from $121-208^{\circ} \mathrm{C}$, the remanent flux density and coercivity decreased from 11.72-10.09 kG and 15.52-6.542 kOe, respectively. The drastic decrease of the coercivity indicates that the magnet is much more susceptible to demagnetization at high temperatures. 


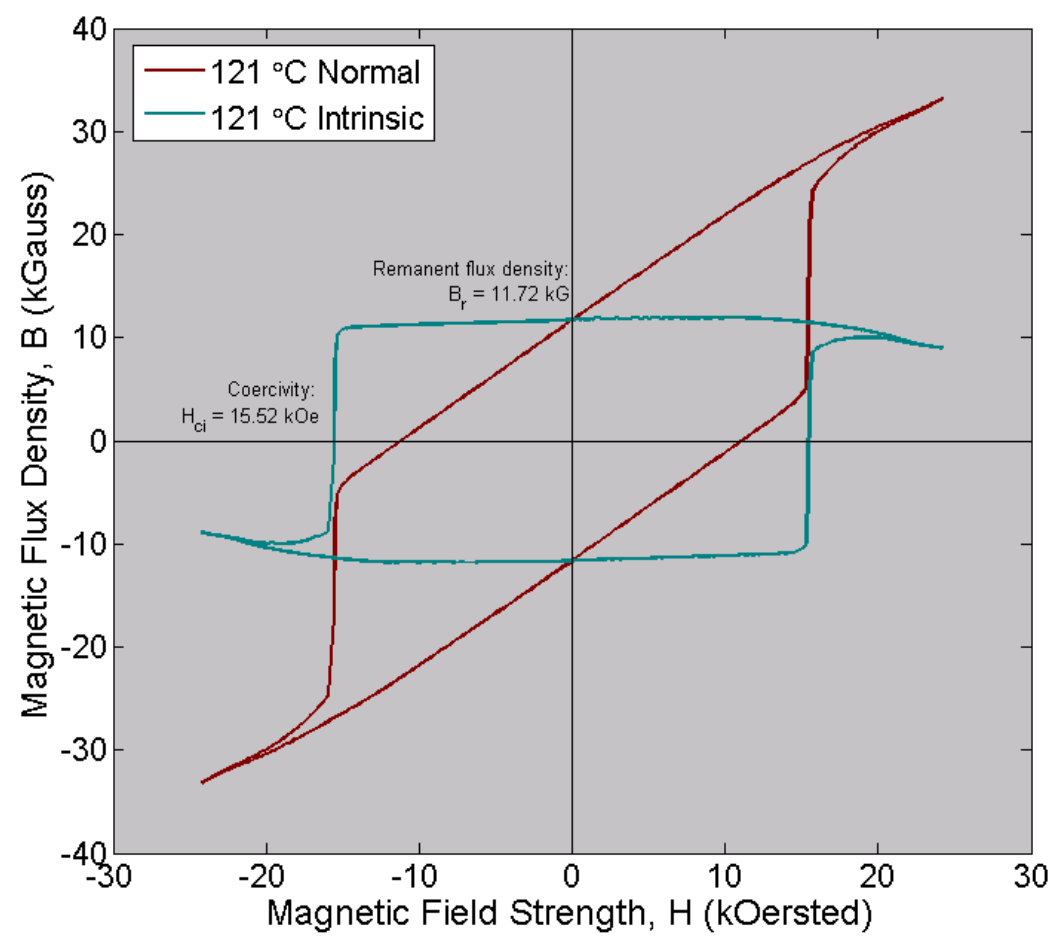

Fig. 2.73. Hysteresis graph for LS $600 \mathrm{~h}$ motor magnet at $121^{\circ} \mathrm{C}$.

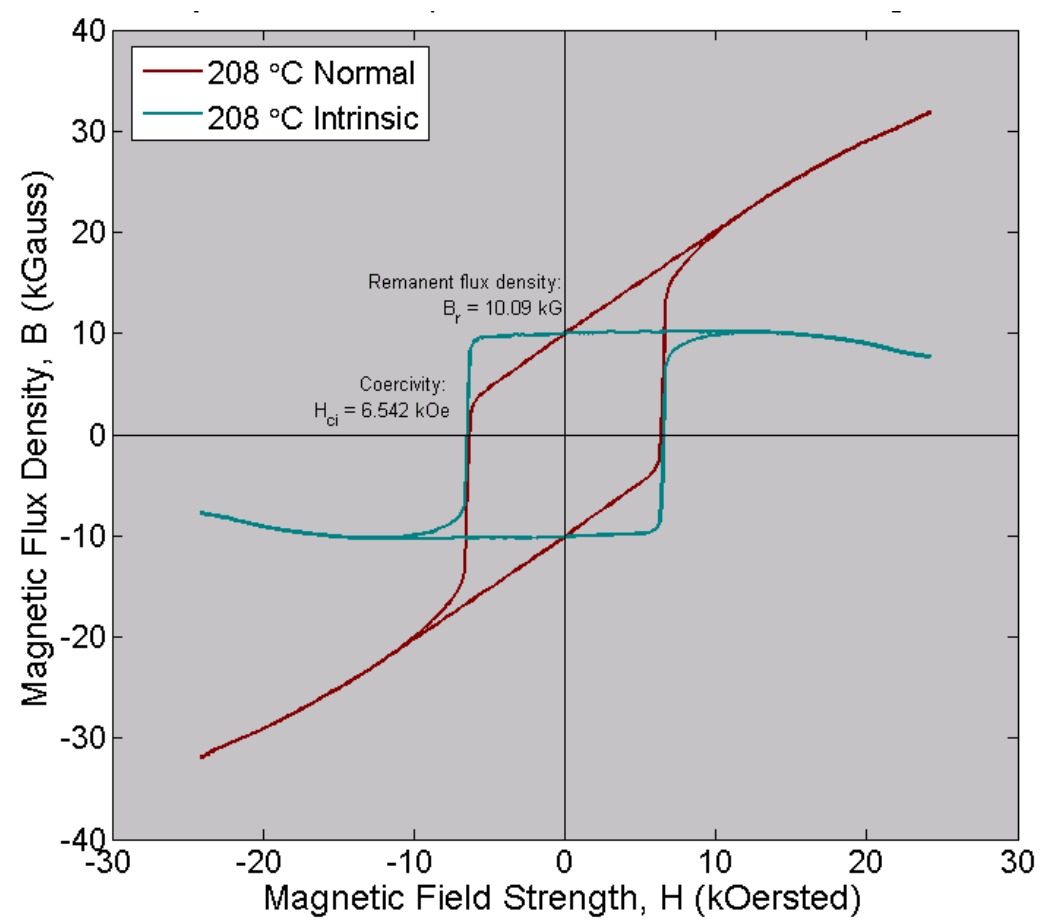

Fig. 2.74. Hysteresis graph for LS $600 \mathrm{~h}$ motor magnet at $208^{\circ} \mathrm{C}$.

Intrinsic curves from hysteresis tests conducted with a LS 600h motor magnet at various temperatures have been combined onto one plot in Fig. 2.75. These curves further exemplify the diminishing nature of the remanent flux density and coercivity with increasing temperature. A similar graph containing the intrinsic curves obtained from the Camry motor magnet hysteresis tests is provided in Fig. 2.76. Although 
it is difficult to make a detailed comparison using these figures, a general comparison indicates that the coercivity of the Camry magnet is significantly lower than that of the Prius. Note that the unnatural flux density characteristics for high field strength magnitudes is a common phenomenon observed during hysteresisgraph measurements. The effect of the phenomenon does not impose significant impact upon the measurement of coercivity since the knee of the curve is well defined for normal and intrinsic traces.

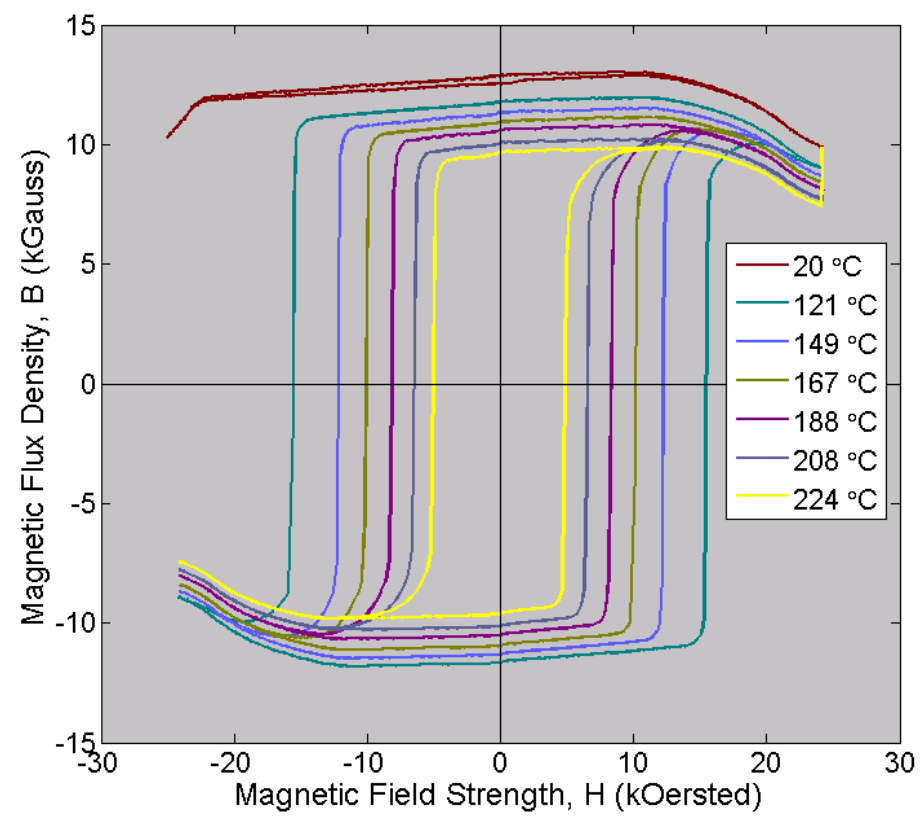

Fig. 2.75. Intrinsic hysteresis graphs for LS 600h motor magnet at various temperatures.

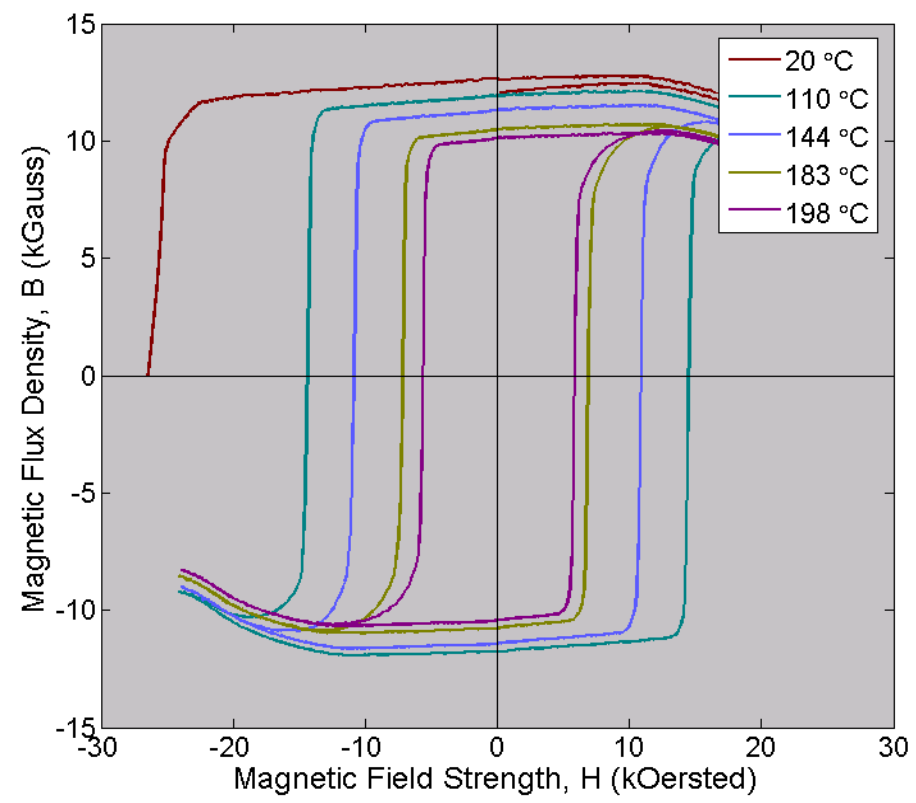

Fig. 2.76. Intrinsic hysteresis graphs for Camry motor magnet at various temperatures.

To provide a more straight forward comparison of the remanent flux density characteristics of the LS 600h, Camry, and Prius motor magnets, the values were plotted versus temperature in Fig. 2.77. The strength of the LS 600h and Camry motor magnets are marginally higher than the strength of the Prius motor magnet, except for temperatures beyond about $215^{\circ} \mathrm{C}$. A similar plot is shown in Fig. 2.78 for the 
coercivity versus temperature relationship of the LS 600h, Camry, and Prius motor magnets. The coercivity of the LS $600 \mathrm{~h}$ motor magnet is generally about $90 \%$ of the coercivity of the Prius magnet, where as the Camry motor magnet coercivity is about $75 \%$ of that of the Prius. Although the LS 600h and Camry motor magnets are slightly stronger than the Prius magnet, their coercivity is lower and are therefore more susceptible to demagnetization when subjected to high temperatures and/or high strength magnetic fields which oppose the direction of the magnetic field of the magnet. It is common to apply opposing magnetic fields to the magnets when operating at high speeds, wherein high back-electromotive force (back-emf) voltages are subdued to enable high speed operation within the voltage constraints. The LS 600h magnets are likely produced by Hitachi Metals under the brand, Neomax, and resemble properties of model S41EH, which is more expensive than the 2007 Camry magnets, but less expensive than the 2004 Prius magnets.

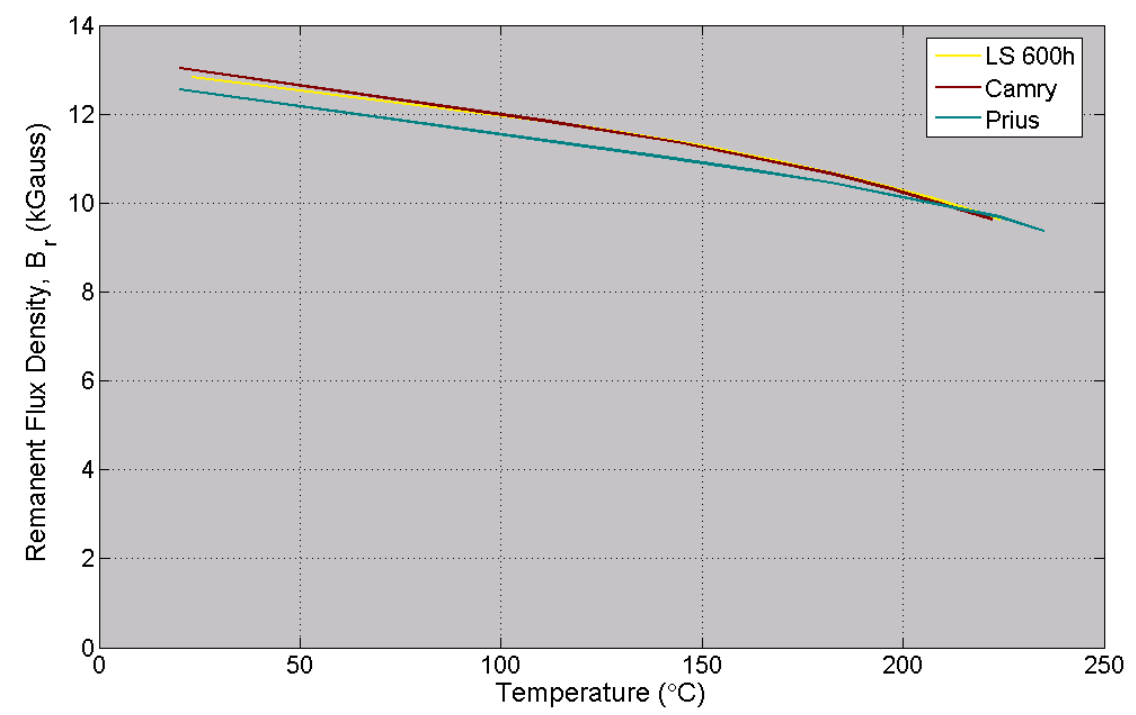

Fig. 2.77. Remanent flux density for LS 600h, Camry, and Prius motor magnet.

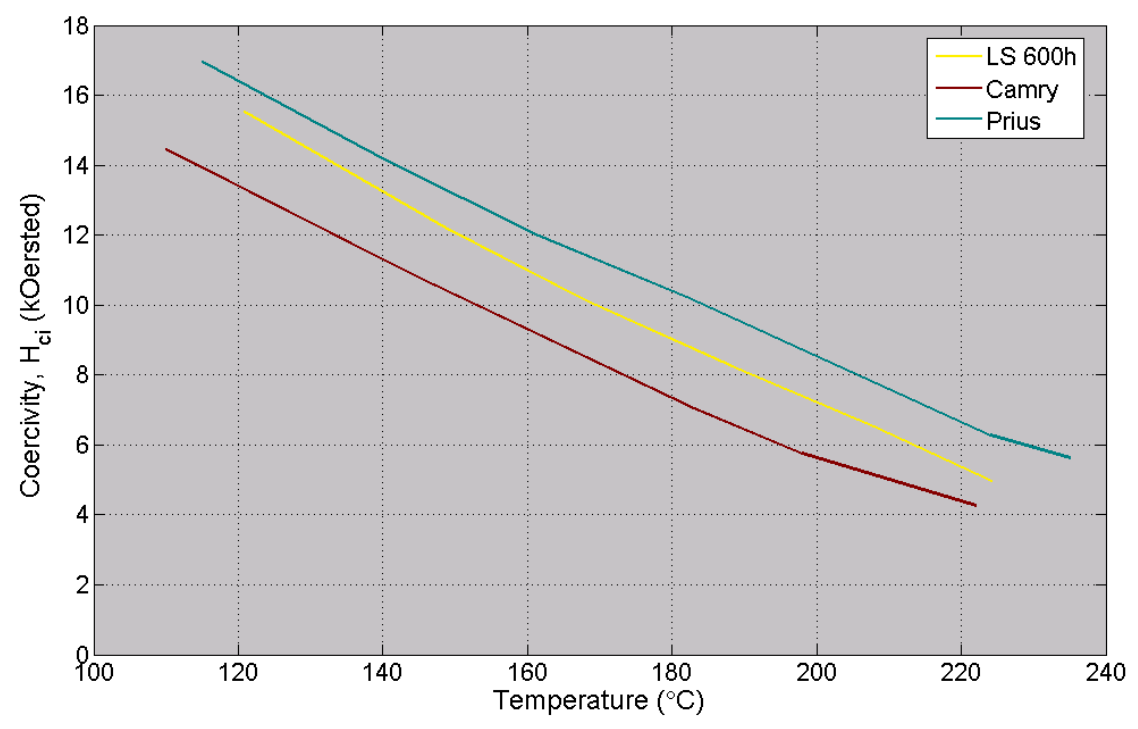

Fig. 2.78. Coercivity of LS 600h, Camry, and Prius motor magnet. 


\section{BENCHMARKING TESTS OF LS 600h PMSM AND PCU}

This section describes the LS 600h subassembly preparation and the back-emf, locked-rotor, performance/efficiency, and continuous load duration tests. With the exception of the back-emf and locked-rotor tests, which do not require inverter operation, each was performed using both the PMSM and inverter subsystems of the LS $600 \mathrm{~h}$.

\subsection{SUBSYSTEM PREPARATION FOR TESTING}

As design and packaging assessments of the ECVT and PCU were being conducted, preparation for testing of the subsystems commenced. These preparations include hardware design and fabrication, controller/interface development, and instrumentation for the DAQ. Although basic framework was available from previous benchmarking efforts, a large portion of the efforts devoted to controller/interface and DAQ development required innovation.

\subsubsection{Hardware Preparation}

Since the LS 600h motor rotor shaft is not directly accessible, the customized shaft shown in Fig. 3.1 was designed and fabricated to provide direct external access to the motor rotor. The shaft was designed such that the Ravigneaux gear system is replaced, with the short splined end of the shaft (on the left) mating with the motor rotor. The other splined end (on the right) interfaces with the face-mount torque transducer. As shown in Fig. 3.2, a large portion of the custom shaft resides in the Ravigneaux gear section (the original gears are removed). The motor interface is shown in the left portion of Fig. 3.2, and the torque transducer interface is shown in the right portion of Fig. 3.2. A sealed bearing provides support for the output to the torque transducer, where the transfer case was originally attached, but is no longer used. Although this task is conceptually simple, many important design considerations must be made prior to the fabrication of this part. For example, the shaft must mate with bearing surfaces appropriately in order for stable support to be obtained. Additionally, various shoulders were strategically positioned in order to provide stability in response to forces in the axial direction. These aspects become of particular concern for high speed operations. Another important consideration is the impact of the removing the Ravigneaux components, in particular the shafts which are used to channel oil to bearings for lubrication. Therefore, intensive oil flow tests were conducted before and after the modifications in order to ensure tests were conducted with these systems operating normally. These tests are further described in Section 3.1.2.

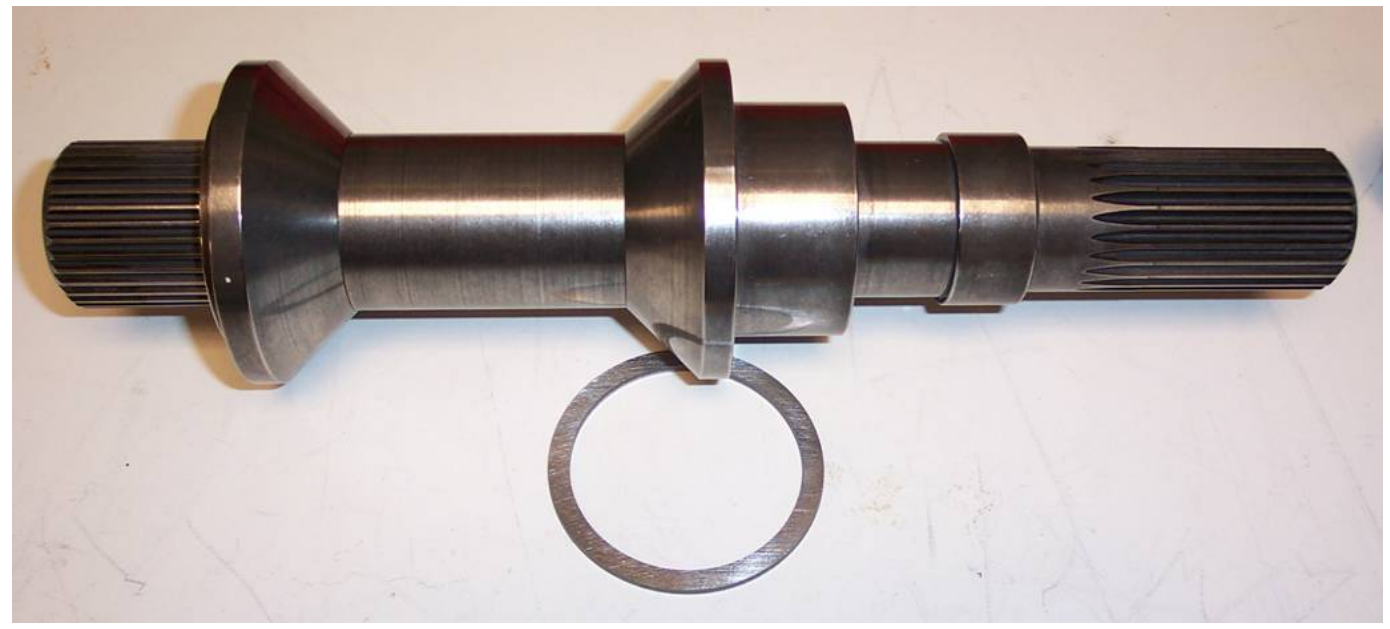

Fig. 3.1. Customized shaft. 

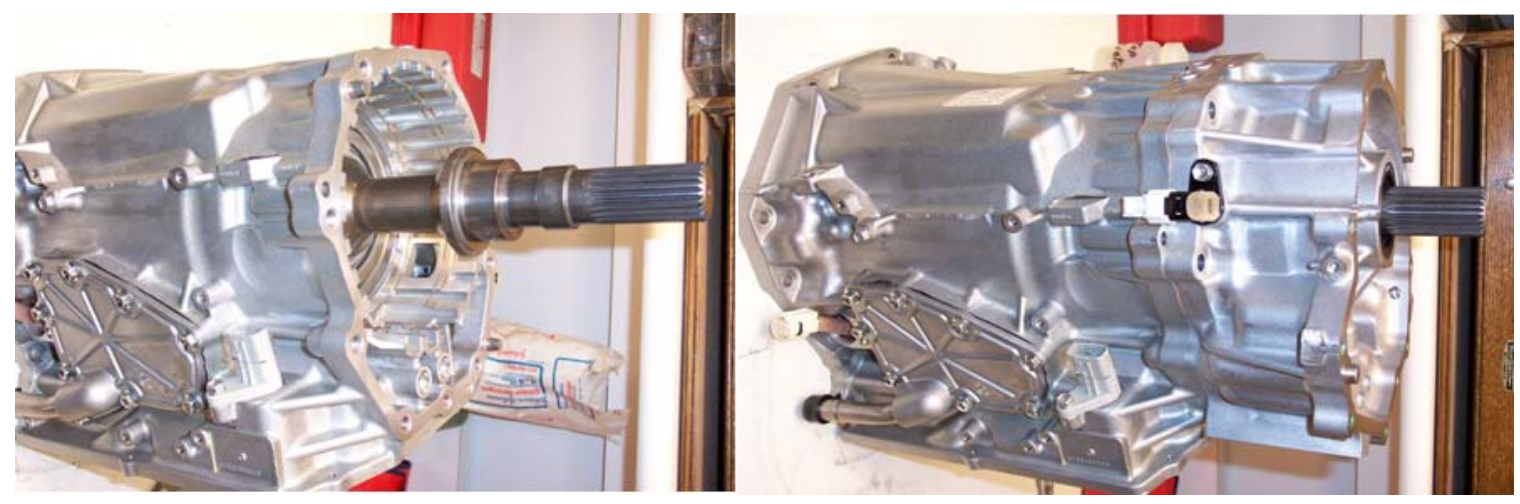

Fig. 3.2. Customized shaft installed.

After the modifications and preparatory tests were executed, the ECVT assembly was installed in an ORNL test cell, shown in Fig. 3.3. A coolant regulator was used to regulate the coolant temperature, which first feeds the PCU and then the ECVT heat exchanger. A $400 \mathrm{hp}$ dynamometer was used to apply a mechanical load as torque and speed were measured with a torque transducer.

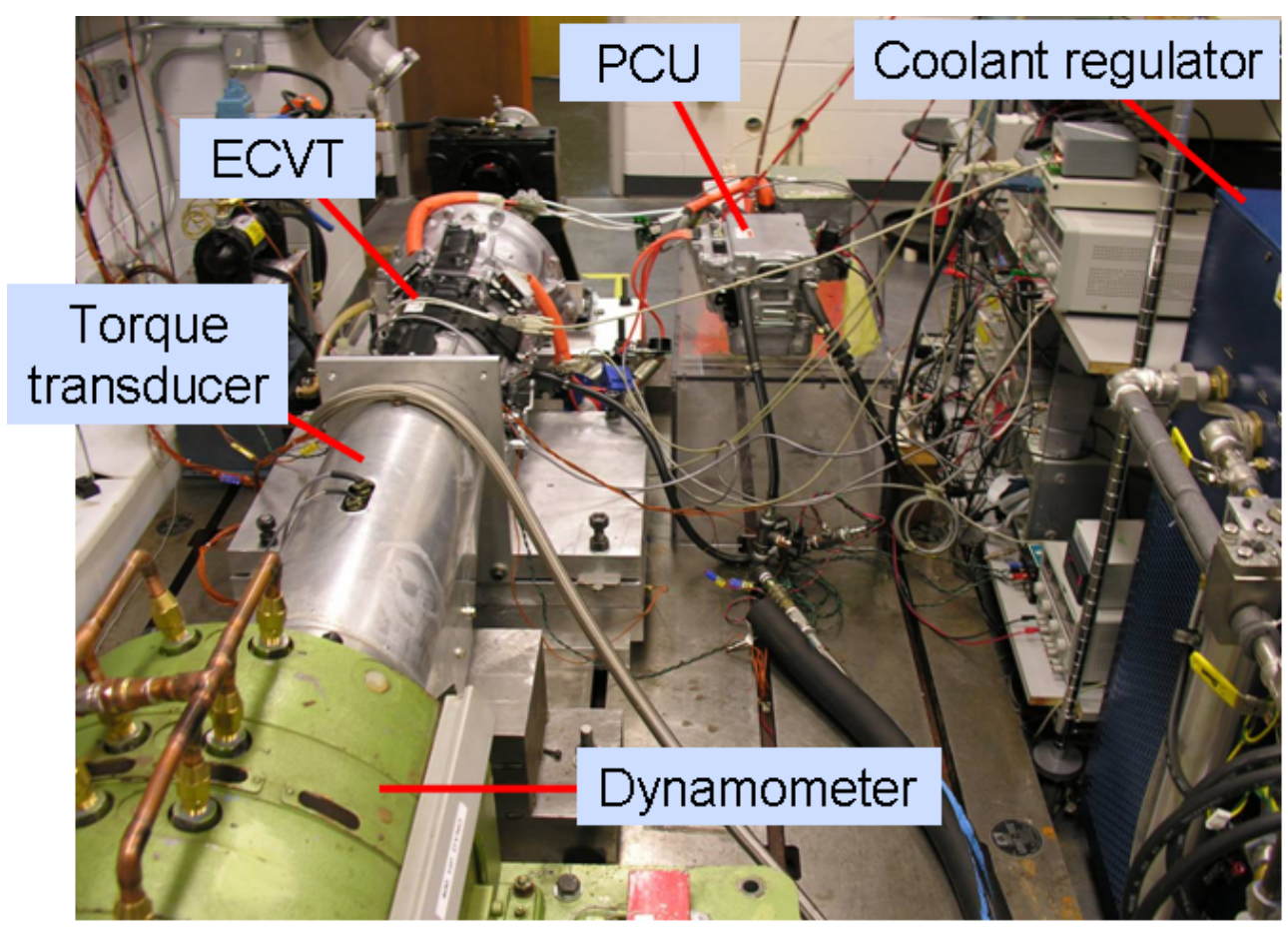

Fig. 3.3. LS 600h installation in ORNL test cell.

The power split planetary gear was welded in order to enable the generator to directly drive the engine shaft in order to drive the mechanical oil pump. Since the generator connects to the sun gear and the ICE connects to the planetary carrier, welding the planets to the sun gear forces the generator shaft and ICE shaft to rotate as one. A separate PCU was used to operate the LS 600h generator, which thereby facilitated precise, closed-loop speed feedback control of the ICE shaft speed, and therefore the mechanical oil pump shaft speed. 


\subsubsection{Oil Flow Tests}

As described in Section 2.3.1, the mechanical oil pump (Fig. 2.56) supplies two oil squirters (Fig. 2.57) which focus oil streams on the motor and generator. These squirters facilitate primary the heat transfer mechanisms of the motor and generator. Modifications made to the ECVT present a potential for various oil pressures to change, thereby affecting the output flow rate of the squirters. Therefore, prior to any modifications, general baseline measurements of oil squirter output flow rates were measured as a function of speed. These tests were conducted prior to the welding of the planetary gear and therefore the ring gear shaft was locked, causing the ICE (carrier) shaft to rotate at a speed that is $10 / 3$ of the generator speed. During the tests, the motor stator was removed and a hose was used to bring oil from the squirter out to a graduated cylinder for measurement. An epoxy shoulder was added to the base of the squirter to provide a grip for the hose, thereby preventing the hose from creating back-pressure/blockage that would affect the flow rate. The generator was operated up to $9,000 \mathrm{rpm}$ and thus the engine shaft was operated up to $2700 \mathrm{rpm}$. A graph containing the results is shown in Fig. 3.4. The behavior of flow rate versus engine speed is somewhat linear, and close approximations can be made for higher engine speeds. These results satisfied the search for a baseline flow rate for common engine speeds. After modifications were made, the squirter flow rate was verified to be within the range of typical operation.

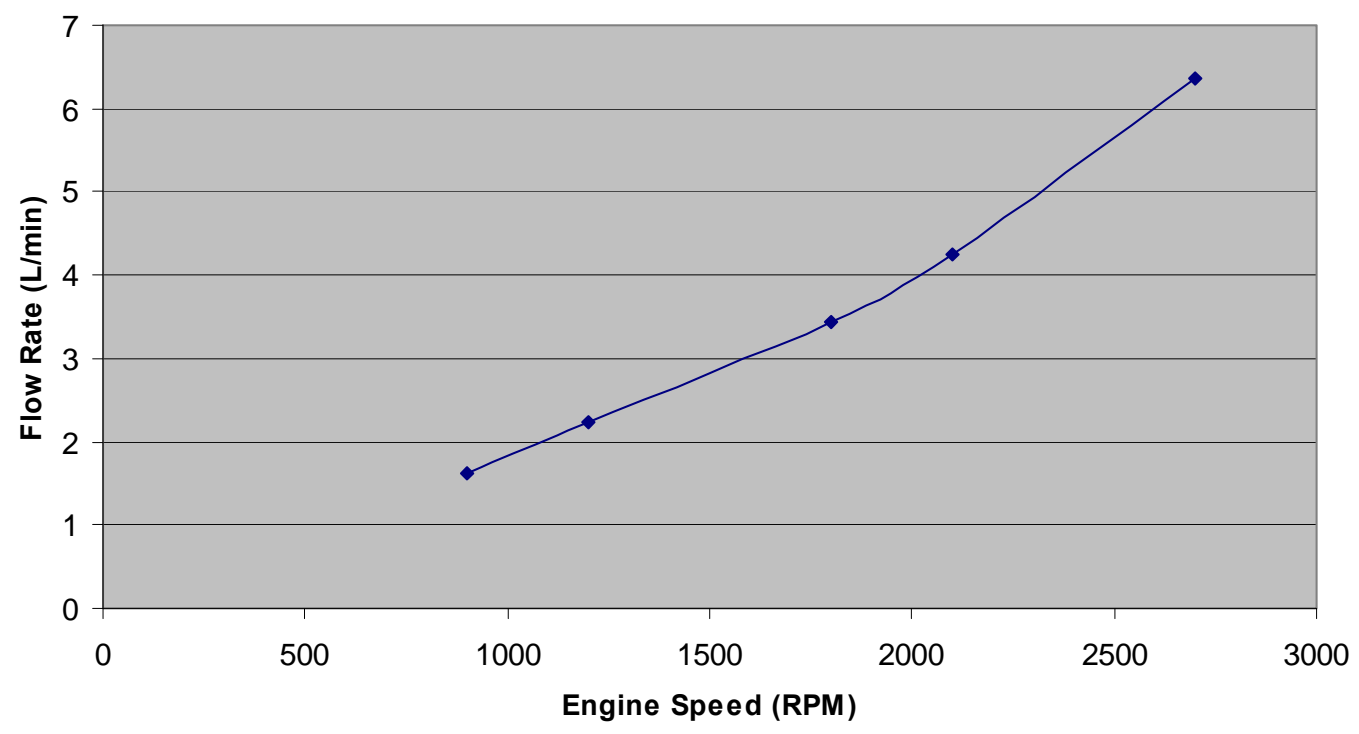

Fig. 3.4. Squirter flow rate vs. engine speed prior to modifications.

\subsubsection{Instrumentation and DAQ Development}

The PCU, PMSM, and ECVT were instrumented with TCs in order to monitor and record thermal conditions and characteristics of the subsystem during various operation conditions. In preparation for performance, efficiency, and continuous duration tests in the ORNL laboratory, the subsystems were instrumented with various measurement devices to monitor the conditions listed in Table 3.1. Details of the TC installations within the ECVT assembly are provided in Fig. 3.5. Red letters indicate the characters assigned to each location for easy identification during data analysis. For example, TCs 'B', ' $C$ ', and ' $D$ ' are installed in the front section of stator windings in the 12,5 , and 7 o'clock positions, respectively. TCs ' $E$ ', ' $F$ ', and ' $G$ ' have similar locations in the rear section of the stator windings. TCs ' $\mathrm{H}$ ' through ' $\mathrm{M}$ ' monitor temperatures at the stator core, 'N'-'P' monitor case temperatures, and ' $Q$ '-' $S$ ' monitor oil temperatures. 
Table 3.1. Conditions monitored during LS 600h evaluations

\begin{tabular}{|l|c|}
\hline \multicolumn{1}{|c|}{ Conditions Measured } & Comments \\
\hline Inverter/dc-dc converter temperatures & $15 \mathrm{TCs}$ \\
\hline Inductor temperature & 1 thermistor \\
\hline Inverter coolant in/out temperature & $2 \mathrm{TCs}$ \\
\hline ECVT coolant in/out temperature & $2 \mathrm{TCs}$ \\
\hline PMSM stator core/winding temperatures & $12 \mathrm{TCs}$ \\
\hline PMSM cooling oil temperatures & $2 \mathrm{TCs}$ \\
\hline ECVT casing temperatures & $3 \mathrm{TCs}$ \\
\hline Coolant flow rate & 1 flowmeter \\
\hline Pressure of coolant & v pressure transducers \\
\hline DC voltage to inverter & voltage taps \\
\hline DC to inverter & 1 CT \\
\hline PMSM input current & $3 \mathrm{CTs}$ \\
\hline PMSM input voltage & 3 voltage taps \\
\hline Shaft speed & Existing Lexus sensor \\
\hline Position & Existing Lexus absolute position sensor \\
\hline Torque & Himmelstein dynamometer torque cell \\
\hline
\end{tabular}

6 TC's embedded in windings (B-G)
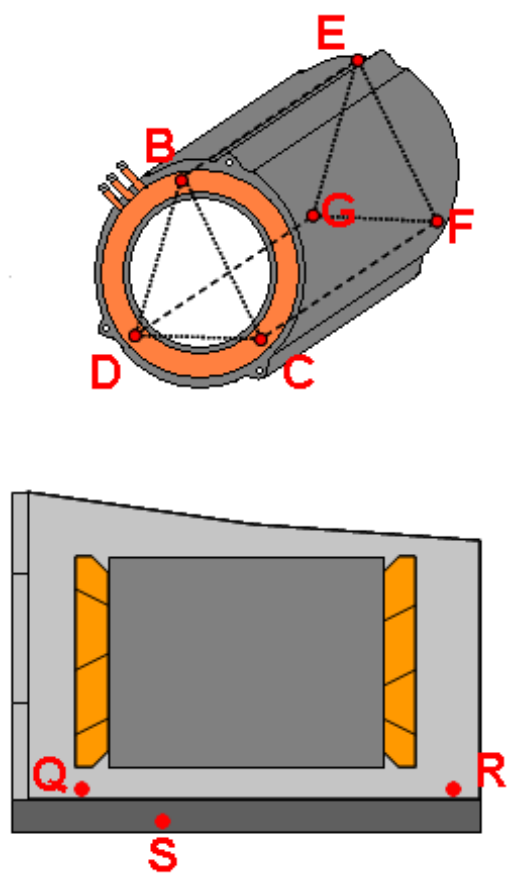

6 TC's on stator core or adjacent housing surface $(\mathrm{H}-\mathrm{M})$ (red labels)

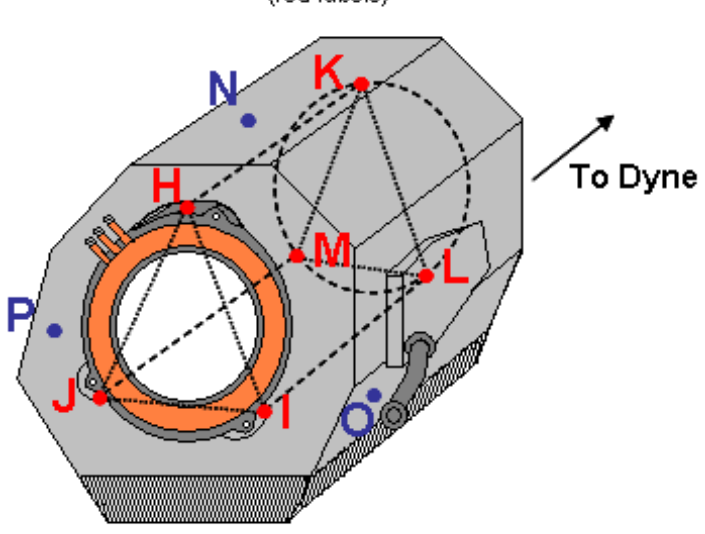

3 TC's on exterior casing (N-P) (blue labels)

\section{Q: Front Oil Drain}

R: Rear Oil Drain

S: Oil Pickup

Fig. 3.5. Locations of TCs within ECVT assembly.

TCs were installed in various locations of the double-sided cooling infrastructure, as shown in Fig. 3.6. An adhesive compound with high thermal conductivity was used to secure the TCs at the mating points of the ceramic insulator and the aluminum cooling channel. TCs 'T', 'U', 'V', 'W', 'Y', 'AA', 'AC', and 'AD' monitor the temperatures of the upper devices, by which coolant flows first before reaching the lower devices, ' $\mathrm{X}$ ', ' $\mathrm{Z}$ ', 'AB', and 'AE'. As indicated, TCs ' $T$ ' and ' $U$ ' are located on the upper devices of phase $\mathrm{V}$ of the motor inverter. TCs ' $\mathrm{V}$ ' through ' $\mathrm{Z}$ ' are located on upper and lower devices of the 
boost converter. An OEM thermistor is embedded in the inductor, and its temperature-resistance relationship was mapped prior to the tests in order to accurately monitor the inductor temperature ('AF'). Three TCs, 'AG', 'AH', and 'AI', were installed on the capacitor module, with 'AI' being closest to the HV terminals. The TC and thermistor labels shown in Figs. 3.5-3.7 will be used for identification in following data analyses.

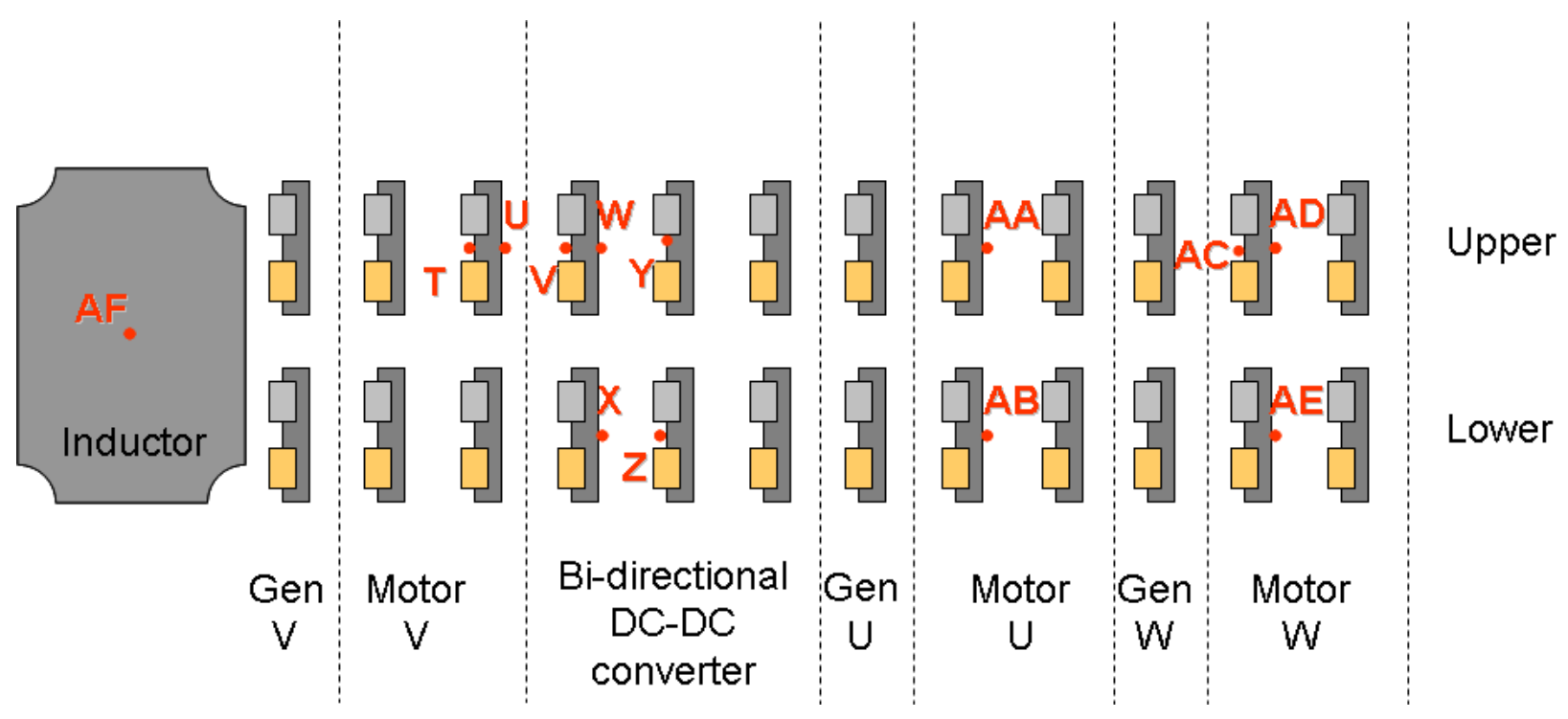

Fig. 3.6. TC locations within LS 600h PCU (underside view of cooling infrastructure).

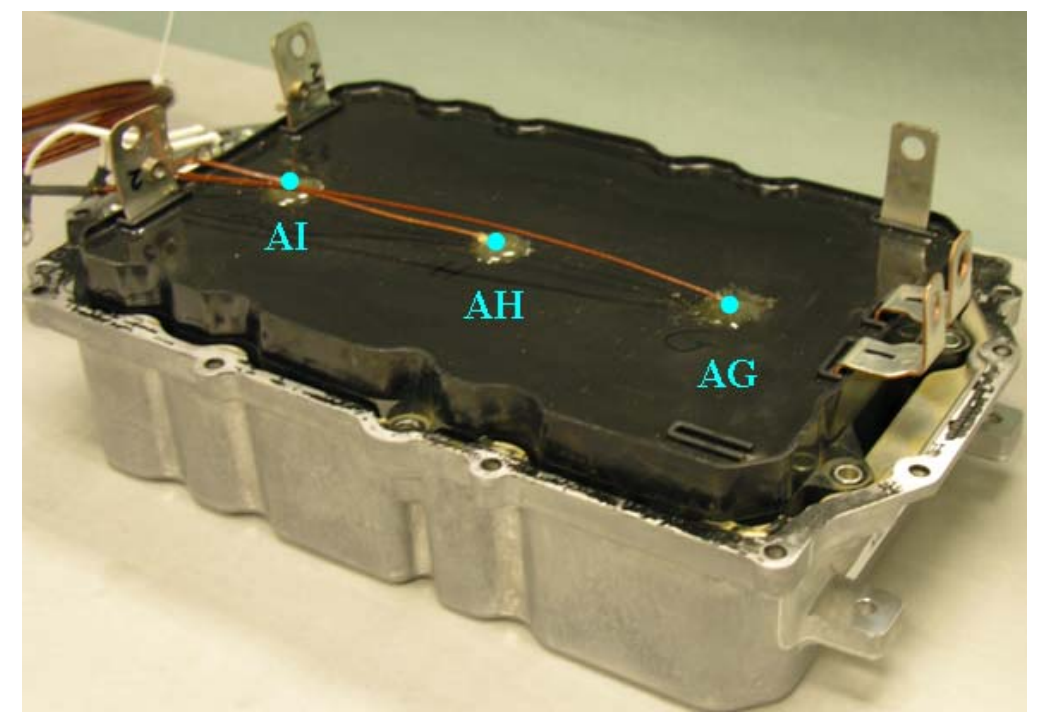

Fig. 3.7. TC locations within capacitor.

A program written in the Visual Basic programming language was developed to collect data from various measurement instruments and merge the data into a convenient spreadsheet format. Torque, speed, and mechanical power were obtained using a Himmelstein torque and speed transducer. Temperature measurement signals from thermistors and TCs were collected with a Keithly 2700 acquisition unit. A Yokogawa PZ4000 power analyzer was used to carry out electrical measurements such as alternating current (ac) and dc rms voltage, rms current, real power, and many other properties of the waveforms. 
The DAQ system was important not only for data logging, but it also served as a real time feedback system in which system conditions were monitored to ensure that operational limitations were not violated and to ensure that the system was being operated in an optimal manner. Temperature and current constraints were the primary limitations of the entire drive system. Efficiencies were calculated using the mechanical and electrical data and were used to verify that the controller operation was optimized.

\subsubsection{Controller and Interface Development}

The hybrid subsystems of the LS 600h were evaluated for performance and efficiency characteristics such as peak and continuous power ratings and motor/inverter efficiency. Continuous operational capabilities are greatly affected by the heat transfer characteristics of the motor, which is cooled through oil circulation and an ethylene-glycol coolant loop. The hybrid subsystems were operated over a broad torque-speed range in order to collect and analyze thermal and electrical data at a multitude of operation points. For each operation point during efficiency evaluations, the system was held in steady state for at least 20 seconds as a minimum of 5 data samples were taken.

ORNL's dynamometer test cell and Opal-RT-based speed and current feedback controller were adapted to provide the torque needed at each reference speed. Thus, as the applied torque from the dynamometer was varied manually, the controller regulated the torque producing current appropriately. The current controller consists of two standard proportional-integral (PI) controllers for the direct and quadrature currents, $i_{d}$ and $i_{q}$, respectively. These $d-q$ components are obtained by applying the $d$ - $q$ transformation to the three-phase currents which have a fixed reference. The transformation converts the three-phase currents into two-phase vectors, which have a reference that rotates with the rotor. Therefore, precise rotor position feedback is used during this transformation.

The steady state torque equation for the salient PM machine is expressed by:

$$
\tau_{L}=n_{p}\left(L_{d}-L_{q}\right) i_{d} i_{q}+n_{p} K i_{q}
$$

where

$n_{p}$ is the number of pole pairs,

$L_{d}$ is the $d$-axis inductance,

$L_{q}$ is the q-axis inductance, and

$K$ is the back-emf and torque-current factor.

The total torque given by Eq. (1) consists of two torque terms which are reluctance torque and PM torque, respectively. PM torque is produced only by the current component along the q-axis. If current is applied which results with a negative component along the $d$-axis, positive reluctance torque is developed since the difference, $L_{d}-L_{q}$, in the first term is negative and all remaining variables and constants are positive in the motoring region. In theory, there is an infinite amount of $d-q$ current combinations that will satisfy a particular operation condition. There is an optimal $d-q$ current combination in which the motor efficiency is maximized for each particular torque. It is difficult to determine the optimal current trajectories for the entire torque-speed range, as complex factors such as effects of saturation and harmonics must be considered. Therefore, the DAQ was used to monitor the system efficiency to ensure that the controller is operating optimally.

A high level diagram of the Opal-RT controller and interface system is shown in Fig. 3.8. A console personal computer (PC) is used to develop and modify control schemes in a block diagram format, which is converted and compiled to traditional programming languages (mostly $\mathrm{C}$ ) and sent to the target nodes 
through an ethernet network. The target nodes execute the controller code in real time and the console PC is used to control the mode of the controller operation as well as to update various parameters if desired. While the development process is more straightforward than microprocessor programming, the PC based architecture of the target nodes introduces a significant degradation in terms of control sampling frequency. Therefore, the system resources must be utilized in an efficient manner.

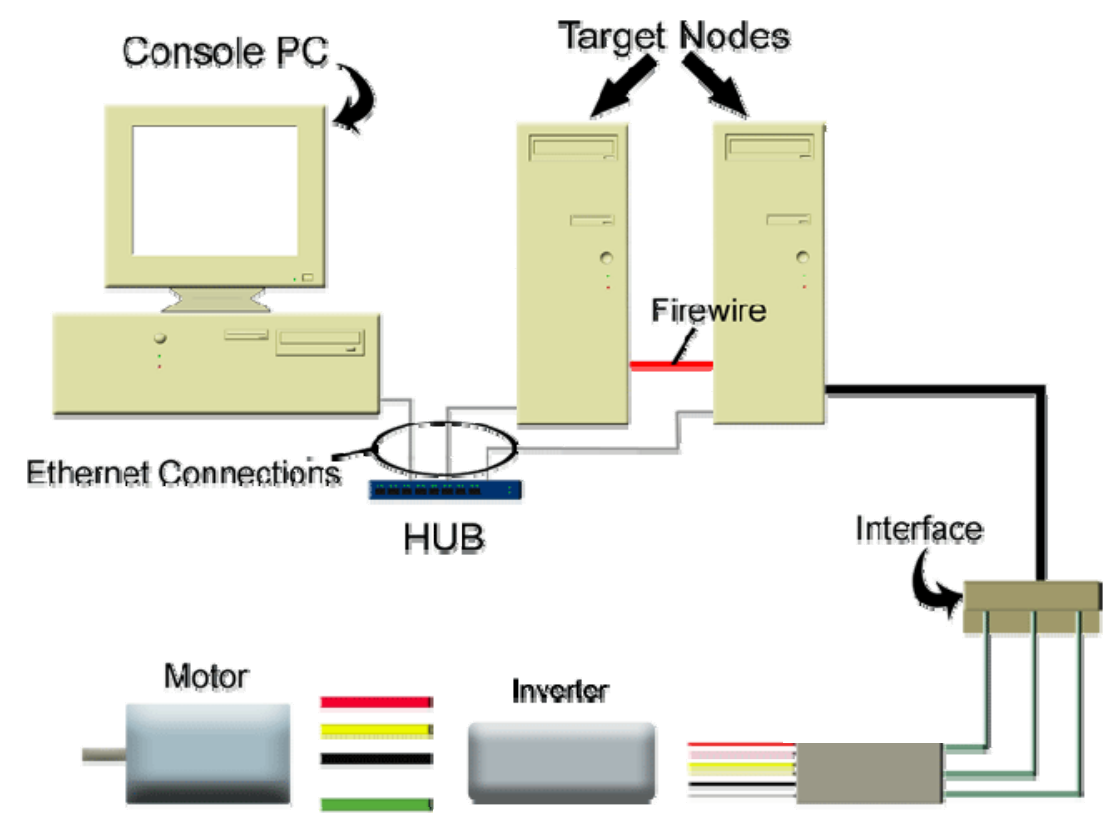

Fig. 3.8. Opal-RT controller and interface system.

\subsection{BACK-EMF TEST RESULTS}

The non-energized LS 600h PMSM was spun at various speeds over its full design range to obtain backemf data. The shaft speed and back-emf data (line-to-neutral rms averaged for the three phases) is plotted in Fig. 3.9. Generally, the induced back-emf voltage of the LS $600 \mathrm{~h}$ is about $84 \%$ of that of the Camry. Shown in Fig. 3.10 is the line-to-neutral back-emf waveform of the LS $600 \mathrm{~h}$ at 3,000 rpm. The waveform is more sinusoidal than its predecessors, which is likely a result of the additional magnet to the ' $\mathrm{V}$ ' configuration, which creates a more uniform flux distribution in the air-gap. Additionally, the smaller diameter and longer stack-length of the stator facilitates a smaller amount of notching due to air-gaps between stator teeth. Back-emf tests were repeated throughout the performance/efficiency mapping test to verify that no magnetic strength was lost in the rotor during performance tests or extended periods of high-temperature testing. As expected, there were no significant differences in the data obtained from the second back-emf test. 


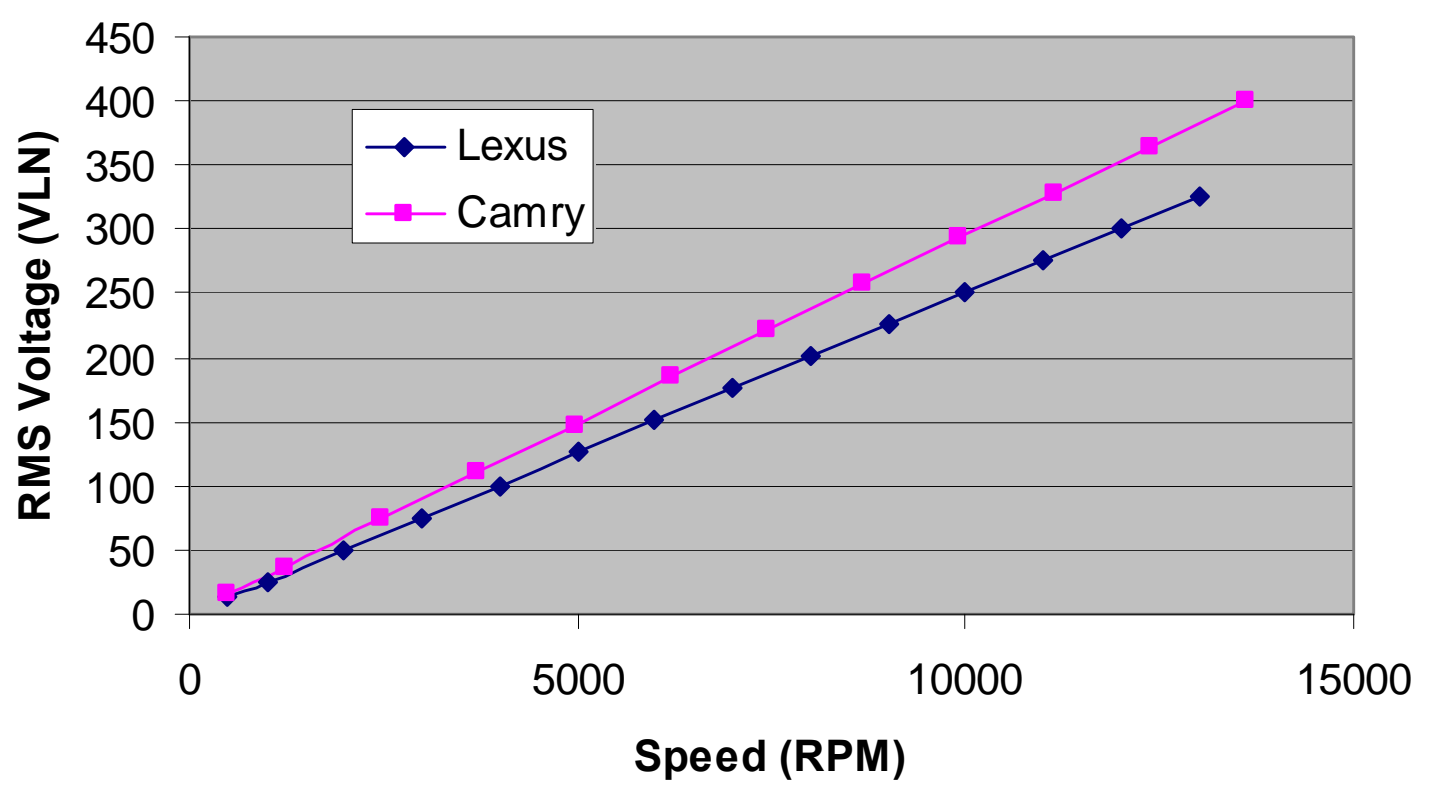

Fig. 3.9. 2008 LS 600h vs. 2007 Camry motor back-emf test results.

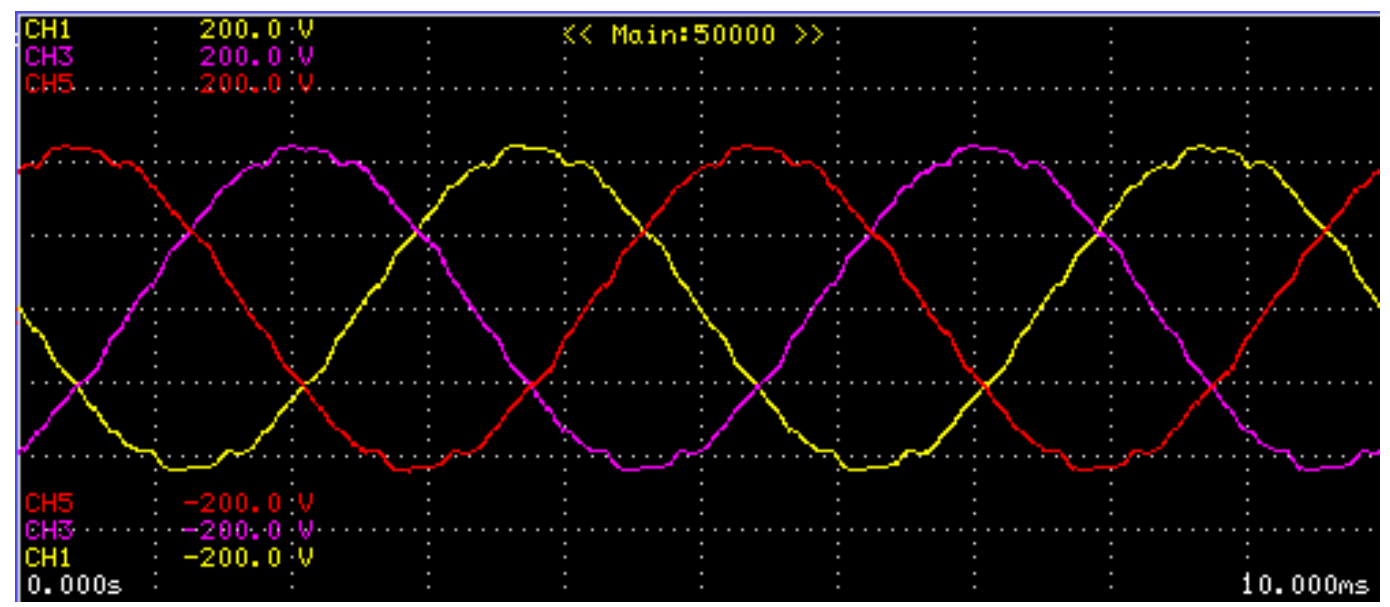

Fig. 3.10. LS 600h line-neutral back-emf waveform at 3,000 rpm.

\subsection{LOCKED ROTOR TEST}

A series of locked rotor tests were performed to determine the torque-producing behavior of the PMSM motor. During locked rotor tests, the rotor is rotated throughout an electrical cycle and the shaft is rigidly locked at each position as dc is applied. Torque values were obtained from an in-line shaft torque sensor when the motor windings were energized. The resulting data was used to produce torque versus electrical position plots, which are shown in Fig. 3.11 for various current levels. For high current levels, the shape of the waveform is significantly different from that of the Camry waveforms, shown in Fig. 3.12. This discrepancy is facilitated by the novel magnet configuration. The peak torque for both systems at each current level was chosen and plotted versus current, as shown in Fig. 3.13. For low current levels, the Camry produces a greater amount of torque for a particular current. However, the LS $600 \mathrm{~h}$ trace does not reveal extreme impacts of saturation, and the curves cross at a dc level just above $300 \mathrm{~A}$. Notice that the published peak torque of $300 \mathrm{Nm}$ for the LS $600 \mathrm{~h}$ requires a dc level of about $430 \mathrm{~A}$. A second look at the minute motor conductor sizes in Fig. 2.66 roughly infers that high current levels are only possible for 
very short amounts of time. Furthermore, conditions within the stator windings are much more extreme, where high-current carrying conductors are bunched together and have limited heat transfer capabilities.

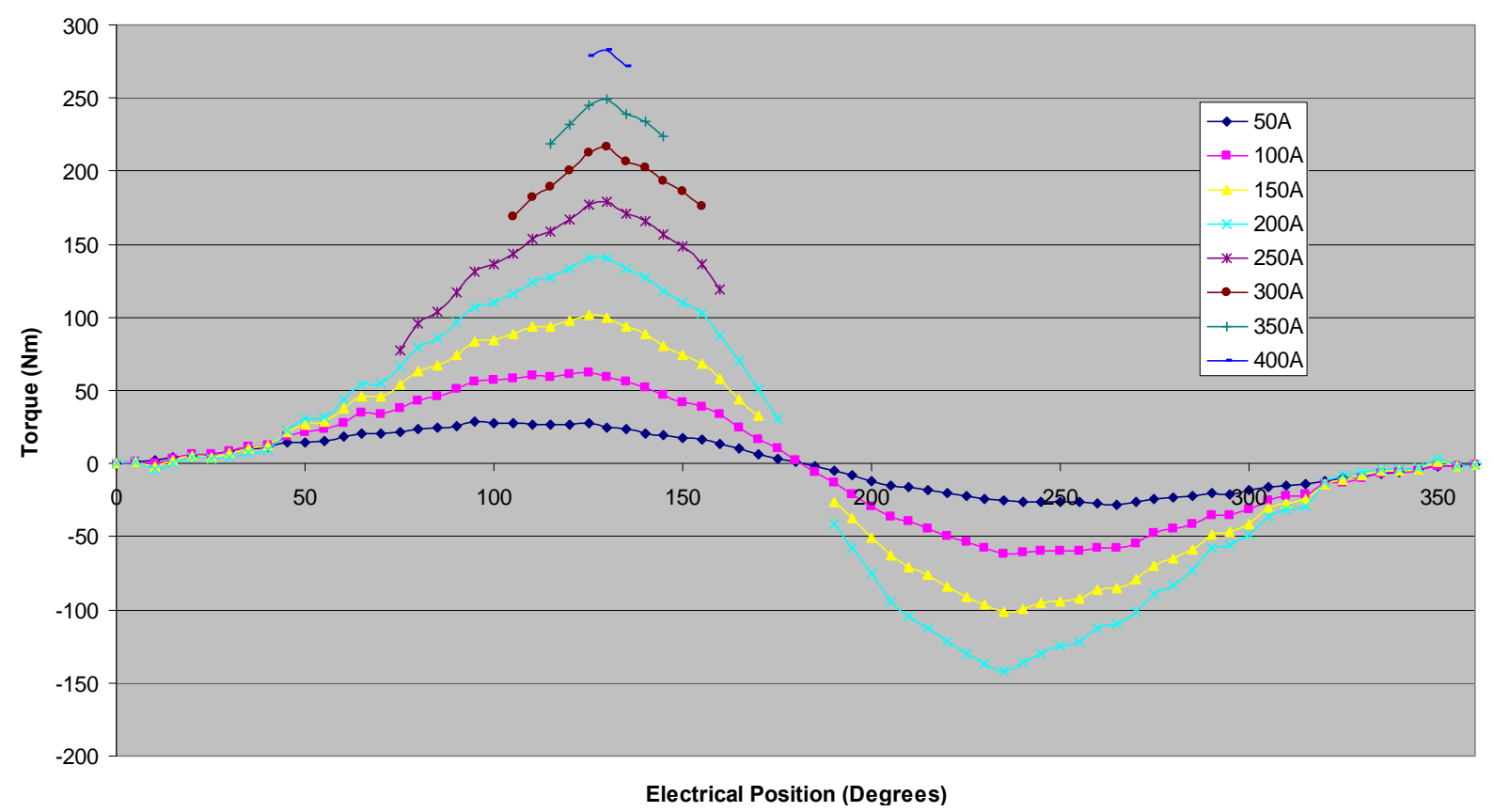

Fig. 3.11. LS 600h locked rotor torque vs. position for various dc.

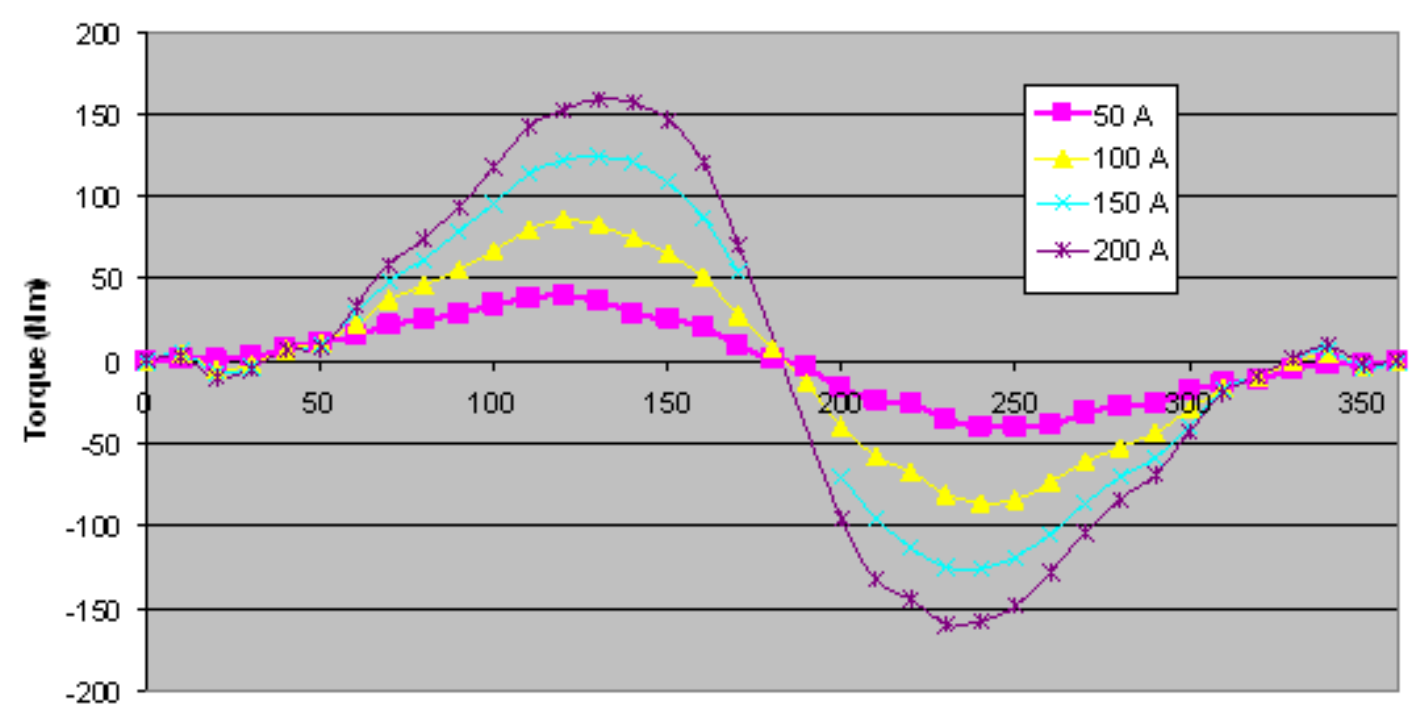

Electrical Position (Degrees)

Fig. 3.12. 2007 Camry locked rotor torque vs. position for various de. 


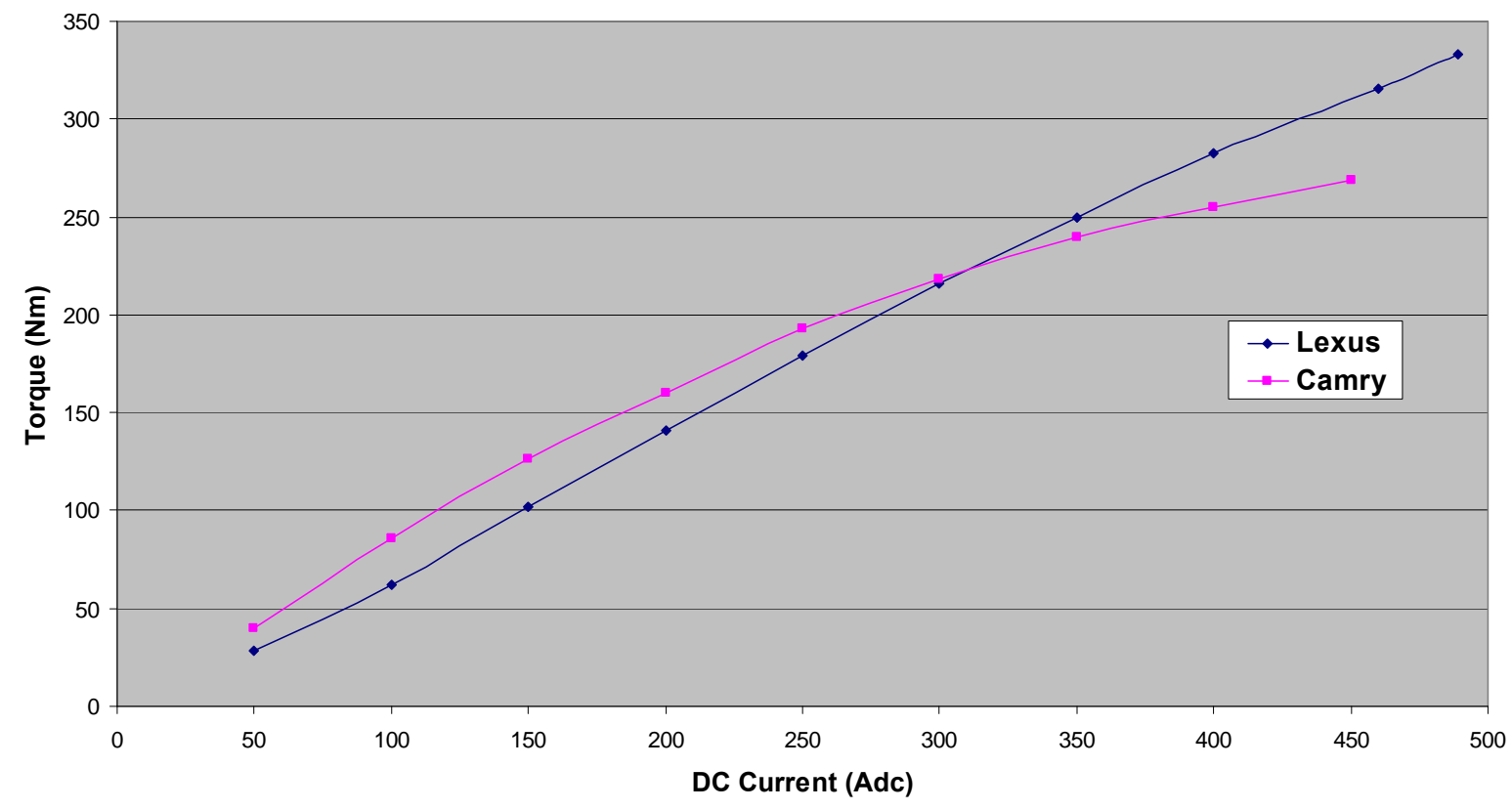

Fig. 3.13. 2008 LS 600h and 2007 Camry peak locked rotor torque vs. dc.

Interior PM motors have two torque components and there is an optimal current angle at which the two torque components produce the maximum torque per current. Figure 3.14 shows the PM torque, reluctance torque, and the total sum of the two torque components for a constant exemplar current magnitude. Although the maximum PM torque is produced at a current angle of zero electrical degrees and the maximum reluctance torque is produced at 45 electrical degrees, the maximum total torque is produced at about 35 electrical degrees. This optimal current angle varies with many conditions such as current magnitude and speed. The novel magnet configuration of the LS 600h produces a more narrow range of near-optimal values for high current levels, thereby increasing the challenge of optimal control.

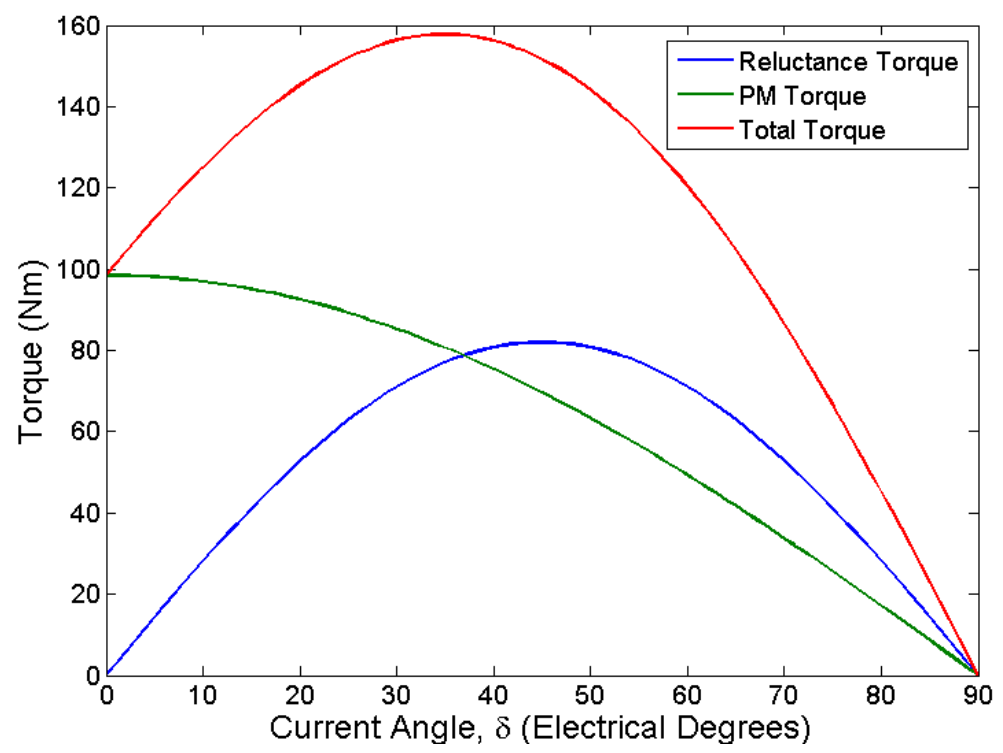

Fig. 3.14. Reluctance and PM components of torque for general PMSM. 


\subsection{PERFORMANCE AND EFFICIENCY EVALUATIONS}

This section provides information about the performance and efficiency evaluations of the LS 600h hybrid subsystem components. The motor and inverter characteristics were evaluated simultaneously with power provided directly to the dc link, as opposed to the power being supplied through the boost converter. Otherwise, the $36.5 \mathrm{~kW}$ power rating of the dc-dc converter would have limited the capabilities of the motor and inverter during the performance and efficiency assessment process. The dclink voltage was maintained at $650 \mathrm{Vdc}$ and a switching frequency of $5 \mathrm{kHz}$ was used. Motor efficiency was measured throughout most of the entire torque-speed range in which the motor is capable of operating. For each operation point, the motor was controlled in steady state for at least 20 seconds and at least 5 data points were averaged to generate the efficiency map in Fig. 3.15.

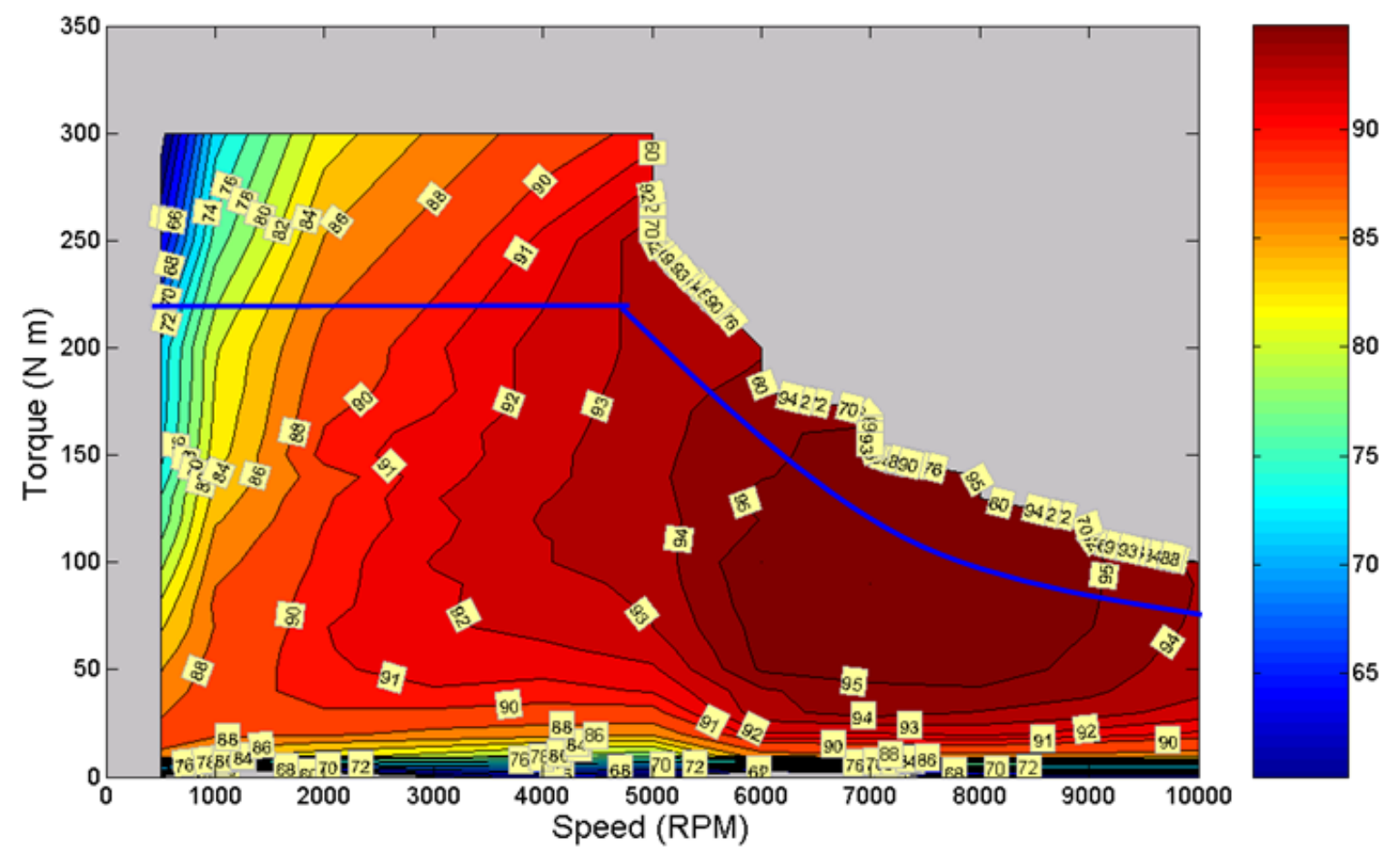

Fig. 3.15. 2008 LS 600h motor efficiency contours.

Efficiencies of the LS $600 \mathrm{~h}$ motor are above $90 \%$ for a large portion of the torque-speed operation region. The low speed and high torque regions tend to incorporate lower operation efficiencies, which is common among all PMSMs. A large portion of the operation region near 7,000-8,000 rpm is above $95 \%$. Note that for high-torque conditions, a coolant temperature of nearly $0^{\circ} \mathrm{C}$ was used in order to enable steady state operation under these high current conditions. Even with such a low coolant temperature, the duration of operation at extreme points was severely limited. It was ensured that reasonable stator winding temperatures were held, thereby ensuring that the winding resistance did not taint the efficiency measurement. The blue line in Fig. 3.15 indicates the projected 18 second capability of the motor. An 18 second duration requirement for FreedomCAR and Vehicle Technologies (FCVT) targets has be implemented in order to establish a generalized peak capability guideline for benchmarked systems as well as developmental systems within R\&D programs. Otherwise, motor designers could tout extremely high power ratings, even though the duration capability at this power level may only be less than a second, for example. The 18 second power capability of the LS $600 \mathrm{~h}$ motor is about $110 \mathrm{~kW}$ with a stator temperature limit of $150^{\circ} \mathrm{C}$. 
A motor efficiency map for the 2007 Camry motor is given in Fig. 3.16. Not only is the LS 600h motor efficiency map (operation range) much broader than that of the Camry, the efficiencies are considerably higher in a relative sense. The Camry motor has a moderately sized region of efficiencies above $94 \%$, whereas the LS $600 \mathrm{~h}$ motor has a region much larger than this, even for efficiencies above $95 \%$. Note that the published speed rating for the LS $600 \mathrm{~h}$ is $10,230 \mathrm{rpm}$, yet the torque capability of the machine observed at 10,000 rpm indicates that voltage is likely not the limiting factor in this speed rating and the rating is likely due to a mechanical limitation such as the small bridge between the additional magnet and the air-gap.

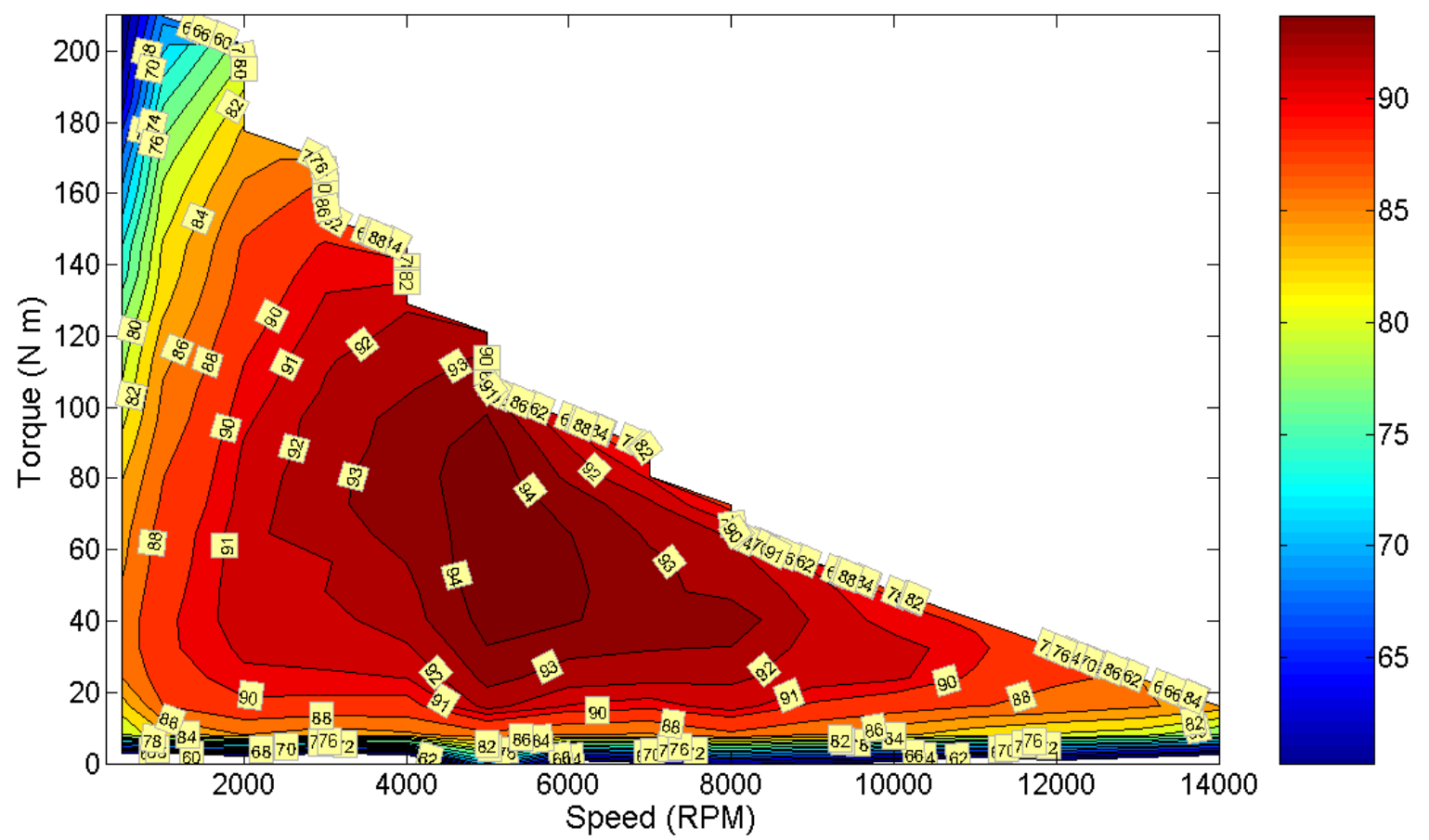

Fig. 3.16. 2007 Camry motor efficiency contours.

Shown in Fig. 3.17 is the efficiency map for the LS 600h motor inverter. The map closely resembles the inverter efficiency map for the 2007 Camry motor inverter, indicating that there was not a significant impact, be it detrimental or beneficial, of the novel power module design to efficiency of the inverter. The LS 600h module facilitates slightly higher operation efficiencies, as the resistance of the pressedpackage contacts is lower than that of a wire bond approach. Additionally, the modules tend to operate at lower temperatures due to improved heat transfer, and therefore have lower component resistances, which provide the benefit of lower $\mathrm{I}^{2} \mathrm{R}$ losses. 


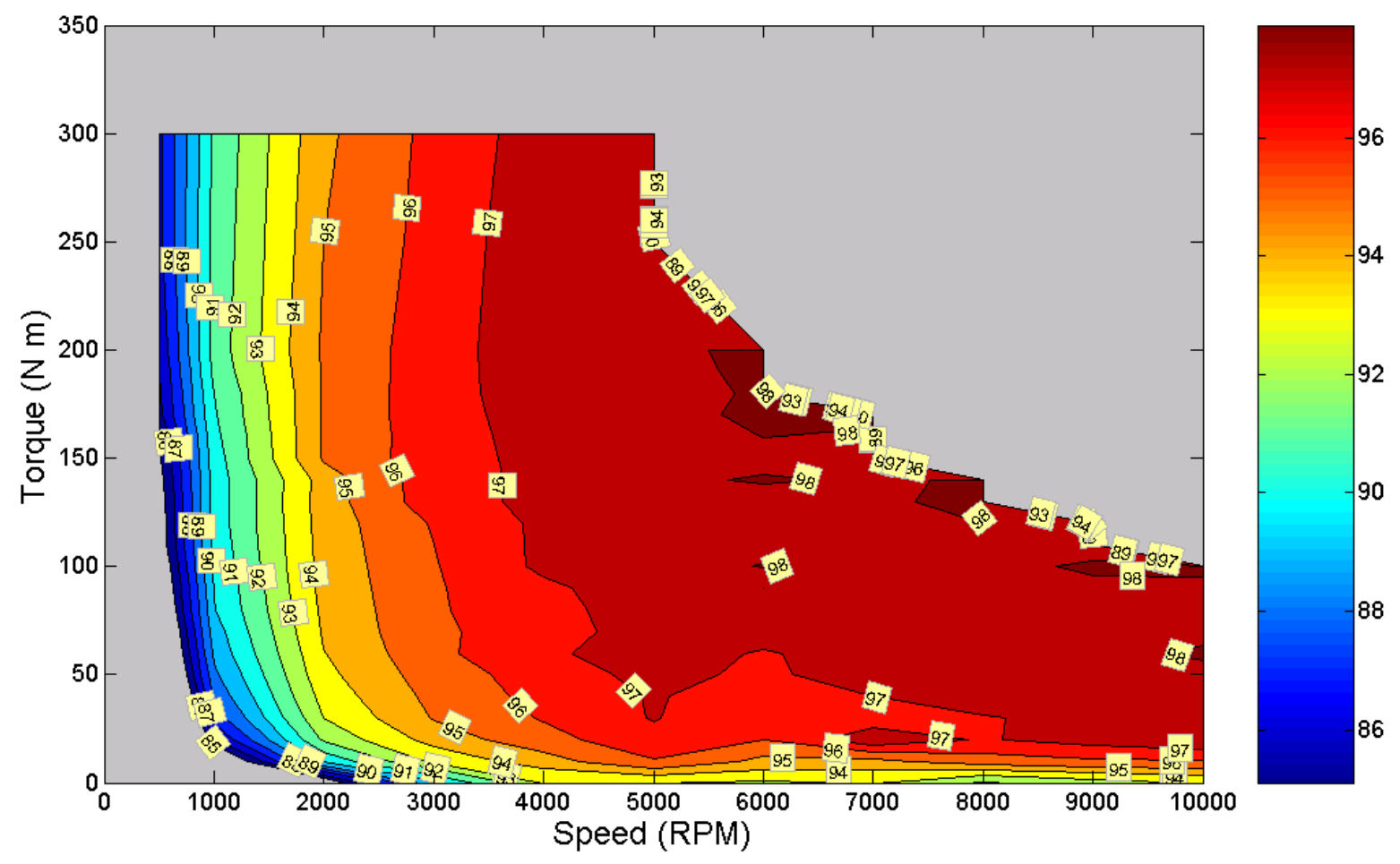

Fig. 3.17. LS 600h inverter efficiency contours.

An efficiency map for the LS $600 \mathrm{~h}$ motor and inverter efficiencies combined is provided in Fig. 3.18. A very similar map is shown in Fig. 3.19, yet only combined efficiencies greater than $77 \%$ are indicated. This approach narrows the numerical range represented by the color spectrum and thereby making the most common efficiency range easier to analyze by color. Similar maps are shown for the Camry and Prius subsystems in Figs. 3.20 and 3.21, respectively. Although the high-speed range of the Camry motor facilitates a larger amount of null (white) space when compared the null (gray) space of the LS 600h, the overall performance and efficiency of the LS $600 \mathrm{~h}$ is superior to that of the Camry and Prius. Only a small portion of the combined Camry efficiencies are above $92 \%$, where as a significant portion of the combined LS $600 \mathrm{~h}$ efficiencies is greater than $93 \%$. The blue-trace on the LS $600 \mathrm{~h}$ efficiency maps indicate the 18 second power rating based on a stator winding temperature limitation of $150^{\circ} \mathrm{C}$. Although the peak performance of the LS $600 \mathrm{~h}$ is greater than that of the Camry, continuous duration tests produced results which match more closely. 


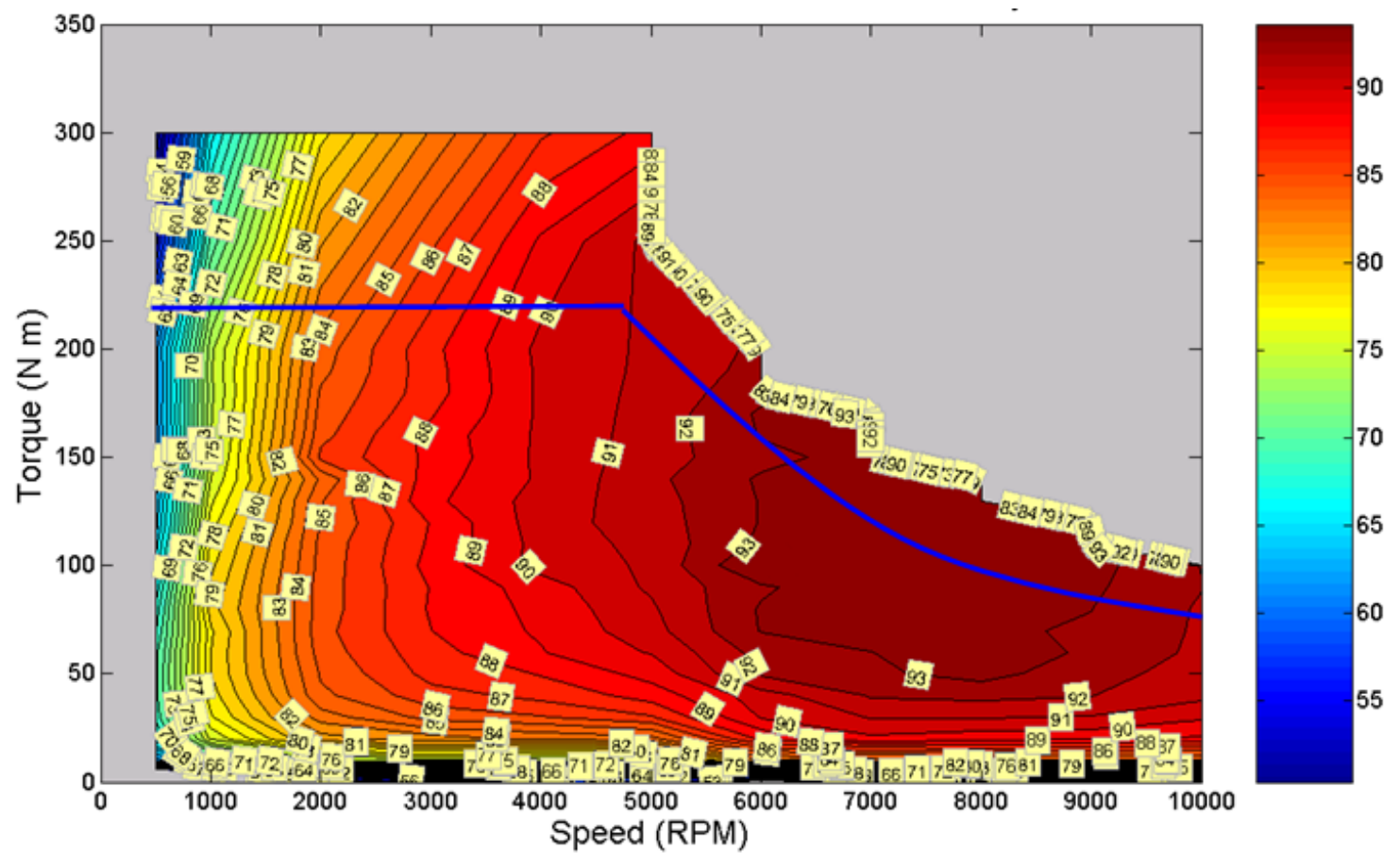

Fig. 3.18. LS 600h motor-inverter combined efficiency contours.

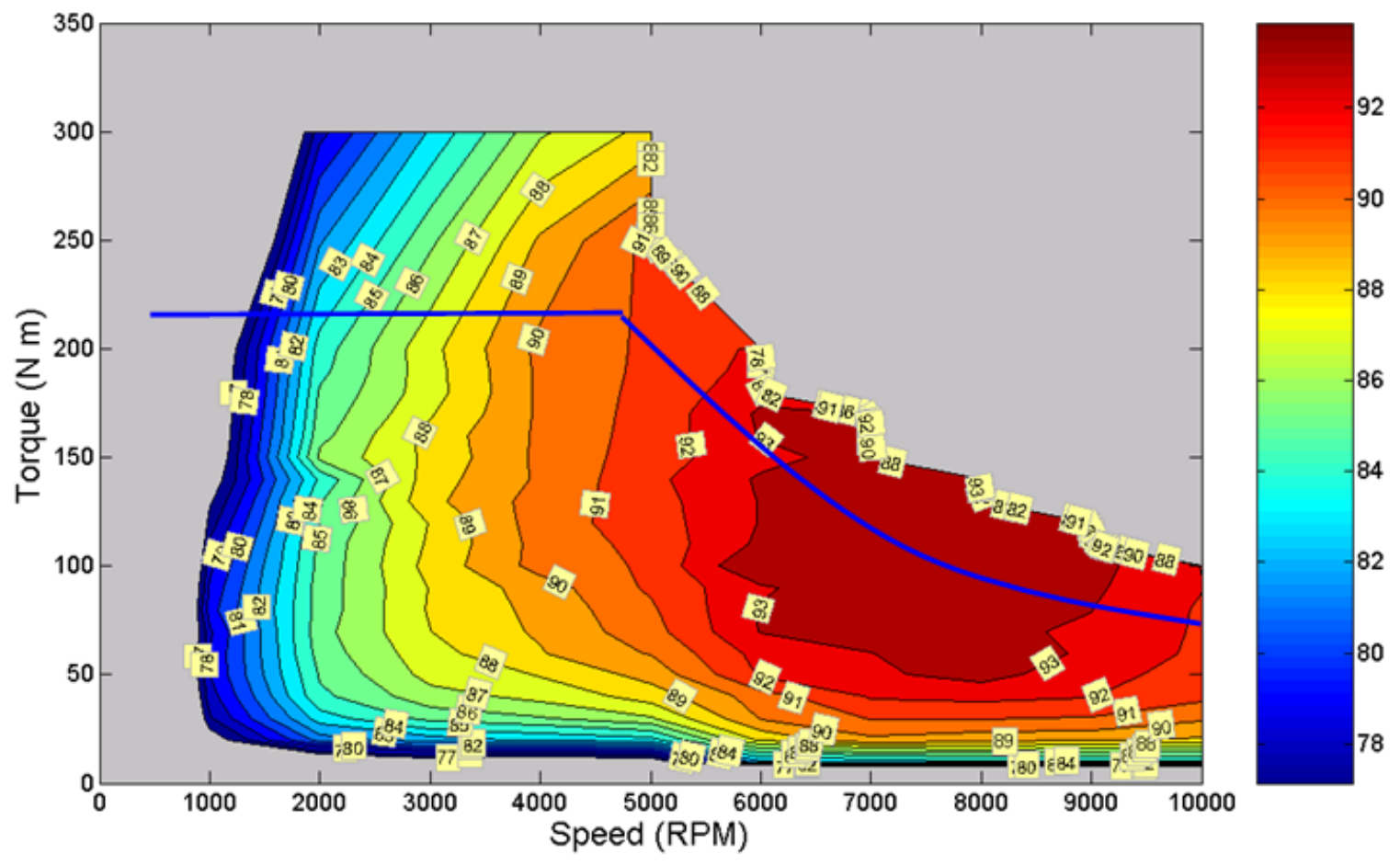

Fig. 3.19. LS 600h motor-inverter combined efficiency contours for $77 \%$ and above. 


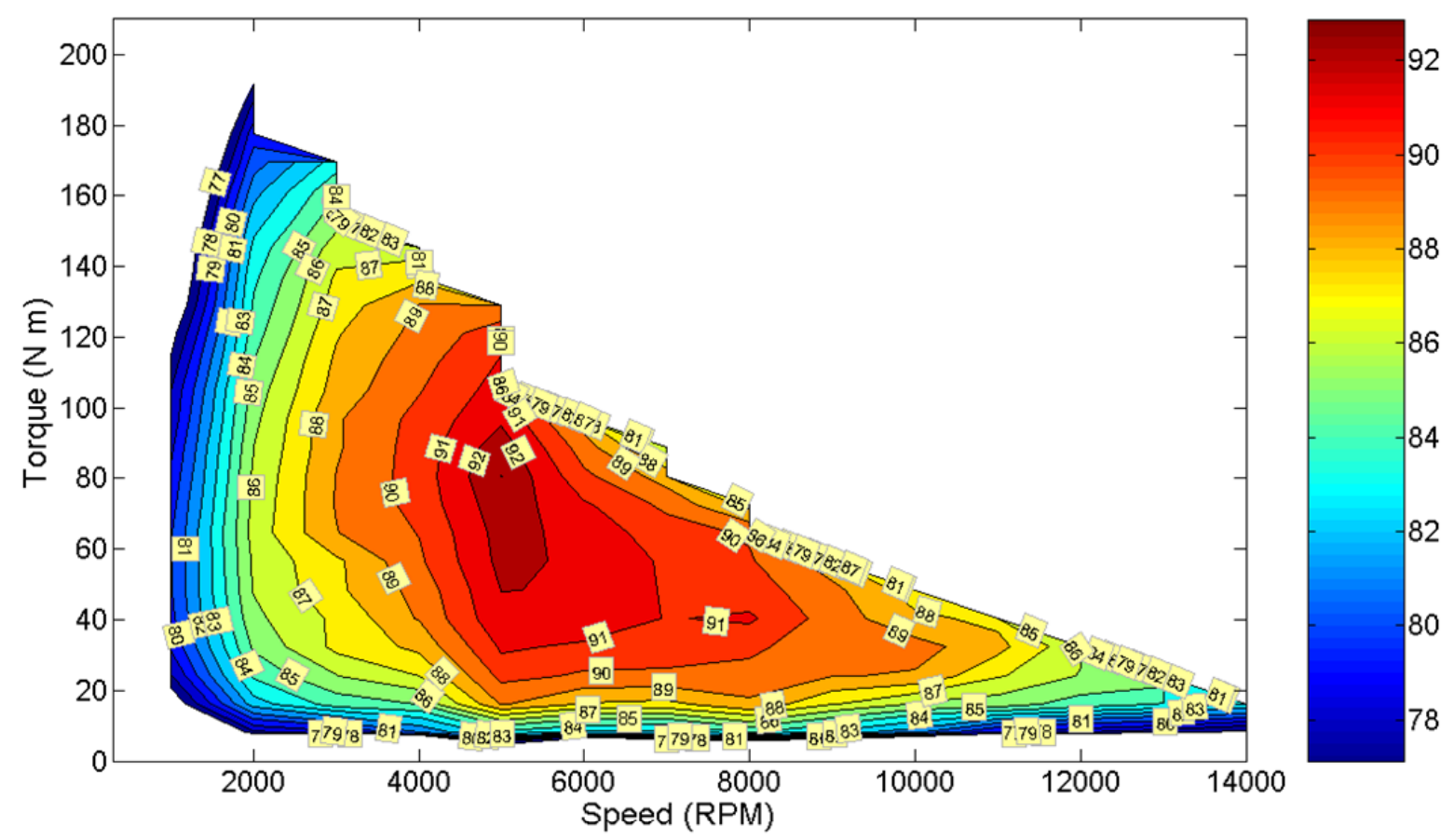

Fig. 3.20. 2007 Camry motor/inverter efficiency contours.

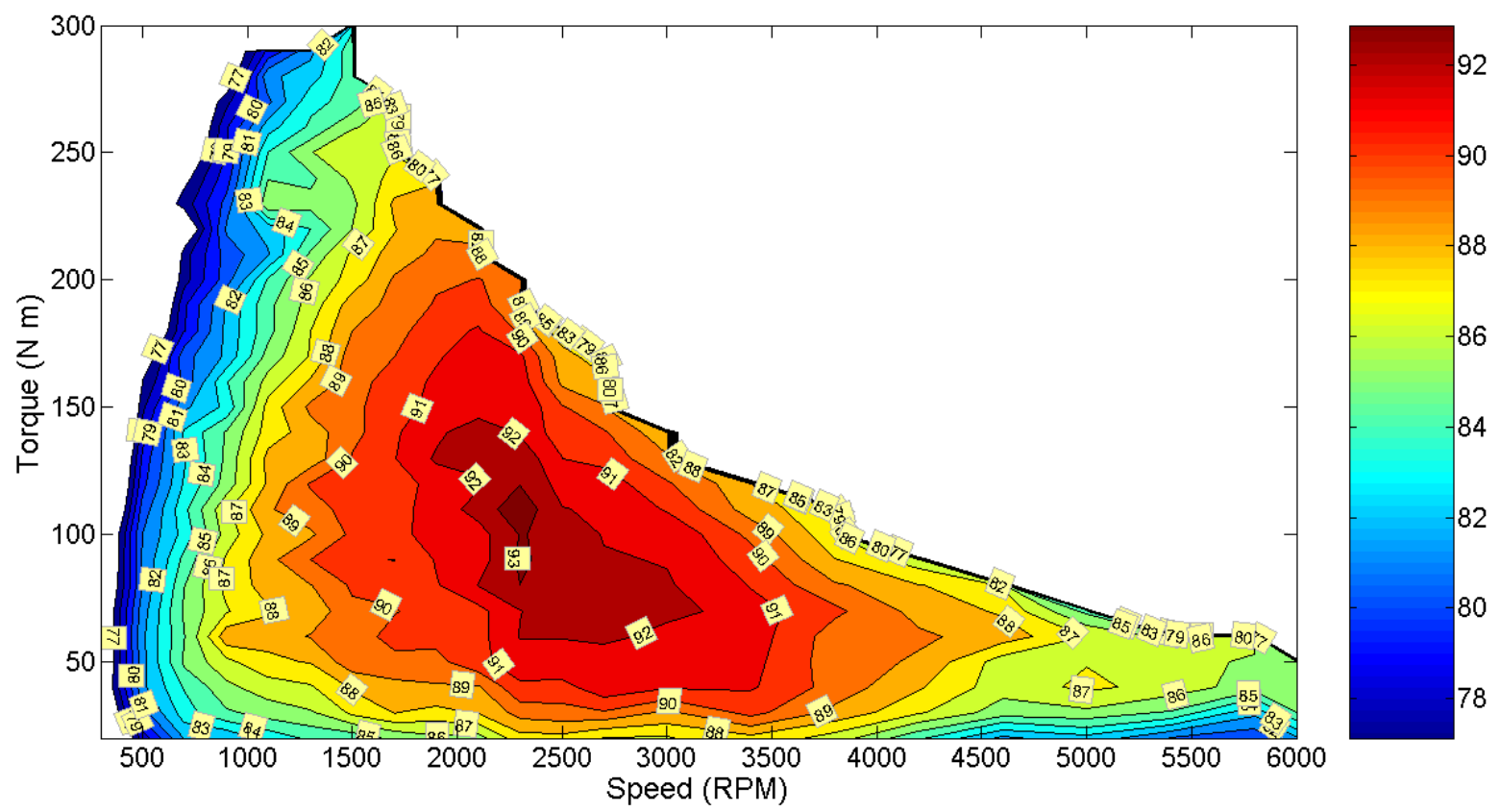

Fig. 3.21. 2004 Prius motor/inverter efficiency contours.

Efficiency assessments were conducted upon the bi-directional dc-dc (boost) converter of the LS 600h with various dc-link voltages, current output levels, and switching frequencies $\left(f_{\mathrm{sw}}\right)$. The evaluations were conducted as the boost converter was operated at 5 and $10 \mathrm{kHz}$ and supplied the motor inverter, which was operated at $5 \mathrm{kHz}$. The motor speed was maintained at $1,000 \mathrm{rpm}$ as torque was increased to increase the boost converter current. LS $600 \mathrm{~h}$ boost converter efficiencies are plotted versus boost converter input current for various output voltages and switching frequencies in Fig. 3.22. Converter efficiencies slightly decrease with increasing dc input current. Generally speaking, converter efficiencies also decrease with 
increasing output voltage as well as switching frequency. For example, the highest efficiency is obtained with an output voltage of $288 \mathrm{~V}$ whereby no switching is required. Only the $\mathrm{I}^{2} \mathrm{R}$ losses of the boost converter components contribute to the decrease from $100 \%$ efficiency in this case. The lowest efficiency is obtained with an output voltage of $650 \mathrm{Vdc}$ and a switching frequency of $10 \mathrm{kHz}$. Efficiencies above $97 \%$ were observed for most of the other test conditions.

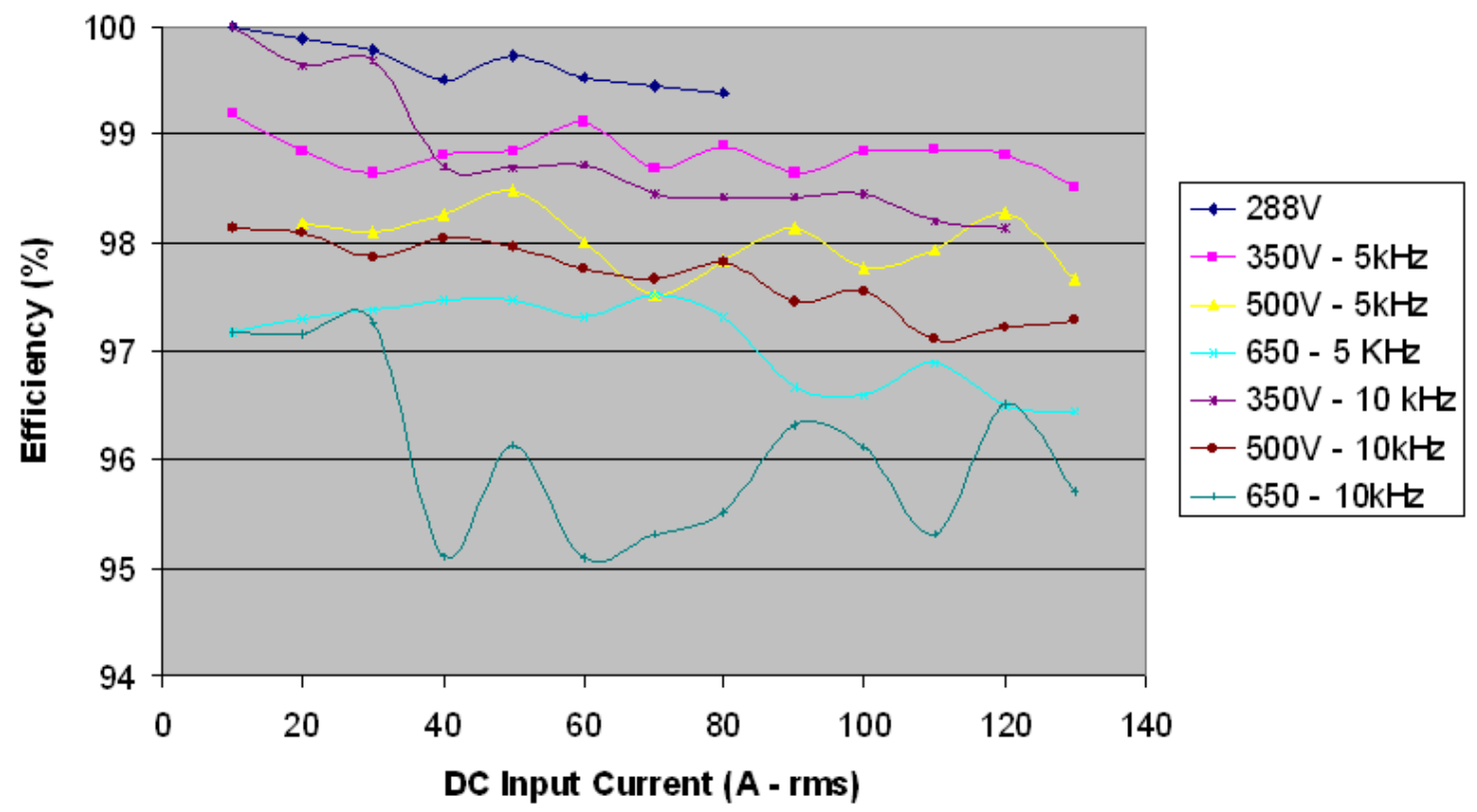

Fig. 3.22. LS 600h dc-dc converter efficiency vs. input current for various dc-link voltages and $f_{\text {sw. }}$.

Similar plots are shown for the Camry and Prius in Figs. 3.23 and 3.24, respectively. These tests were conducting with a boost converter switching frequency of $5 \mathrm{kHz}$. The same color scheme is used throughout all three of the figures to facilitate a straight-forward comparison. Operation efficiency of the LS 600h converter is slightly higher than the Prius and Camry with an output voltage of $350 \mathrm{Vdc}$ and a switching frequency of $5 \mathrm{kHz}$. However, operation efficiencies of the LS $600 \mathrm{~h}$ converter with a $500 \mathrm{Vdc}$ output and $5 \mathrm{kHz}$ switching frequency are much higher than that of the Camry for low input currents. When comparing the Camry and Prius boost converter results, the Prius boost converter has a slightly higher efficiency for much of the operation range. Low dc-current limitations were set for initial tests of the Camry converter to prevent potential failures from preventing completion of general tests.

Nonetheless, a failure occurred with an output voltage of $500 \mathrm{Vdc}$ and input current of about $70 \mathrm{~A}$ and anticipated tests at $650 \mathrm{Vdc}$ as well as a second series of tests at $10 \mathrm{kHz}$ were not conducted. The failure was associated with an extremely high ripple current and the Toyota controller likely uses a switching frequency of $10 \mathrm{kHz}$ for these conditions. 


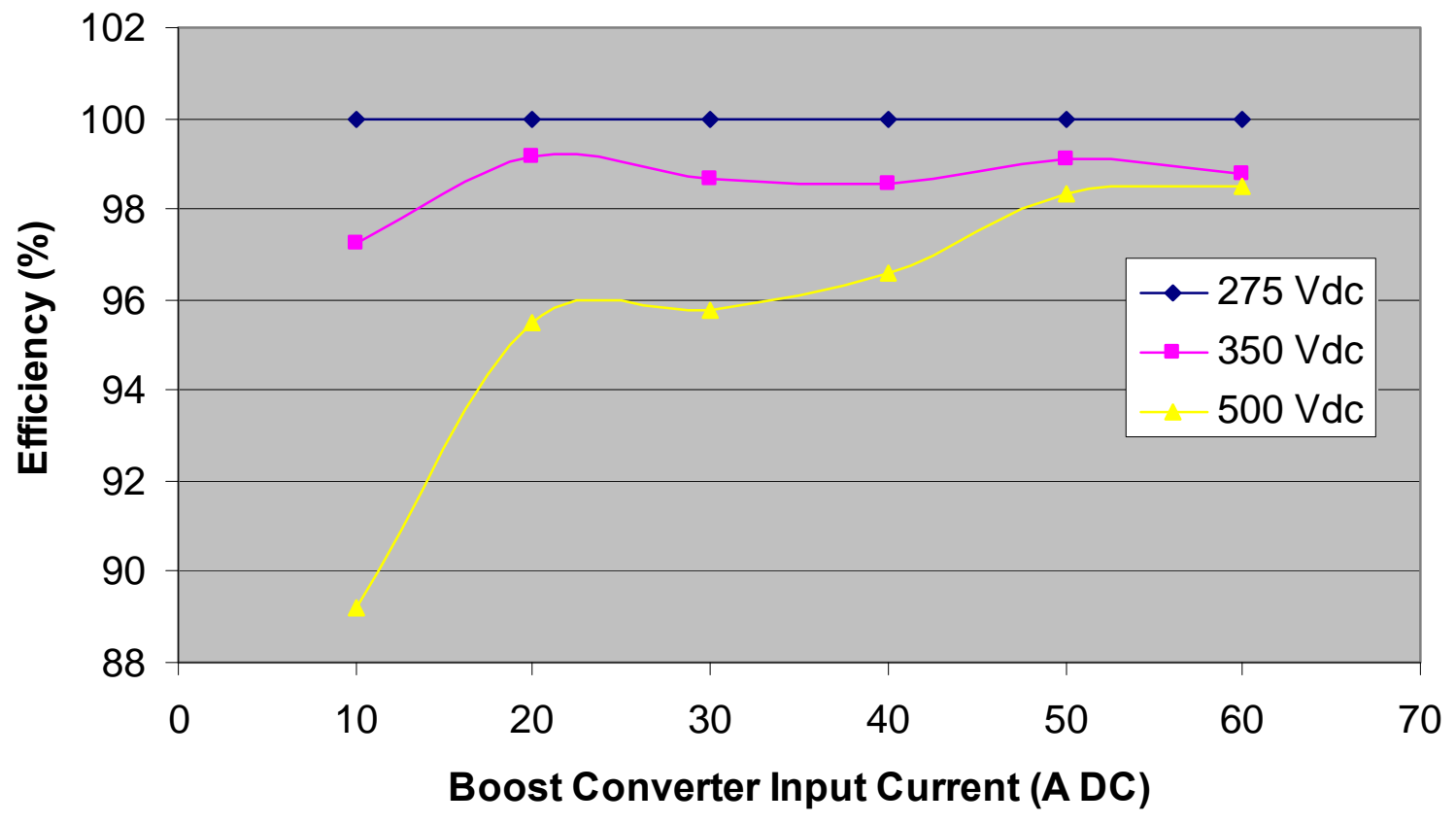

Fig. 3.23. 2007 Camry boost converter efficiency vs. input current for various dc-link voltages.

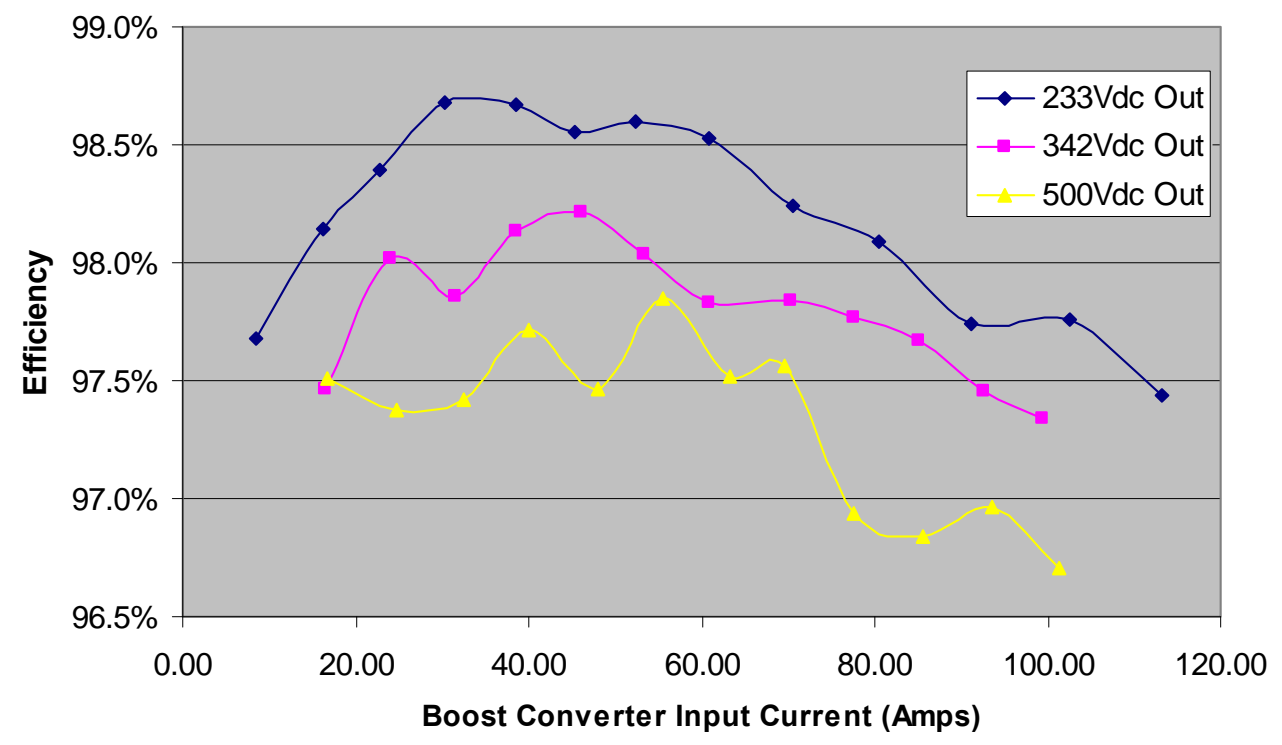

Fig. 3.24. Prius boost converter efficiency vs. input current for various de-link voltages.

\subsection{CONTINOUS LOAD DURATION TESTS}

The LS 600h motor was operated at continuous power levels for different speeds to observe the continuous capability of the motor under various conditions. Continuous tests were conducted at 25 and $50 \mathrm{~kW}$ at $3,000,5,000$, and 7,000 rpm with a coolant temperatures of $50^{\circ} \mathrm{C}$. For each case, motor temperatures were allowed to stabilize prior to initiating the continuous tests and the Bay-Voltex coolant temperature regulation unit was used to regulate the coolant at a desired temperature. 
TCs and thermistors were installed in various locations throughout the ECVT and PCU with locations described in Section 3.13 and indicated in Figs. 3.5, 3.6, and 3.7. Coolant temperatures are indicated by the traces labeled "InvCooIn", "MotCooIn", and "MotCooOut", to represent the inverter coolant input, motor coolant input, and motor coolant output temperatures, respectively.

Figure 3.25 shows the measured ECVT temperatures during conducted at a power level of $25 \mathrm{~kW}$ and a motor speed of 3,000 rpm. The traces are labeled and identified by color in the key provided on the left. The most extreme PCU temperature, "InvPEM-VD", is indicated by a red-orange trace. Mechanical power, "Pmech," is represented by a blue trace. The data point symbols for each trace are not distinguishable in the figure since the time scale is so large and the datapoints are close together. A table indicates the time duration for the associated stator temperature limitation in the upper left corner of the figure. For example, the motor can operate at $25 \mathrm{~kW}$ for about 13:52 (minutes:seconds) prior to reaching a stator temperature of $130^{\circ} \mathrm{C}$. If the stator temperature limit is raised to $150^{\circ} \mathrm{C}$, the motor can operate for about 24:57 under these conditions. Thus, the extent of continuous operation capabilities depends greatly upon stator temperature limitations. Even at this low power level, the most extreme temperature, labeled "G: 7 RrSt", quickly become considerably higher than the closest temperature measurement. Aside from $\mathrm{TC}$ ' $\mathrm{D}$ ', temperature measurements of the rear windings ('E', ' $\mathrm{F}$ ', and ' $\mathrm{G}$ ') were the most extreme throughout all continuous tests. The most extreme PCU temperature closely follows the coolant temperature in this case.
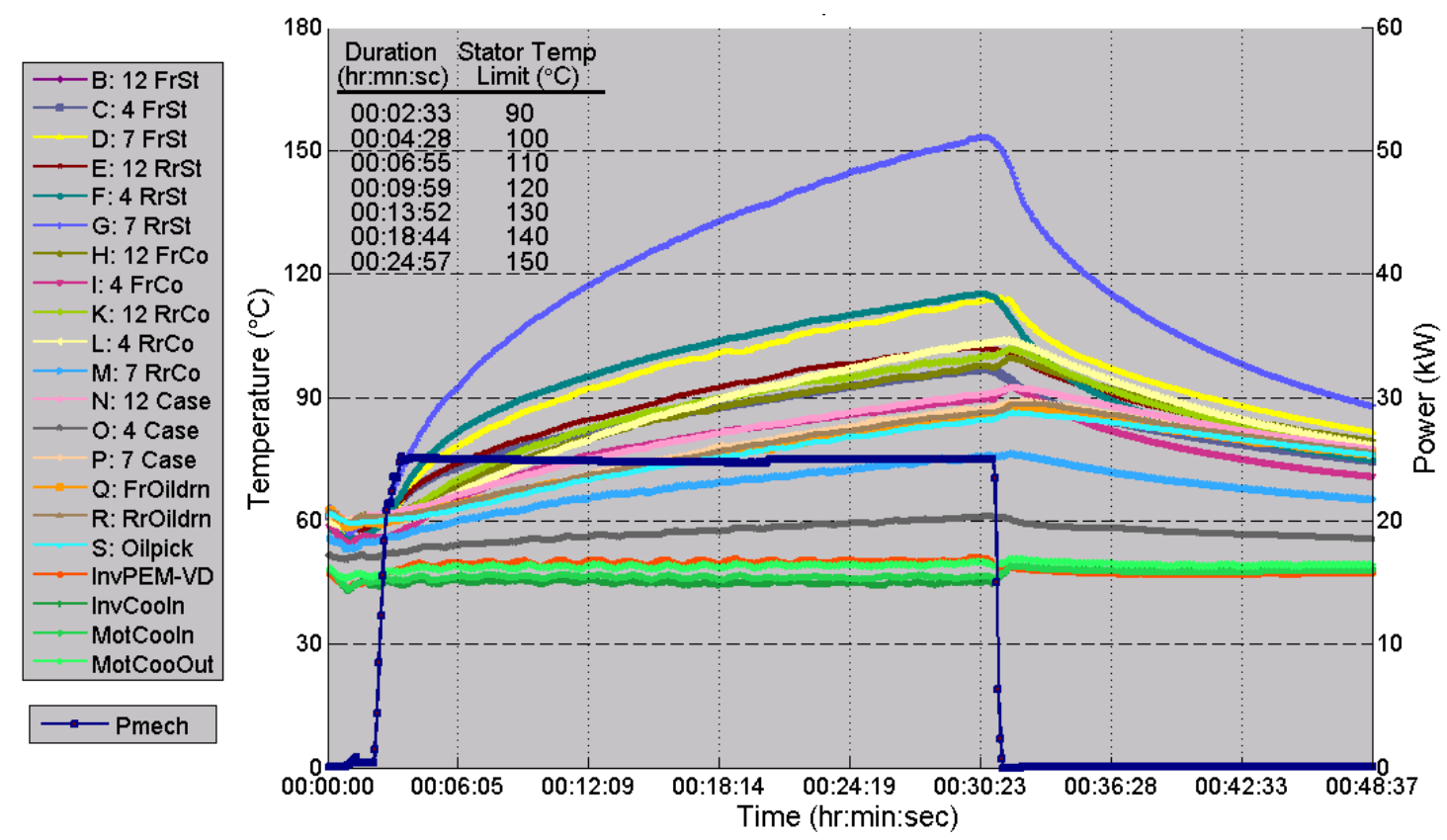

Fig. 3.25. LS 600h motor temperatures during $25 \mathrm{~kW}$ continuous duration test at $3,000 \mathrm{rpm}$.

Stator temperature limitations are set to prevent potential damage within the stator windings and to prevent demagnetization of the PMs. Long term effects which affect the life of the PMSM must also be considered when choosing a stator temperature limitation. According to the LS 600h repair manual, the stator temperature is generally kept below $100^{\circ} \mathrm{C}$. Figure 3.26 shows the motor temperatures measured during tests conducted at a power level of $50 \mathrm{~kW}$ and a rotor speed of $3,000 \mathrm{rpm}$. This test condition facilitated the most extreme limitation of operation duration among all test cases, with a duty of only 3:17 (minutes : seconds) with a stator temperature limit of $150^{\circ} \mathrm{C}$. 

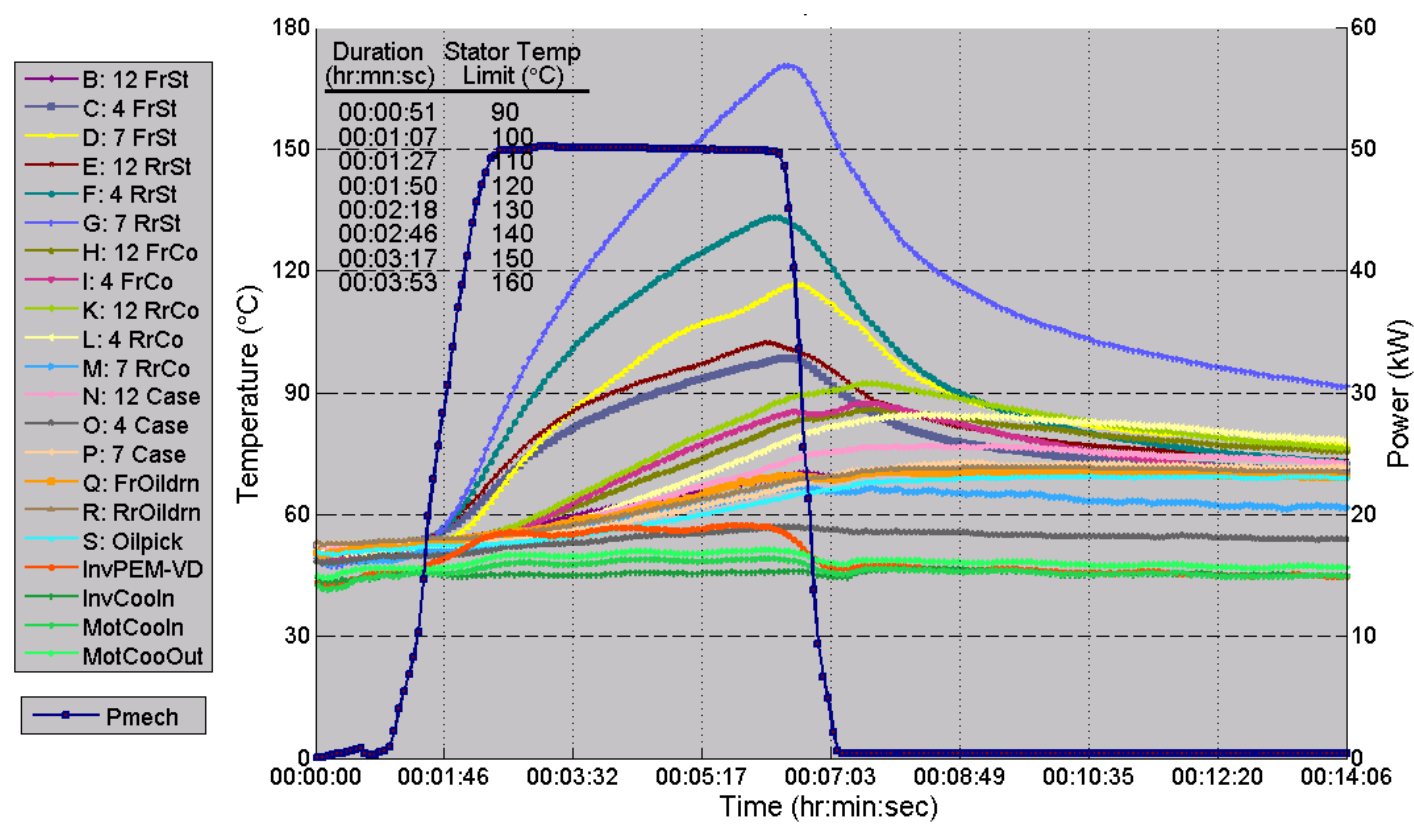

Fig. 3.26. LS 600h motor temperatures during $50 \mathrm{~kW}$ continuous duration test at $3,000 \mathrm{rpm}$.

Since such a vast amount of temperatures were monitored during the continuous tests, only the ECVT temperatures and the most extreme PCU temperature have been shown in previous figures. Figure 3.27 shows the PCU temperatures which were measured at the same time as the ECVT temperatures of Fig. 3.26 were measured. The most extreme PCU temperature, now under the label 'AE', is indicated by a yellow trace. TCs 'AE', 'AD', 'T', and ' $U$ ' often indicated temperatures which where significantly higher than the other PCU temperatures. The three lowest traces 'AG', 'AH', and 'AI' represent the temperatures measured at the capacitor, 'AI' being the hottest of the three. Of all continuous duration tests, the maximum PCU temperature was reached during the evaluation at $50 \mathrm{~kW}$ and 3,000 rpm.

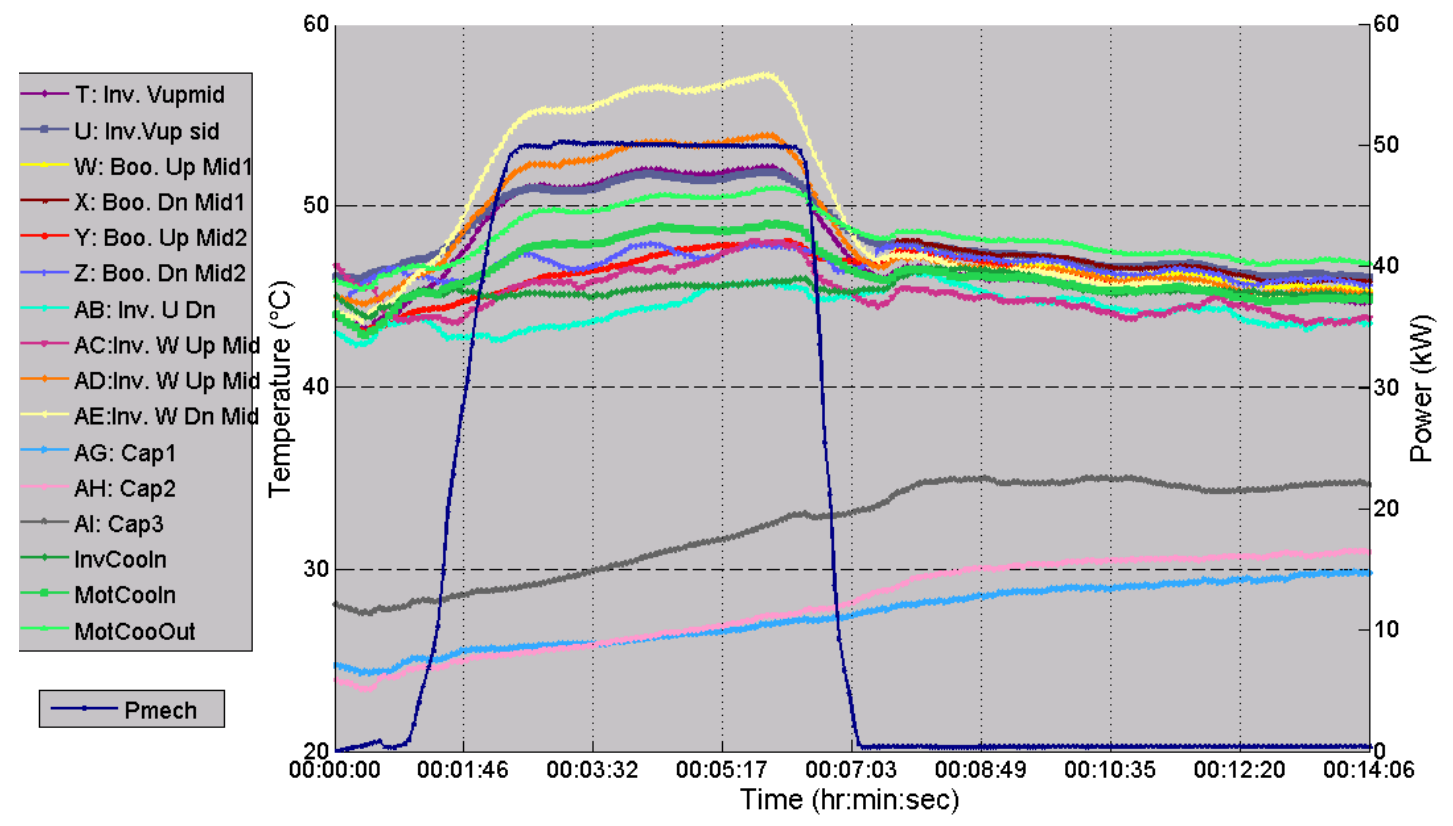

Fig. 3.27. LS 600h PCU temperatures during $50 \mathrm{~kW}$ continuous duration test at $3,000 \mathrm{rpm}$. 
Plots similar to those in Figs. 3.26 and 3.27 are shown for operation at $50 \mathrm{~kW}$ and 5,000 rpm with ECVT and PCU temperature in Figs. 3.28 and 3.29, respectively. Although the power level has not changed from the previous case analysis, $50 \mathrm{~kW}$ operation at 5,000 rpm can be continued for 10:14 and 14:13 with stator temperature limits of $130^{\circ} \mathrm{C}$ and $150^{\circ} \mathrm{C}$, respectively. This improvement of duration capability is expected, as the efficiency maps for the motor and inverter indicate that operations at 5,000 rpm tend to be more efficient than at 3,000 rpm. Similar to the previous tests, TCs 'D', 'E', 'F', 'G', 'T', 'U', 'AE', and 'AD' indicate the most extreme conditions within the subassemblies. Nonetheless, even the most extreme PCU temperature ('AE' in the case) is only slightly higher that the PCU (inverter) input coolant temperature for this moderately high power level. Although the PEs cooling system reached thermal steady state, the capacitor and motor temperatures were still increasing at the end of the test.
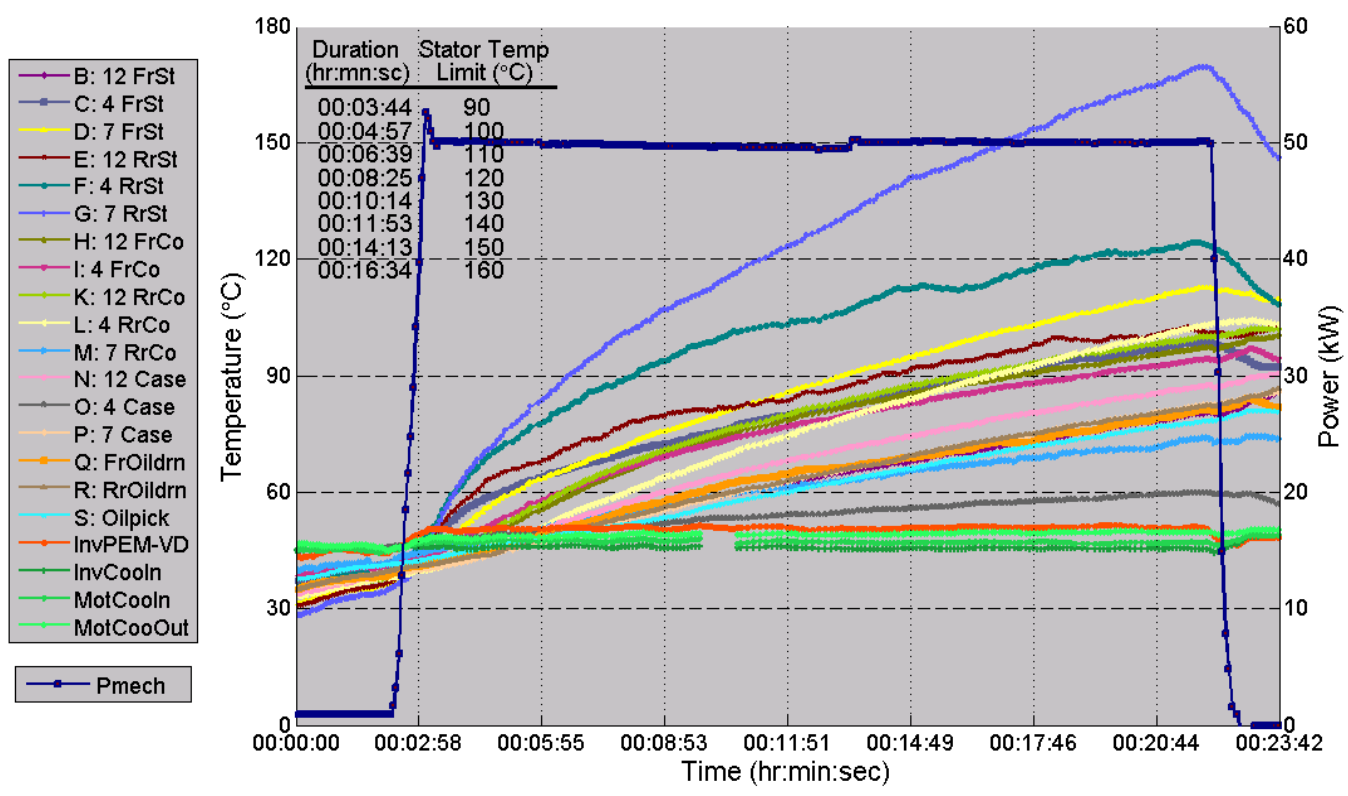

Fig. 3.28. LS 600h motor temperatures during $50 \mathrm{~kW}$ continuous duration test at $5,000 \mathrm{rpm}$.
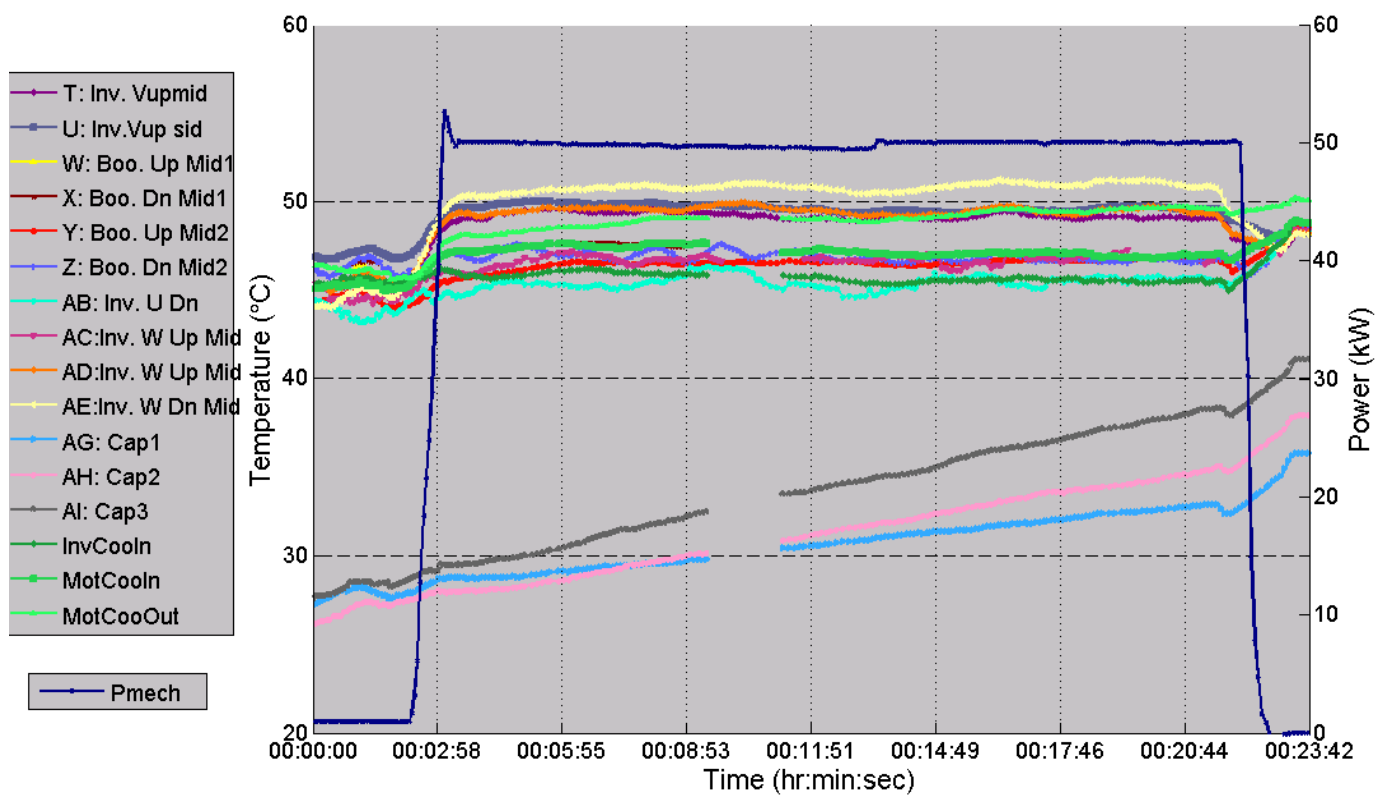

Fig. 3.29. LS 600h PCU temperatures during $50 \mathrm{~kW}$ continuous duration test at 5,000 rpm. 
Graphs similar to Figs. 3.28 and 3.29 were generated for each test condition and while they are informative, it is difficult to fully study the impact of various power levels, motor speeds, and stator temperature limitations upon the extent of time at which the motor can operate under these conditions. Therefore, the duration times shown in the upper left corner of the previous figures were used to produce graphs which provide more meaningful comparisons. In Fig. 3.30 the time durations associated with operation at $25 \mathrm{~kW}$ is graphed versus speed. Each trace represents time durations which correlate to a particular stator temperature limit. Through inspection of this graph, it is more evident that the duration of operation at $25 \mathrm{~kW}$ is greater at 7,000 rpm than for any other speed at which these continuous tests were conducted. Note that in this case, the stator temperature essentially stabilized near $148^{\circ} \mathrm{C}$ at $5,000 \mathrm{rpm}$, which is represented by the upper most trace. Thus, the trace for a temperature of $170^{\circ} \mathrm{C}$ would theoretically have a data point at 5,000 rpm that approaches infinity. A similar graph is shown in Fig. 3.31 for a power level of $50 \mathrm{~kW}$. At 5,000 rpm, the motor operated for over 15 minutes before reaching a stator temperature of $150^{\circ} \mathrm{C}$. For low stator temperature limits, the duration capability does not change significantly as the motor speed increases from 5,000-7,000 rpm.

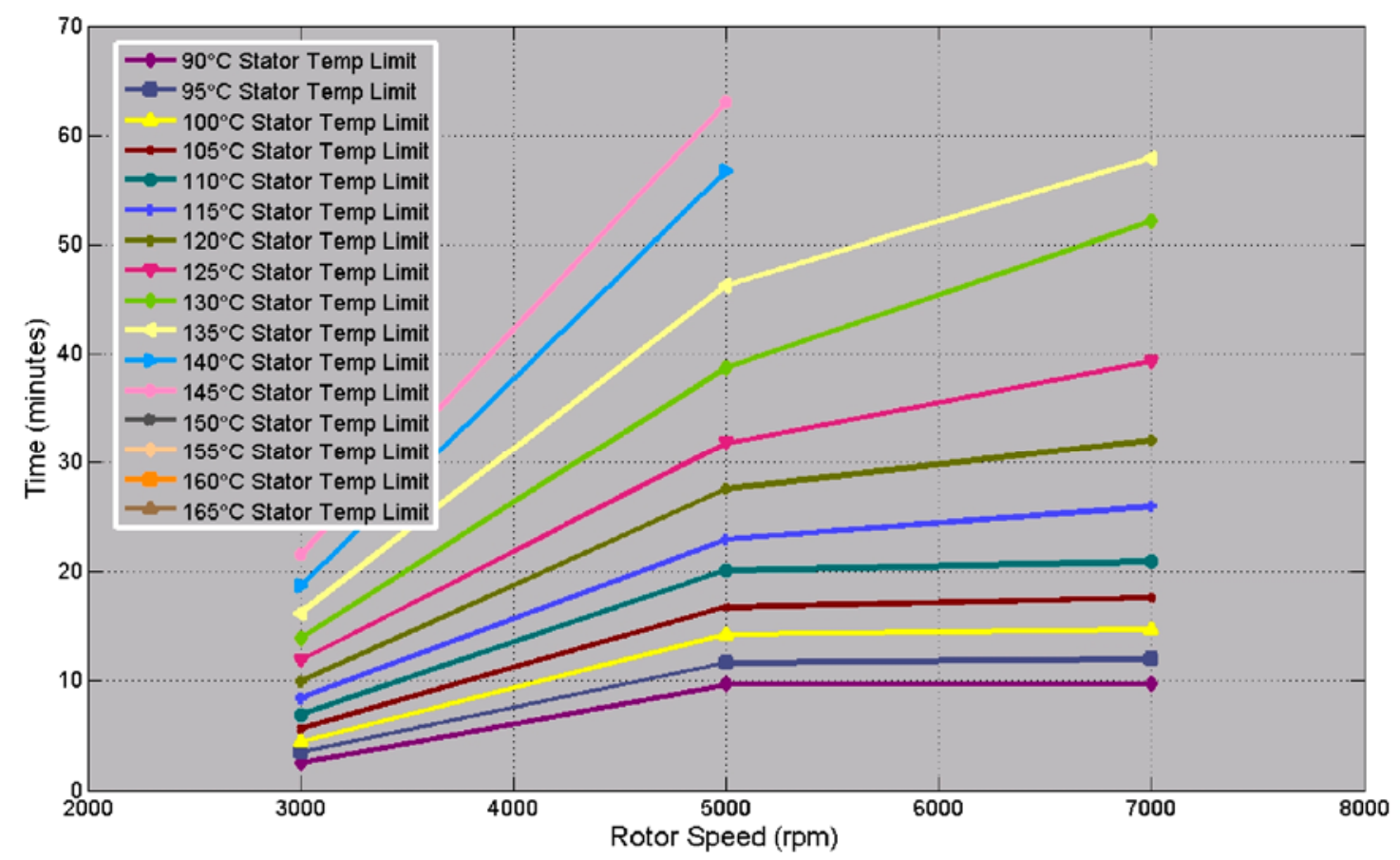

Fig. 3.30. LS 600h $25 \mathrm{~kW}$ continuous duration vs. speed. 


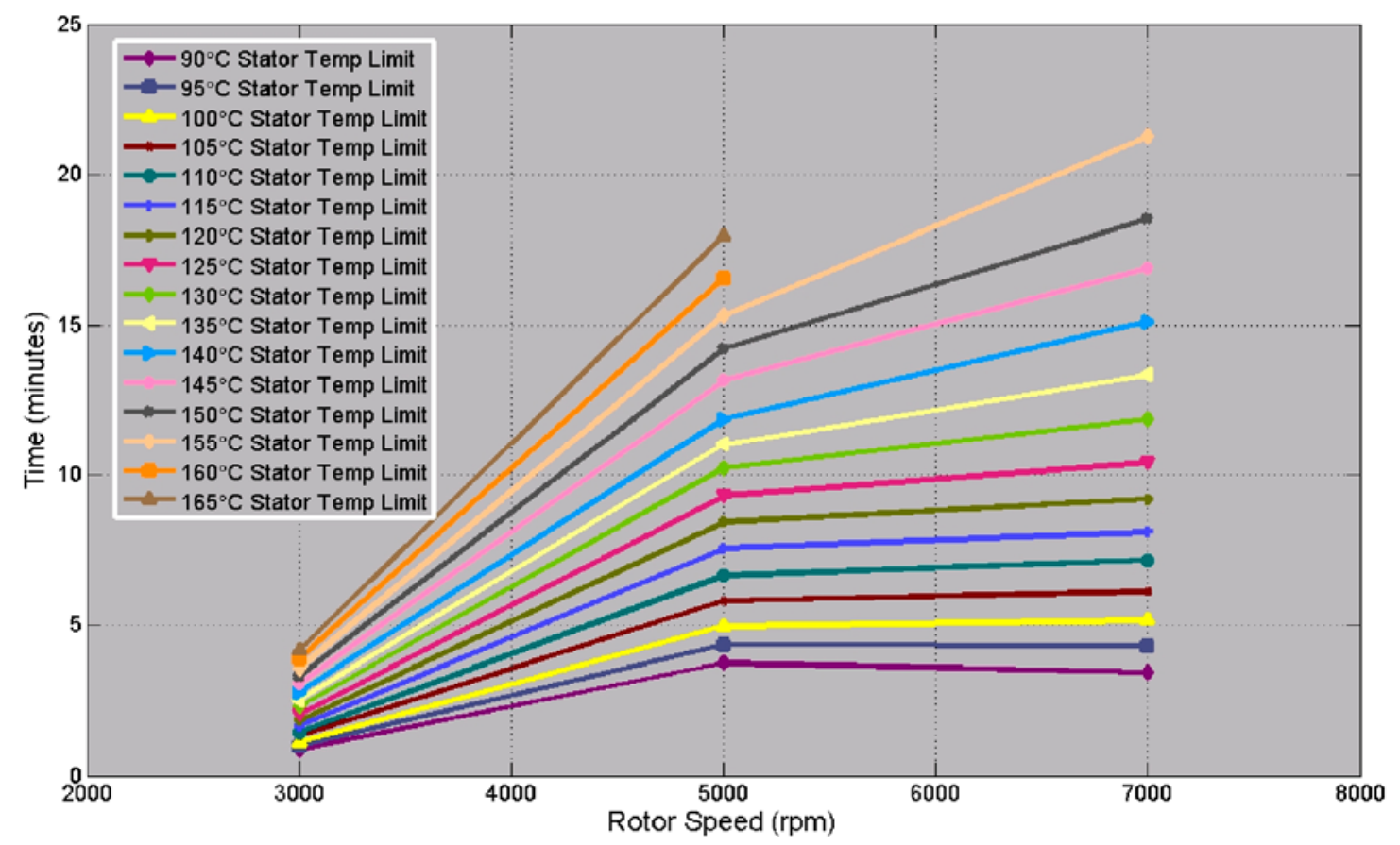

Fig. 3.31. LS 600h $50 \mathrm{~kW}$ continuous duration vs. speed.

The previous graphs provided a clear indication of the influence of speed and power level upon duration capabilities. To provide a more clear assessment of the impact of stator temperature limitations and power level upon duration capability, duration time is plotted versus the stator temperature limit in Fig. 3.32 for operations at 3,000 rpm. Each trace represents a particular power level and coolant temperature combination. Duration information from the continuous studies upon the Camry motor is also included in the graph. In studying the figure, it is interesting to note that the duration capability of the Camry motor at $25 \mathrm{~kW}$ and 3,000 rpm is greater than that of the LS $600 \mathrm{~h}$, even though a higher coolant temperature was used in this specific case. Characteristics similar to what are observed in Fig. 3.32 are observed in Fig. 3.33, where duration time is plotted versus stator temperature limit at 5,000 rpm for various power levels. The Camry motor again has a longer duration capability at $25 \mathrm{~kW}$ and 5,000 even with a higher coolant temperature. However, the $50 \mathrm{~kW}$ duration capability of the LS $600 \mathrm{~h}$ is slightly higher than that of the Camry. For tests wherein thermal steady state was nearly reached, the curves approach a vertical asymptote which is located at the steady state stator temperature. A graph of duration versus stator temperature limit at 7,000 rpm with various power and coolant temperature combinations is shown in Fig. 3.34. The $25 \mathrm{~kW}$ duration capability of the LS $600 \mathrm{~h}$ motor slightly surpasses that of the Camry, yet note that a higher coolant temperature is shown for the Camry. However, duration capability of the LS $600 \mathrm{~h}$ to operate at $50 \mathrm{~kW}$ at 7,000 rpm is moderately greater than that of the Camry, even though a much lower coolant rate is associated with this trace for the Camry.

It is clear that defining the continuous operation capability of a motor depends on many variables, which even includes the definition of continuous operation. For example, continuous operation could be defined to be operation at a particular power level for an infinite amount of time, or a particular time restraint could be included in the definition. For HEV and particularly electric vehicle (EV) applications, it is crucial that the motor is capable of operating continuously within particular power levels. Many aspects must be considered for these conditions, and if properly designed, the volume and mass of the electric drive system can be optimized to match the demands of the system. 


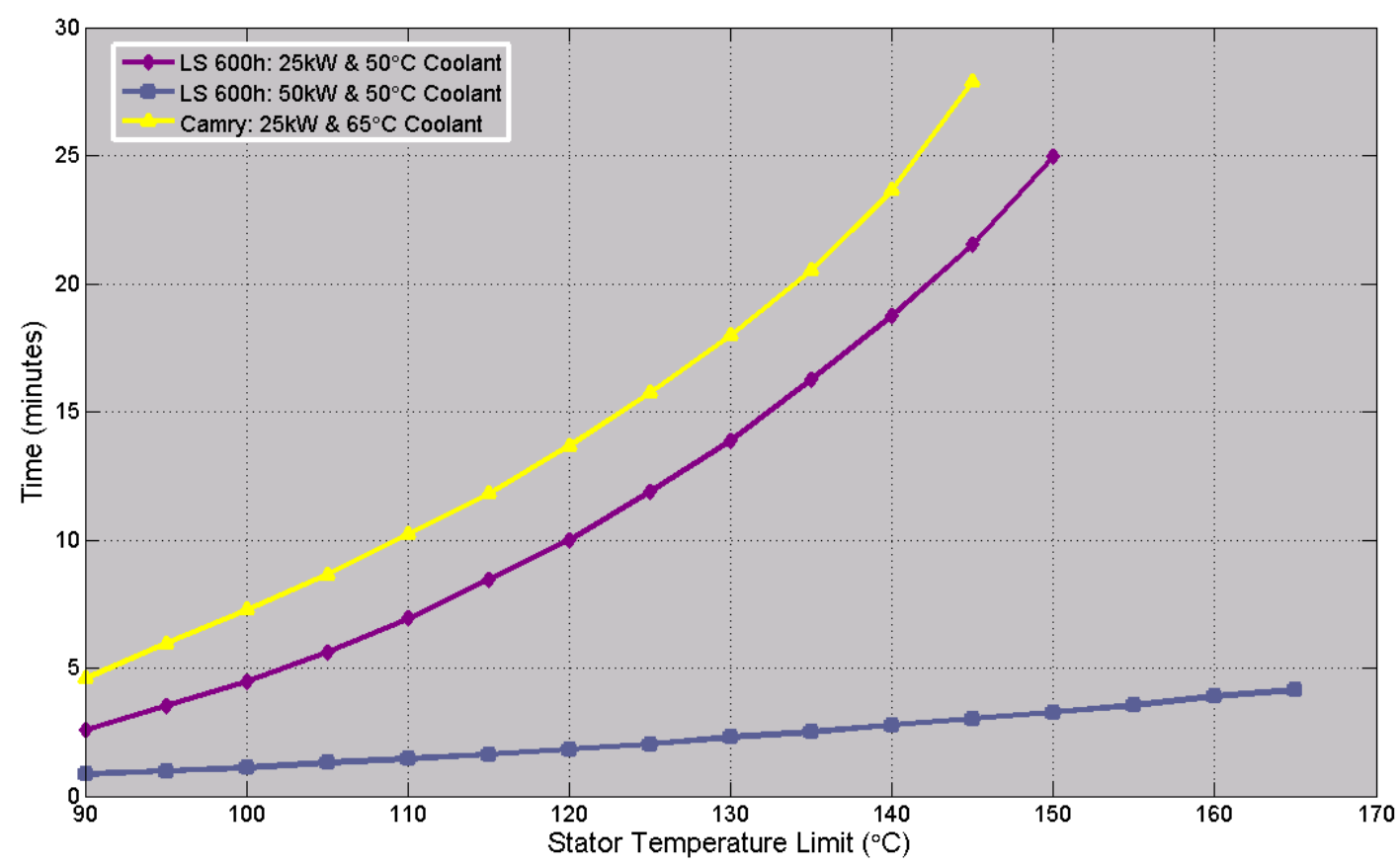

Fig. 3.32. LS 600h continuous duration at $3,000 \mathrm{rpm}$ with various power levels.

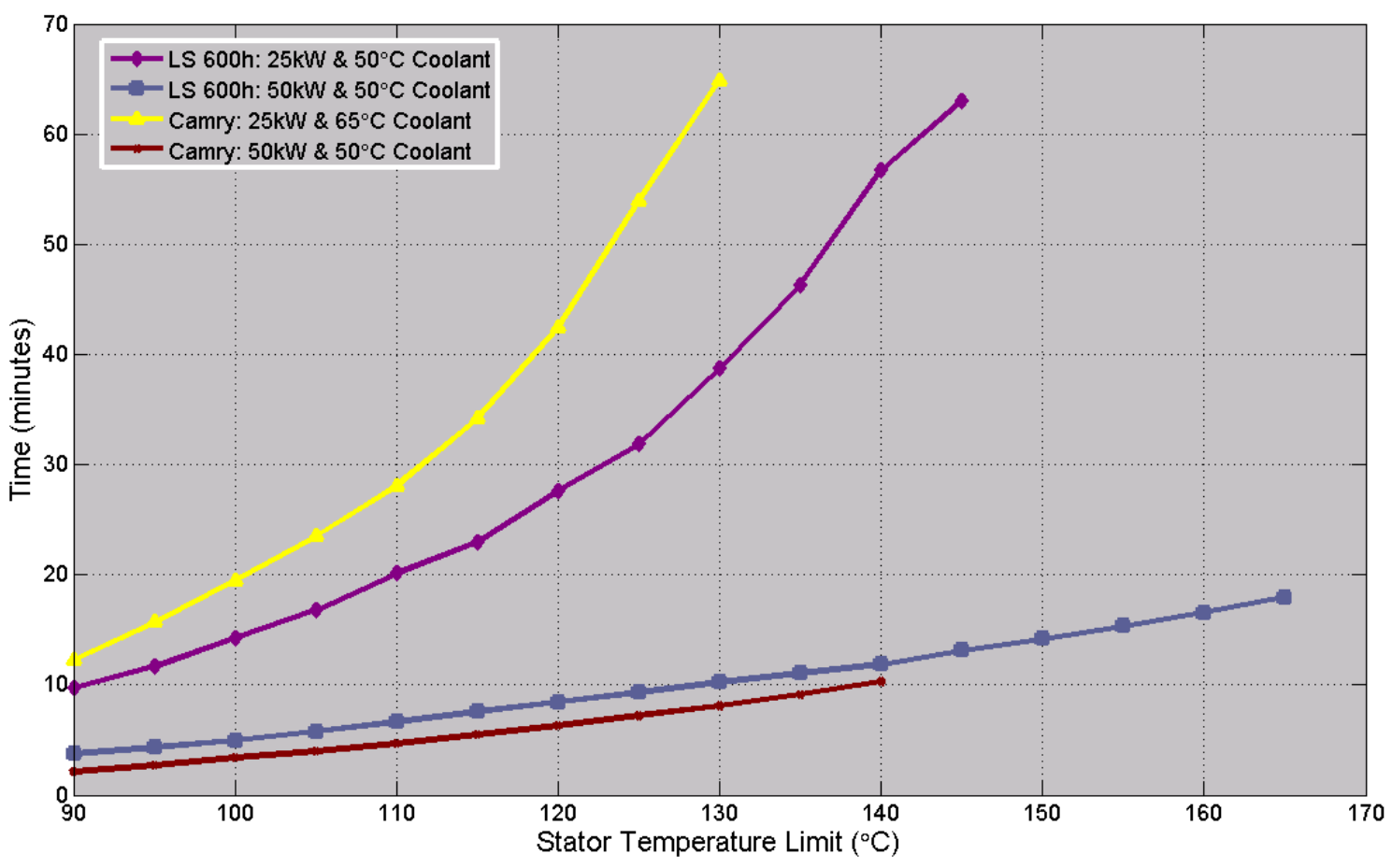

Fig. 3.33. LS 600h and Camry continuous duration at 5,000 rpm with various power levels. 


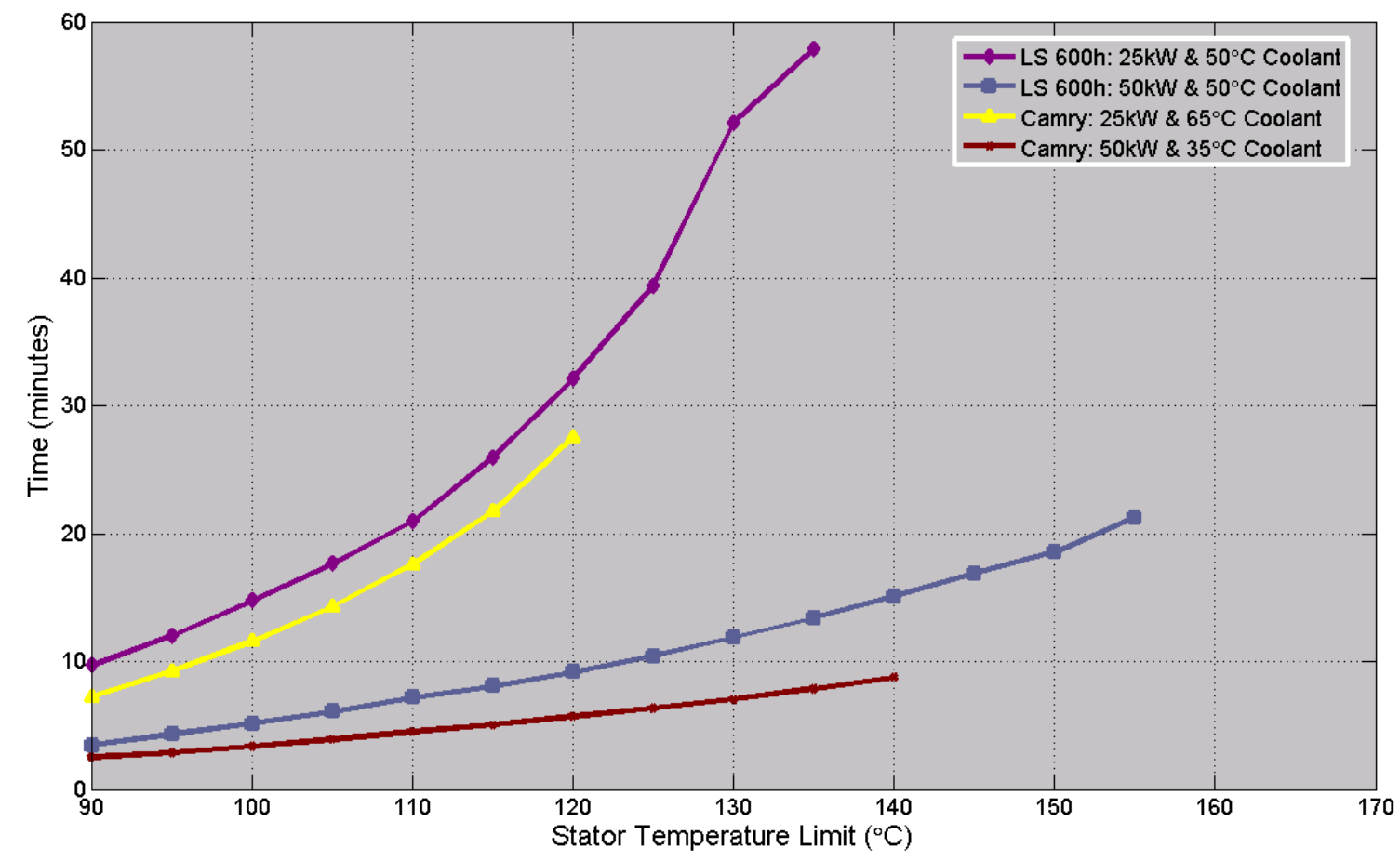

Fig. 3.34. LS 600h and Camry continuous duration at 7,000 rpm with various power levels.

\section{SUMMARY AND CONCLUSIONS}

The 2008 LS 600h HEV subsystem assemblies were physically evaluated and comprehensively tested in the laboratory to fully assess their performance, efficiency, design, and packaging characteristics. Laboratory evaluations included back-emf, locked rotor, performance, efficiency mapping, and continuous load tests. Overall, the LS 600h motor outperformed the Camry motor in terms of efficiency, torque, and power, while the mass and volume of the system only increased slightly. The use of a different motor geometry and PM configuration are the primary factors which provide the enhanced characteristics of the LS 600h PMSM. Additionally, the improved thermal management system used in the PCU led to a reduction of the PEs device tally even though the power capability of the PCU increased considerably. The LS 600h inverter efficiencies are similar to that of the Camry and the LS 600h motor efficiency map contains large areas of high efficiencies and is generally moderately superior to that of the Camry, especially for the low speed, high torque operation region. These advantageous motor efficiency characteristics have significant impact upon the efficiency map for the motor and inverter combined.

Evaluations illustrate the benefits of moving to a new motor geometry and PCU thermal management system through improved packaging, higher efficiencies, increased performance, and improved continuous operation test results. Motor efficiencies are above $90 \%$ for a great portion of the operation range and the 18 second power capability of the primary LS $600 \mathrm{~h}$ motor is about $110 \mathrm{~kW}$ at $4,500 \mathrm{rpm}$. PCU design improvements led to about a 50\% increase of SP and PD for the motor electronics. As the diameters of the LS 600h PMSM rotor and stator were reduced, their lengths increased, thereby facilitating a $37 \%$ reduction of copper but a $50 \%$ increase of PM material in comparison with the Camry PMSM design. The approach leads to a significant improvement (47\%) of SP, but only a slight improvement (11.9\%) of PD. Although there are apparent advantages of the LS 600h subsystem designs, fabrication costs associated with the innovative LS 600h PCU and ECVT subsystems are likely higher than that of previous designs. 
Continuous duration varies significantly with motor speed and specified stator temperature limit for each power level. For example, the LS 600h PMSM is able to sustain a power level of $50 \mathrm{~kW}$ at 5,000 rpm for about 14-15 minutes with a stator temperature limit of $150^{\circ} \mathrm{C}$. However, the duration for the same conditions held at 3,000 rpm is only about 3-4 minutes. There is no standard for establishing continuous or peak power rating specifications for motors designed for HEV applications such as the LS 600h, Camry, and Prius motors. The significant impact of these conditions highlights a very important reason for performing benchmarking tests on HEV subsystems - current technologies must be verified and thoroughly examined objectively before the results are used by the FCVT program and researchers. The influence of HEV specifications on technical goals and program planning would be drastically different if unclear published specifications of HEV systems were used as a baseline.

Among the vast amount of information obtained during benchmarking efforts, the significant findings are summarized in Table 4.1. Some of the information obtained from the LS 600h, Camry, and Prius benchmarking studies has been and will be used by researchers to improve/verify analytical models. As a next step in the benchmarking efforts at ORNL, focus in FY2009 will be placed on reliability, as end-oflife evaluations will be carried out upon used HEV components and comparisons will be made with results from previous benchmarking efforts to determine the condition of the components throughout the lifetime of the vehicle. Technological advances which facilitate higher power capability, PD, SP, efficiency, reliability, and cost effectiveness of HEV components are essential as HEVs become increasingly dependant upon the electrical portion of the drive system and as the EV and HEV market continues to expand in the future. 
Table 4.1. 2008 LS 600h, 2007 Camry, and 2004 Prius design comparison highlights

\begin{tabular}{|c|c|c|c|c|}
\hline Parameter & LS 600h & Camry & Prius & Comments \\
\hline \multicolumn{5}{|l|}{ Transaxle } \\
\hline Motor power rating & $110 \mathrm{~kW}$ & $70 \mathrm{~kW}$ & $50 \mathrm{~kW}$ & Tested 18 second power rating \\
\hline Motor stator OD & $7.87^{\prime \prime}$ & $10.39^{\prime \prime}$ & $10.59^{\prime \prime}$ & \\
\hline Motor lamination stack length & $5.33^{\prime \prime}$ & $2.39^{\prime \prime}$ & $3.3^{\prime \prime}$ & \\
\hline Motor mass & $44.7 \mathrm{~kg}$ & $41.7 \mathrm{~kg}$ & $45.0 \mathrm{~kg}$ & \multirow{2}{*}{ Includes casing and cooling system } \\
\hline Motor volume & $16.7 \mathrm{~L}$ & $14.8 \mathrm{~L}$ & $15.4 \mathrm{~L}$ & \\
\hline Motor SP & $2.46 \mathrm{~kW} / \mathrm{kg}$ & $1.68 \mathrm{~kW} / \mathrm{kg}$ & $1.11 \mathrm{~kW} / \mathrm{kg}$ & \\
\hline Motor PD & $6.59 \mathrm{~kW} / \mathrm{L}$ & $4.73 \mathrm{~kW} / \mathrm{L}$ & $3.25 \mathrm{~kW} / \mathrm{L}$ & \\
\hline Toque rating & $300 \mathrm{Nm}$ & $270 \mathrm{Nm}$ & $400 \mathrm{Nm}$ & \\
\hline Motor speed rating & $10,230 \mathrm{rpm}$ & $14,000 \mathrm{rpm}$ & $6,000 \mathrm{rpm}$ & \\
\hline Motor winding configuration & Parallel & Parallel & Series & \\
\hline \multicolumn{5}{|l|}{ PCU } \\
\hline Nominal battery voltage & $288 \mathrm{~V}$ & $244.8 \mathrm{~V}$ & $201.6 \mathrm{~V}$ & \\
\hline Maximum dc-link voltage & $650 \mathrm{Vdc}$ & $650 \mathrm{Vdc}$ & $500 \mathrm{Vdc}$ & \\
\hline Boost converter power rating & $36.5 \mathrm{~kW}$ & $30 \mathrm{~kW}$ & $20 \mathrm{~kW}$ & \\
\hline Filter capacitor (battery level) & $500 \mathrm{Vdc}$ & $500 \mathrm{Vdc}$ & $600 \mathrm{Vdc}$ & \\
\hline $\begin{array}{l}\text { Smoothing capacitor } \\
\text { (boosted level) }\end{array}$ & $\begin{array}{l}750 \mathrm{Vdc}, \\
2,629 \mu \mathrm{F}\end{array}$ & $\begin{array}{l}750 \mathrm{Vdc}, \\
2098 \mu \mathrm{F}\end{array}$ & $\begin{array}{l}600 \mathrm{Vdc} \\
1,130 \mu \mathrm{F}\end{array}$ & \\
\hline Entire PCU mass & $17.9 \mathrm{~kg}$ & $17.86 \mathrm{~kg}$ & $21.2 \mathrm{~kg}$ & \\
\hline Entire PCU volume & $13.7 \mathrm{~L}$ & $11.7 \mathrm{~L}$ & $17.8 \mathrm{~L}$ & \\
\hline Motor inverter mass & $7.4 \mathrm{~kg}$ & $7.5 \mathrm{~kg}$ & $8.8 \mathrm{~kg}$ & \\
\hline Motor inverter volume & $6.4 \mathrm{~L}$ & $6 \mathrm{~L}$ & $8.7 \mathrm{~L}$ & \\
\hline Motor inverter SP & $14.9 \mathrm{~kW} / \mathrm{kg}$ & $9.3 \mathrm{~kW} / \mathrm{kg}$ & $5.7 \mathrm{~kW} / \mathrm{kg}$ & \\
\hline Motor inverter PD & $17.2 \mathrm{~kW} / \mathrm{L}$ & $11.7 \mathrm{~kW} / \mathrm{L}$ & $5.7 \mathrm{~kW} / \mathrm{L}$ & \\
\hline DC-dc (boost) converter mass & $6.9 \mathrm{~kg}$ & $6.6 \mathrm{~kg}$ & $4.8 \mathrm{~kg}$ & \\
\hline DC-dc (boost) converter volume & $4 \mathrm{~L}$ & $3.5 \mathrm{~L}$ & $5.1 \mathrm{~L}$ & \\
\hline DC-dc (boost) converter SP & $5.3 \mathrm{~kW} / \mathrm{kg}$ & $4.5 \mathrm{~kW} / \mathrm{kg}$ & $4.2 \mathrm{~kW} / \mathrm{kg}$ & \\
\hline DC-dc (boost) converter PD & $9.1 \mathrm{~kW} / \mathrm{kg}$ & $8.6 \mathrm{~kW} / \mathrm{L}$ & $3.9 \mathrm{~kW} / \mathrm{L}$ & \\
\hline
\end{tabular}




\section{REFERENCES}

1. Source: http://www1.eere.energy.gov/vehiclesandfuels/, April 2008.

2. J. S. Hsu, S. C. Nelson, P. A. Jallouk, C. W. Ayers, R. H. Wiles, S. L. Campbell, C. L. Coomer, K. T. Lowe, and T. A. Burress, Report on Toyota Prius Motor Thermal Management, ORNL/TM2005/33, UT-Battelle, LLC, Oak Ridge National Laboratory, Oak Ridge, Tennessee, February 2005.

3. R. H. Staunton, C. W. Ayers, J. Chiasson, T. A. Burress, and L. D. Marlino, Evaluation of 2004 Toyota Prius Hybrid Electric Drive System, ORNL/TM-2006-423, UT-Battelle, LLC, Oak Ridge National Laboratory, Oak Ridge, Tennessee, May 16, 2006.

4. R. H. Staunton, T. A. Burress, and L. D. Marlino, Evaluation of 2005 Honda Accord Hybrid Electric Drive System, ORNL/TM-2006-535, UT-Battelle, LLC, Oak Ridge National Laboratory, Oak Ridge, Tennessee, September 2006.

5. T. A. Burress, C. L. Coomer, S. L. Campbell, L. E. Seiber, L. D. Marlino, R. H. Staunton, and J. P. Cunningham, Evaluation of the 2007 Toyota Camry Hybrid Synergy Drive System, ORNL/TM2007/190, UT-Battelle, Oak Ridge National Laboratory, Oak Ridge, Tennessee, Revised April 2008.

6. Source: http://www.edmunds.com/lexus/1s600h1/2008/picturearchive.html, December, 2008.

7. Source: http://pressroom.toyota.com/presstxt/20081exuskit/2008LS600hL_sf.pdf, April 2008. 


\section{DISTRIBUTION}

\section{Internal}

\author{
1. D. J. Adams \\ 2. T. A. Burress \\ 3. S. L. Campbell \\ 4. C. L. Coomer \\ 5. J. P. Cunningham \\ 6. K. P. Gambrell
}

7. J. S. Hsu

8. L. D. Marlino

9. M. Olszewski

10. L. E. Seiber

11. R. H. Staunton

12. Laboratory Records

\section{External}

13. F. D. Barlow III, University of Idaho, Department of Electrical \& Computer Engineering, Buchanan Engineering Laboratory, Rm. 211, 607 Urquhart Avenue, Moscow, ID 83844-1023, fbarlow@uidaho.edu.

14. R. Al-Attar, DCX, raa9@chrysler.com.

15. P. A. Blais, KEMET, 66 Concord Street, Suite Z, Wilminton, Massachusetts 01887-2179; PeterBlais@kemet.com.

16. S. J. Boyd, U.S. Department of Energy, EE-2G/Forrestal Building, 1000 Independence Avenue, S.W., Washington, D.C. 20585.

17. J. Czubay, General Motors Corporation, GM Powertrain Headquarters, Mail Code: 483-710-270, 895 Joslyn Avenue, Pontiac, Michigan 48340.

18. H. Dadkhah, Chrysler, LLC, CIMS 526-00-00, 1960 Technology Drive, Building D, Troy, Michigan 48083.

19. P. B. Davis, U.S. Department of Energy, EE-2G/Forrestal Building, 1000 Independence Avenue, S.W., Washington, D.C. 20585.

20. R. R. Fessler, BIZTEK Consulting, Inc., 820 Roslyn Place, Evanston, Illinois 60201-1724.

21. S. Gopalakrishnan, General Motors Corporation, RMB-356, Mail Code 480-106-390, 30500 Mound Road, Warren, Michigan 48090.

22. G. Hagey, 501 Randolph St., Williamsburg, Virginia 23185.

23. E. Jih, Ford Motor Company, Scientific Research Laboratory, 2101 Village Road, MD-1170, Rm. 2331, Dearborn, Michigan 48121.

24. K. J. Kelly, National Renewable Energy Laboratory, 1617 Cole Boulevard, Golden, Colorado 80401.

25. F. Leonardi, Ford Motor Company, 15050 Commerce Drive, North, Dearborn, Michigan 481201261.

26. F. Liang, Ford Motor Company, Scientific Research Laboratory, 2101 Village Road, MD1170, Rm. 2331/SRL, Dearborn, Michigan 48121.

27. M. W. Lloyd, Energetics, Inc., 7164 Columbia Gateway Drive, Columbia, Maryland 21046.

28. M. Mehall, Ford Motor Company, Scientific Research Laboratory, 2101 Village Road, MD-2247, Rm. 3317, Dearborn, Michigan 48124-2053.

29. N. Olds, United States Council for Automotive Research (USCAR), nolds@uscar.org

30. S. A. Rogers, U.S. Department of Energy, EE-2G/Forrestal Building, 1000 Independence Avenue, S.W., Washington, D.C. 20585.

31. A. Rousseua, Argonne National Laboratory, arousseau@anl.gov.

32. G. S. Smith, General Motors Advanced Technology Center, 3050 Lomita Boulevard, Torrance, California 90505.

33. R. A. Sullivan, U.S. Department of Energy, EE-2G/Forrestal Building, 1000 Independence Avenue, S.W., Washington, D.C. 20585. 